\title{
MULTISTAGE HIERARCHICAL OPTIMIZATION FOR LAND USE ALLOCATION TO CONTROL NONPOINT SOURCE WATER POLLUTION
}

\author{
DISSERTATION \\ Presented in Partial Fulfillment of the Requirements for \\ the Degree Doctor of Philosophy in the Graduate \\ School of The Ohio State University \\ By \\ In-Young Yeo, M.S., B.S. \\ $* * * * *$ \\ The Ohio State University \\ 2005
}

Dissertation Committee:

Approved by:

Prof. Steven I. Gordon, Adviser

Prof. Jean-Michel Guldmann, Adviser

Prof. Carolyn J. Merry

Approved by:
Adviser
Adviser
Graduate Program in
City and Regional Planning




\begin{abstract}
Nonpoint source (NPS) water pollution, the leading cause of water quality impairment in the U.S and Lake Erie, has been difficult to address because of technical and administrative problems. The nature and characteristics of NPS require site-specific land-use planning within multiple political jurisdictions, and the coordination of conservation management efforts among stakeholders within watershed boundaries. However, this watershed-based approach has been inefficient because there is no systematic way to guide decision makers in selecting appropriate management practices and their spatial locations. This task requires a comprehensive understanding of the physical and geographical characteristics of the watershed and an assessment of the cumulative impacts of the proposed management plans.

To effectively and systematically analyze complex spatial watershed systems, a hierarchical optimization approach is proposed. At the top level, a stormwater runoff simulation model is used to generate peak discharge pseudo data, that are input to a regression analysis, where the functional relationship between peak discharge and land-use variables is approximated as a quadratic function $\left(\mathrm{R}^{2}=0.94 \%\right)$. This function is then used in an optimization model to allocate future land uses (urban, conservation, and agriculture) at the subwatershed level, in a way that minimizes the resulting peak discharge at the watershed outlet. The same
\end{abstract}


process is repeated at the drainage area level, for each subwatershed. Finally, an integrated hydrological-land-use optimization (IHLUO) model is developed at the level of 30 -meter cells for each drainage area. Each optimization level takes as exogenous inputs the land allocations generated by the previous optimization. This modeling methodology (1) investigates the NPS pollution generation/transport mechanisms and the spatial variability/interdependencies of land uses and watershed hydrology, (2) systematically evaluates different land-use patterns and their response to rainfall, and (3) searches for the optimal land-use pattern at the cell level. The results are very promising, with a $46 \%$ reduction of the peak discharge rate, as compared to the rate corresponding to the current land-use pattern. The most downstream and upstream areas are to be protected with more conservation, and most urban activities are allocated to the minimal impact subwatershed. Sensitivity analyses are performed and suggest maintaining at least $30 \%$ of the land in a conservation state, developing no more than $12 \%$ for urban purposes, and no more than $70 \%$ for agricultural purposes. The results from the IHLUO model produce site-specific detailed land conservation guidelines. The proposed methodology is applied to the Old Woman Creek watershed, located in the southwestern basin of Lake Erie (Ohio).

The proposed research provides a new way to evaluate the locational impacts of alternative land-use patterns on NPS runoff, delineating site-specific land-use plans and identifying critical areas for preservation according to their suitability for conservation or susceptibility to pollution. This research is the first to demonstrate how to integrate a runoff simulation model into an optimization scheme, illustrating how NPS pollution levels can be reduced by changing the spatial configuration of land uses in a watershed. 
Dedicated to my parents 


\section{ACKNOWLEDGMENTS}

Most of all, I wish to express my deepest gratitude to Drs. Steven I. Gordon and JeanMichel Guldmann for support, encouragement, patience and intellectual insight throughout this research and my studies at OSU. Their broad knowledge and keen intuition have wisely guided my work. I would like to express my sincere thanks to Dr. Carolyn Merry for guidance and thoughtful suggestions on this dissertation and some interesting remote sensing applications. Valuable discussion and research coordination with Dr. Klarer (National Estuarine Research Reserve at Old Woman Creek) are appreciated. I also thank the Faculty of City and Regional Planning at OSU, including Prof. Pearlman, the administrative and technical staff, and fellow students and friends for support and encouragement. They made my stay at OSU joyful and meaningful. Prayers and love from my friends at church are greatly appreciated. Sincere gratitude is due to my mentor, Dr. Rolf Skrinde (Seattle University) for his guidance and encouragement.

I would like to express my deepest appreciation to my family who always has faith in me. I am in debt to my parents and deeply thank them for love, encouragement, and sacrifice. I especially thank my husband who brought joy and comfort, and excitement and spice in my life. 
He was the best fan and critic of my work and taught me the joy of research. Finally, I always thank God for His love, grace, and guidance.

This research has been supported by a National Estuarine Research Reserve graduate research fellowship from the National Oceanic Atmospheric Administration (NA16OR2408) and the Ohio State University. A summer research grant has been provided by the Environmental Policy Initiatives (EPI) at OSU. The receipt of the Jerrold R. Voss scholarship is also appreciated. Computational resources awarded by the Ohio Supercomputer Center are acknowledged. Finally, presentations of this research at professional conferences were made possible by travel grants from NASA, NOAA, and EPI. 


\section{VITA}

June, 1997

June, 1999

Sept., 1996 - June, 1997

Jan., 1998 - June, 2002

July, 2002 - June, 2004

July, 2004 - June, 2005

July, 2002 - June, 2004

June, 2004

June, 2004
B.S., Civil and Environmental Engineering, Seattle University, Washington

M.S., Civil and Environmental Engineering and Geodetic Science, The Ohio State University, Ohio

Intern, Boeing Company, Everett Environmental Affairs, Seattle, Washington

Graduate Research/Teaching Associate, The Ohio State University, Columbus, Ohio

Graduate Research Fellow, The Ohio State University, Columbus, Ohio

Graduate Teaching Associate and Instructor, The Ohio State University, Columbus, Ohio.

NERR Graduate Research Fellowship, National Oceanic Atmospheric Administration

Jerrold R. Voss Scholarship, City and Regional Planning, The Ohio State University, Columbus, Ohio

Summer Dissertation Research Grant for Graduate Students, Environmental Policy Initiative, The Ohio State University, Columbus, Ohio

\section{PUBLICATIONS}

$\underline{\text { Peer-reviewed articles }}$ 
Yeo, I., J-M, Guldmann, and S.I. Gordon. 2005. Multistage (Top-Down) Optimization Approach To Watershed Conservation to Control Nonpoint Source Water Pollution. Proceeding of Watershed Management Conference 2005, the Environmental \& Water Resources Institute of the American Society of Civil Engineers.

Yeo, I. and J-M, Guldmann. 2005. Land Use Optimization to Control Stormwater Runoff. Environment and Planning $B$ (In review)

Yeo, I. and C.J. Merry. 2004. Modeling Spatio-Temporal Patterns of Turbidity and Nutrients. Remote Sensing of the Environment (In review)

Yeo, I., S.I., Gordon, and J-M, Guldmann. 2004. Optimizing Patterns of Land Use to Reduce Peak Runoff Flow and Nonpoint Source Pollution with an Integrated Hydrological and LandUse Model. Earth Interactions, 8, 8-006:1-20.

$\underline{\text { Technical reports }}$

Yeo, I. 2004. Multistage Optimization for Land Allocation to Control Nonpoint Source Water Pollution at the Old Woman Creek Watershed $(\mathrm{OH})$. Technical Report to NOAA.

Dufour, K., M., Meehan, A., Van Kley, B., Weber, I., Yeo, With Gordon, S. I. and Conroy, M.M. 2001. Development and Change in the Big Darby Watershed. Technical Report to the Darby Creek Association. The Ohio State University, Columbus, $\mathrm{OH}$.

Almer, H., W., Chan, J., Grech, S., Weyrauch, and I., Yeo. 1999. Environmental Impact Statement for the Allen Glen Development. Report to Columbus City Council, Metropolitan Park District of Columbus and Franklin County, The Nature Conservancy Franklin Soil and Water Conservation District, Natural Resources Conservation Service, Ohio Department of Natural Resources, United States Fish and Wildlife Service, Planning Effectively for Tomorrow, M/I Schottenstein Homes, Mid Ohio Regional Planning Commission, School of Natural Resources, The Ohio State University. Columbus, OH.

Falemban, K., D., Keil, N., Miller, Y., Yen, and I., Yeo. 1997. Feasibility Study of Geographic Information Systems for Environmental Monitoring. Technical Report to Boeing Company and Seattle University. Seattle, WA.

$\underline{\text { Presentations (published in the form of abstract, extended abstract, or article in CD-ROM) }}$

Yeo, I., S.I. Gordon, and J-M, Guldmann. 2005. Multistage (Top-Down) Optimization Approach To Watershed Conservation to Control Nonpoint Source Water Pollution. Presented at Watershed Management Conference 2005. Environmental \& Water Resources Institute of the American Society of Civil Engineers.

Yeo, I., J-M, Guldmann, and S.I. Gordon. 2004. Land Use Optimization for Nonpoint Source Water Pollution. 2004 Annual Conference of Association of Collegiate Schools of Planning (October 21-25). 
Yeo, I., J-M, Guldmann, and S.I., Gordon. 2003. Hierarchical Regression Approach to the Global Optimal Solution. AGU Annual Fall Meeting 03, San Francisco, CA (December 10-14).

Yeo, I. 2003. How Does Land-Use Change in the Watershed Influence the Characteristics of the Estuary? - Lessons from the Old Woman Creek Estuary, Ohio. 17th Biennial Conference of Estuarine Research Federation, Seattle, WA (September 14-18)

These research results were cited in the Seattle Post Intelligence (Experts offer sound advice, http://seattlepi.nwsource.com/local/139788_sound16.html)

Yeo, I., S.I., Gordon, and J-M, Guldmann. 2003. Development of the Optimal Land Use Pattern with Minimal Nonpoint Source Pollution. American Geophysical Union(AGU) Chapman Conference on Ecosystem Interactions with Land Use, Santa Fe, NM (June 14-18).

Yeo, I. and Weavers, L. 1998. Investigation of Photoactive Periodate as Advanced Oxidation Process. 21th Midwest Water Chemistry Workshop. Ann Arbor, Michigan

\section{FIELD OF STUDY}

Major Field: City and Regional Planning,

Environmental Planning, Environmental Science and Engineering

Computer Simulation, Geographic Information Systems, Remote Sensing

Optimization and Location Analysis, Quantitative Method 


\section{TABLE OF CONTENTS}

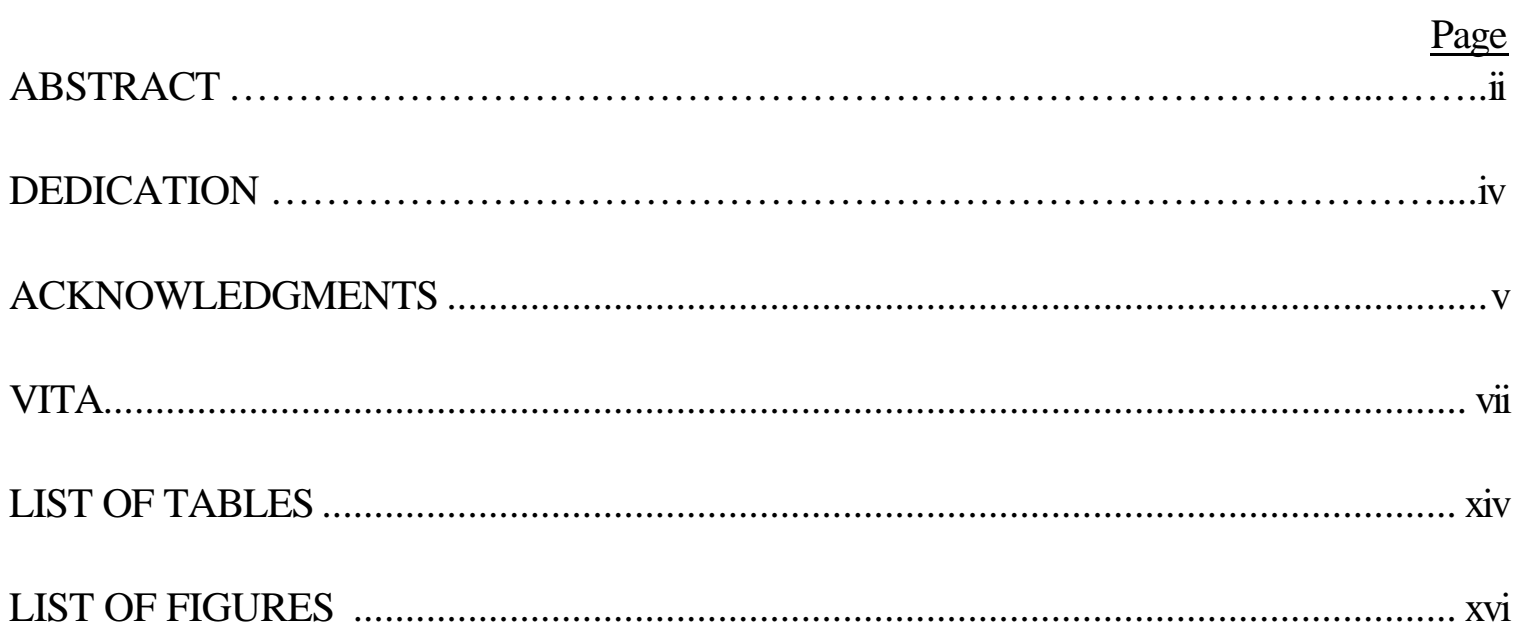

\section{CHAPTERS:}

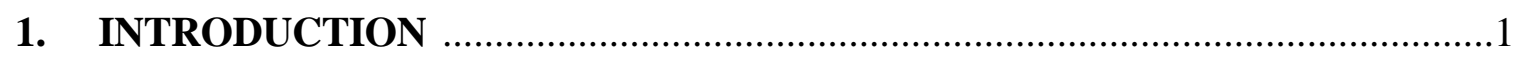

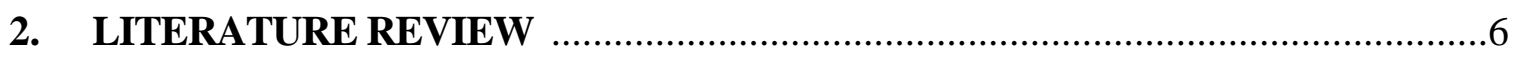

2.1. NPS pollution: General Characteristics....................................................................6

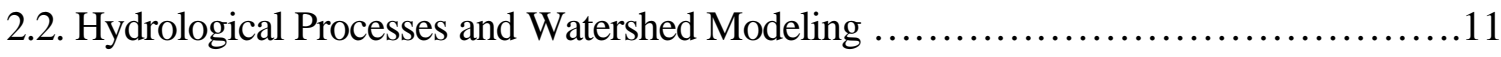

2.2.1. Hydrological Processes ............................................. 12

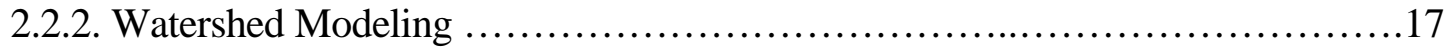

2.3. Land-Use Planning and Optimization ...................................... 19

2.3.1. Land-Use Planning Models ............................................20

2.3.1.1. Fundamentals of Land-Use Planning Models .......................21

2.3.1.2. Multi-objective Land-Use Planning ..............................25 
2.3.2. Optimization Approach to Environmental Problems .27

2.3.2.1. Land-Use Planning Model with Environmental Considerations ...........27

2.3.2.2 Optimization for Water Quality Control .............................30

2.3.2.2.1. Point Source Pollution ................................30

2.3.2.2.2. Nonpoint Source Pollution .............................32

2.4. Optimization for Spatial Land Pattern ........................................... 34

2.5. Integrated Simulation and Optimization Approach .................................35

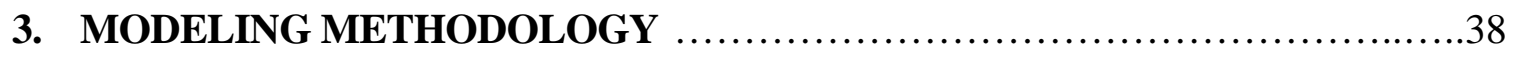

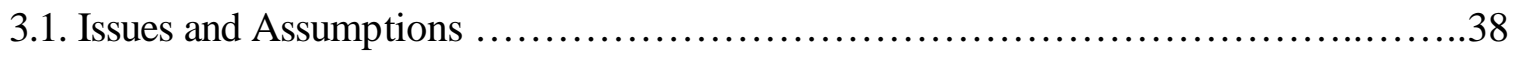

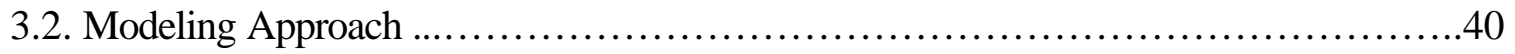

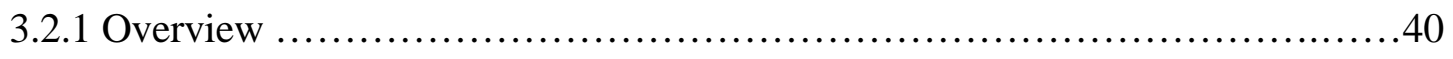

3.2.2. Hydrological Simulation Model ............................................44

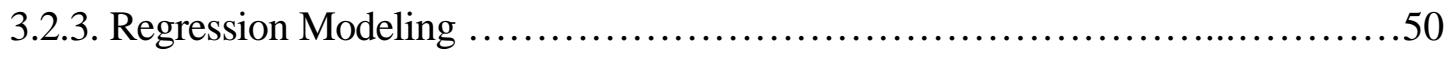

3.2.3.1. Modeling at the Subwatershed level ..............................50

3.2.3.2. Modeling at the Drainage Area Level ...............................53

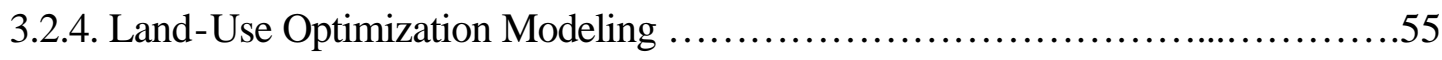

3.2.5. Integrated Hydrological - Land Use Optimization Model (IHLUO) ................56

4. DATA SOURCES AND PROCESSING ................................61

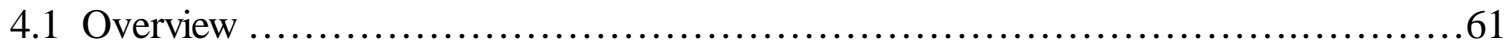

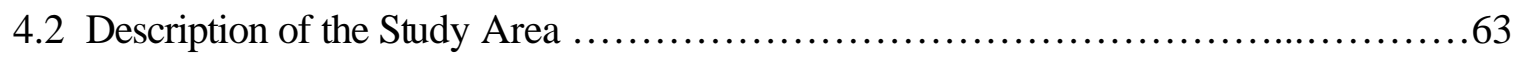

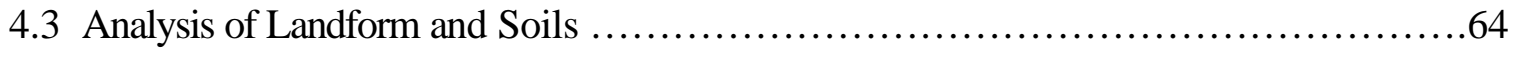

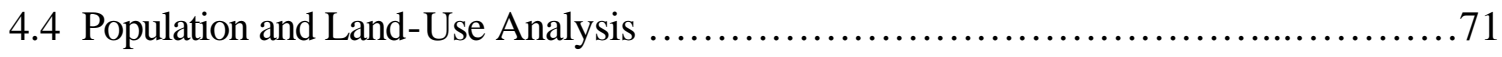

4.5 Hydrological Data Analysis and Model Calibration ................................ 78

5. REGRESSION ESTIMATION OF THE PEAK RUNOFF FUNCTIONS .........80

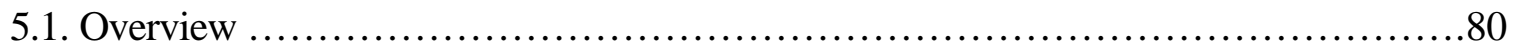


5.2. Regression Model Results at the Subwatershed Level ............................84

5.3. Regression Model Results at the Drainage Level .............................90

6. QUADRATIC LAND-USE OPTIMIZATION ........................... 100

6.1. Subwatershed and Drainage Optimization ................................... 100

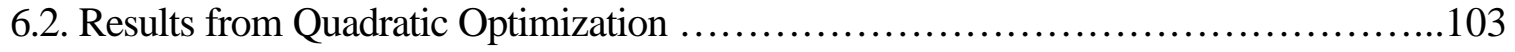

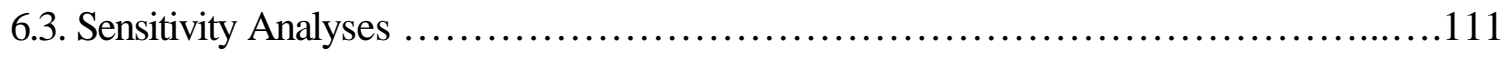

6.3.1. Minimum Conservation Land ........................................ 111

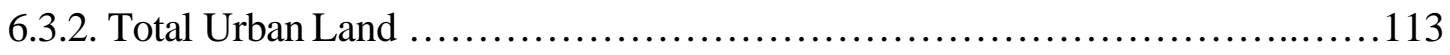

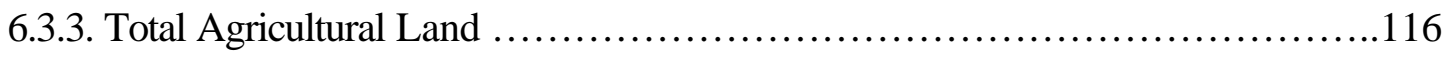

7. APPLICATION OF THE INTEGRATED HYDROLOGICAL LAND-USE

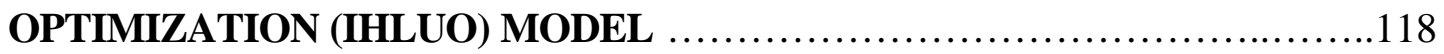

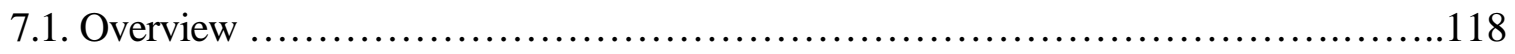

7.2. Optimal Land-Use Patterns for the Entire Watershed ............................119

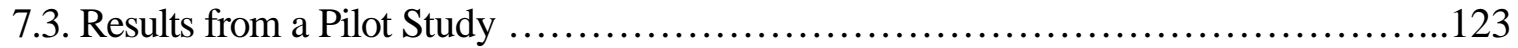

7.3.1. Spatial Land-Use Patterns and Stormwater Runoff ......................... 123

7.3.2. Storm Intensity and Spatial Land-Use Patterns ........................... 126

7.3.3. Urban Sprawl and Spatial Land-Use Patterns ............................ 129

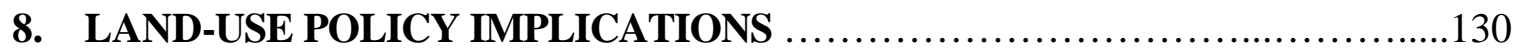

8.1. Agricultural Land-Use Techniques for Conservation ............................130

8.2. Site-Design and Management Practices for Agricultural Watershed Protection .........133

8.3. Qualitative Analysis of the Optimal Land-Use Pattern .......................... 138

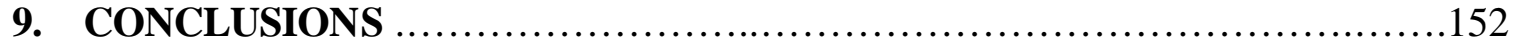


BIBLIOGRAPHY

\section{APPENDICES}

A. ASSESSMENT OF LOCAL OPTIMA FOR GLOBAL OPTIMALITY ..............172

B. PSEUDO CODES FOR THE HYDROLOGICAL SIMULATION, TWO-LEVEL REGRESSION- ALLOCATION, AND THE IHLUO MODEL 


\section{LIST OF TABLES}

Table $\quad \underline{\text { Page }}$

3.1. Subwatershed Combination Sets .........................................52

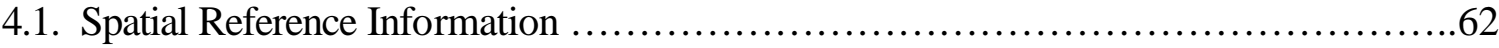

4.2. Hydrologic Soil Groups (HSG), Textures, and Infiltration Rates ......................68

4.3. Soil Distribution in the Old Woman Creek Watershed ............................69

4.4. Parameters for Population Projections .........................................72

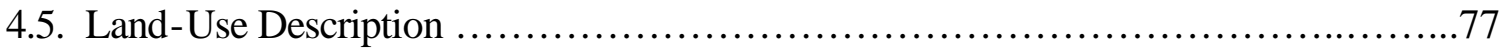

4.6. Curve Number for Different Land-Use and Soil Types ..........................77

4.7. Curve Number for Regrouped Land-Use and Soil Types ......................78

4.8. Hydrological Data Analysis and Model Calibration Results .........................79

5.1. Linear Regression Estimation of the Peak Runoff Function

at the Watershed Outlet ..................................................... 85

5.2. Quadratic Regression Estimation of the Peak Runoff Function

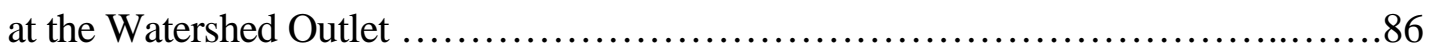

5.3. Descriptive Statistics of $M$ over the Sample Land-Use Patterns $(n=9660)$.............87

5.4. Quadratic Regression Estimation of the Peak Runoff Function

for Subwatershed 1 ........................................................ 92

5.5. Quadratic Regression Estimation of the Peak Runoff Function

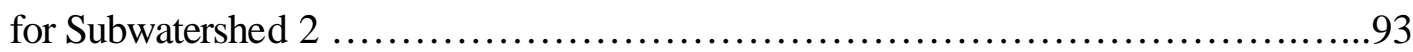

5.6. Quadratic Regression Estimation of the Peak Runoff Function

for Subwatershed 3 
5.7. Quadratic Regression Estimation of the Peak Runoff Function for Subwatershed 4

5.8. Quadratic Regression Estimation of the Peak Runoff Function

for Subwatershed 5 .96

5.9. Descriptive Statistics of $M$ over the Sample Land Use Patterns $(n=9660)$ .98

6.1. Current (2000) Land Use by Subwatershed .105

6.2. Future (2020) Land Allocations by Subwatershed 105

6.3. Current(2000) Land Use by Drainage Area (\%) 108

6.4. Future (2020) Land Allocations by Drainage Area (\%) 109

6.5. Comparison of Peak Discharge Rates after Optimal Allocations 110

6.6. Sensitivity Analysis of Land Allocation: Minimum Total Conservation Land 112

6.7. Sensitivity Analysis of Land Allocation: Total Urban Land 115

6.8. Sensitivity Analysis of Land Allocation: Total Agricultural Land 116

7.1. Comparison of Peak Discharge Rates at Drainage Outlets:

Current Condition vs. Optimal IHLUO Allocations

7.2. Comparison of Peak Discharge Rate by Different Approximation Methods

7.3. Storm Runoff vs. Optimal Land-use Patterns 126

8.1. Alternative Land-Use Techniques for Agricultural Watersheds 131

A.1. Weibull Distribution Data Fitting .176

A.2. Global Optimum and Confidence Interval .178 


\section{LIST OF FIGURES}

$\underline{\text { Figure }}$

$\underline{\text { Page }}$

2.1. Hydrological Cycle in Watershed .......................................13

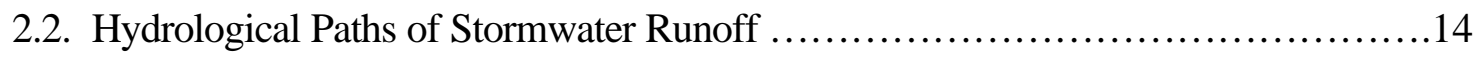

3.1. Multistage Land-Use Optimization Framework $\ldots \ldots \ldots \ldots \ldots \ldots \ldots \ldots \ldots \ldots \ldots \ldots . . .43$

3.2. Runoff Process and Flow Path .......................................... 47

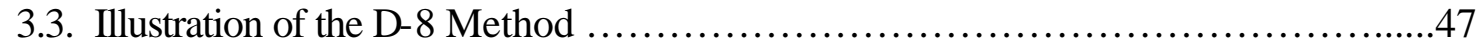

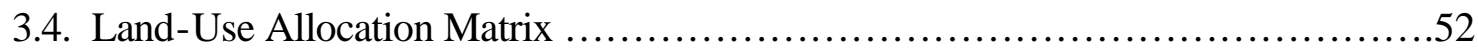

3.5. Sample Land-Use Map with Different Subwatershed Combination Sets .............52

3.6. Sample Land-Use Maps with Different Drainage Combinations in

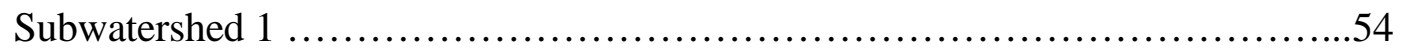

3.7. Step Sizes and the Behavior of the Objective Function ........................60

4.1. Location of the Study Area .............................................63

4.2. Watershed Hierarchy and Elevations ...................................67

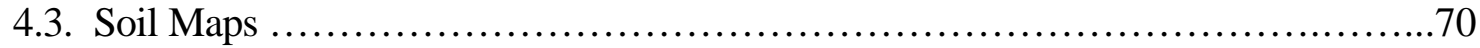

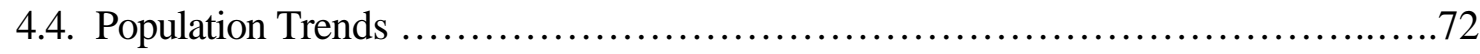

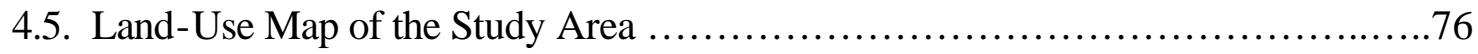

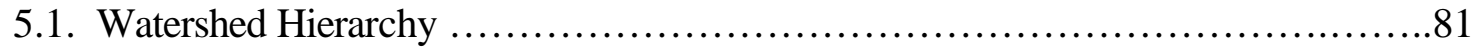

5.2. Spatial Land Allocation Maps for Subwatershed 1 and Drainage 1 .................83

5.3. Distributions of the Average Land-Use Coefficients (M) Over the Sample

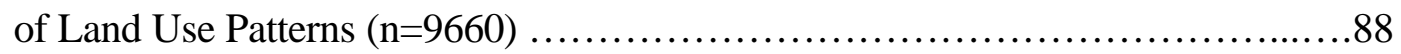

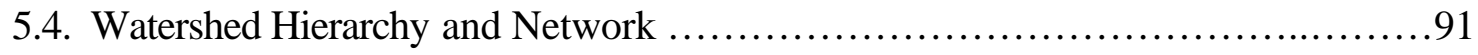


5.5 Diagrams for the Conceptual Statistical Models in Drainage Areas ....................91

6.1 Changes in the Distributions of Land Allocation at the Drainage Level (\%) ...........110

6.2 Impacts of Minimum Total Conservation Land Requirement .....................113

6.3 Impacts of Total Urban Land Requirement ................................115

6.4 Impacts of Total Agricultural Land Requirement .............................. 117

7.1 Spatial Pattern of Optimal Land Allocation at the Cell Level (30-meter) .............121

7.2 Site Characteristics -Land Use, Soil Type, and Slope ........................125

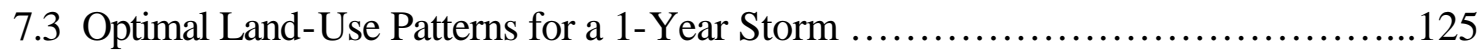

7.4 Optimal Land-use Patterns with Different Storm Sizes ............................128

7.5 Optimal Land-use Patterns for Urban Sprawl ..............................129

8.1 A Ladder Pattern of Stream Corridor ...................................... 137

8.2 Spatial Pattern of Optimal Land Allocation at the Cell Level (30-meter) ..............138

8.3 Optimal Land Use Patterns of Drainage Areas 1 and 3 .......................... 141

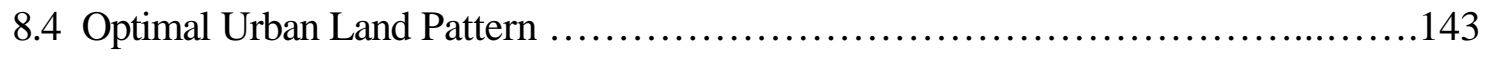

8.5 Distribution of Uneven Conservation Land in Buffer Zones ...................... 145

8.6 Optimal Land-Use Pattern in Buffer Zones ..................................146

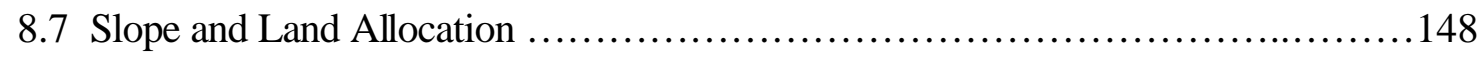

8.8 Soil Types vs. Optimal Land-Use Patterns ...................................151

A.1 Sample Data and Fitted Probability Density Distribution .........................177

A.2 Comparison of Sample Data and Fitted Data ..................................177 


\section{CHAPTER 1}

\section{INTRODUCTION}

The impact of pollution from diffuse sources on surface waters has been of increasing concern during the past several decades, and nonpoint source (NPS) water pollution has become the leading cause of water quality impairment (US EPA, 2000a; Novotny, 1999). Despite its detrimental impact, NPS water pollution has not been well regulated, due to technical, social, economical, and political difficulties.

NPS water pollutants are introduced into a natural water system as waste materials on the ground that are washed off by surface storm runoff. The identification of NPS pollution sources and their linkages to water pollutants, and the understanding of their generation and transport mechanisms, are technically challenging tasks, requiring knowledge of the interrelationships between land use/cover, watershed hydrology, and NPS pollution. Even if generation and transport mechanisms are understood, apportionment of NPS water pollution among different sources is nearly impossible. There is no one-to-one relationship between pollution concentrations and pollution sources, and multiple diffused polluters may create synergistic reactions among 
pollutants, making it impossible to separate individual contributions to water pollution. The dynamic nature of water and its pollutants requires interdisciplinary and multijurisdictional efforts, where collaborations are difficult to coordinate (Jones and Gordon, 1998). The control of land uses and human activities is economically and socially challenging.

The management of NPS pollution calls for a watershed or holistic approach to coordinate efforts among stakeholders within natural hydrological boundaries. The concept of Total Maximum Daily Loads is used to control pollution from nonpoint (NPS) and point (PS) sources. Under current law (i.e., Clean Water Act), pollution from PS is regulated with technology-based effluent limits, while an area planning approach is applied to address NPS pollution via Best Management Practices (BMPs) (Findly et al., 2003). BMPs are defined as cost-effective and reasonable methods, measures, or practices used to meet NPS pollution control goals. Structural or non-structural measures, and operation and maintenance procedures are included in BMPs (USEPA, 1997). Since land uses and hydrological characteristics are the major determinants of NPS pollution, land conservation planning is one of the most effective and direct management methods for NPS pollution control. The question is how to allocate conservation areas in critical locations, and to delineate land-use patterns to minimize environmental impacts.

To achieve this goal, one must first identify the pollution stressors, and understand their transport mechanism. Studies have been undertaken to trace these pollutants back to their sources, to understand transport mechanisms, and to investigate the impacts of land uses/covers on watershed hydrology (Jolánkai et al., 1999; Jordan et 
al., 1997; Bingner and Theurer, 2001; Moglen and Beighley, 2002; Novotny and Chester, 1982; Singh, 1995). However, their findings have been used only to estimate the pollution levels resulting from given land-use scenarios. Results from hydrological research have not been fully utilized for spatial decision-making processes.

Comprehensive land/site allocation programming, widely used in planning, could be of great help in identifying and implementing land conservation measures. When applied to land-use planning, optimization is used to allocate different land-use types to specific locations, in order to stimulate regional activities and to maximize economic benefits (Lundqvist and Mattsson, 1983; Gilbert et al., 1985; Wright et al., 1983). However, most such models ignore the environmental consequences of development, or their impacts are estimated in an over-simplified fashion (Haith, 1982; Das and Haimes, 1979; Hopkins et al., 1981). The spatial variability of land uses has not been well accounted for. Similarly, optimization has been used in the biological/ecological field to design natural reserve systems (Williams and ReVelle, 1997; Williams and ReVelle, 1998; Cova and Church, 2000; McDonnell et al., 2002; Possingham et al., 2000; Aerts et al., 2003), providing spatially cohesive natural reserve systems that preserve biodiversity at minimum cost.

The goal of this research is to create a methodology for developing optimal landuse management/allocation plans to control NPS pollution in the coastal area of Lake Erie, using an environmental process simulation model within the framework of a landuse allocation model. Since land use and hydrological characteristics are the major determinants of NPS water pollution, the focus is on developing land plans that minimize the surface storm runoff in the watershed. 
Land development in the nearshore areas of the Great Lakes has become the major stressor of the ecosystem and the environment, resulting in eutrophication (Henry and Heinke, 1996; McGucken, 2000; Meyer et al, 2000). In order to protect Lake Erie, the Ohio Lake Erie Commission has proposed a strategic plan to reduce soil erosion and nutrient loading from the surrounding watershed by $67 \%$, and to implement more active and comprehensive plans to control NPS pollution (Ohio Lake Erie Commission 2000). To attain this goal, various financial assistance programs are available to encourage conservation land in this coastal region (Forster and Rausch, 2002). However, the implementation of BMPs is still problematic, because decision makers and land managers are not well informed, due to a lack of reliable scientific data and land use/allocation guidelines to coordinate their efforts.

The proposed approach accounts for the spatial variability and interdependency of land uses, and their relationship with watershed hydrology, allocates buffer land uses at critical locations, and delineates site-specific optimal land use patterns at a high spatial resolution $(30 \mathrm{~m}$ by $30 \mathrm{~m})$. The results should be useful to land managers and decision makers, providing site-specific guidelines for BMPs and prioritizing conservation efforts. The results of this land application optimization can also provide a test of the attainability of environmental goals. The approach is empirically applied to the Old Woman Creek Watershed (Ohio), in the southwestern coastal basin of Lake Erie.

The remainder of the dissertation is organized as follows. Chapter 2 consists of a literature review. The modeling methodology is presented in Chapter 3. Data sources and processing are described in Chapter 4. The estimations of the peak runoff functions are discussed in Chapter 5, and the quadratic land-use optimization results are described 
in Chapter 6. The application of the Integrated Hydrological Land-Use Optimization (IHLUO) model is presented in Chapter 7. Qualitative analyses of the optimal land-use patterns and their land-use policy implications are reported in Chapter 8. Chapter 9 concludes this dissertation and outlines areas for future research. 


\section{CHAPTER 2}

\section{LITERATURE REVIEW}

This chapter presents a review of existing research on the characteristics of NPS pollution and its sources, watershed hydrology and modeling, and use of optimization models for environmental management and planning.

\subsection{NPS pollution: General Characteristics}

NPS pollution is closely related to hydrological cycles and human-induced activities in a given watershed area. Due to the stochastic nature of hydrological and meteorological phenomena, the behavior of NPS pollution is very erratic. Novotny and Chesters (1982) note that: (1) NPS is highly dynamic and randomly occurs at intervals closely related to the hydrological cycle; (2) NPS is highly variable, ranging across several orders of magnitude; (3) the most severe NPS water quality impacts occur during or after storm events, in Winter and early Spring; (4) NPS pollution sources are unidentifiable, as pollution arises typically from extensive land areas; (5) NPS is difficult to quantify with traditional water quality monitoring techniques; (6) the primary water

quality parameters related to NPS pollution are sediments, nutrients, heavy metals, 
synthetic organics, $\mathrm{pH}$ and dissolved oxygen; and (7) the NPS control programs involve the regulation of individuals and their activities on the land.

Generation, transport, and transformation of NPS pollutants are highly related to human activities and natural factors (Karr and Schlosser, 1978; Karr and Dudley, 1981; Wang 1995; Gordon and Majumder, 2001; Yoder and Rankin 1995, Richards and Host 1994; Hunsacker et al., 1995; Osborne and Wiley, 1988; Schueler and Holland, 2000). Field observations and modeling results show that (1) a watershed in a natural state (forest) has the best water quality; (2) an agricultural watershed displays degradation due to nutrients and sediments, but maintains acceptable biological conditions; and (3) an urban watershed displays degradation with regard to most physical, biological, and chemical parameters. Human- induced activities can modify natural hydrological processes, which become a direct cause of water quality impairment in aquatic ecosystems, and the geology and physiography of the watershed can influence the magnitude and dynamics of land runoff. Ryding and Thornton (1999) discuss the main factors that influence the magnitude of NPS contaminant loads after storm events, including: (1) drainage basin physiography (Hunsacker et al., 1995), (2) type and chemistry of soil (Brasseau et al., 1994), (3) type, and extent of vegetative cover (Gordon and Majumder 2001), (4) density of drainage channels, (5) types and quantities of materials applied to the land surface, (6) duration of the dry period preceding the rainfall event, and (7) volume/intensity/quality of the rainfall. Among land-use activities that affect the generation of NPS, Novotny and Chesters (1982) find that population density, atmospheric fallout, degree of impervious areas, vegetation covers, traffic density, and street cleaning/litter accumulation have a strong correlation with NPS 
generation. The imperviousness of urban area dramatically changes watershed hydrology (Moglen and Beithly, 2001). Schueler and Holland (2000) show that water quality becomes impaired, if the amount of imperviousness in the watershed exceeds $10 \%$.

All types of land uses and activities can directly or indirectly affect the water quality of stormwater runoff. The term "land use" refers to the prevailing activity occuring in an essentially uniform geographical area (Brown et al., 2000). Due to wide variations in pollution loadings across land uses, these are grouped together according to similar surface characteristics for effective pollution management and controls. Two major groups are distinguished: urban and rural areas. NPS pollution from rural areas is due to agricultural activities that disturb the land surface. Typical NPS agricultural pollutants include sediments, nutrients, and synthetic organic chemicals, such as pesticides and herbicides, and their loads are affected by surface runoff, interflow, and groundwater base flow from farms and cropland (Claphamm Jr. et al., 1999; Johnson and Randall 2001; Johnson et al., 2001; David et al, 1997; Robinson 1971; Novotny 1999; Jordon et al., 1997). Although pasture and rangeland are not considered hazardous and require little or no pollution control, livestock located close to a watercourse can pose a threat to water quality in the nearby stream (Novotny 1982;1999). Feedlots are the most hazardous land uses in rural areas and are commonly classified as point sources (PS) rather than NPS (Findly, 2003). However, the solid disposal requirements and methods of management are rather area-wide processes and are closely related to the hydrological activity in the watershed.

General urban areas include developed or developing urban zones. The developed urban zones have been categorized as residential, commercial, industrial, and 
transportation corridors, by the Pollution from Land-Use Activities Group (PLUARG) of the International Joint Commission on Nonpoint Source Pollution in North American Great Lakes Basin (Claphamm Jr. et al., 1999). The factors that determine pollution loadings from residential areas are the degree of imperviousness, the accumulated pollutants over the impervious areas, street sweeping practices, curb heights, types of storm-water drainage systems, soil and slope of pervious surfaces, traffic impact, and atmospheric pollution (Schueler and Holland 2000; Claphamm Jr. et al., 1999). Although commercial land use has a relatively high degree of imperviousness, high traffic volumes, and elevated pollutant accumulation, the frequent sweeping and cleaning practices in these areas reduce their sediment loadings. The primary sources of NPS pollution in many industrial areas are air pollution and subsequent atmospheric deposition caused by industrial operations. Construction sites are classified as developing urban zones and are considered hazardous, producing the highest amount of pollutant. Stripping topsoil and exposing bare soils are the main causes of sediments to the stream, and compaction of soils reduces permeability and surface storage of moisture. Slope, proximity of the site to a stream channel, existence of buffer zones of natural vegetation, erodibility of soils, meteorological factors, use of heavy machinery, and duration of soil exposure are the main factors that affect sediment and other pollutant losses from a construction site.

Management practices and measures for NPS pollution are different from those for PS, as NPS requires area-wide control measures, known as Best Management Practices (BMPs). BMPs can include structural and nonstructural controls, operation and maintenance procedures, and management practices, such as schedules of activities and prohibition of practices. Site- and pollutant-specific BMPs are required for effective NPS 
control, considering the types of land-use activities and physical conditions of the watershed. BMPs can be classified into three groups, based on pollution control approaches: (1) first, control pollutants on site (i.e., minimization of pollution generation), (2) then, collect or reduce NPS pollution delivery to the receiving water body, and (3) last, treat the runoff. On-site pollution minimization is recommended to be prioritized. In other words, the treatment of the most hazardous lands is the top priority of BMP practices (Novotny, 1982; Claphamm et al., 1999).

Source control is often achieved by: (1) prohibiting certain land-use activities on hazardous lands by zoning; (2) preventing topsoil loss as erosion control practices; (3) enhancement of infiltration and surface water storage of the land; and (4) reduction of contaminant levels in soils and on impervious surfaces (Novotny and Chesters, 1982). Vegetation cover is an excellent source control method. It protects the surface land and reduces runoff. Vegetation increases infiltration and surface roughness, which dissipates rainfall energy and reduces erosion. Collection control and delivery reduction methods are more expensive and difficult than source control. They include removal of pollutants by sedimentation and infiltration, or removal of contaminants from collection systems, and commonly require engineering structures and designs to segregate runoff from environmentally disturbed areas. Examples of runoff collection and conveying systems include grass waterways, riprap, sediment traps, and retention basins (Center for Watershed Protection, 2000). Trenches and ponds are the most popular infiltration methods. Treatment of runoff is needed for highly developed large urban areas, where a large-scale structural treatment method may be the only effective way to remove pollutants from stormwater discharges (see Novotny and Chesters (1982), Schueler and 
Holland (2000), US EPA (1993), and the Center for Watershed Protection (1998) for various watershed protection techniques).

\subsection{Hydrological Processes and Watershed Modeling}

The administrative and technical problems related to NPS pollution control arise because the link between pollution sources and cumulative pollution loads are not straightforward. Therefore, management and regulation of NPS pollution becomes very difficult and inefficient, as pollution sources and their pathways are not clearly identified.

Previous studies in watershed science have been focused on understanding the principles and mechanisms of NPS pollution generation and transport, and on developing tools to predict water quality more accurately at different spatial and temporal scales. Hornberger and Boyer (1995), and Preti (1996) provide good overviews on recent advances in NPS water pollution, watershed science, and modeling. Watershed models are very useful tools to identify pollution source areas and pollutant paths to waterways, to quantify the cumulative impacts of pollution, to develop different management plans, and to evaluate their efficiency for pollution reduction and control (Mostaghimi et al., 1997; Yuan et al., 2003; Tim et al 1992). Advances in computing, Geographic Information Systems (GIS), and remote sensing make modeling tools more powerful, allowing for efficient spatial analysis and data collection for NPS modeling (Beven and Kirby,1979; Moore et al., 1991; ASCE. 1999; Wilson and Gallant,. 2000; Garbrecht and Martz, 1997; Tarboton 1997; Mariza et al., 1994; León et al, 2001). In this section, the principles of the hydrological processes that generate and deliver NPS pollutants to waterways, and previous watershed models that relate water quantity and quality to land 
uses and covers are discussed (refer to Haan et al. (1994), Chow et al. (1989), McCuen (1982), USDA (1986), Singh (1995), Toy et al. (1997), Maidment (1993), Novotny and Chester (1982), Ryding and Thornton (1999), Hann at al.(2001), and Ward and Elliot (1995) for detailed descriptions of watershed hydrology modeling, and NPS water

pollution). Section 2.2.1 describes the principles of important hydrological processes and presents general approaches to watershed modeling. Much of the information is drawn from the above references.

\subsubsection{Hydrological Processes}

NPS pollution originates from diffuse sources in the landscape, from runoff or groundwater, and its generation, transport, and fate result from the interactions among three environmental media - water, land, and atmosphere. Hydrological processes link these three media together and become the most important factors determining pollution loads. Pollutants are delivered to receiving waters by overland flow whose formation, transport, and fate in the environment are closely related to watershed hydrology. Overland flows are a function of runoff and infiltration, and they occur when rainfall intensity exceeds the infiltration capacity of the soil (Domencico and Schwartz, 1990; Wang, 1995). The hydraulics of overland flows are important in determining flow depth, velocities, and capacity to detach, entrain and transport dissolved and suspended materials (Parsons and Abraham, 1993; Jordon et al., 1997). Figures 2.1 and 2.2 displays the hydrologic cycle that affects watershed hydrology and NPS pollution. 


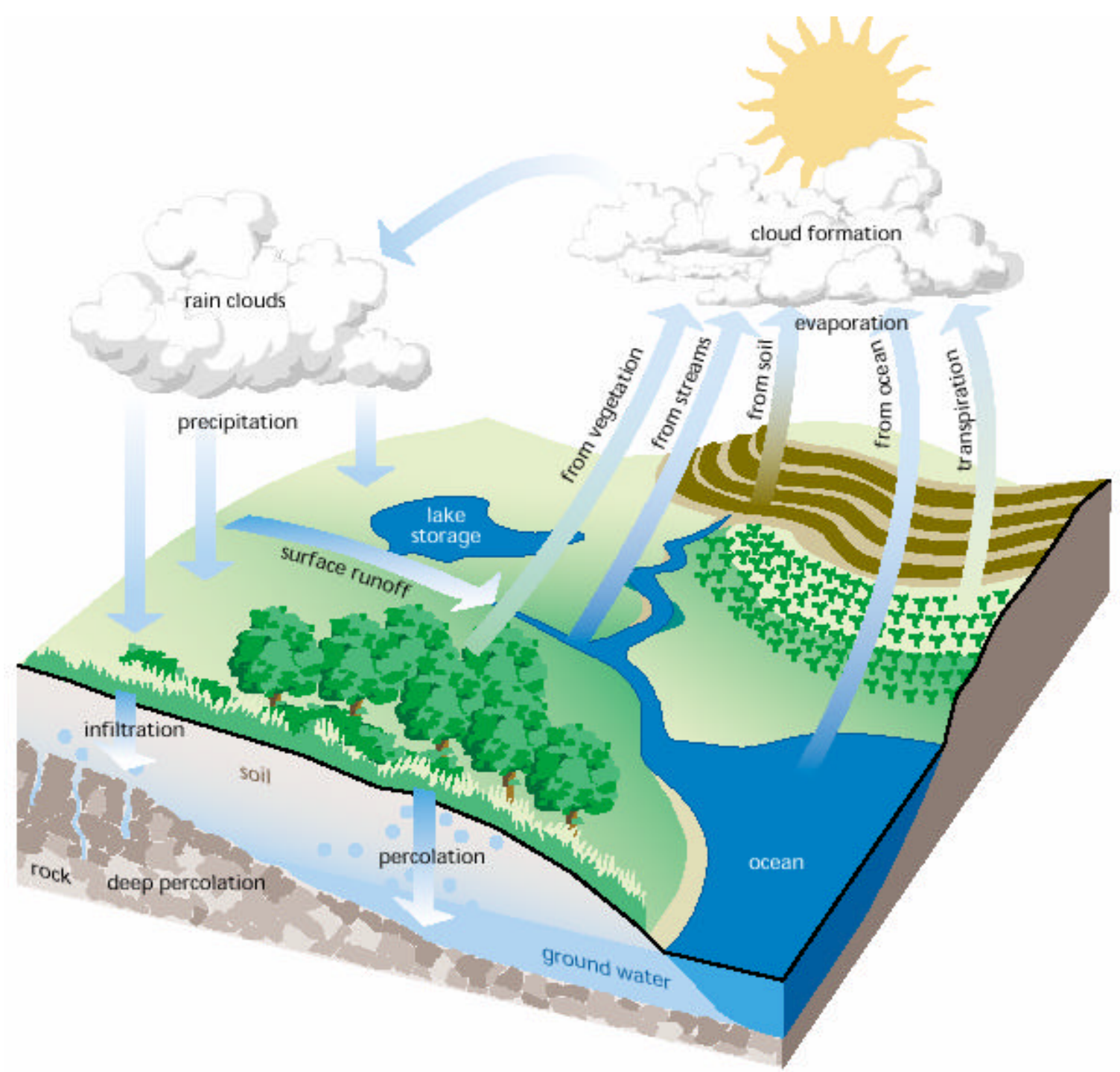

Excerpted from USDA (1998).

Figure 2.1. Watershed Hydrological Cycle 


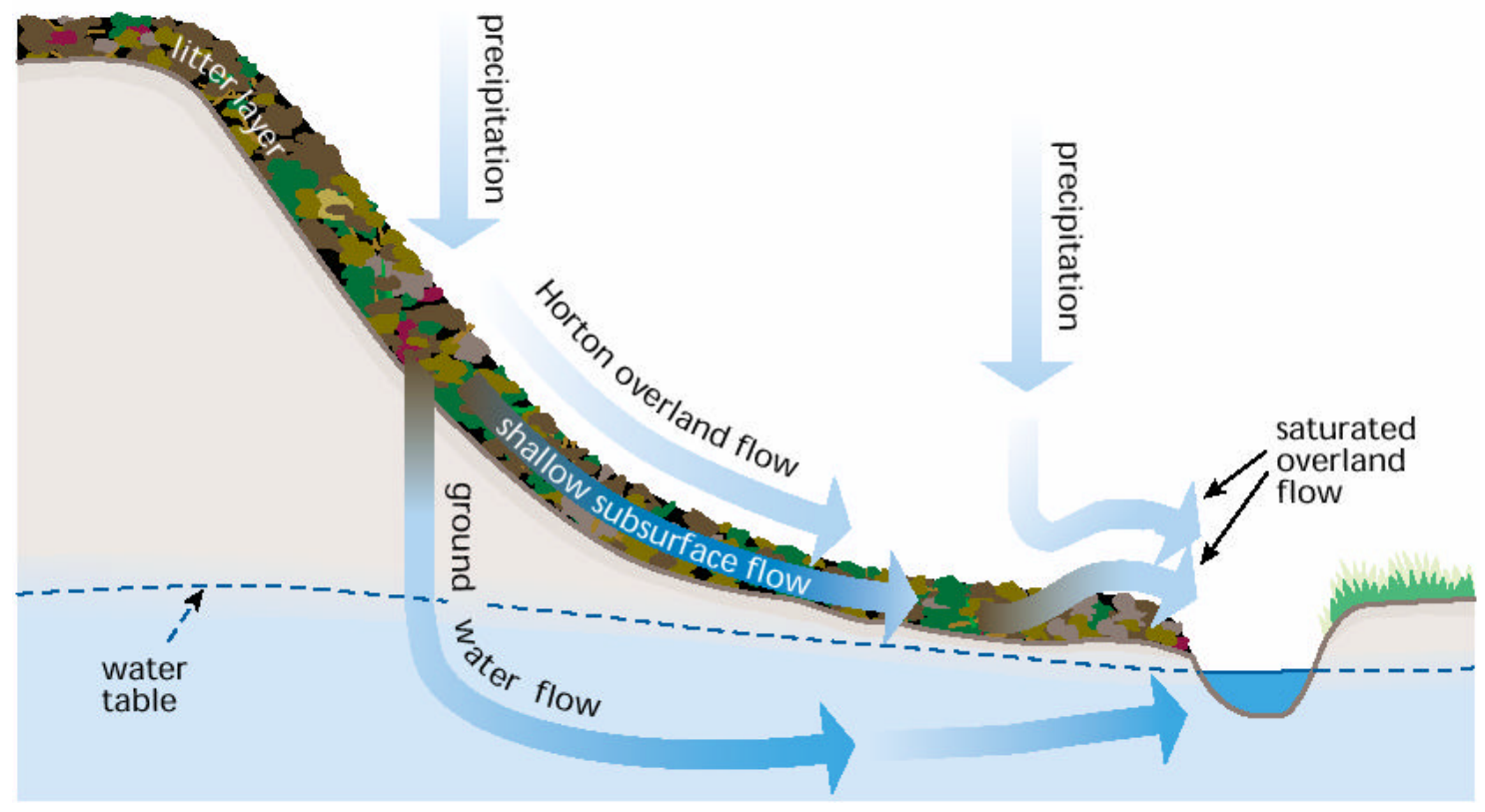

Excerpted from USDA (1998).

Figure 2.2: Hydrological Paths of Stormwater Runoff

The USDA curve number procedure and the Universal Soil Loss Equation (USLE) are empirical models used to describe runoff and erosion. They describe hydrological processes in many popular simulation models, such as AnnAGNPS, CREAMS, SWAT, BASIN, and HEC. The USDA curve number method estimates runoff volume as a function of precipitation and infiltration, where infiltration is determined by the hydrological condition of the soil and land use (USDA, 1986; McCuen, 1982; Chow et al., 1989). Although the curve number method is very popular and easy to use, it does not account for the effects of intensity, duration, and distribution of rainfall, as well as the effect of surface roughness (Chow et al., 1989). The accuracy of the model is very sensitive to changes in soil moisture (USDA, 1986; Hawkins and 
VerWeire, 2005). The USLE method estimates the amount of soil losses from a given field, as a function of rainfall, soil erodability factors, slopes, land cover, and management factors (Renard et al, 1997; Wischmeir and Smith 1978). The USLE method predicts the average annual soil loss from sheet and rill erosion, but cannot provide information on deposition or concentrated flow phenomena (i.e., sediment yields) (Jolanki et al., 1999). Analysis of sediment routing is needed to calculate sediment yields at the watershed outlet.

Physically - based approaches have been developed to mathematically model the mechanisms of overland flows and infiltration. The Green-Ampt infiltration model and Horton's infiltration equation have been developed to describe the physical phenomenon of infiltration (Scoging, 1992; Wang 1995; Parsons and Abrahams, 1993; Moore et al., 1991). Examples of simulation models based on physical equations include WEPP, PRMS, WASIM-ETH, TALES, and TAPES-C (Wang 1995; Singh 1995; Uhlenbrook and Leibundgut 2002; Canter, 1996).

The Saint-Venant equations explain the movement of overland flows in time and space, and are formulated based on the continuity and momentum equations (Maidment, 1993; Wang 1995). However, their complexity prohibits a full implementation of the Saint-Venent equations, and they are often overly simplified and used only numerically (Haque 2002; Szymkiewicz 2002; Dominique et al., 1999). The Kinematic-Wave approximation is a widely used simplified form of these equations to describe overland flows (Scorging 1992; Maidment, 1993; Dominique et al., 1999). However, even simplified Saint-Venant equations are still difficult to be readily implemented in watershed models. The watershed simulation models often include many different 
components to describe the physical processes, and use of the Kinematic-Wave approximation may be computationally costly. Rather, current models are built by improving the empirical runoff models with physical equations. For example, the curve number method is often modified and improved by re-calibrating the soil moisture process using the Green-Ampt equation (Nearing et al., 1995, 1996).

NPS pollutants can be transported in soluble or insoluble forms, depending on the physical, biological, and chemical characteristics of the surrounding environment and the types of pollutants (Novotny 1999; Robien et al., 1997). The transport mechanisms can be inert (i.e., conservative) or reactive (i.e., nonconservative). The physical processes of pollutant transport mechanisms include advection and dispersion (Bobba, 2000; Brusseau et al., 1994). Advection describes the movement of pollutants in the trajectory of water flows, and dispersion of pollutants is caused by molecular diffusion and shear stress caused by velocity variation. Fick's law is used for diffusion and the continuity equation (i.e., the mass balance equation) for advection (Chapra, 1997; AWWA, 1990). Chemical and biological reactions among pollutants can occur. A chemical reaction may redistribute mass among gas, liquid, and solid phases, and can change the concentrations of pollutants in the streams. The solubility of compounds is important to understand chemical reactions of dissolution-precipitation. Sorption and desorption processes are also important chemical reactions to be accounted for in measuring detached or entrapped NPS pollutants (Snoeyink and Jenkins, 1980; Tchobanoglous and Schroeder, 1985; Chapra, 1997). Chemical reactions for NPS pollution are often simulated assuming that a thin soil surface zone interacts with stormwater runoff (Bingner and Theurer, 2001; Wang 1995). Existing NPS simulation models such as CREAMS, ARM, ANSWERS, 
and AGNPS, estimate chemical entrainment using empirical equations and account for advection transport mechanism in overland flow during rainfall events (Foster et al., 1981; Bouraoui and Dillaha, 2000; Yoon et al., 1993; Reyes et al., 1995; Wang 1995; Singh, 995; Julien 1995). Refer to Sun (2001), Cryer et al.(2001), Hunsaker et al. (1995) for NPS simulation models for sediments, nutrients, and pesticides.

\subsubsection{Watershed Modeling}

Using scientific knowledge and observations on watershed hydrology, a number of watershed hydrological and water quality models have been developed and implemented. These models can be characterized as (1) deterministic or stochastic, (2) mechanistic (i.e., statistically-derived) or functional (process-based), (3) lumped or distributed, and (4) continuous or event based (i.e., single storm event) model (Moore and Gallant, 1991; Singh 1995). Stochastic/probabilistic models include consideration of uncertainty and probability in hydrologic processes, while deterministic models (i.e., physical model) assume that model variables follow a predictable and certain behavior (Zielinski and Ponnambalam, 1994). Depending on their spatial scale, models can be distributed or lumped by hydrological unit groups (Léon et al., 2001; Hornberger and Boyer, 1999). Distributed systems at finer spatial resolutions can better account for the variability of site characteristics, while homogenous hydrological units sharing the same characteristics are used in lumped models. Kite and Kouwen (1992) propose a "zonal approach", which subdivides areas only if different land-use or land-cover characteristics are visible. 
Process-based simulation models account for the generation and transport of stormwater runoff and NPS pollutants (Jolánkai et al., 1999; Jordon et al., 1997; Bingner and Theurer, 2001; Toy et al., 2002; Beighley and Moglen, 2003; Novotny and Chesters, 1982; Singh, 1995; Arnold et a1., 1995). Analytically-described surface water dynamics are embedded into these models. These models are implemented in a distributed or lumped fashion, and are used to identify best management practices (BMPs) to mitigate NPS, under multiple land-use scenarios and for critical locations (Hundecha and Bárdossy, 2004; Land et al., 2001; Kepner et al., 2004). Some relevant NPS models include ARM-HSPF (Donigian and Davis, 1995). AGNPS (Young et al., 1989), ANSWERS (Beasley and Huggings, 1982), CREAMS (Kinsel, 1980), SWAT (Arnold et al., 1995), and SWWM (Krysanova et al., 1998). However, these models cannot guarantee optimality, as they cannot provide an explicit link between locational land-use changes and pollution yields at the watershed outlet. Assigning disaggregated cumulative pollution loads to pollution sources is not possible with watershed modeling alone.

Empirical modeling provides a more explicit linkage between water and land, but surface water dynamics are not considered explicitly. Some models have been developed to relate water quality/NPS indicators to land use using regression analysis (Gordon and Majumder, 2002; Aspinall and Pearson, 2000; Hunsacker and Levin, 1995; Roth et al., 1996; Young and Jarvis, 2001). For example, indicators that represent pollution potential and cumulative impacts (e.g., biological indicators such as the Index of Biotic Integrity) are estimated as functions of water quality variables, landscape indicators, or amounts of different land-use types in the watershed. Some indices are also created using the physical equations used in simulation models (e.g., universal soil erosion equation), or 
based on human activities (chemical uses, tillage practices) and local physical characteristics (Johnson et al., 2001; Millward and Mersey, 2001). However, the empirical approach is limited to the spatial processes of transport of NPS and its delivery to waterways. Also, environmental/ecological variables are scale dependent and often cannot address local environmental characteristics at a high level of spatial resolution.

\subsection{Land-Use Planning and Optimization}

Optimization is a mathematical method to find a best or optimal solution to given problems. It has been widely used for resources allocation/management and even for comprehensive planning. It is capable of integrating all relevant information in a systematic fashion and allows users to understand the behavior of the decision variables to attain the desired goals. Solutions from an optimization model are guaranteed to be optimal under all imposed requirements and constraints. Optimization models can be easily extended to generate planning alternatives under identical or modified planning goals, with significantly different considerations and conditions. The outputs of alternatives can be easily evaluated and quantified. They can also be used to guide policy-makers to alter specific policies to induce desirable outcomes, providing a variety of policy and planning alternatives and their consequences (Hopkins, 1974; Skjei, 1972; Chang et al., 1979, 1980).

Applied to land-use planning, optimization is used as a systematic process to allocate different land uses and activities to specific locations/zones to meet certain constraints and planning goals. In this section, the role, use, and limitations of optimization for land-use and environmental planning are reviewed. A number of 
examples of land-use optimization models are explored, with special attention to conceptual structure and important modeling components.

\subsubsection{Land-Use Planning Models}

Land-use planning models are necessarily rooted in economic theory, to understand activity systems and their interrelations. The objective functions and constraints are developed on the basis of economic principles. The problem is often framed as the allocation of exogenously-determined populations or land-use types, while keeping the system in equilibrium. To build such a model, it is necessary to understand the economic and social interactions among different land-use zones. Therefore, spatial economic models are often used to model such relationships. The underlying assumption of these models is that land-use activities are the outcomes of the growth of economic activities and population. Models are generally formulated to maximize net profits while keeping supply and demand for land in equilibrium.

In the early stages of land-use optimization modeling, the use of linear programming was dominant, due to its simplicity and ease of computation. However, linear models cannot be used to model interdependent land-use decisions simultaneously (Hopkins, 1979). The model becomes more complicated as the interactions between different land-use zones or between land uses and transportation are considered. Models with interdependency involve integer or nonlinear programming.

Land-use planning should be comprehensive. It is desirable to fully describe planning problems and goals and to analyze the impacts of missing objectives. As a 
consequence, problems are often formulated with multiple planning goals and a method to assess the missing objective is developed.

\subsubsection{Fundamentals of Land-Use Planning Models}

By the nature of their applications, land-use planning models should be able to deal with spatial interrelationships among entities. It is often assumed that there are different activity zones (with, in many cases, exclusive activities) in the region. The goal of the optimization model is to allocate population and land uses within the region to maximize net benefits while minimizing costs. The interactions between land uses and transportation are one of the most important considerations. To understand regional growth patterns and spatialeconomic interrelationships, economic theory and socialphysics models (such as the gravity model) come into play. The objective functions and constraints sets are formulated largely based on economic constraints. Most land-use planning models are formulated at the regional scale.

The Lowry (1965) model is a classic example of a land-use planning model, developed as a system of equations. Although it is not an optimization model, some derivative models have introduced analytic functions subject to the Lowry equations as constraints. The model allocation is to reach equilibrium among land uses, populations, and economic activities over a given region, where the area is classified into different types of land-use tracts, according to major economic activities. The problem may be formulated as the minimization of development costs subject to supply (i.e., land-use availability) and demand (i.e., exogenously determined land activities.) constraints. Urban land use is expressed as a function of employment, and a gravity model is used to 
describe the spatial interrelationships among different land-use sectors. Odland (1976) models the location patterns of employment, residential populations, and transportation, and proposes a theoretical land-use planning model to relate these three components. It evaluates the impacts of economic agglomeration and produces more detailed land-use location patterns, assuming a large finite number of non-overlapping and exclusive zones. The objective function to minimize represents the costs of production, transportations, and living, in a nonlinear form.

A general equilibrium approach is also used by Andersson and Persson (1979), to allocate transportation commodity flows dynamically with determined, yet variable growth rates over a region. The ultimate goal is to maximize the regional growth rate for the production system while the transportation flows are optimally allocated to support such growth. The idea of equilibrium is derived from two economic principles: equilibrium in consumer commodities and neoclassic welfare economics. The problem is formulated based on the closed, interregional, and dynamic input-output model. Lundqvist (1973) also analyzes the mutual relationship between land-use patterns and the transportation network. The previously discussed models simplify the complexity of the real world by disregarding dynamic aspects, separating transportation planning from the spatial allocations of land uses, by pre-assigning activities and avoiding the simultaneous treatment of interdependencies, by aggregating land-use zones with clustering techniques, and by using an iterative scheme over time. To overcome these shortcomings, Lundqvist models individual behavior under uncertainty with a normative welfare criterion, via sensitivity analysis, and explicitly treats interdependencies, indivisibilities, and economies of scale, by adopting a hierarchical urban structure. The interrelationship 
between transportation and land-use allocation is expressed through a quadratic function, but this nonlinear function cannot be solved by conventional optimization techniques. Therefore, a two-stage modeling framework is suggested to solve this problem - a trial land-use allocation is determined first, and then transportation patterns are analyzed based on the pre-assigned land uses. In these two stages, a different level of spatial and sectoral aggregation is assumed, and this modeling framework is extended to a dynamic approach, by incorporating the time component for the economic aspects of land-use planning, such as the temporal variations of production activities. Environmental considerations are also made, assuming that a low density decentralized urban structure is environmentally favorable. However, the mathematical formulation of the model does not explicitly deal with the environmental quality indicators.

The land-use model by Hartwick and Hartwick (1974) also displays the interrelationships between land uses and transshipments/transportations. The model is formulated to locate production sites (i.e., urban areas) among undeveloped large agricultural areas at a minimum development and transshipment cost. Unlike Lundqvist (1973), who allocates land uses prior to analyzing transportation patterns, Hartwick and Hartwick (1974) analyze first commodity flows and transshipment patterns, and then locate land uses. The proposed developing area is divided into regular-sized grid cells and mass balance constraints for commodity flows in each grid cell are implemented in four different directions (N, S, E, W). Integrating land use into a transportation model, land allocation is based on the results of transportation flow simulation within the optimization model framework. The spatial scale is rather coarse, as it represents the size 
or degree of urbanization according to production capacity and the required transshipments for each cell.

The interactions between land use and transportation are more broadly investigated by Coelho and Williams (1978). This model is more advanced than the Lowry model, because the decision-making process is evaluated at an individual level and residential choices are determined by the distance to work and shopping. Lundqvist and Mattsson (1983) take a further step in the spatial allocation of land uses. Although their model is restricted to the spatial allocation of residential zones, it distributes a given population into residential areas on the basis of their accessibility to work places and population density. It is aimed at long-term as well as short-term land-use planning, considering residential land use patterns. Assuming that residential land-use patterns are influenced by the transportation network, a quadratic program is developed to minimize population density and the travel time from one zone to the other. Two objectives are combined by using weights.

Smith and Liebman (1978) feature the simultaneous optimization of land-use assignment and transportation network design. A hierarchical structure of the region is adopted, with three planning levels: regional, urban-design, and architectural. The regional planning level deals with land-use zones/districts, the urban design planning level is related to the site design of land use zones (i.e., housing types, street patterns, etc), and the architectural planning level is to layout detailed building structures and arrangements. In addition, transport network flows are uniquely defined by zero-one formulations from one sub-area to another. The objective of the model is to minimize the total costs of the assignment and transportation. 
Karlqvist (1977) summarizes the challenges for land-use planning models. Limited knowledge and a shortage of the required data can lead to misrepresentation of the actual planning goals and problems, and to omission of important planning objectives and constraints. Planning objectives can be very abstract and may not be always translatable into mathematical terms. The output from an optimization model may not be optimal if important planning issues are missing in the model. The results may be very sensitive to omitted objectives and constraints. Sensitivity analyses should be implemented to evaluate the reliability of the solutions (Taha, 1971).

Also, the assessment and comparison of planning objectives are often made by using ratings and indicators. Indicators represent abstract planning concepts in the model formulations, and ratings are used to express preferences in integrating multiple goals. However, constraints or objective functions defined by these measures can be abstract and misleading, and might be irrelevant in representing realworld problems. Another difficulty is related to the treatment of incommensurable objectives. This problem can be solved if different objectives are expressed in the same measurement units (such as monetary units). The grand objective functions then can be written as the weighted sum of all individual objectives.

\subsubsection{Multi-objective Land-Use Planning}

Evaluation and integration of incommensurate multiple objectives are done with multi-objective programming. The advantage of the multi-objective approach is to optimize independent objectives simultaneously. Multi-objective problems are often reduced to a single objective functions through utility and efficiency functions (Gilbert et 
al., 1982). The utility function is a linear transformation function, which integrates multiple objectives, using the preferences of decision makers.

Barber (1976) demonstrates the use of the utility function to combine independent, incommensurate, and conflicting objectives into urban land-use design, such as minimization of land development costs, minimization of energy consumption, and maximization of residential accessibility. The utility function is interactively formulated and updated with the preferences of the decision-makers and planners, which provides weights to the objectives. On the other hand, Gilbert et al. (1982) deal with multiobjective optimization problems by generating efficient solution sets. This method avoids the involvement and interactions of decision-makers to generate a utility function. Rather, a number of alternative plans are iteratively generated by selecting a single objective, to improve over its current level to acceptable levels (determined by the decision makers), and then the procedure is repeated for the remaining objectives.

The multiobjective programming model by Dökmeci et al (1993) takes a very different approach. Rather than applying utility and efficiency principles, their method is based on the critical comparisons of the alternatives. The most important objective (i.e., more preferred objective) is first optimized to explore the feasible solution space, and then the remaining objectives are optimized sequentially, to search for the optimal solution. Their problem is to maximize economic returns, while minimizing the sum of weighted distances among different land uses. Land-use allocation is determined while considering not only economic, physical, and social suitability, but also the surrounding areas or the overall land pattern. This approach is used because the objective functions are very complicated and direct searching methods for solution sets are not available. 
Through sensitivity analyses of these alternative sets, the weights for each objective are determined, and then the multiobjective functions are integrated and expressed as one combined function

\subsubsection{Optimization Approaches to Environmental Problems}

Some land-use optimization models consider environmental quality and include this component in their model objective or constraints. However, environmental considerations are often overly simplified or analyzed implicitly. For example, a landuse planning model may be formulated to favor a low-density decentralized urban pattern for sustainability (Lundqvist 1973), or the model may prefer a small and compact landuse pattern to reduce its impact on the surrounding environment (Gilbert et al, 1982, 1985). On the other hand, a number of optimization models are formulated for water resources problems. This section provides an overview of the uses of optimization models for environmental management, with special attention to water quality problems. Refer to Greenberg (1995) for more applications of mathematical programming models to environmental quality control.

\subsubsection{Land-Use Planning Models with Environmental Considerations.}

In most cases, the environment is considered by formulating constraint sets to meet environmental quality and regulations requirements. For example, the land-use model by Chang et al. $(1979,1980)$ sets aside floodplain zones from land allocation. The urban land planning model by Guldmann (1979) presents a classic land-use model with environmental considerations. While the land-use models presented in the previous 
discussion heavily emphasize socio-economic factors, Guldmann (1979) focuses on the allocation of land-use activities while considering environmental, as well as socioeconomic impacts. This comprehensive model analyzes the impacts of industrial landuse expansion and its impacts on population growth, residential land use, the transportation network, and air quality. The model incorporates the time component, uses integer programming, and accounts for the impacts of relocating industrial plants over time. The objective function is to minimize pollution abatement costs and fuel costs. The model is a mixed-integer linear program. The application to the Haifa metropolitan area shows how these different components are integrated for explicit spatial analysis.

Taking a further step, Guldmann (1987) presents a conceptual modeling framework to integrate environmental planning into land-use planning. The basic problem is to allocate land uses for maximum regional welfare, subject to technological, mass balance, locational, and environmental constraints. The model is comprised of five subsystems: land-use, residuals generation, centralized treatment, the natural environment, and externality reception systems. The basic decision variables in the above subsystems include land-uses, pollution abatement measures at the sources, centralized treatment systems characteristics, environmental interactions, and protection/treatment measures at the receptor sites.

The land-use subsystem describes the interrelationships between land-use activities and sites. This subsystem links land-use activities, generated in-situ residuals, and pollution abatement measures at a given location. The final amount of residuals are assumed to be released directly into the environment or sent to the central treatment 
systems. The centralized treatment subsystem is to describe the interactions among the treatment systems, treatable residuals, and untreatable residuals (which will be sent to the disposal site). The environmental subsystem shows the residual inputs to the environment and their interactions with other media such as air, water, and land. The receptors of the residuals include passively-used land for agriculture, outdoor recreation, or residential areas. The basic equation of the environmental subsystem represents mass balance, expressed as a first order differential equation system. The externality reception subsystem expresses the effects of the standard enforcement constraints for the activities at the given locations through protection/treatment measures. Guldmann (1987) suggests extending this comprehensive model to account for short-term and long-term changes in land, in order to evaluate the variability of environmental quality and to guarantee the attainment of environmental standards over time. Pollution emission balance, concentration calculations, environmental standard constraints, socio-economic changes, technology advances in pollution abatement, and population shifts are considered to model temporal dynamics.

Overall, the environmental components in the land-use model are overly simplified to handle spatial and temporal dynamics. Environmental interactions are represented by a constant and linear reaction/transfer coefficient. As Guldmann (1987) noted, conventional environmental/land use planning modeling is limited for NPS pollution control, because of its complexity and randomness. The next section discusses water quality optimization models used to handle point and nonpoint source pollution. 


\subsubsection{Optimization for Water Quality Control}

\subsection{Point Source Pollution}

Previous optimization applications to water quality problems have mostly focused on point source pollution. An optimization model may be used to determine the locations and treatment capacity of water supply or wastewater stations to meet regional water quality and quantity requirements (Deininger and Su 1973, Das and Haimes 1979). Applications also include the design of water utility network systems. The basic problem is formulated to minimize capital and operational costs, while meeting the requirements of water demand and environmental quality. The most widely used water quality indicator is biological oxygen demand (BOD) or dissolved oxygen (DO). The BOD-DO reaction is often linearized along the stream.

Graves et al. (1969) suggest bypass piping to control for wastewater, using linear programming. Optimization is used to determine which share of the wastewater to discharge into less polluted water bodies, so that the pollution loads into treatment facilities are within capacity, without violating the ambient water quality standards in any part of the water body. Using linear programming, the spatial distributions of bypass pipes and the cost allocation among polluters are determined. Following this study, Graves et al. (1972) propose a comprehensive regional water quality management model, where the locations of the treatment facilities, pollution treatment at the polluters' sites, and piping network systems are evaluated simultaneously. Pollution load balances at dischargers and at regional plants, and water quality requirements are formulated as constraints, and the objective is to minimize pollution abatement costs and transport piping costs. 
Ecker (1975) proposed an optimization model to allocate different water treatment facilities (locations and capacity) along a river. The stream is divided into smaller reaches, and the ambient water quality is investigated in each reach. BOD and DO are used as water quality variables. The objective is to minimize the operational and capital costs for treatment plants, subject to dissolved oxygen deficit constraints. After evaluating pollution loads in each reach, an optimal treatment plan is selected to handle pollution loads, considering combinations of available treatment options. McNamara (1976) provides a general water quality management model capable of assessing different pollution abatement techniques. It simultaneously considers waste treatment processes, bypass piping, flow regulation, and artificial aeration. The objective is to minimize total treatment costs, while accounting for pollution standards and the technical/legal limitations of different abatement techniques. The constraints are simplified for geometric programming, as shown by Ecker (1975). Similarly, Arbabi and Elzinga (1975) present a linear water quality optimization model to ensure water quality in the stream, using BOD and DO. Assuming that the river is a closed system, each stream segment is checked for the BOD standard.

Deininger and Su (1973) present a model to find the locations and numbers of treatment plants for multiple water basins. The problem is to minimize the total costs for treatment facilities and waste transport, including flow network and piping to central treatment facilities. The constraint sets are formulated using the mass balance equation, to trace wastewater from one node to another, eventually linking it to the treatment facilities. 
The above studies are examples of optimization models to handle PS problems. The motivation of these studies is to develop economically efficient regional water management plans. Therefore, the planning objectives are to minimize total costs for treatment facilities, waste transport, and further treatment of residuals in stream, and to find the best combination of treatment options and their locations. The optimization takes the form of linear, nonlinear, or geometric programming. Water quality is mainly measured in terms of DO and/or BOD. Therefore, the optimal solutions may not be the best way to treat different pollution loads, and synergistic reactions with other pollutants cannot be accounted for in such models. In summary, the previous optimization models for water resources are inadequate to describe biological, chemical, or physical processes in the environment. Also, note that the discussed models are formulated at a large regional scale.

\subsubsection{Nonpoint Source Pollution}

Model formulation for NPS problems is more difficult than for PS problems for at least three reasons: (1) the analysis of NPS pollution requires an understanding of the precipitation-runoff-pollution transport processes, which cannot be written in a closedform equation in the optimization model; (2) there are no evident effluent water quality standards to regulate them; and (3) NPS processes involve more explicit spatial analysis and spatial interaction modeling at a very detailed spatial scale.

NPS water pollution is strongly correlated with land-use activities and land cover, and is addressed via area-wide planning. However, there is no clear method to link pollution sources (i.e., spatial land-use patterns) to cumulative pollution, and therefore it 
is difficult for land-use mangers to select different BMP options and their locations in the watershed. Optimization can be used to overcome these challenges. Advanced knowledge on watershed hydrology and NPS pollution processes and improved computing power allows for the formulation of optimization models that can support this spatial decision making.

Haith (1982) presents a model to handle stormwater runoff from dairy farms and to select best management practices for nutrient and sediment reduction. The challenge in formulating the optimization model is to evaluate cumulative NPS impacts from multiple dairy farms. Effluent pollution loads from large farms are estimated, and sediment and nutrient losses due to infiltration or vegetation uptakes are parameterized. A linear program is applied to maximize net economic benefits, while minimizing soil and nutrient (nitrogen and phosphorous) losses from field areas. NPS generation and transport processes are very much simplified and parameterized in this model. The constraint which addresses on-site (or field) sediment/nutrient losses is not clear and explicit, as there is no specific environmental quality requirement in this field. Pollutant runoff routing is not considered, and therefore the pollution load to the stream is unknown. Since NPS pollution concentration is a function of climate, topography, geology, land uses, and human activities, finding reasonable parameters to represent their spatial interactions can be difficult, if not impossible.

The integrated water quality and land-use planing model by Das and Haimes (1979) is formulated using multiobjective optimization. Presenting a real case of the land-use planning problem in the Maumee River Basin $(\mathrm{OH})$, this study delivers a general framework of (agricultural) land-use planning and water quality modeling for PS and 
NPS. The multiobjective optimization program is formulated to: (1) minimize the total cost for water quality and management of point and nonpoint pollutants, (2) minimize sediment erosion, (3) minimize phosphorus runoff, and (4) minimize BOD, while meeting constraints for agricultural productivity and land availability. To deal with these incompatible objectives, the Surrogate Worth Trade-Off (SWT) method is proposed. According to this method, the first objective (minimization of the total pollution abatement costs for NPS/PS) is selected as the primary objective, while the other three objectives are set up as constraints expressing the maximum tolerable pollution level.

\subsection{Optimization for Spatial Land Pattern}

Improvement in computing resources and computational algorithms have stimulated studies that optimize configurations of the landscape to design spatially explicit land-use plans. These models are used: (1) to design spatially cohesive conservation-reserve systems to meet biodiversity requirements, to protect habitats, or to manage natural resources (McDonnell et al., 2002, Seppelt and Voinov 2002; Hof et al., 1999; Loehle 2000), and (2) to support spatial locations, shapes, and attributes for specific land-use patterns (Williams 2003, 2002; Cova and Church 20000; Williams and ReVelle 1996; Gilbert et al., 1985; Pressy et al., 1996, 1997; Diamond and Wright, 1989). Spatial attributes such as contiguity, compactness, proximity, shape of patches, perimeters, and number of patches are considered and modeled.

This type of optimization is very challenging and computationally intense, as it requires a detailed spatial analysis of the landscape, and formulation of optimization models that describe complex constraints. Models are formulated as nonlinear or integer 
programs, or combination of them, and are difficult to solve mathematically and numerically (McDonnell et al., 2002; Possingham, 2000; Williams 2003, 2002; Williams and ReVelle 1996; Gilbert et al., 1985). Improvements in computing and algorithms allow for solving these problems mathematically (if not too complicated or too large), or heuristic-based optimization methods such as the genetic algorithm (GA) or simulated annealing (SA) are used to tackle these problems. In general, the problems are formulated to minimize land acquisition costs, while satisfying requirements for spatial attribute characteristics. Landscape indicators and graph theory are also widely used to formulate spatial attribute constraints. Spatial pattern optimization is an important research area and current methods need to be improved to accomplish its goal: (1) mathematical programs are still limited to solve small-size and relatively simple problems; (2) ecological indicators can be misleading and are erratic ways to measure desirable spatial attributes; and (3) the outputs from heuristic methods must be carefully analyzed to assess their optimality.

\subsection{Integrated Simulation and Optimization Approach}

To analyze the spatial variability of land-use changes and to delineate land-use patterns reducing NPS pollution, optimization methods have been recently integrated into process-based models (Kalin et al., 2004; Srivastava et al., 2002; Muleta and Nicklow 2002; Veith et al., 2004). These models are used to find types and locations of BMPs at field or watershed scale. The integrated simulation-optimization approach is also used to assign cumulative sediment yields to sources (inverse problem), by analyzing 
sedimentographs generated at the catchment level within the watershed (Kalin et al. 2004).

Srivastava et al. (2002) applies a genetic algorithm (GA) to manipulate the input parameters (such as land-use practice parameters) of the (semi) distributed erosion model. The combination of the input parameters that provides the best result is declared the optimum solution, and is used to determine the type and locations of BMPs. The integrated simulation-optimization approach is also used to assign cumulative sediment yields to sources (inverse problem), by analyzing sedimentographs generated at the catchment level within the watershed (Kalin et al. 2004). Veith et al. (2004) apply a GA to improve current BMP management strategies, using a scenario-based approach (i.e., targeting) and a sediment simulation model. The goal is to find alternative management plans which provide NPS reduction as compared to current plans, but at lower costs.

Muleta and Nicklow (2002) propose an integrated NPS and land-use multiobjective model, which controls sediments while meeting other socio-economic goals in a watershed. The Strength Pareto Evolutionary Algorithm (SPEA), a GA based multiobjective optimizer, is integrated into the SWAT model and is used to generate a Pareto-optimal set. SWAT is a continuous (long-term), distributed, erosion simulator. The modeling unit is a Hydrologic Responses Unit (HRU), which is delineated by partitioning the watershed on the basis of characteristics such as vegetation type, precipitation distribution, slope, aspect, and soil type. The goal is to minimize the annual average sediment yield and to maximize the annual average economic benefits for farms. Constraints are developed from the physical equations that describe hydrological 
processes, and crop management practices. The combination of BMPs is first selected randomly for a HRU, and then updated by a GA algorithm.

Recent heuristic-based approaches seem to be very promising and efficient, providing better alternatives for scenario-based land management (targeting) plans. Compared to previous NPS optimization models, they capture the spatial heterogeneity and the interactions of land and water, and decisions are made based on more accuratelyestimated NPS pollution loads. They are proven to be cost effective and to reduce NPS pollution to a greater extent than BMP plans by targeting. A number of alternative management plans are generated, and this approach may require less a priori knowledge of the watershed for management. However, these combined approaches require technical skills and expertise to implement such computing models, as they are not readily available to users at this time. Even with current computing resources, an integration of process-based simulation and optimization models is still limited to smallsize problems with coarse spatial resolutions. More importantly, results from heuristicbased optimization models cannot be assessed in terms of their optimality, or nearoptimality. 


\section{CHAPTER 3}

\section{MODELING METHODOLOGY}

This chapter presents the research issues, assumptions, and methodology. The general modeling approach involves a stormwater runoff simulation model, hierarchical multi-step regression analysis, quadratic land-use optimization, and the integration of the runoff simulation model with nonlinear land-use optimization. This multi-step approach is adopted to quantitatively reflect watershed hierarchy, to model the spatial relationships between land and water, and to search for optimal land-use patterns at a high level of spatial resolution.

\subsection{Issues and Assumptions}

The following issues are raised and investigated:

1. Is watershed hydrology strongly influenced by the spatial pattern of land use?

2. What is the best way to quantify the land-water relationship, while accounting for:

a. The spatial variability of the physical characteristics of the watershed, and

b. The spatial processes/interactions of stormwater runoff?

3. Where are the critical areas to be preserved or developed in the future? How can these areas be prioritized? 
4. What is the maximum amount of land development that can take place in the watershed, without having detrimental impacts on watershed hydrology? What is the minimum amount of land conservation within the watershed?

5. How can an optimal future land-use pattern, which minimizes the hydrological impacts of land-use changes, be delineated?

To simplify the spatial analysis of nonpoint source (NPS) water pollution and land use changes, two assumptions are made: (1) there is a positive correlation between stormwater runoff and NPS pollution, and (2) the peak discharge rate is a sensitive indicator of detrimental hydrological impacts. Therefore, the land-use optimization model is formulated to minimize the peak storm runoff discharge rate at the watershed outlet.

The positive correlation between NPS pollution and storm runoff is widely accepted, and numerous statistical and simulation models of NPS pollution have been built on the basis of this assumption (Jolánkai et al. 1999, Jordon et al., 1997). The physical equations describing soil erosion and transport capacity are also expressed as a function of surface runoff volume and peak runoff rate (Bingner and Theurer, 2001). Previous studies have concluded that reducing storm runoff decreases nonpoint source pollution. Also, field monitoring data obtained in the study area, the Old Woman Creek watershed, show a strong tie between sediment flux and the storm runoff hydrograph. The highest suspended sediment concentrations occur immediately prior to the peak discharge, and the sediment flux is derived from the observed storm runoff hydrograph (Matisoff et al., 1998). 
The proposed land allocation model reduces the peak discharge rate instead of the total runoff volume, because the peak discharge rate represents a more sensitive response to the intensity of rainfall, unlike the surface runoff volume. Therefore, the peak discharge rate can be considered as a more sensitive indicator of detrimental hydrological impacts, such as on-site flooding. According to the extended TR55 method, which was adapted to represent the hydrograph of the watershed in this study, the peak discharge rate is calculated as a nonlinear function of runoff volume and time of concentration (Bingner and Theurer, 2001). Details of the TR-55 method are discussed in Section 3.2 2, where the hydrological modeling approach is described. The proposed modeling methodology can be easily expanded to account for actual NPS pollution, by linking NPS pollution generation to land use. If NPS pollution processes were included, the land allocation model would be set up to reduce pollution yield at the watershed outlet.

\subsection{Modeling Approach}

\subsubsection{Overview}

Two important features of the proposed methodology are: (1) the integration of hydrological and land-use allocation modeling, and (2) multi-spatial hierarchical optimization. The integrated modeling approach allows for investigating the spatial impacts of land-use changes and their hydrological interdependency. On the basis of the runoff simulation results, the critical locations for conservation and optimal land-use patterns are simultaneously delineated in the optimization model.

The multi-spatial hierarchical optimization approach is proposed to systematically understand the impacts of land use at different spatial levels, by reducing the complexity 
of spatial analysis. The integrated land-water modeling at a high resolution (30 meter) requires a large programming model and huge computing resources. The hierarchical approach is to efficiently deal with a large spatial system, expediting the land allocation processes in a watershed while preserving spatial cohesiveness at each stage. This topdown approach is very useful to understand the general hydrological response of land-use changes at the watershed level first, then to make more specific decision making in geographically more specific and refined areas.

The hierarchical approach has been widely used in environmental and ecological modeling, because it helps manage the complexity of a system by isolating the dynamics at one level and by ignoring details at lower levels (O’Neill et al.,1986, 1988, 1996). Similarly, this approach is applied to watershed system hierarchy, based on their physical characteristics and stream network configuration. Four different modeling (hierarchical) units are proposed: (1) the watershed, (2) the sub-watershed, (3) the drainage area, and (4) the cell. The watershed is the largest modeling unit, and is delineated by the USGS. This is the "official" boundary of any watershed in the U.S. The subwatershed is a subdivision of the watershed. The drainage area is created by subdividing the subwatershed into smaller units. The cell is the smallest spatial unit, with a resolution of 30 meters. The watershed hierarchy is consistent with the recommendations by the USGS (McCammon, 1994).

Five sub-models are proposed. The first is to investigate the issues of spatial variability and interdependency of land uses in the watershed hydrology. The second is to develop and estimate an empirical function, describing the relationship between locations and amounts of land uses in a given watershed, and the runoff discharge rate. 
The third is to optimally allocate land uses at the watershed and subwatershed levels, using this function and a nonlinear programming algorithm. At the subwatershed level, the second and third sub-model processes are applied to determine the land allocation at the drainage area level. Once the land allocation at the drainage area is determined, the integrated hydrological - nonlinear land-use optimization model is applied at the cell level. This fourth sub-model is to numerically evaluate changes in the objective function, resulting from very small changes in land uses, cell by cell and land use by land use. This algorithm is based on standard principles of nonlinear programming, using the gradient as direction of steepest ascent (Wagner 1976), and leads to local optima only. To improve the solution from this nonlinear program, a combinatorial statistical optimization approach is used to analyze the distributions of local optima (Los and Lardinois, 1982) and to investigate their relationship with the initial solution, using regression. The Weibull distribution is utilized to analyze local optima. The overall modeling approach is outlined in Figure 3.1. Details of each sub-model are discussed in the following sections. 


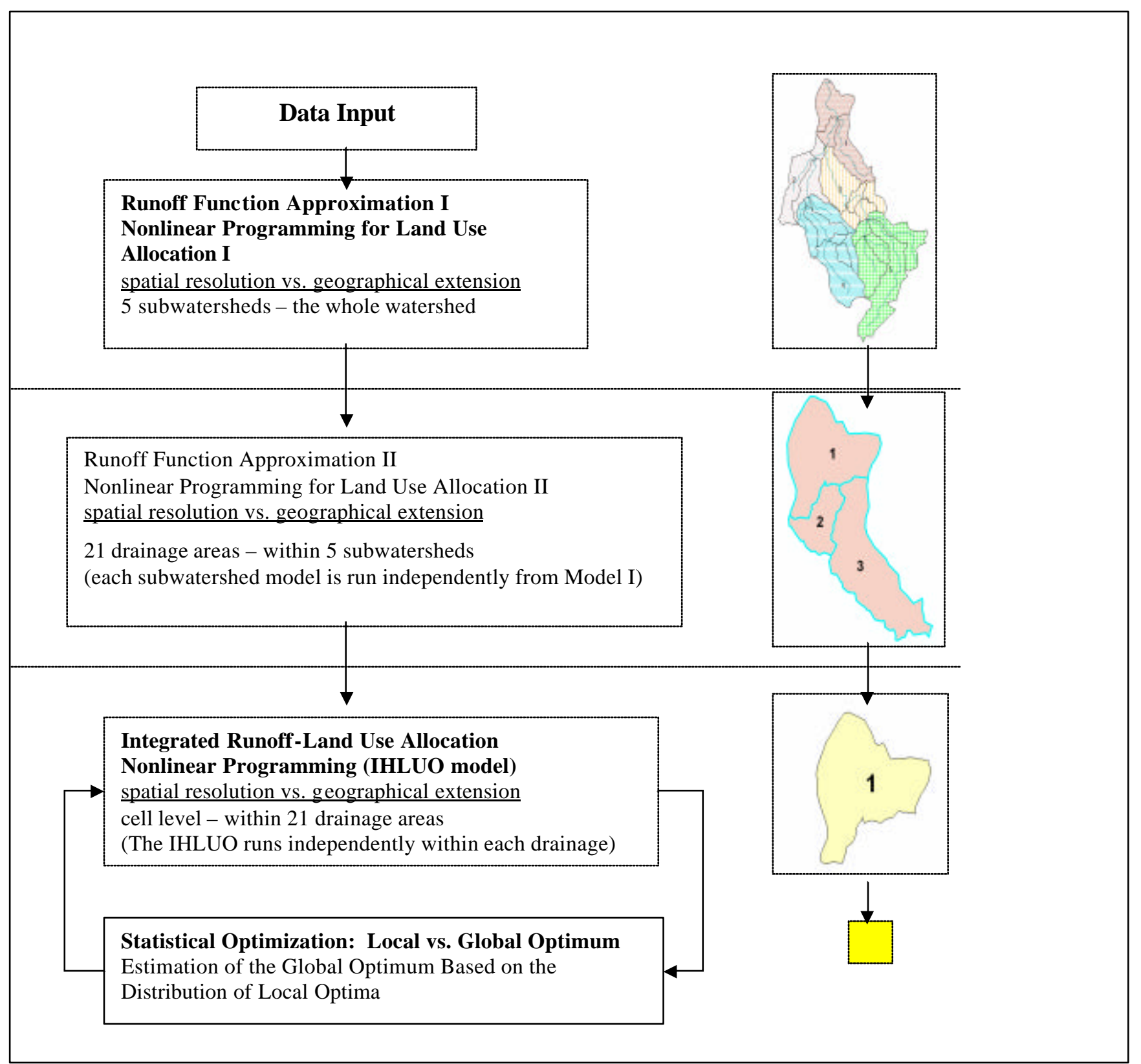

Figure 3.1: Multistage Land-Use Optimization Framework. 


\subsubsection{Hydrological Simulation Model}

To investigate the locational impacts of land-use changes on watershed hydrology, the runoff model is implemented as a cell-based distributed system. The model is developed at a high resolution (30 meters). Since all the spatial data used for input parameters in the hydrological simulation are provided at the 30-meter resolution, this resolution is a natural choice for modeling, and eliminates the need to aggregate spatial data. The model is therefore able to account for detailed spatial variations within the watershed, and hopefully to provide better estimates.

Two types of models were considered - physically-based and empirically-based. A physically-based model is developed from the mathematical equations describing the runoff phenomena. These equations, the Saint Venant equations, have been found to be too complex and difficult to implement. They have been simplified to become the kinematic wave model, the diffusion wave model, and the dynamic wave model for practical computer modeling (Chow et al 1989, Singh 1995). However, these simplified versions of physical models are still too complicated for the purpose of this research. When combined with the optimization model, the runoff model is required to simulate the storm runoff change with respect to land-use changes occurring in every cell. The high resolution hydrological simulation and the consequent optimization process require huge computer resources. As the improvement of physically-based models is beyond the scope of this study, these models are not further considered.

A typical empirical model is based on the statistical analysis of field data to measure the rainfall-runoff processes. A curve number is developed to link the impacts of on-site land uses and soil types to storm runoff. Due to its simplicity and good 
accuracy, when compared with actual measurements, this model has often been used. The conventional SCS curve number models yield lumped effects of land-use changes in a watershed, a subwatershed, or a field, but cannot account for the spatial effects of landuse changes (McCuen 1982, USDA 1986).

To meet computing resources constraints and to evaluate the locational impacts of land-use change, the SCS curve number method (a.k.a. the TR-55 method) is modified to create a spatially explicit runoff model. A spatially explicit hydrological model was implemented in a GIS environment by Moglen and Beighley (2002), who applied a spatially-weighted and dynamically-changing curve number for each cell. Similar to this GIS approach, the proposed model is implemented by considering the watershed as a networked system of flow cells. The distributed cells are interconnected through flow paths, and form a stream network system within the watershed boundaries (Maidment, 1993). Then, two model assumptions are made: homogeneity and linearity. The physical properties of the cells are assumed to be homogeneous. The second assumption is based on the fact that the runoff process tends to be linear as the flow increases (Pilgrim 1993, Olivera 1996). In this model, linearity is assumed at the water cell level as well as at the watershed level. This assumption leads to the application of the proportionality and superposition principles in the model.

The SCS curve number method involves the equation:

$$
Q=\frac{(P-0.2 S)^{2}}{P+0.8 S}
$$

where $\mathrm{Q}$ is the volume of runoff, $\mathrm{P}$ is the precipitation, and $\mathrm{S}$ is the retention parameter, which is estimated from the runoff curve number $(\mathrm{CN})$ with Equation (3.2): 


$$
S=\frac{100}{C N}-1
$$

Details on this method are provided by McCuen (1982), USDA (1986), and Bingner and Theurer (2001).

Under the assumption of homogeneity applied at the watershed or catchment level, the conventional SCS approach calculates the curve number as a weighted average for the modeling unit, watershed or catchment, and updates it with changes in land use/cover. In the proposed model, the curve number is explicitly calculated for a given cell, under the assumption of homogeneity at the cell level. The runoff volume $\mathrm{Q}$ then characterizes the cell.

Under the linearity assumption, the runoff process at the cell level is described by a first-order linear differential equation (Chow et al., 1989)

$$
\frac{d S_{i}}{d t}=I_{i}-Q_{i}-\lambda_{i} S_{i}
$$

where $S_{i}$ denotes moisture storage, $I_{i}$ the input, $Q_{i}$ the runoff, $\lambda_{i}$ the loss coefficient, and $i$ the ith flow cell. Equation (3.3) applies the principle of conservation of matter and states that the change in the water content of cell $\mathrm{i}\left(\mathrm{d} \mathrm{S}_{\mathrm{i}} / \mathrm{dt}\right)$ is equal to the balance between inflows $\left(\mathrm{I}_{\mathrm{i}}\right)$ and outflows $\left(\mathrm{Q}_{\mathrm{i}}\right.$ and $\left.\lambda_{\mathrm{i}} \mathrm{S}_{\mathrm{i}}\right)$. This process is illustrated in Figure 3.2 in the case of a hypothetical path made of three consecutive cells. In this model, precipitation $(\mathrm{P})$ is assumed to be uniformly distributed over the watershed.

The flow path is determined by topography. Stormwater runoff flows throughout the entire watershed area to its outlet according to the watershed topography. The flow routing is determined by the D-8 method (i.e., eight flow direction), which assigns the runoff on a given cell to the lowest-elevation cell, among the eight surrounding cells 
(O'Callaghan and D. M. Mark, 1984). Figure 3.3 illustrates the fundamentals of the D-8 method.

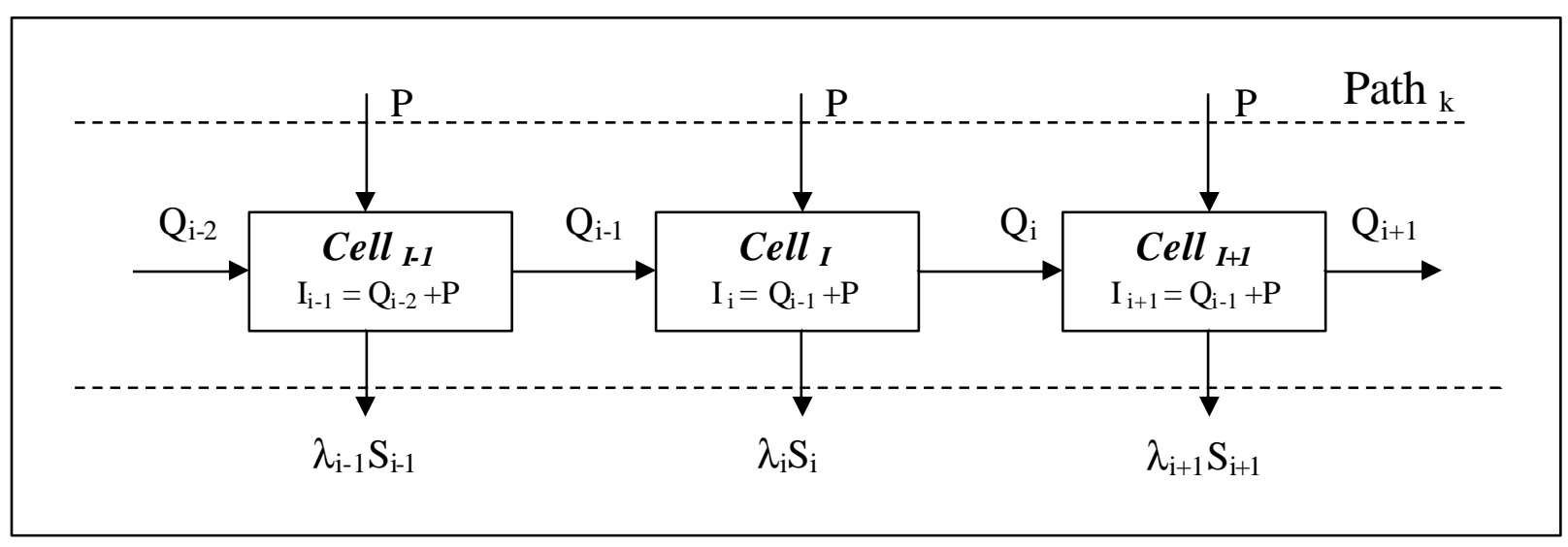

Figure 3.2: Runoff Process and Flow Path

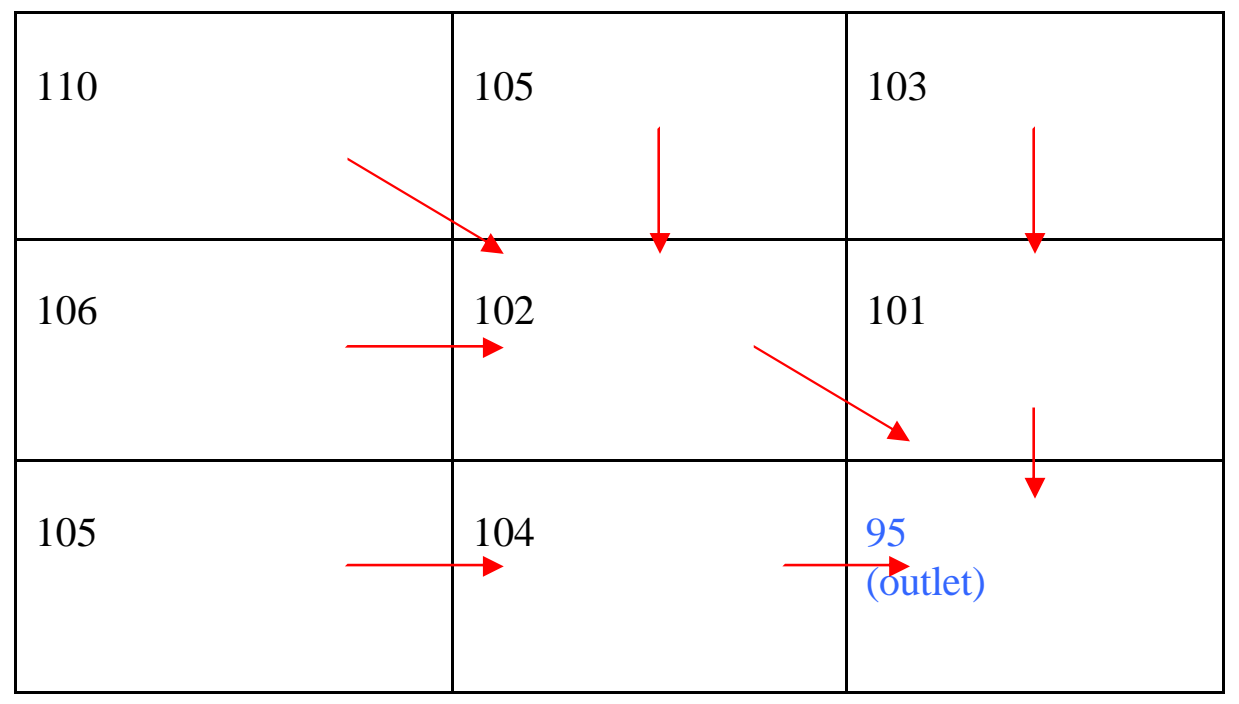

The number inside a cell indicates its elevation and the arrow indicates the flow path directions.

Figure 3.3: Illustration of the D-8 Method 
Since the watershed system is assumed to be linear, the properties of linearity, proportionality and superposition are applied. The runoff process is analyzed at the flow cell level, then at the flow path level, then at the subwatershed level, and finally at the whole watershed level, down to the outlet. The runoff over a flow path is obtained by summing up the storm runoffs occurring at the flow cells along the flow path (See Figure 3.2). The total runoff at the watershed outlet is obtained by summing up the runoffs occurring along all flow paths within the watershed (Olivera 1996), with:

$$
\begin{aligned}
& Q_{p}=\sum_{\mathrm{i} \in p} Q_{i}: \text { volume of storm runoff from flow path } \mathrm{p}, \\
& Q_{c}=\sum_{\mathrm{p} \in c} Q_{p}: \text { volume of storm runoff from drainage area c, } \\
& Q_{s_{w}}=\sum_{\mathrm{c} \in S_{w}} Q_{c}: \text { volume of storm runoff from subwatershed } \mathrm{s}_{\mathrm{w}}, \\
& Q_{w}=\sum_{s_{w} \in w} Q_{s_{w}}: \text { volume of storm runoff from watershed } \mathrm{w}
\end{aligned}
$$

where $\mathrm{Q}_{\mathrm{i}}$ is the flow over cell $\mathrm{i}$ along flow path $\mathrm{p}, \mathrm{p}$ is a path within drainage area $\mathrm{c}$, and $\mathrm{c}$ is located within subwatershed $\mathrm{s}_{\mathrm{w}}$, which is a subset of watershed $\mathrm{w}$. The runoff process is analyzed at the cell, path, subwatershed, and finally watershed levels, down to the outlet. By adopting this cell routing approach based on the linearity assumption, the distributed water flow cells are integrated systematically into a whole watershed, and the SCS method can be used as a spatially explicit model. While the method of cumulating runoff from cell to watershed is adapted from Maidment (1993), the distributed SCS method is an original contribution of this research.

Similar processes are applied to estimate the time of concentration. Travel time is determined for each cell according to its flow type: overland flow, shallow concentrated 
flow, or channel flow (USDA, 1986). Three different methods are drawn from the TR-55 model (see USDA 1988), and are used to approximate the travel time for each cell, depending on its flow type. Surface roughness, channel shapes and flow patterns, and slope are the main factors affecting time of concentration and flow time. Overland flow is estimated using Manning's kinematic solution, and channel flow is calculated by Manning's equation. The velocity from shallow concentrated flow cell is calculated using the empirical formula developed by USDA. Using field observations, the shallow concentrated flow cell velocity is expressed as a function of watercourse slope and type of channel. See TR-55 for details of this method (USDA, 1986).

The travel times of all the flow paths to the watershed outlet are calculated by summing up the travel time at the cell of each cell along the paths, and the maximum travel time is selected as the time of concentration. After calculating the time of concentration and the total amount of runoff, the peak runoff rate is determined using the extended TR-55 procedure (Bingner and Theurer 2001). The peak rate is determined as follows:

$$
Q_{p}=2.78 \cdot 10^{-3} P_{24} D_{a} \cdot\left[\frac{a+\left(c \cdot T_{c}\right)+\left(e \cdot T_{c}^{2}\right)}{1+\left(b \cdot T_{c}\right)+\left(d \cdot T_{c}^{2}\right)+\left(f \cdot T_{c}^{3}\right)}\right]
$$

where $\mathrm{Q}_{\mathrm{p}}$ is the peak discharge $[\mathrm{m} / \mathrm{s}], \mathrm{D}_{\mathrm{a}}$ the area of the spatial unit [ha], $\mathrm{P}_{24}$ the 24 hour effective rainfall over the total drainage area $[\mathrm{mm}], \mathrm{T}_{\mathrm{c}}$ the time of concentration $[\mathrm{hr}]$, and the constants $\mathrm{a}, \mathrm{b}, \mathrm{c}, \mathrm{d}$, e, and $\mathrm{f}$, the unit peak discharge regression coefficients, which are determined by the ratio of initial abstraction $\left(\mathrm{I}_{\mathrm{a}}\right)$ to 24 hour precipitation $\left(\mathrm{P}_{24}\right)$. Refer to Bingner and Theurer (2001) for the values of these coefficients. The model is storm- 
event-based and assumes the SCS hydrograph. Ground water flows are not modeled and this constitutes a limitation of the model.

\subsubsection{Regression Modeling}

The hierarchical statistical modeling approach is applied to characterize the relationships between peak stormwater runoff and spatial land-use patterns at multiple scales. Regression analysis is first applied at the subwatershed level, and second at the drainage area level. The following sections describe how data are generated and used to estimate these relationships.

\subsubsection{Modeling at the Subwatershed level}

The watershed is subdivided into $\mathrm{n}$ subwatersheds, based on their physical and geographical characteristics, and their hydrological relationships. A number of land-use patterns are generated and the runoff simulation model is used to estimate their peak discharge rates. Next, using regression analysis, this rate is related to the amounts of land uses. A systematic data sampling process is used to generate spatial patterns at various spatial levels, guaranteeing enough variability in terms of land composition and location, particularly in upland areas.

At the subwatershed level, different subwatershed combinations are chosen first.

The total number of all combinations is $\sum_{k=1}^{n}\left(\begin{array}{l}n \\ k\end{array}\right)$, where $\mathrm{n}$ is the total number of subwatersheds and $\mathrm{k}$ is the number of elements in each combination $(\mathrm{k}=1$ ? $\mathrm{n})$. See Table 3.1. for possible combination sets. Second, for each combination, different allocations of 
land uses ${ }^{1}$ (e.g., agriculture, conservation, and urban) are selected as follows: (1) fix the share of one land-use $\left(\mathrm{LU}_{1}\right)$; (2) randomly choose the share of another land-use $\left(\mathrm{LU}_{2}\right)$, so that the sum of the shares of $\mathrm{LU}_{1}$ and $\mathrm{LU}_{2}$ does not exceed 100\%; (3) the residual share $\left(100 \%-\mathrm{LU}_{1}-\mathrm{LU}_{2}\right)$ represents the third land use $\left(\mathrm{LU}_{3}\right)$. This procedure is repeated for all land-use types and for all the elements of a given combination set, as shown in Figure 3.4. For example, if a combination set with two elements is considered, the allocation process is repeated twice. The share of $\mathrm{LU}_{1}$ is varied by $5 \%$ increments (i.e., 20 allocation for each land use), and, in total, sixty different land allocations (i.e., 20 allocation * 3 land use type) are generated for each combination. Third, the precise spatial land use pattern corresponding to an allocation is generated randomly at the level of 30-meter cells. The land type assignment only occurs in the designated subwatershed areas by the chosen combination set, while the outside area remains in current condition. Sample maps created by the above procedure are presented in Figure 3.5. Finally, the runoff simulation model is run for this land-use pattern with a 1-year storm. A land management technique such as BMP is usually a conservative approach to control stormwater runoff and NPS. It alone may be not sufficient to handle larger storms, and constructive engineering measures are often required to control more intense storms. Therefore, the storm runoff estimation function and land allocation is only based on smaller-size storms, which can be handled efficiently by land-use practices.

\footnotetext{
${ }^{1}$ To simplify the stormwater runoff function and land optimization, only three land use types are considered: impervious urban cover, agriculture, and conservation. Detailed modeling parameters and their land cover types are discussed in the next section, Data Sources and Processing.
} 


\begin{tabular}{ll}
\hline $\begin{array}{l}\text { No. of } \\
\text { Elements }\end{array}$ & Possible Combinations \\
\hline 1 & $\{1\},\{2\},\{3\},\{4\},\{5\}$ \\
2 & $\{12\},\{13\},\{14\},\{15\},\{23\},\{24\},\{25\},\{34\},\{35\},\{45\}$ \\
3 & $\{123\},\{124\},\{125\},\{134\},\{135\},\{145\},\{234\},\{235\},\{245\},\{345\}$ \\
4 & $\{1234\},\{1235\},\{1245\},\{1345\},\{2345\}$ \\
5 & $\{12345\}$ \\
\hline
\end{tabular}

Table 3.1: Subwatershed Combination Sets

\begin{tabular}{|c|c|c|c|}
\hline Land Type & $\frac{\text { Urban }}{\left(\operatorname{LU}_{\mathrm{u}}\right)}$ & $\frac{\text { Agriculture }}{\left(\mathrm{LU}_{\mathrm{a}}\right)}$ & $\frac{\text { Conservation }}{\left(\mathrm{LU}_{\mathrm{c}}\right)}$ \\
\hline$\left(\mathrm{LU}_{\mathrm{u}}\right)$ & Fixed [1-100\%] & Random $\left(100-\mathrm{LU}_{\mathrm{u}}\right)$ & $100-\mathrm{LU}_{\mathrm{u}^{-}}-\mathrm{U}_{\mathrm{a}}$ \\
\hline$\left(\mathrm{LU}_{\mathrm{a}}\right)$ & $100-\mathrm{LU}_{\mathrm{a}}-\mathrm{LU}_{\mathrm{c}}$ & Fixed [1-100\%] & Random $\left(100-\mathrm{LU}_{\mathrm{a}}\right)$ \\
\hline$\left(\mathrm{LU}_{\mathrm{c}}\right)$ & Random $\left(100-\mathrm{LU}_{\mathrm{c}}\right)$ & $100-\mathrm{LU}_{\mathrm{u}}-\mathrm{LU}_{\mathrm{c}}$ & Fixed [1-100\%] \\
\hline
\end{tabular}

Figure 3.4: Land-Use Allocation Matrix

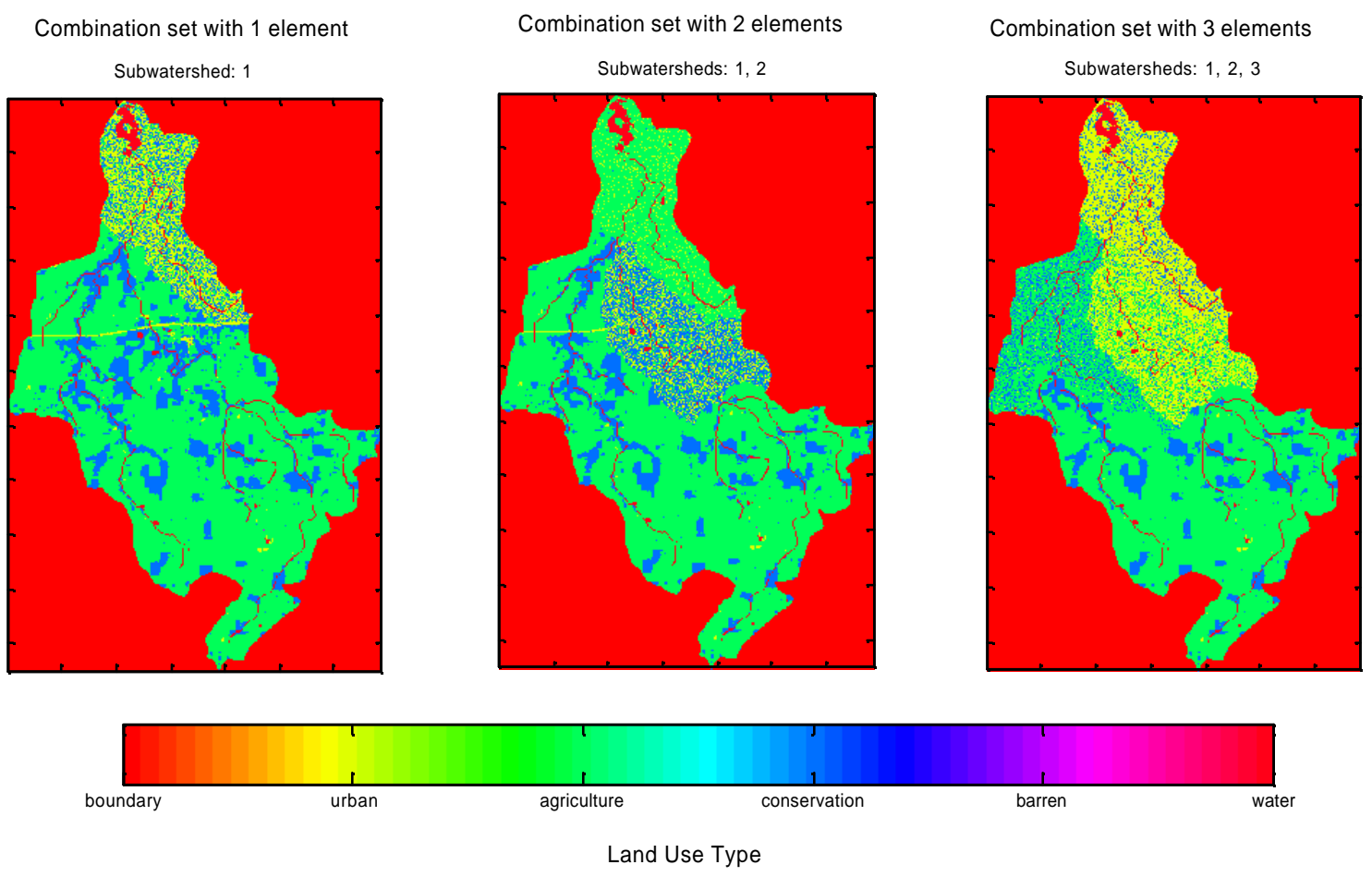

Figure 3.5: Sample Land-Use Map with Different Subwatershed Combination Sets 
Once the simulation pseudo-data are generated, an empirical relationship between peak runoff and land-use amounts is estimated using regression modeling. The peak discharge rate at the watershed outlet $\left(\mathrm{Q}_{\mathrm{p}}\right)$ is expressed as a function of the amounts of various land uses in each subwatershed, with:

$$
\mathrm{Q}_{\mathrm{p}}=\mathrm{f}(\mathbf{x}) \quad \mathbf{x}=\left\{x_{k}^{i}\right\}
$$

where $x_{k}^{i}=$ amount of land use $\mathrm{k}$ in subwatershed $\mathrm{i}$. The amount of land use is taken as a share $(\%)$ of the total subwatershed area.

\subsubsection{Modeling at the Drainage Area Level}

The same process carried on at the subwatershed level is repeated at the drainage area level. The modeling focus is the impacts of land-use changes within the drainage areas nested within a subwatershed, on the peak discharge at the subwatershed outlet, while accounting for stormwater runoff from upstream areas.

A data generation method similar to the one used for subwatersheds is applied to drainage areas. Different combinations of drainage areas are considered for each subwatershed. For each combination, sixty different land allocations (with 5\% increments of land-use changes) are determined at the 30-meter cell level. Figure 3.6 presents sample land-use maps generated for the drainage areas in subwatershed 1. 


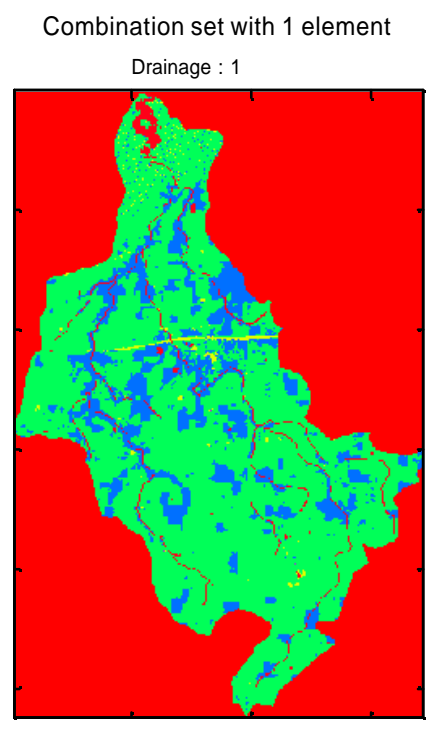

Combination set with 2 elements Drainage : 1,3

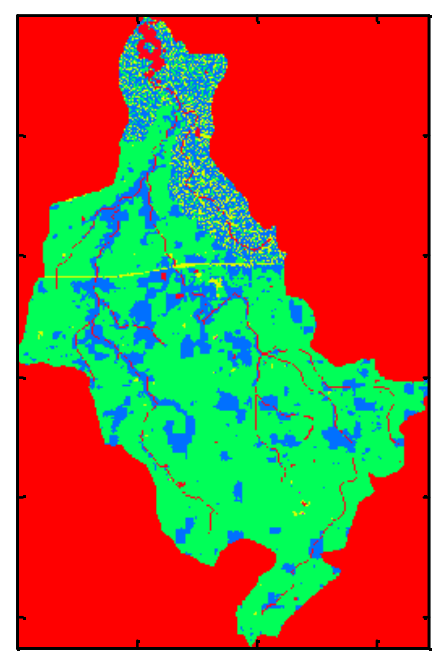

Combination set with 3 elements Drainage : 1, 2, 3

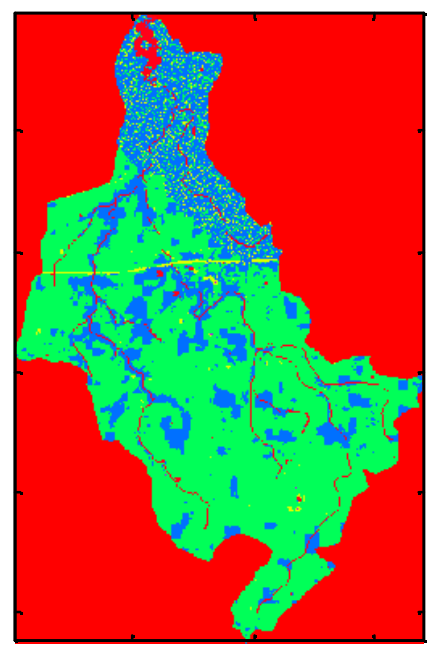

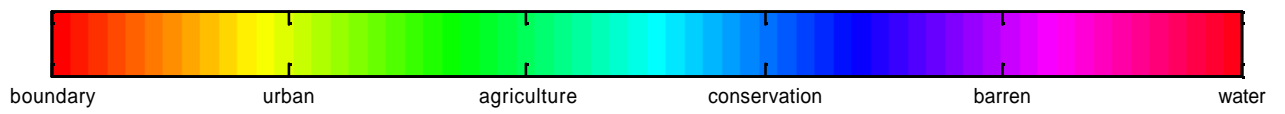

Land Use Type

Figure 3.6: Sample Land-Use Maps with Different Drainage Combinations in Subwatershed 1

Simulation pseudo-data are generated and used to relate the peak discharge rate at the subwatershed outlet to land-use amounts in the drainage areas, using regression analysis. Five different regression models are formulated for five subwaterdsheds. The function is slightly modified at this level, in order to account for stormwater runoff contributed by upstream subwatersheds. As described in the hydrological modeling section, the peak discharge rate (observed at the drainage area outlets, the subwatershed outlets, or the watershed outlet) is determined by two main parameters, the time of concentration and the total runoff volume. Instead of using the geographically longest distance as the longest hydraulic distance, the hydrological model used in this study 
traces all flow paths from the most upstream flow-initiating areas to the drainage, subwatershed, and watershed outlets. Upstream land-use patterns, therefore, can indirectly affect spatial land allocation in the downstream subwatersheds, by changing the time of concentration and total runoff volume. This physical phenomenon is accounted for by including the peak discharges from the upstream subwatershed(s) in the land-water relationship for the downstream subwatershed. Therefore, the peak discharge rate at the subwatershed $\mathrm{w}$ outlet $\left(Q_{s_{w}}^{i}\right)$ is expressed as a function of the amounts of various land uses in each drainage area of the subwatershed and the peak storm runoffs from upstream subwatershed(s), with:

$$
Q_{s_{w}}=f(\mathbf{x}), \mathbf{x}=\left\{x_{k}^{i_{s_{w}}}, \quad Q_{s_{w-1}}\right\}
$$

The amount of land-use $\mathrm{k}$ in drainage area $\mathrm{i}$ within subwatershed $\mathrm{w}, x_{k}^{i_{s_{w}}}$, is taken

as a share $(\%)$ of the drainage area. $Q_{s_{w-1}}$ is the peak discharge rate from the upstream subwatershed, w1. Agricultural land use does not appear in the model (Eq. 3.9 and 3.10) to avoid perfect collinearity, as the sum of three land-use shares is always $100 \%$. The detailed form of the function $\mathrm{f}(\mathbf{x})$ is discussed in Chapter 5 .

\subsubsection{Land-Use Optimization Modeling}

A land-use allocation optimization model is formulated, using the regressionestimated land-water relationship (3.9 - 3.10) as the objective function of the optimization model. A land allocation is determined hierarchically, from the watershed to the subwatershed, then to the drainage area, and to the cell. The land allocation at a higher 
level of the watershed hierarchy provides the boundary conditions for land-use constraints at the lower level.

The goal of the optimization model is to allocate land uses to minimize the peak discharge rate at the watershed outlet, subject to land-use constraints, with:

$$
\begin{gathered}
\text { Min } \mathrm{Q}_{\mathrm{p}}=\mathrm{f}(\mathbf{x}), \\
\text { subject to: } \\
\mathbf{x} \in \mathbf{X}, \\
\mathbf{x}=\mathbf{0},
\end{gathered}
$$

where $\mathbf{X}$, the feasible domain for the land-use variables, represents the constraints set. A similar optimization program is used to allocate optimal land uses at the drainage level, taking as constraints the total amounts of land uses determined at the subwatershed level.

\subsubsection{Integrated Hydrological - Land Use Optimization Model (IHLUO)}

Once land allocation is determined at the drainage level, the IHLUO model is applied to delineate spatially explicit land-use plans at the cell level, and to identify critical areas for conservation. The mathematical program for land-use allocation is formulated as:

$$
\operatorname{Min} f(X)=\text { Peak Runoff Rate at the Outlet }
$$

Subject to:

$$
\sum_{i=l}^{n} x_{i l}=T_{l} \quad \forall l=1,2, \ldots, m
$$




$$
\sum_{l=1}^{m} x_{i l}=1 \quad \forall i=1,2, \ldots, n
$$

where $x_{i l}$ is the amount of land use 1 in cell $i$, and $T_{1}$ is the total amount of land use 1 in the drainage areas. The objective function, $f(X)$, of the IHLUO is numerically evaluated using the runoff simulation model, in contrast to the empirically-formulated analytical functions used for the land allocation models at the subwatershed and drainage levels. The numerical evaluation of $\mathrm{f}(\mathrm{X})$ at the cell level is to fully capture spatial variability.

In general, the site allocation problem assumes exclusive site assignment (Aerts et al., 2003, Wright et al.,1983), e.g., only one facility can be assigned to one location. This notion is equivalent to a homogeneity requirement for a cell, i.e., allocating only one type of land use to a given cell. This is also the fundamental concept of the raster data structure used in mapping and Geographic Information Systems (DeMers 1997). The assumption of cell homogeneity requires that the decision variables $\left(\mathrm{x}_{\mathrm{il}}\right)$ be integer $(0$ or 1), indicating the absence or presence of a specific land-use type. However, the branchand-bound structure of integer programming, combined with nonlinearity and the need to compute $f(X)$ with the simulation model, renders the model nearly impossible to solve with any reasonable number of variables. As an alternative approach, the integer constraints are relaxed, and the land-use variables are taken as continuous: $\mathrm{x}_{\mathrm{il}}$ is defined as the proportion [0-1] of land use 1 in cell $\mathrm{i}$. The continuous land-use variable refers to a mixed land-use type at the cell level. This relaxation allows for solving the problem using standard optimization techniques, with the constraint (Eq. 3.16) that the sum of the different land uses in a given cell always equals 1 (normalized cell area). 
The challenge is now to solve a nonlinear program with an objective function that can only be evaluated through simulation. This problem is solved using sequential linear programming, also known as the method of convex combinations (Wagner 1976, Venkataraman 2001), with a linear approximation of the nonlinear objective function, through a first-order Taylor's series expansion. The linear approximation of the original function, $\mathrm{f}(\mathbf{Z})$, is:

$$
f(\mathbf{Z}) \approx f\left(\mathbf{X}^{k}\right)+\sum_{j=1}^{J} \frac{\partial f\left(\mathbf{X}^{k}\right)}{\partial x_{j}}\left(z_{j}-x_{j}^{k}\right)
$$

where $f(\mathbf{Z})$ is the linear approximation of the original function, $\mathbf{X}^{\mathrm{k}}$ is the $\mathrm{k}$-th trial point, $\left\{x_{j}^{k}\right\}$, and $\mathbf{Z}$ is any point in the neighborhood of $\mathbf{X}^{\mathrm{k}},\left\{\mathrm{z}_{\mathrm{j}}\right\}$.

With this linear approximation, the programming goal is now changed to minimize the second term, the sum of the first derivatives, subject to constraints (3.15) (3.16), and the model becomes a linear program. The advantage of using linear programming is that very large programs can be solved with this technique, in contrast to the size limitations of earlier techniques, such as dynamic programming (e.g., Hopkins et al. 1981).

Next, it is necessary to find the optimal step size (t) along the gradient $\left(\mathbf{Z}-\mathbf{X}^{\mathrm{k}}\right)$, with components $\left(z_{j}-x_{j}^{k}\right)$. To do so, the objective function is evaluated for steps varying in the interval [0-1], with increment of 0.01 . The step size yielding the minimum runoff is optimal one. Then, the decision variables are updated using equation (3.18):

$$
x_{j}^{k+1}=(1-t) x_{j}^{k}+t z_{j}, t \in[0,1]
$$


However, the linear approximation is not straightforward because the objective function is not analytically closed. To overcome this difficulty, the partial derivatives are approximated by a finite difference method (Guldmann, 1979b). This method numerically evaluates changes in the objective function (storm runoff at the watershed outlet), resulting from very small changes in land uses, cell by cell and land use by land use. The objective function is, each time, computed using the hydrological simulation model. The partial derivatives are approximated as:

$$
\frac{\partial f(\mathbf{X})}{\partial x_{k i}} \approx \frac{\Delta f(\mathbf{X})}{\Delta x_{k i}}=\frac{f(\mathbf{X}+\Delta \mathbf{X})-f(\mathbf{X})}{\Delta x_{k i}},
$$

where $\mathrm{f}(\mathbf{X})$ is the peak discharge rate.

A pilot study for a test drainage illustrates the complexity and irregularities (e.g., discontinuities) of the objective function computed with the simulation model. Figure 3.7 shows the computed peak runoff rates (i.e., the objective function) of the drainage outlet for various step sizes and for three iterations in the optimization process. The step size $t$ (see Equation (3.17)) varies between 0 and 1. In the first iteration, the function is minimized at $t=1$. In the second iteration, it is minimized at $t=0.2$, and in the third one at $t=0.8$. The pattern of variations in the objective function is characterized by abrupt discontinuities. The optimal step size at each iteration provides the initial point of the next iteration.

The optimization model is fundamentally nonlinear, and therefore, the optimal solution cannot be guaranteed to be the global one, without knowing the property of the objective function. An analysis of the distribution of local optima generated by the IHLUO is presented in Appendix A. The model results also provide mixed 
agricultural/conservation or urban/conservation land uses, due to using continuous decision variables, and may be unrealistic in practice. This issue constitutes an area for future research. The computing pseudo-code of the IHLUO model and the two-level regression-optimization models are presented in Appendix B.

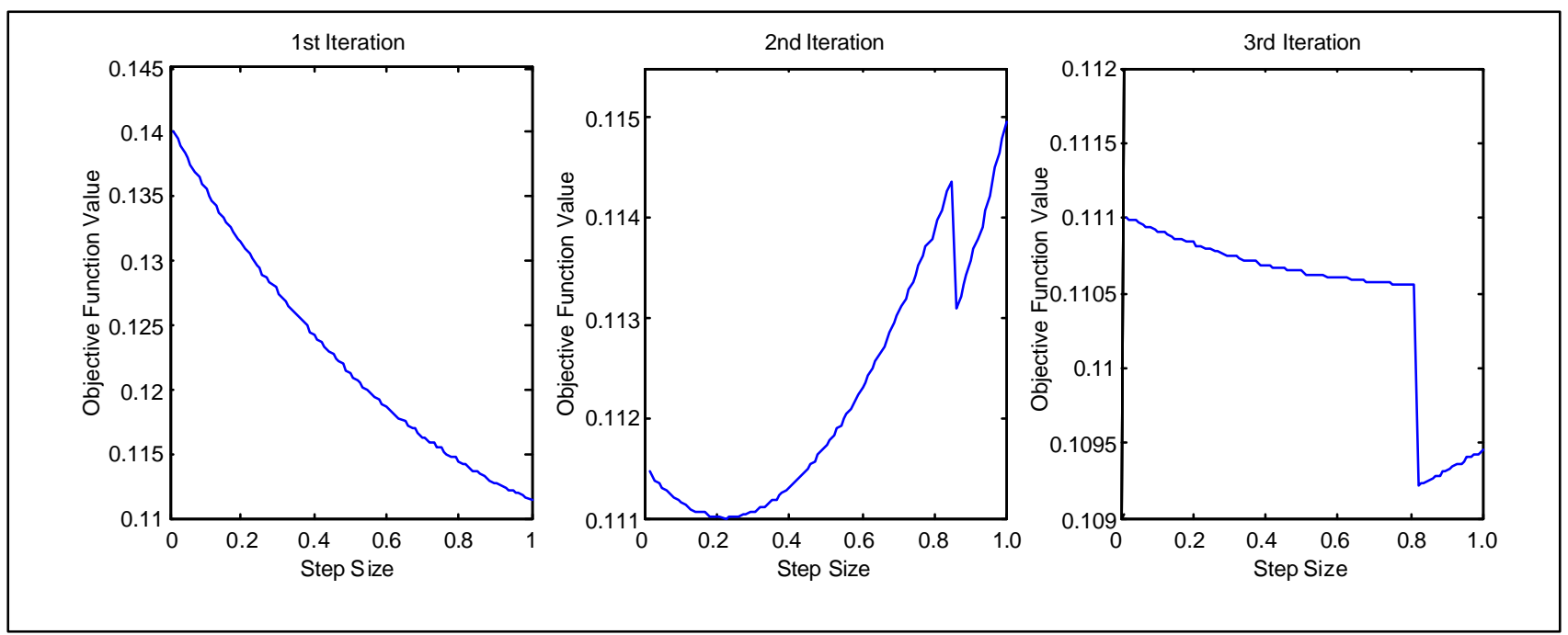

Figure 3.7: Step Sizes and the Behavior of the Objective Function 


\section{CHAPTER 4}

\section{DATA SOURCES AND PROCESSING}

This chapter provides a description of the data, their sourcess and processing

methods. A variety of data are used to characterize population, physical characteristics, land-use patterns/practices, and environmental conditions and policies in the study area.

\subsection{Overview}

Several spatial data sets are used to implement the modeling approach: (1) digital elevation from the USGS; (2) surface water features (National Hydrography Dataset) from the USGS-EPA; (3) soil data from the Soil Survey Geographic Database; and (4) land-use information from the Ohio Department of Natural Resources (ODNR). The land-use/cover information is interpreted from satellite images (Landsat Thematic Mapper), taken in September and October, 1994 and 2000. All data are provided at the 1:25,000 scale, with a 30-m resolution. Historical land-use and population trends in the study area and the state of Ohio are obtained from the US census and a public report from The Ohio State University Extension Program (Irwin and Reece, 2002). Land-use practices and policies in the watershed are assessed through personal interviews and published statistics [e.g., USDA Web site for the National Agricultural Statistics Service 
(http://www.usda.gov/nass/); Conservation Technology Information Center, 2002)]. Land-use practices and population trends are the basis for the land-use constraints used in the optimization model. All GIS data are projected into the UTM zone 17 with the North American Datum 1927. The detailed projection information is as follows:

\begin{tabular}{|c|c|}
\hline $\begin{array}{l}\text { Grid Coordinate } \\
\text { System: }\end{array}$ & $\begin{array}{l}\text { Grid Coordinate System Name: Universal Transverse Mercator } \\
\text { UTM Zone Number: } 17 \\
\text { Scale Factor at Central Meridian: } 0.9996 \\
\text { Longitude of Central Meridian: }-81.0 \\
\text { Latitude of Projection Origin: } 0.0 \\
\text { False Easting: } 500000 \\
\text { False Northing: } 0.0\end{array}$ \\
\hline $\begin{array}{l}\text { Planar Coordinate } \\
\text { Information: }\end{array}$ & $\begin{array}{l}\text { Planar Coordinate Encoding Method: coordinate pair } \\
\text { Coordinate Representation: } \\
\text { Abscissa Resolution: } 0.61 \\
\text { Ordinate Resolution: } 0.61 \\
\text { Planar Distance Units: Meters }\end{array}$ \\
\hline Geodetic Model: & $\begin{array}{l}\text { Horizontal Datum Name: North American Datum of } 1927 \\
\text { Ellipsoid Name: Clarke } 1866 \\
\text { Semi-major Axis: } 6378206.4 \\
\text { Denominator of Flattening Ratio: } 298.257\end{array}$ \\
\hline
\end{tabular}

Table 4.1: Spatial Reference Information 


\subsection{Description of the Study Area}

The modeling approach is applied to a coastal agricultural watershed, the Old Woman Creek (OWC), located in the southwestern basin of Lake Erie, between Cleveland and Toledo, Ohio. The watershed stretches across two counties (Huron and Erie) and over two townships (Berlin and Townsend), as presented in Figure 4.1. About $60 \%$ of this small watershed (total area $=68.6 \mathrm{~km}^{2}$ ) is used by agriculture. The OWC estuary functions as a transitional zone between land and water, preserving distinct habitats. In recognition of its significant ecological role, it was designated a National Estuarine Research Reserve (NERR) and State Estuarine Research Reserve (SERR) in 1980. Therefore, protecting this estuary from harmful ecological stressors, in particular from nonpoint source pollution, has become a priority.
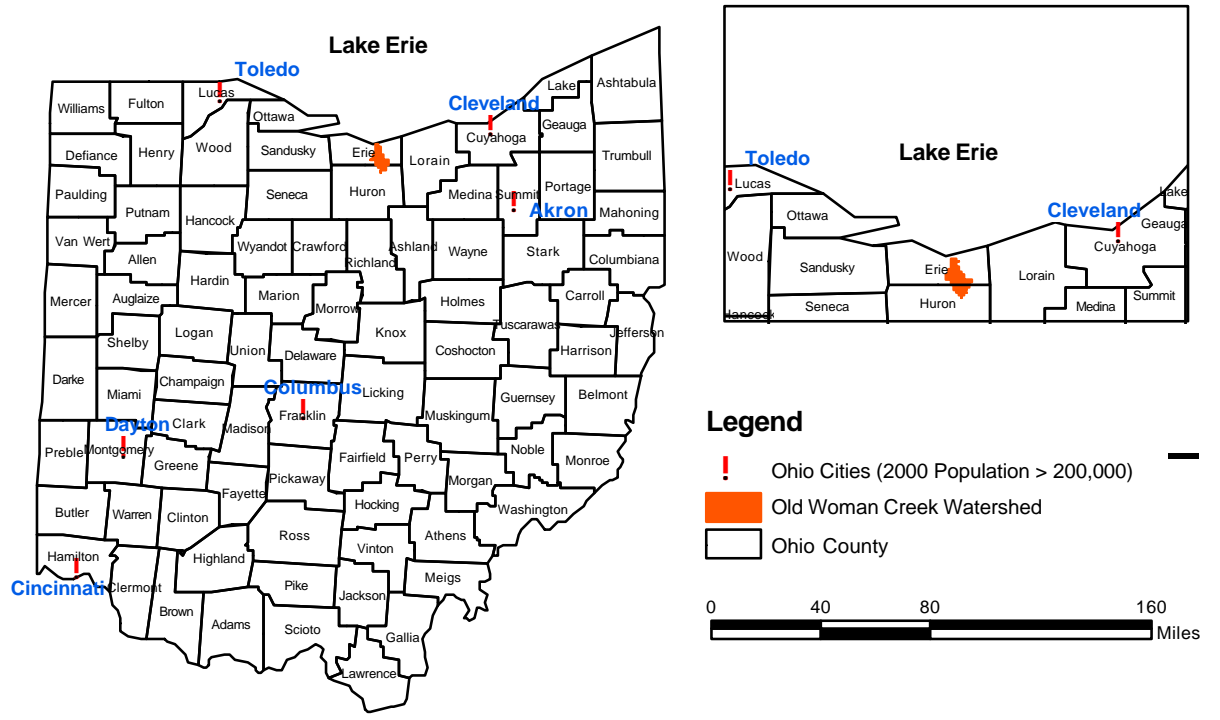

Figure 4.1: Location of the Study Area 


\subsection{Analysis of Landform and Soils}

The spatial extent of the study area is delineated by the USGS in cooperation with the Ohio Department of Natural Resources (ODNR) and publicly available as a vector data format. The study area is at the third level of the hydrological hierarchy and is identified as USGS cataloging unit 0410012. The subwatershed and drainage area boundaries are delineated, using the Digital Elevation Models (DEMs), using spatial GIS (Geographic Information Systems) techniques (Maidment, 2002). The DEM data sets for the study area are downloaded from the Ohio Department of Administrative Services (ODAS), as a 7.5-minute quadrangle map at the scale of 1:24,000. The spatial resolution of the DEMs is 30 meter.

The accuracy of the DEMs varies, depending on the source and spatial resolution. The USGS provides DEM data in three classification levels. Data at the lowest level are created by scanning National High Altitude Photography with a vertical mean accuracy (root mean square error, RMSE) of 7 meter. The second level DEMs are data sets that have been smoothed for consistency and corrected to remove systematic errors. The third level DEMS are derived from DLG (Digital Line Graph) data by incorporating selected elements from hypsography (contours, spot elevations), and hydrographs (lakes, shorelines, and drainages), and are recommended for deriving subwatershed boundaries and stream network. However, only the second-level DEMs are available publicly, and the spatial watershed analysis with these data may not be appropriate.

To overcome the accuracy problem, the second-level DEMS are pre-processed with hydrography and hypsography datasets. Once the unit quadrangle maps are joined together to cover the study area, the elevation data are checked against the contour data. 
The contour data are acquired from the DLG (spatial resolution: $10 \mathrm{ft}$.$) and the OWC$ NERR site (spatial resolution: $4 \mathrm{ft}$.). The contour data are used to create a smooth surface data set with various interpolation routines available from the ArcGIS spatial analysis module. Also, the contour data sets are transformed into a TIN (Triangular Irregular Network) format. The interpolated data or TIN data are further used to create a raster data set at different spatial resolutions (5-, 10-, 15-, 20-, and 30-meters) and compared with the second-level downloaded DEMs. Once the second-level DEMs are checked and edited, they are pre-processed with hydrographs. The pre-processing step is necessary to re-condition the DEM surface, in order to align the drainage lines of the DEMS with the published hydrograph data. This re-conditioning process is done by lowering the elevations at the stream lines and the surrounding areas of the stream, in order to create valleys. This reconditioning procedure changes the landform around the stream areas, but these changes are not as drastic as "burning" the streamlines onto the DEMs. This burning process is a common technique used by hydrological modelers to create streams in DEMs, by encoding "zero"- values at the stream line. This technique is inappropriate to delineate the sub-unit boundaries in the watershed, due to dramatic changes in elevation. The re-conditioning routine is incorporated into ArcHydro tool (ASCE, 1999; Hellweger and Maidment, 2004).

Once the topography of the study area is pre-processed, a routine surface hydrologic analysis with ArcInfo is implemented to create sub-unit areas. GRID commands are applied at multi-steps: (1) fill, (2) flow direction/accumulation, (3) stream network delineation, and (4) watershed delineation. The first surface process, "fill" is to remove a peak or a sink, which is usually created by an error of the DEM. A peak refers 
to a depression or pit, and a sink to an area surrounded by higher elevation. The second surface process, "flow direction-accumulation" is to identify the flow direction, based on its elevation and the neighboring areas, and to count the number of accumulated cells (or accumulated weights) from the upstream areas. The D-8 method is applied to identify the flow direction (Jenson and Domingue, 1988). The third step is to delineate the stream network from the flow accumulation, with a threshold value (Mark 1988). The last step is to delineate the sub-areas of the watershed hierarchy, with a threshold value to define the contributing area. The threshold for contributing area and stream initiation is carefully selected to match the existing drainage density, as it is a landscape measure used to identify source areas for channel initiation (Montgomery and Dietrich, 1989). The delineated stream is compared with the public stream vector data. Details of the ArcInfo process and the fundamental concepts of GIS operation for hydrologic analysis are well documented by ESRI (1994). Figure 4.2 shows the hierarchy of the watershed system of the study area. 


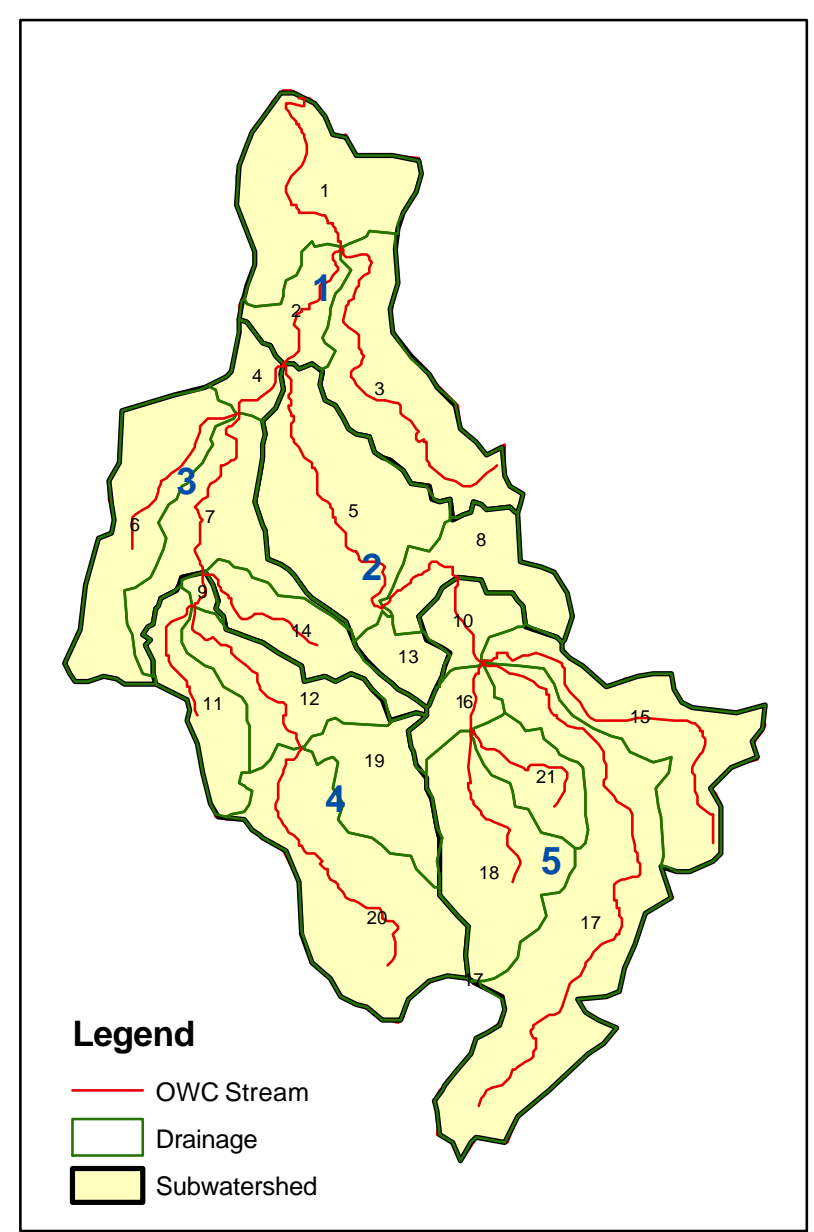

(A) Watershed Hiearchy

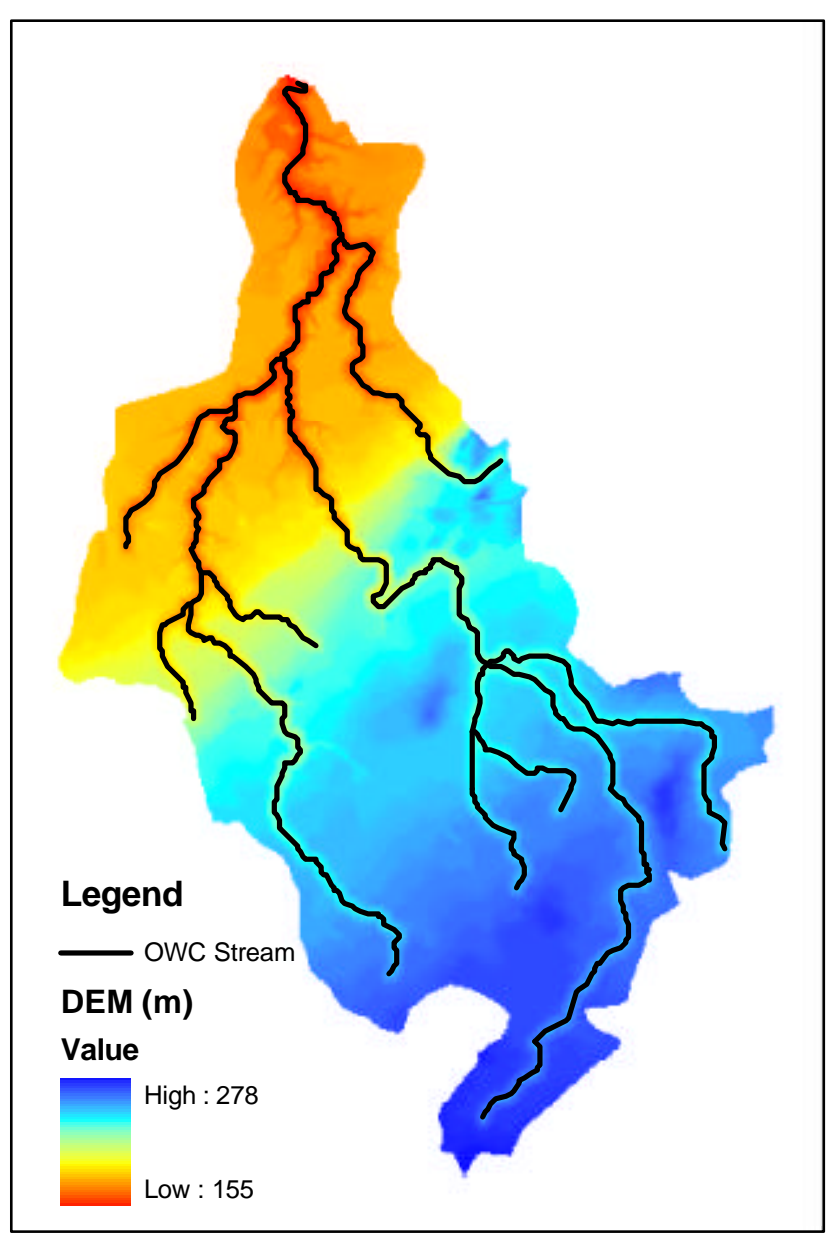

(B) Watershed Elevations

Figure 4.2: Watershed Hierarchy and Elevations 
The spatial soil data (GIS layer in vector format) are obtained from the OWC NERR, located within the study watershed. Detailed soil information is obtained from the Soil Survey Geographic Database. Soil data are classified into SCS hydrological soil groups, using the Map Unit Use File (MUUF), to be used as an input to the simulation model. Depending on minimum infiltration rates, all soils can be classified into four hydrological soil groups (A, B, C, and D). The infiltration rate is an important determinant of the storm water runoff, as it represents the moisture storage capacity. The infiltration rate is determined by permeability and surface intake rates, and can be affected by impervious surface and disturbance on soil profiles (USDA, 1986). Table 4.2 shows four soil groups and their infiltration rates. The MUUF program is developed by the Natural Resources Conservation Service (NRCS), to provide the properties of most soils in the U.S. All soil types within the watershed area are identified, and a batch program is created to determine the properties of each soil. The MUUF documentation by Baumer et al. (1994) provided a detailed step-by-step procedure. The hydrologic soil map in the study area is presented in Figure 4.3. The soil characteristics of the study area are summarized in Table 4.3.

\begin{tabular}{|l|l|l|}
\hline HSG & Soil textures & Infiltration Rates (in/hr) \\
\hline A & Sand, loamy sand, or sandy loam & $>0.3$ \\
\hline B & Silt loam or loam & $0.15-0.3$ \\
\hline C & Sandy clay loam & $0.05-0.15$ \\
\hline D & Clay loam, silty clay loam, sandy clay, silty clay, or clay & $<0.05$ \\
\hline
\end{tabular}

Table 4.2: Hydrologic Soil Groups (HSG), Textures, and Infiltration Rates (USDA, 1986) 


\begin{tabular}{|c|c|l|c|}
\hline Soil Association & $\begin{array}{c}\text { Percent of } \\
\text { Watershed }\end{array}$ & Soil Texture & $\begin{array}{c}\text { Soil } \\
\text { Erodability } \\
\text { K factors }\end{array}$ \\
\hline Mahoning-Bogart-Haskins-Jimtown & $67 \%$ & & \\
Mahoning & $27 \%$ & Silt Loam & 0.49 \\
Bogart & $10 \%$ & Loam & 0.32 \\
Haskins & $7 \%$ & Loam & 0.32 \\
Jimtown & $7 \%$ & Loam & 0.28 \\
Minor Soils & $17 \%$ & & \\
Kibbie-Tuscola-Colwood & $21 \%$ & & 0.37 \\
Kibbie & $7 \%$ & Fine Sandy Loam & 0.37 \\
Tuscola & $7 \%$ & Fine Sandy Loam & N/A \\
Colwood & $4 \%$ & Silt Loam & \\
& & & 0.28 \\
Arkport-Galen & $4 \%$ & & 0.28 \\
Arkport & $2 \%$ & Loamy Fine Sand & \\
Galen & $1 \%$ & Loamy Fine Sand & \\
Minor Soils & $1 \%$ & & 0.43 \\
Del Ray & $4 \%$ & & N/A \\
Lenawee & $3 \%$ & Silt Loam & \\
Minor Soils & $1 \%$ & Silty Clay Loam & N/A \\
\hline Allis & $<1 \%$ & & \\
Fries & $2 \%$ & Silty Clay Loam & \\
\hline
\end{tabular}

Table 4.3: Soil Distribution in the Old Woman Creek Watershed (Buchanan, 1982) 


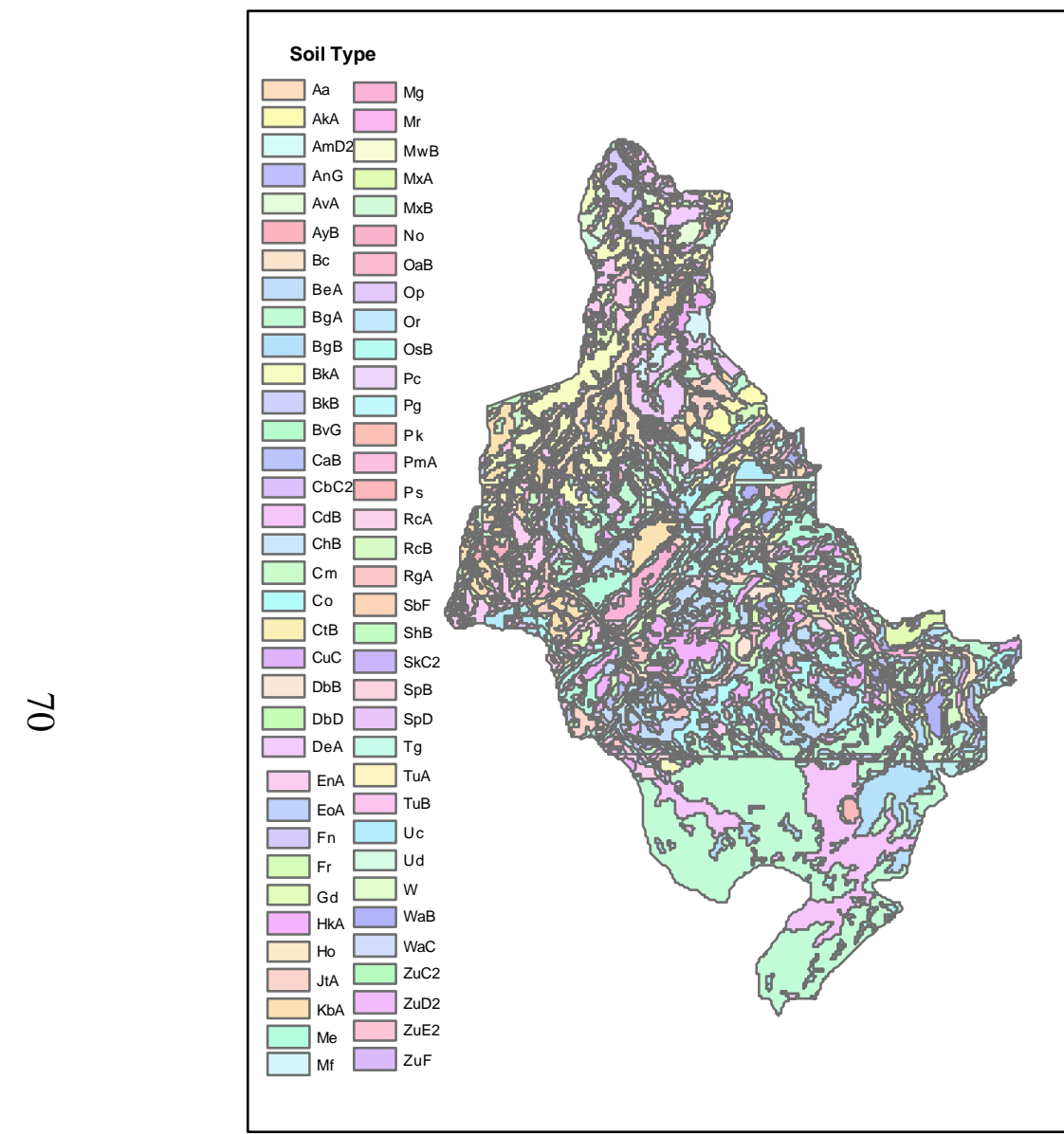

(A) Soil Types from Soil Survey Database

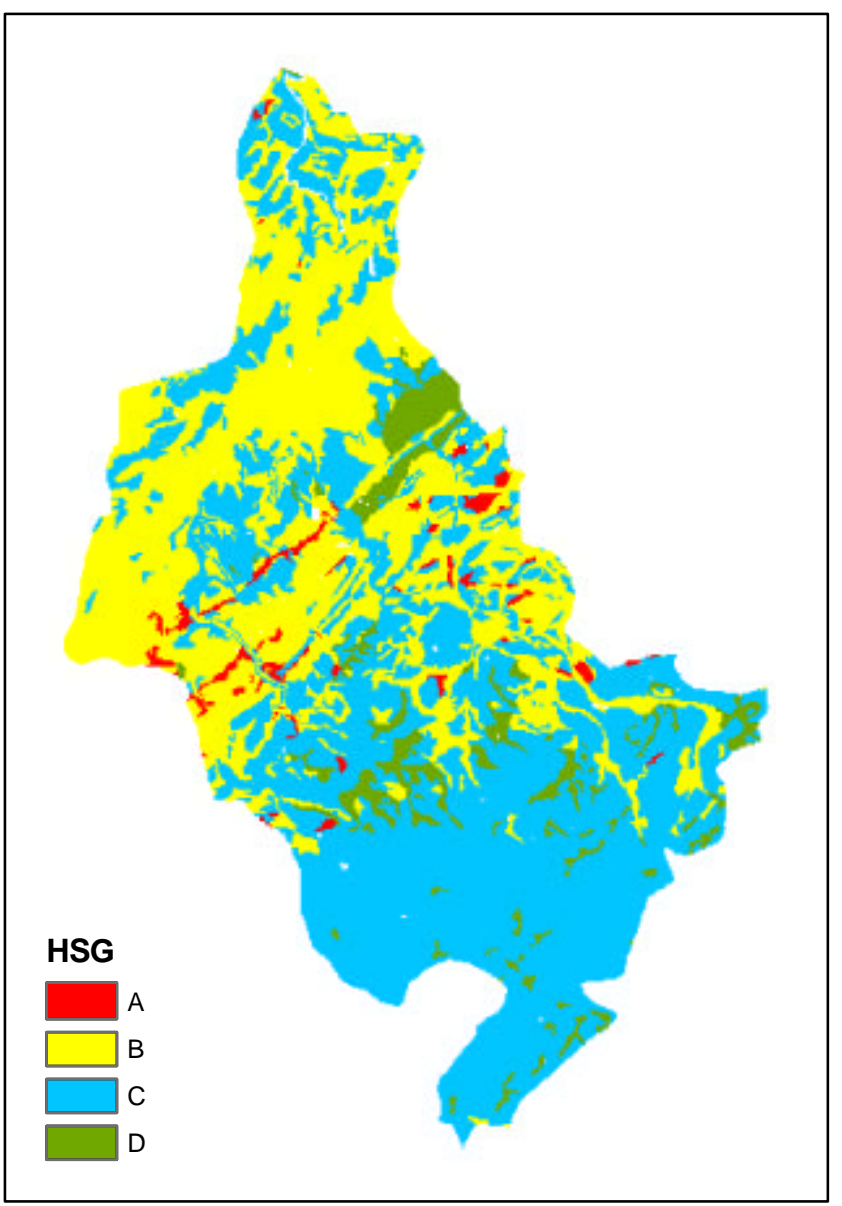

(B) Hydrologic Soil Groups (HSG)

Figure 4.3: Soil Map 


\subsection{Population and Land-Use Analysis}

In order to allocate future land uses, it is first necessary to prepare urban land use projections, based on population projections. As the hydrological model simulates stormwater runoff based on surface cover characteristics, projected urban land cover is derived from projected urban land use. Note that land use refers to the use of the land, while land cover refers to the physical state of the land (Brown et al., 2000). The OWC watershed is predominantly used for agricultural and residential purposes. It is assumed that urban development is primarily for residential purposes.

Most of the OWC watershed covers the townships of Berlin and Townsend. The population and land-use characteristics of the watershed are therefore assumed to be those of the townships. Because of limited township population data, population trends

are first analyzed at the county level, as such data are available since 1860 . County population data display an sshaped curve over the period 1950-2000, and therefore a logistic model is used to depict the data and to forecast population, with:

$$
P_{t}=\frac{1}{\left(\frac{1}{P_{0}}-\frac{b}{a}\right) e^{-a t}+\frac{b}{a}}
$$

where $\mathrm{P}_{0}$ is the current population (year 2000), $\mathrm{P}_{\mathrm{t}}$ the population at time $t$, and a and b parameters (see Oppenheim, 1980). Table 4.4 presents these parameters for the two counties, as well as current (2000) and projected (2020) populations. Figure 4.4 depicts historical population data. 


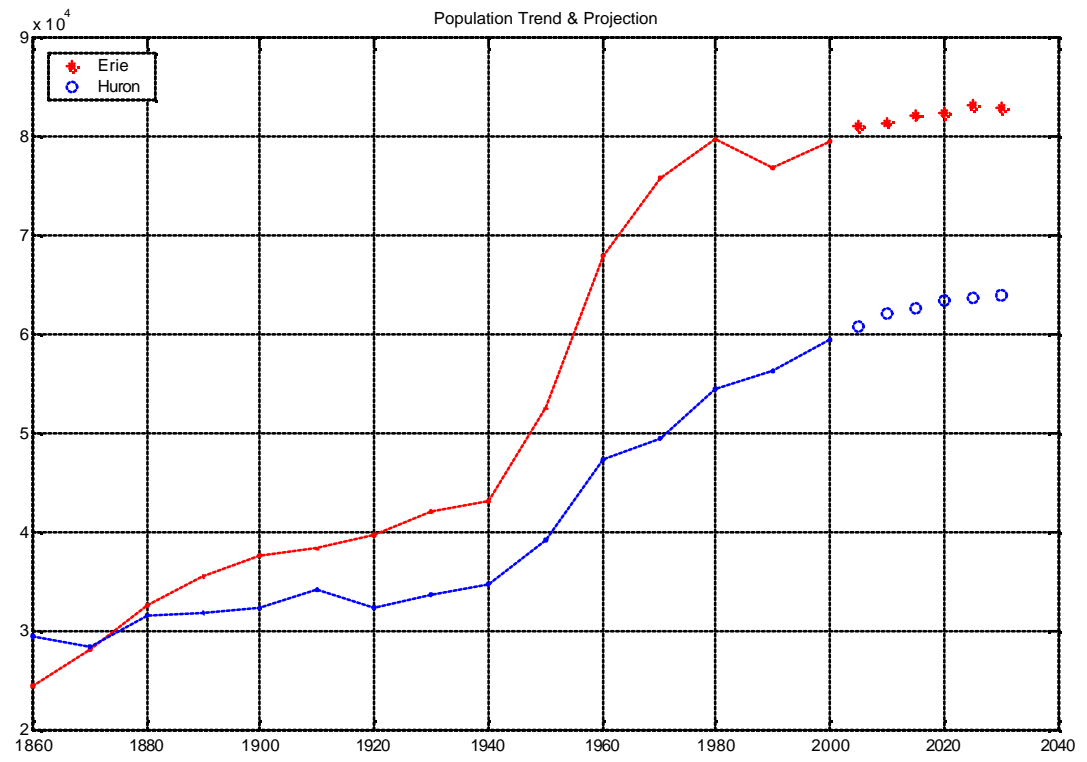

Data Source: Ohio State University Extension Data Center (http://www.osuedc.org/profiles/)

Figure 4.4: Population Trends

\begin{tabular}{lcc}
\hline Parameters/Variables & Erie County & Huron County \\
\hline \hline $\mathrm{a}$ & 0.8294 & 0.4885 \\
$\mathrm{~b}$ & $1.0 * 10^{-5}$ & $8.0^{*} 10^{-6}$ \\
\hline Pop 2000 & 79,551 & 59,487 \\
Pop 2020 & 80,540 & 60,658 \\
\hline Population Growth & $1.2 \%$ & $1.9 \%$ \\
\hline
\end{tabular}

Table 4.4: Parameters for Population Projections 
Once the population is determined at the county level, township population is estimated under the assumption that both the county and township grow at the same rate. The watershed population is taken as the weighted sum of the Berlin and Townsend populations, the weights representing the shares of township land within the watershed (0.25 for Townsend and 0.75 for Berlin). The OWC watershed population for 2000 and 2020 is 3,213 and 3,429 , respectively.

Next, future urban land use is estimated using: (1) the Urban Land Consumption Index (ULCI) published by the U.S. Census, and (2) historical land use/population and housing density analyses in Ohio (Irwin and Reece, 2004). The ULCI, defined as the number of developed acres per person, was equal to 0.43 and 0.61 in 1998 in Erie and Huron, respectively. It is consistent with published township population density data and is approximately equivalent to suburban land-use density (2.5 persons per 1.5 -acre house). Future residential land then represents 2057.4 acres $(3429 * 1.5 / 2.5)$ or 8.326 $\mathrm{km}^{2}$, which makes up $12.4 \%$ of the watershed area.

The spatial pattern of historic and current land use/cover condition is assessed using satellite imagery. The land use/cover map in 1994 is obtained from ODNR. This map is created by interpreting Landsat-5 imagery, taken in September and October of 1994. A more current land use pattern is delineated with Landsat-7 imagery taken in September and October of 2000. Landsat-7 images are downloaded from OhioView, and the images are interpreted using a land cover classification method. The classification technique is done, based on the statistics of the spectral response (i.e., digital value) of the pixel in the image. Unsupervised image classification is used to identify different land cover features. The Iterative Self-Organizing Data Analysis Technique (ISODATA) 
is used as a clustering algorithm. ISODATA uses a maximum likelihood procedure to analyze the statistics of pixel values. Once each pixel in the image is grouped into a land cover group, each land use category is manually identified using aerial photographs and panchromatic images. Aerial photographs are obtained from the NERR site and are also available as digital ortho quarter quads (DOQQ) data from USGS. The 15 meter panchromatic images are available from Landsat-7, via OhioView. Details on image classification technique are discussed by Lillesand et al (2004). Image classification is done using the commercial software ERDAS IMAGINE $8.7^{\mathrm{TM}}$. The image analysis with 2000 data does not indicate a significant change from 1994. Also, a classification accuracy assessment for 2000 data is not conducted. Hence, this result is only used to provide baseline land cover information to understand land use trends, and to formulate land use constraints for the ptimization model. Therefore, the spatial land use map obtained in 1994 is used as the base map for land allocation at the cell level (30 meter). In addition, Digital Line Graph (USGS) and TIGER data from the Census Bureau us are used to identify urban features.

Seven different land-use/cover types are identified by the land-use map of 1994, and are reclassified into three distinct land-use categories: agriculture, conservation, and urban. The urban land cover only includes impervious areas, identified from the satellite image. This regrouping, necessary to simplify the regression modeling of the runoff function and to reduce the number of decision variables in the optimization model, is implemented based on similarities of land cover and hydrological characteristics. The residential areas for 2020, based on the population projections, are approximated as $12.4 \%$ of the watershed area (i.e., 2057.4 acres or $8.326 \mathrm{~km}^{2}$ ). If an average housing unit 
is assumed to be built on a 2 -acre lot, then approximately $12 \%$ of a 2 -acre lot housing unit is impervious (USDA, 1986). Future impervious residential land then represents $0.999 \mathrm{~km}^{2}$, or $1.5 \%$ of the watershed area. Road areas in 2000 represent $1.7 \%$ of the watershed, and are assumed not to change from 2000 to 2020. Road areas are identified with DLG data and image interpretation of satellite data. Thus, the total impervious area is projected to represent $3.2 \%$ of the watershed. Table 4.5 and Table 4.6 present different land use categories and their hydrological characteristics. These land-use categories are regrouped into three different land types and their modeling parameters are slightly modified as shown Table 4.7. This regrouping may change the estimation of the peak discharge rate, as modeling parameters are altered. As higher curve numbers are used, reclassified parameters yield higher peak discharge rates. Inclusion of small road areas from the DLG data also increases the peak discharge rate. This causes the land allocation model to delineate spatial land patterns that can efficiently handle higher peak runoffs. The hydrological simulation model is calibrated using the land-use map of 1994. The land-use conditions in 1994, as obtained from ODNR, and reclassified for modeling are depicted in Figure 4.5. 


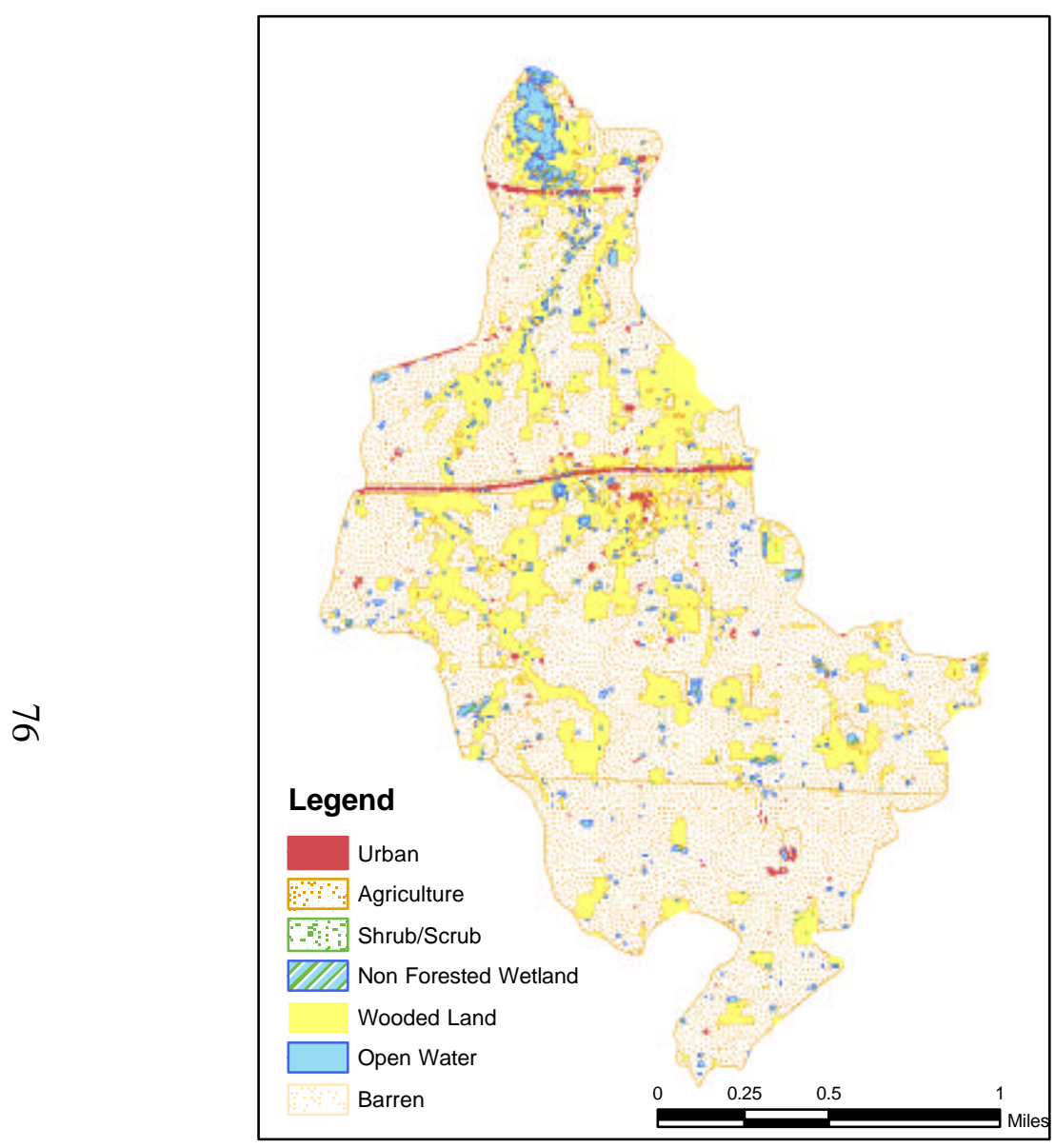

(A) Land-Use Map of the Study Area (1994, ODNR)

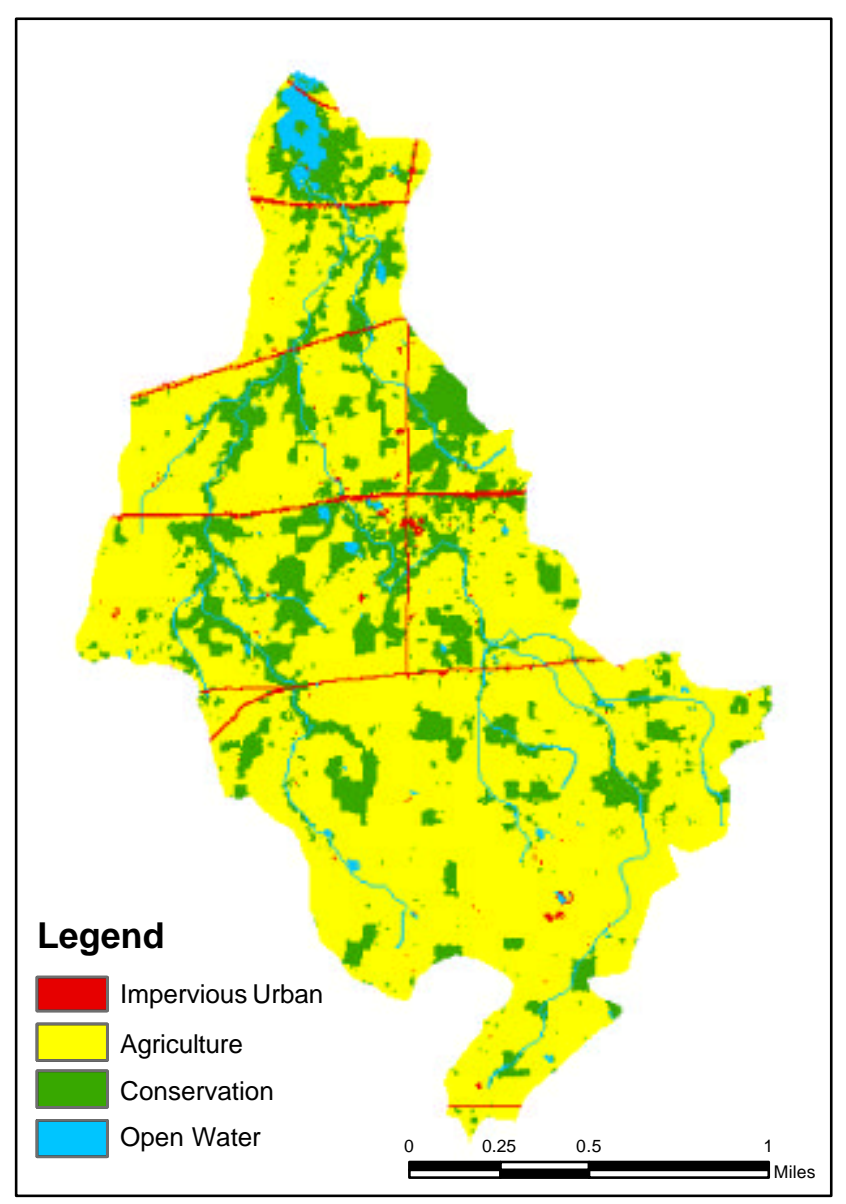

(B) Reclassified Land-Use Map (1994)

Figure 4.5: Land-Use Map of the Study Area. 


\begin{tabular}{|l|l|l|}
\hline Code & Classification & Description \\
\hline 1 & Urban & $\begin{array}{l}\text { Open impervious surfaces: roads, } \\
\text { buildings, parking lots and similar hard } \\
\text { surface areas which are not obstructed } \\
\text { from aerial view by tree cover }\end{array}$ \\
\hline 2 & $\begin{array}{l}\text { Agriculture/open urban } \\
\text { areas }\end{array}$ & $\begin{array}{l}\text { Cropland and pasture; parks, golf } \\
\text { courses, lawns and similar grassy areas } \\
\text { not obstructed from view by tree cover }\end{array}$ \\
\hline 3 & Shrub/scrub & $\begin{array}{l}\text { Young, sparse, woody vegetation; } \\
\text { typically areas of scattered young tree } \\
\text { saplings }\end{array}$ \\
\hline 4 & Wooded & Deciduous and coniferous \\
\hline 5 & Open water & $\begin{array}{l}\text { Open water } \\
\text { Thematic Mapper data as well as from } \\
\text { the Ohio Wetlands Inventory }\end{array}$ \\
\hline 6 & Non forested wetlands & $\begin{array}{l}\text { Strip mines, quarries, sand and gravel } \\
\text { pits, beaches }\end{array}$ \\
\hline 7 & Barren &
\end{tabular}

Table 4.5: Land-Use Description

\begin{tabular}{|l|l|c|c|c|c|c|}
\hline Land-use Type & $\begin{array}{l}\text { USDA Land-use } \\
\text { Classification and } \\
\text { conditions }\end{array}$ & \multicolumn{4}{|c|}{ Curve Number } & Manning's \\
\cline { 3 - 6 } & Soil A & Soil B & Soil C & Soil D & Roughness \\
\hline Urban & $72 \%$ impervious & 81 & 88 & 91 & 93 & 0.075 \\
\hline Agriculture & $\begin{array}{l}\text { Single Rows and } \\
\text { Crop Residue } \\
\text { Good condition }\end{array}$ & 64 & 75 & 82 & 85 & 0.04 \\
\hline Shrub & $\begin{array}{l}\text { Brush } \\
\text { Fair condition }\end{array}$ & 35 & 56 & 70 & 77 & 0.37 \\
\hline Wooded & $\begin{array}{l}\text { Woods } \\
\text { Good condition }\end{array}$ & 30 & 55 & 70 & 77 & 0.600 \\
\hline Open Water & $\begin{array}{l}\text { Open Water } \\
\text { Natural channel bed }\end{array}$ & - & - & - & - & 0.037 \\
\hline $\begin{array}{l}\text { Non forested } \\
\text { wetland }\end{array}$ & $\begin{array}{l}\text { Herbaceous } \\
\text { Good condition }\end{array}$ & 0 & 62 & 74 & 85 & 0.130 \\
\hline Barren & $\begin{array}{l}\text { Fallow } \\
\text { Bare condition }\end{array}$ & 77 & 86 & 91 & 94 & 0.050 \\
\hline
\end{tabular}

Source: Ohio Department of Natural Resources (2002) and USDA (1986)

Table 4.6: Curve Number for Different Land-Use and Soil Types 


\begin{tabular}{|l|l|c|c|c|c|c|}
\hline \multirow{2}{*}{ Land-use Type } & Cover Condition & \multicolumn{4}{|c|}{ Curve Number } & Manning's \\
\cline { 3 - 6 } & & Soil A & Soil B & Soil C & Soil D & Roughness \\
\hline Urban & $72 \%$ impervious & 81 & 88 & 91 & 93 & 0.075 \\
\hline Agriculture & $\begin{array}{l}\text { Single Rows and Crop } \\
\text { Residue } \\
\text { Good condition }\end{array}$ & 64 & 75 & 82 & 85 & 0.04 \\
\hline Conservation & $\begin{array}{l}\text { Wooded-Grass } \\
\text { (Fair Condition) }\end{array}$ & 43 & 65 & 76 & 82 & 0.4 \\
\hline Open Water & $\begin{array}{l}\text { Open Water } \\
\text { Natural channel bed }\end{array}$ & - & - & - & - & 0.037 \\
\hline
\end{tabular}

Table 4.7: Curve Number for Regrouped Land-Use and Soil Types

\subsection{Hydrological Data Analysis and Model Calibration}

Hydrological data, precipitation and streamflows, are analyzed to understand the baseline relationship between precipitation and storm runoff in the watershed, and to calibrate the hydrological simulation model using actual flow data. The flood analysis uses stream gauge data obtained from the USGS (\#0419915) over the period 1987-2002. Daily precipitation data are obtained from the National Weather Service Center from the period $1985-2002$.

The hydrological model is a single-event distributed system. In calibrating an event-based model, the design storm serves as input, and the hydrological model calculates the stream runoff. The design storm can be specified by: (1) a precipitation depth at a site, (2) a design hyetograph with a time distribution, or (3) an isohyetal map (Chow et al, 1989). To validate the model with more realistic data, the design storm is determined by using historical data on site (OWC watershed), rather than the published isohyetal map. Also, an assumption is made about the rainfall pattern. Since the data are only available in daily steps, it is assumed that the precipitation follows a SCS rainfall time distribution. The return period for the design storm is determined using the 
Extreme Value Type I probability distribution function (Chow et al 1989, Haan et al. 2002).

Flood frequency is then analyzed, with observed stream data and the Bulletin 17B method (IACWD, 1982). The Log-Pearson Type III distribution is used as a base method for flood analysis. After determining the frequency curve, the stream runoff rates corresponding to the probabilities of 1-, 2-, 5-, and 10-year storms are computed. The results of the hydrological model solved with the estimated design storms are compared with the stream runoff rates estimated from the flood frequency analysis. Only rainfall data are considered for this analysis, as the $\mathrm{CN}$ is primarily applicable to unfrozen soil conditions. The results of the hydrological data and model calibration analyses for a test drainage (drainage 2) are presented in Table 4.8. Compared with the actual monitored values, the simulation model outputs appear to be reliable (all within 95\% confidence intervals). The large confidence intervals are due to the relatively small samples (15 observations of stream flows), which may result in a biased estimation. Also, the simulation model does not consider evapotranspiration, which may lead to overestimating the streamflow. Groundwater flows are not modeled, and this is a limitation of the hydrological model.

\begin{tabular}{|c|c|c|c|c|c|}
\hline $\begin{array}{c}\text { Return Period } \\
(\mathrm{yr})\end{array}$ & $\begin{array}{l}\text { Design Storm } \\
(\mathrm{cm})\end{array}$ & $\begin{array}{c}\text { Observed Mean } \\
\text { Peak Flow Rate } \\
\qquad\left(\mathrm{m}^{3} / \mathrm{s}\right)\end{array}$ & $\begin{array}{c}\text { Simulated Mean Peak } \\
\text { Flow Rate* } \\
\left(\mathrm{m}^{3} / \mathrm{s}\right)\end{array}$ & \multicolumn{2}{|c|}{$\begin{array}{l}95 \% \text { Confidence } \\
\text { Interval } \\
\left(\mathrm{m}^{3} / \mathrm{s}\right)\end{array}$} \\
\hline 1 & 2.8811 & 0.9508 & 0.9377 & 0.5446 & 2.2385 \\
\hline 2 & 4.9347 & 8.8030 & 7.1342 & 5.7142 & 11.4827 \\
\hline 5 & 6.1638 & 15.6292 & 18.1865 & 11.0592 & 25.2408 \\
\hline 10 & 6.9776 & 20.1845 & 28.3018 & 14.9837 & 39.5620 \\
\hline
\end{tabular}

* The peak discharge rate is calculated with seven different land use types as shown in Table 4.6.

Table 4.8: Hydrological Data Analysis and Model Calibration Results 


\section{CHAPTER 5}

\section{REGRESSION ESTIMATION OF THE PEAK RUNOFF FUNCTIONS}

This chapter presents two regression statistical models developed to relate peak runoff to land-use patterns for both subwatersheds and drainage areas. Model functional specifications and their implications are discussed.

\subsection{Overview}

Two-level regression models are formulated to relate the peak discharge rate to the amounts of land uses. At the higher level, the peak discharge rate $\left(\mathrm{Q}_{\mathrm{p}}\right)$ at the watershed outlet is regressed on the amounts of conservation $\left(x_{c}^{i}\right)$ and urban $\left(x_{u}^{i}\right)$ land in each subwatershed i. At the lower level, the peak discharge rate at the subwatershed outlet i $\left(Q_{s_{w}}^{i}\right)$ is related to the amounts of land use in each dainage area within the subwatershed boundary, and to the flow received from the upstream subwatershed, $\mathrm{s}_{\mathrm{w}-1}$. The hydrological model simulates storm-water runoff and estimates the stream discharge with a 1-year design storm. Overall, pseudo-data are created for 5 subwatersheds and 21 drainage areas. Figure 5.1 and Table 5.1 present the watershed hierarchy. 


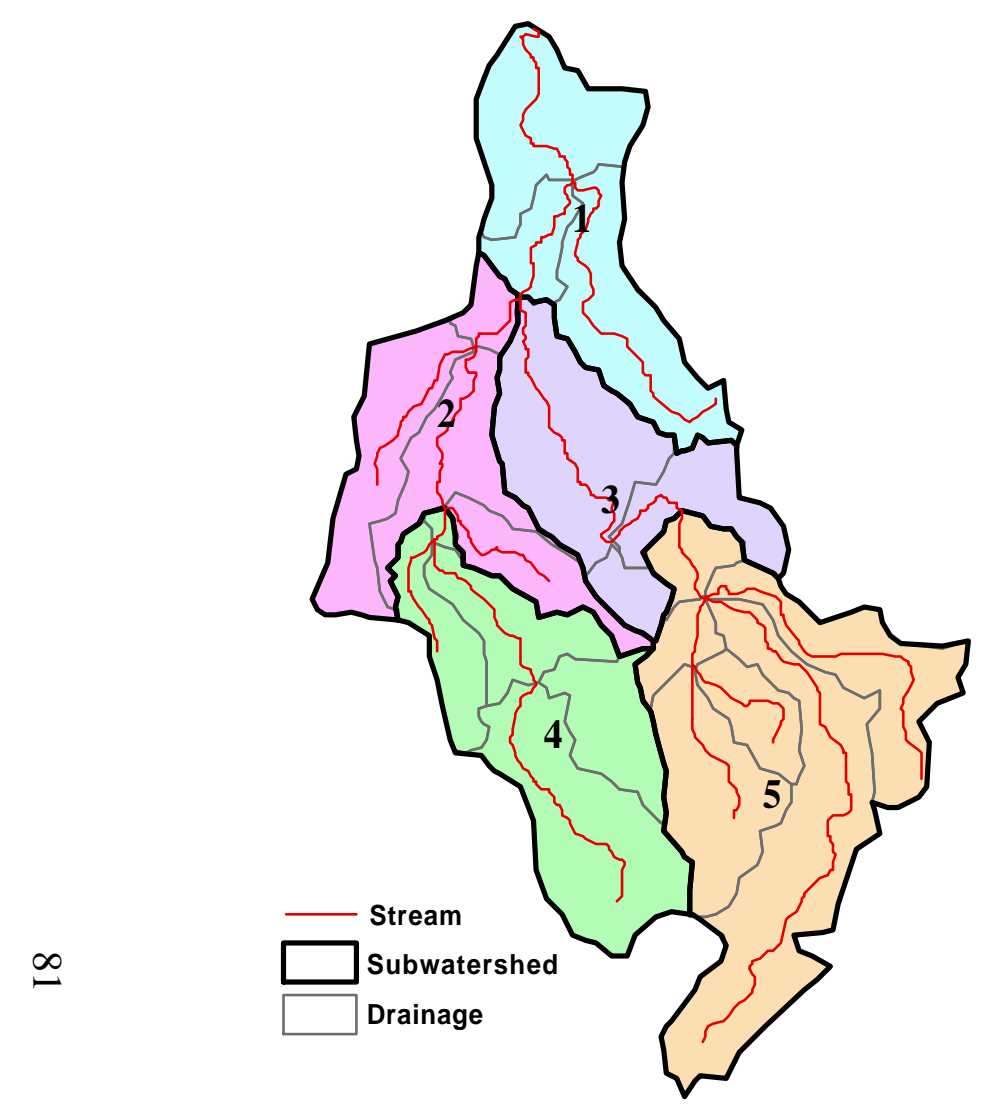

(A) Subwatershed

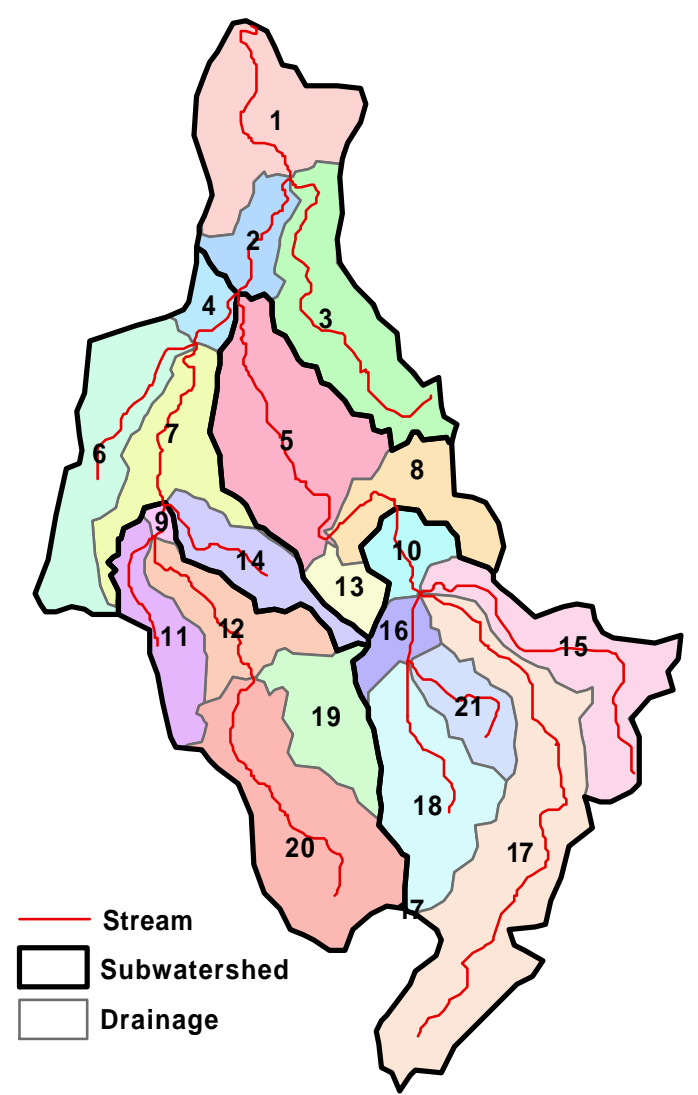

(B) Drainage Areas

Figure 5.1: Watershed Hierarchy 
With 5 subwatersheds, the total number of subwatershed combinations is 31 (see Table 3.1 for the possible combination sets). Sixty different land allocations are generated for each combination (refer to Figure 3.4), leading to a sample of 1860 observations. However, the sample data created at the subwatershed level do not display variability at the drainage area level, as the modeling unit is based on subwatershed boundary. The regression coefficients at the drainage level, using this data set, appears to be statistically insignificant. Therefore, the data sampling process is repeated at the drainage level within each subwatershed, to create meaningful data samples. For instance, one set is created for subwatershed 1 by allocating different land-uses to the drainage areas 1,2 , and 3, while the areas outside subwatershed 1 remain the same as the current land-use pattern. 


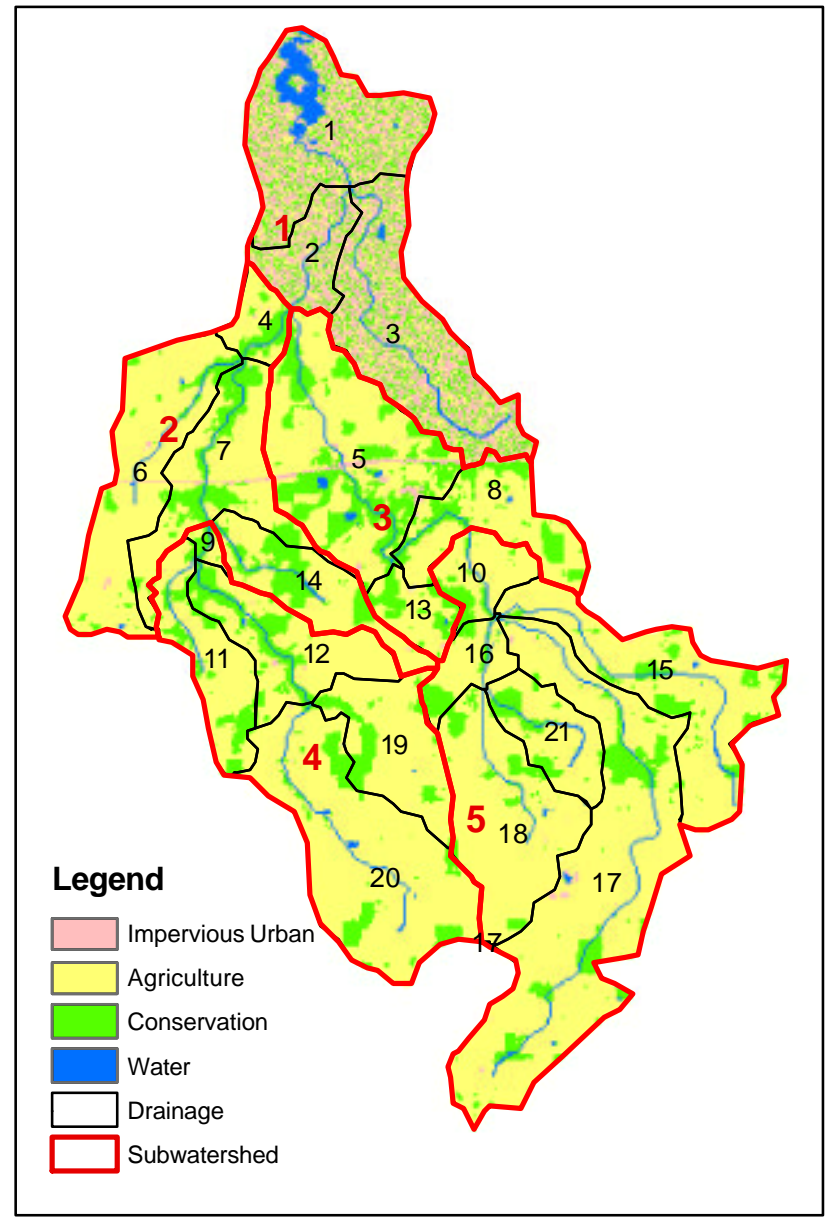

(A) Land Use Allocation in Subwatershed 1

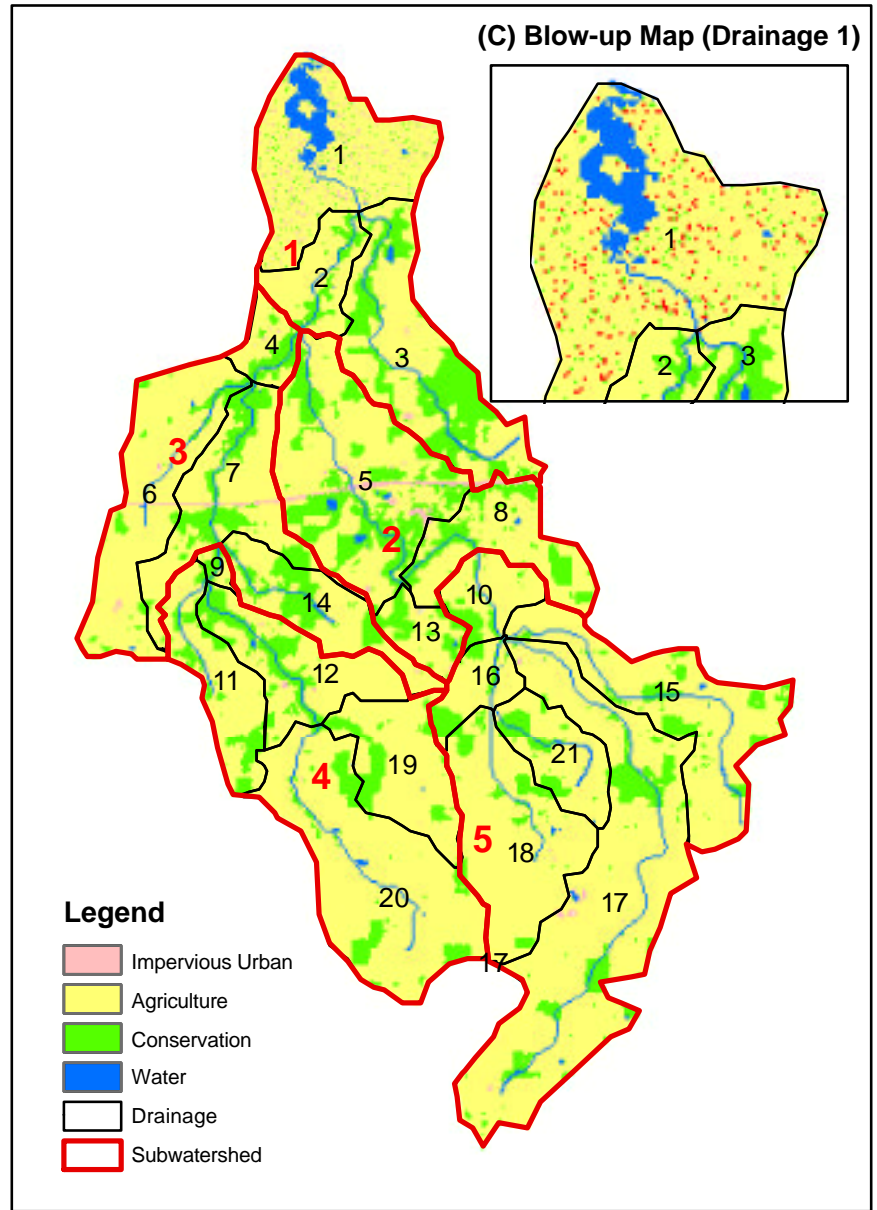

(B) Land Use Allocation in Drainage Area 1

Figure 5.2: Spatial Land Allocation Maps for Subwatershed 1 and Drainage 1 
The same land allocation process is applied for drainage areas: (1) all combination sets of drainage areas (only within the subwatershed) are considered; (2) different amounts of urban, agriculture, and conservation land are allocated at a 5\% increment, generating 60 different land patterns for each combination set; and (3) the spatial pattern corresponding to each allocation is generated randomly at the level of 30meter cells. Finally, the runoff simulation model is run for this land-use pattern with a one-year storm. In total, $9660^{2}$ spatial patterns are generated. The two-step regression models are developed using all 9660 data sets to preserve the consistency of sampling data and statistical models. Figure 5.2 explains how land allocation is done for different spatial modeling units. Figures 3.6 and 3.7 in Chapter 3 depict the land-use patterns created for a sample subwatershed and drainage combination set.

\subsection{Regression Model Results at the Subwatershed Level}

At the subwatershed level, a linear model was first estimated, with:

$$
Q_{p}=f(\mathbf{x})=\mathbf{c x}, \mathbf{x}=\left\{x_{k}^{i}\right\}
$$

where $\mathbf{x}$ is the vector of the shares of conservation and urban land in each subwatershed. The results for this linear model are summarized in Table 5.1. All land-use coefficients are significant at the $95 \%$ confidence level, and the estimated linear function explains relatively well the variability in the data $\left(\mathrm{R}^{2}=0.80\right)$. Large land-use coefficients are found for subwatersheds 1 and 5. Although the linear model seems to explain the land-water relationship quite well, it was discarded because it produced negative peak discharge

\footnotetext{
${ }^{2}$ Two pseudo-data sets were created for the $4^{\text {th }}$ subwatershed, as its boundary was re-delineated.
} 
rates in extreme situations (i.e., 100\% conservation land). A second-order quadratic model was then estimated, to correct for this problem. The quadratic model is:

$$
Q_{p}=f(\mathbf{x})=\mathbf{c x}+\frac{1}{2} \mathbf{x}^{T} \mathbf{H} \mathbf{x}, \mathbf{x}=\left\{x_{k}^{i}\right\}
$$

The new model, which includes 11 linear components and 55 quadratic/cross terms, has a higher fit than the linear model, with $\mathrm{R}^{2}=0.934$. The estimated coefficients of the quadratic regression are presented in Table 5.2.

MODEL Qp $p_{1} \sim \mathrm{f}\{\mathrm{XU} 1, \mathrm{XC1}, \mathrm{XU} 2, \mathrm{XC} 2, \mathrm{XU} 3, \mathrm{XC} 3, \mathrm{XU} 4, \mathrm{XC4}, \mathrm{XU}, \mathrm{XC5}\}$

Dependent Variable: Qp1 $\left(\mathrm{R}^{2}=0.803, \mathrm{~N}=9660\right)$

\begin{tabular}{|l|c|c|c|l|c|c|c|}
\hline Variable & Coefficient & t-value & P-value & Variable & Coefficient & t-value & P-value \\
\hline Intercept & 4.509 & 70.81 & $<.0001$ & XU3 & 1.176 & 14.03 & $<.0001$ \\
XU1 & 11.942 & 131.66 & $<.0001$ & XC3 & -0.236 & -1.97 & 0.0493 \\
XC1 & -5.084 & -38.78 & $<.0001$ & XU4 & 2.354 & 34.14 & $<.0001$ \\
XU2 & 1.308 & 18.03 & $<.0001$ & XC4 & -0.359 & -3.95 & $<.0001$ \\
XC2 & -0.682 & -6.86 & $<.0001$ & XU5 & 2.763 & 35.31 & $<.0001$ \\
& & & & XC5 & -4.923 & -51.07 & $<.0001$ \\
\hline
\end{tabular}

Qp1= peak discharge rate observed at the watershed outlet;

$\mathrm{XCi}=$ conservation land use in subwatershed $\mathrm{i}$;

$\mathrm{XUi}=$ urban land use in subwatershed $\mathrm{i}$.

Table 5.1: Linear Regression Estimation of the Peak Runoff Function at the Watershed Outlet 
MODEL Qp 1 f $\{X U 1, X C 1, X U 2, X C 2, X U 3, X C 3, X U 4, X C 4, X U 5, X C 5\}$

Dependent Variable: Qp1 $\left(\mathrm{R}^{2}=0.9398, \mathrm{~N}=9660\right)$

\begin{tabular}{|c|c|c|c|c|c|c|c|}
\hline Variable & Coefficient & t-value & $\mathrm{P}$-value & Variable & Coefficient & t-value & P-value \\
\hline Intercept & 4.365 & 34.36 & $<.0001$ & XU4*XC1 & -2.503 & -7.69 & $<.0001$ \\
\hline XU1 & 9.888 & 28.91 & $<.0001$ & XU4*XU2 & 0.308 & 1.33 & 0.1819 \\
\hline $\mathrm{XC1}$ & -5.681 & -16.49 & $<.0001$ & $\mathrm{XU} 4 * \mathrm{XC} 2$ & -0.268 & -1.05 & 0.2931 \\
\hline XU2 & -0.032 & -0.14 & 0.8912 & XU4*XU3 & 0.164 & 0.7 & 0.4835 \\
\hline $\mathrm{XC} 2$ & -0.780 & -2.49 & 0.0129 & $\mathrm{XU} 4 * \mathrm{XC} 3$ & -0.317 & -1.04 & 0.2969 \\
\hline XU3 & 1.136 & 3.61 & 0.0003 & XU4*XU4 & -1.768 & -8.64 & $<.0001$ \\
\hline $\mathrm{XC} 3$ & 0.253 & 0.76 & 0.4488 & $\mathrm{XC} 4 * \mathrm{XU} 1$ & -2.880 & -10.19 & $<.0001$ \\
\hline XU4 & 4.316 & 18.7 & $<.0001$ & $\mathrm{XC} 4 * \mathrm{XC} 1$ & -0.627 & -1.82 & 0.0692 \\
\hline $\mathrm{XC4}$ & 1.461 & 5.16 & $<.0001$ & XC4*XU2 & -0.640 & -2.53 & 0.0114 \\
\hline XU5 & 3.962 & 16.68 & $<.0001$ & $\mathrm{XC} 4 * \mathrm{XC} 2$ & -0.170 & -0.54 & 0.5869 \\
\hline XC5 & -7.790 & -26.37 & $<.0001$ & XC4*XU3 & -0.577 & -2.08 & 0.0377 \\
\hline XU1*XU1 & 6.722 & 21.6 & $<.0001$ & $\mathrm{XC} 4 * \mathrm{XC} 3$ & 0.171 & 0.48 & 0.6324 \\
\hline $\mathrm{XC1} * \mathrm{XU} 1$ & -12.192 & -19.81 & $<.0001$ & XC4*XU4 & -3.165 & -6.63 & $<.0001$ \\
\hline $\mathrm{XC} 1 * \mathrm{XC} 1$ & 3.274 & 12.55 & $<.0001$ & $\mathrm{XC} 4 * \mathrm{XC} 4$ & -1.078 & -4.08 & $<.0001$ \\
\hline XU2*XU1 & 3.867 & 17.22 & $<.0001$ & XU5*XU1 & 6.393 & 26.64 & $<.0001$ \\
\hline $\mathrm{XU} 2 * \mathrm{XC} 1$ & -1.496 & -4.84 & $<.0001$ & XU5*XC1 & -2.906 & -8.41 & $<.0001$ \\
\hline XU2*XU2 & 1.235 & 5.52 & $<.0001$ & XU5*XU2 & 0.933 & 4.53 & $<.0001$ \\
\hline $\mathrm{XC} 2 * \mathrm{XU} 1$ & -1.222 & -4.02 & $<.0001$ & $\mathrm{XU} 5 * \mathrm{XC} 2$ & -0.005 & -0.02 & 0.9859 \\
\hline $\mathrm{XC} 2 * \mathrm{XC} 1$ & 0.336 & 0.85 & 0.3955 & XU5*XU3 & 1.523 & 6.36 & $<.0001$ \\
\hline XC2*XU2 & 1.506 & 2.91 & 0.0036 & XU5*XC3 & 0.694 & 2.27 & 0.023 \\
\hline $\mathrm{XC} 2 * \mathrm{XC} 2$ & 0.351 & 1.24 & 0.2162 & XU5*XU4 & 0.680 & 3.14 & 0.0017 \\
\hline XU3*XU1 & 2.334 & 9.4 & $<.0001$ & $\mathrm{XU} 5^{*} \mathrm{XC} 4$ & -0.323 & -1.12 & 0.2628 \\
\hline $\mathrm{XU} 3 * \mathrm{XC} 1$ & -1.170 & -3.38 & 0.0007 & XU5*XU5 & -1.785 & -7.57 & $<.0001$ \\
\hline XU3*XU2 & 1.158 & 5.11 & $<.0001$ & XC5*XU1 & -13.025 & -46.44 & $<.0001$ \\
\hline $\mathrm{XU} 3 * \mathrm{XC} 2$ & -0.269 & -0.95 & 0.3409 & $\mathrm{XC} 5^{*} \mathrm{XC} 1$ & 4.618 & 12.6 & $<.0001$ \\
\hline XU3*XU3 & 0.190 & 0.66 & 0.509 & XC5*XU2 & -1.224 & -4.74 & $<.0001$ \\
\hline XC3*XU1 & 0.502 & 1.44 & 0.1494 & $\mathrm{XC} 5 * \mathrm{XC} 2$ & 0.272 & 0.89 & 0.3734 \\
\hline $\mathrm{XC} 3 * \mathrm{XC} 1$ & 0.498 & 1.12 & 0.2646 & XC5*XU3 & -1.311 & -4.42 & $<.0001$ \\
\hline XC3*XU2 & -0.111 & -0.39 & 0.6968 & $\mathrm{XC} 5^{*} \mathrm{XC} 3$ & -0.261 & -0.7 & 0.4865 \\
\hline $\mathrm{XC} 3 * \mathrm{XC} 2$ & -0.162 & -0.42 & 0.672 & XC5*XU4 & -2.565 & -8.85 & $<.0001$ \\
\hline XC3*XU3 & -1.733 & -3 & 0.0027 & $\mathrm{XC} 5 * \mathrm{XC} 4$ & -0.077 & -0.25 & 0.8049 \\
\hline $\mathrm{XC} 3 * \mathrm{XC} 3$ & -0.265 & -1.01 & 0.3108 & XC5*XU5 & -5.517 & -10.37 & $<.0001$ \\
\hline XU4*XU1 & 3.142 & 14.16 & $<.0001$ & $\mathrm{XC} 5 * \mathrm{XC} 5$ & 5.528 & 18.42 & $<.0001$ \\
\hline
\end{tabular}

$\mathrm{Qp} 1=$ peak discharge rate observed at the watershed outlet;

$\mathrm{XCi}=$ conservation land use in subwatershed $\mathrm{i}$;

$\mathrm{XUi}=$ urban land use in subwatershed $\mathrm{i}$.

Table 5.2: Quadratic Regression Estimation of the Peak Runoff Function at the Watershed Outlet 
A quadratic function is not as straightforward to read as a linear function in terms of the impacts of the independent variables (i.e., the amounts of urban or conservation land). However, it is possible to measure the average effect of each component of $\mathbf{x}$ by rearranging (5.1) as follows:

$Q_{p}=f(\mathbf{x})=\left(\mathbf{c}+\frac{1}{2} \mathbf{x}^{T} \mathbf{H}\right) \mathbf{x}=\mathbf{M} \mathbf{x}$,

where $\mathbf{M}$ represents the average effect of $\mathbf{x}$ on $\mathrm{Q}_{\mathrm{p}}$. Figure 5.1 presents the frequency distributions of the elements of $\mathrm{M}$ computed for each subwatershed and land use over the whole sample ( $n=9660)$. Descriptive statistics (i.e., maximum, minimum, and mean values) of $\mathrm{M}$ over the sample land use patterns are summarized in Table 5.3.

\begin{tabular}{clcccc}
\hline \multirow{2}{*}{ Subwatershed } & Land Use & Maximum & Minimum & Mean & $\begin{array}{c}\text { Standard } \\
\text { Deviation }\end{array}$ \\
\hline \hline \multirow{2}{*}{1} & Urban & 24.479 & -4.5196 & 7.3459 & 1.7066 \\
& Conservation & 0.0064 & -15.8137 & -4.7901 & 1.1607 \\
\hline \multirow{2}{*}{2} & Urban & 4.3358 & -1.2433 & -0.0118 & 0.4389 \\
& Conservation & 0.0464 & -1.4989 & -0.6649 & 0.1482 \\
\hline \multirow{2}{*}{3} & Urban & 3.9154 & -1.3933 & 0.6479 & 0.2991 \\
& Conservation & 0.7397 & -0.7366 & 0.1883 & 0.1278 \\
\hline \multirow{2}{*}{4} & Urban & 5.6326 & -0.0929 & 3.2459 & 0.4733 \\
& Conservation & 1.4613 & -2.3309 & 0.8561 & 0.3929 \\
\hline \multirow{2}{*}{5} & Urban & 7.3889 & -0.0664 & 3.2704 & 0.6737 \\
& Conservation & 0.0143 & -19.6112 & -6.8712 & 1.3246 \\
\hline
\end{tabular}

Table 5.3: Descriptive Statistics of M over the Sample Land Use Patterns ( $n=9660)$ 

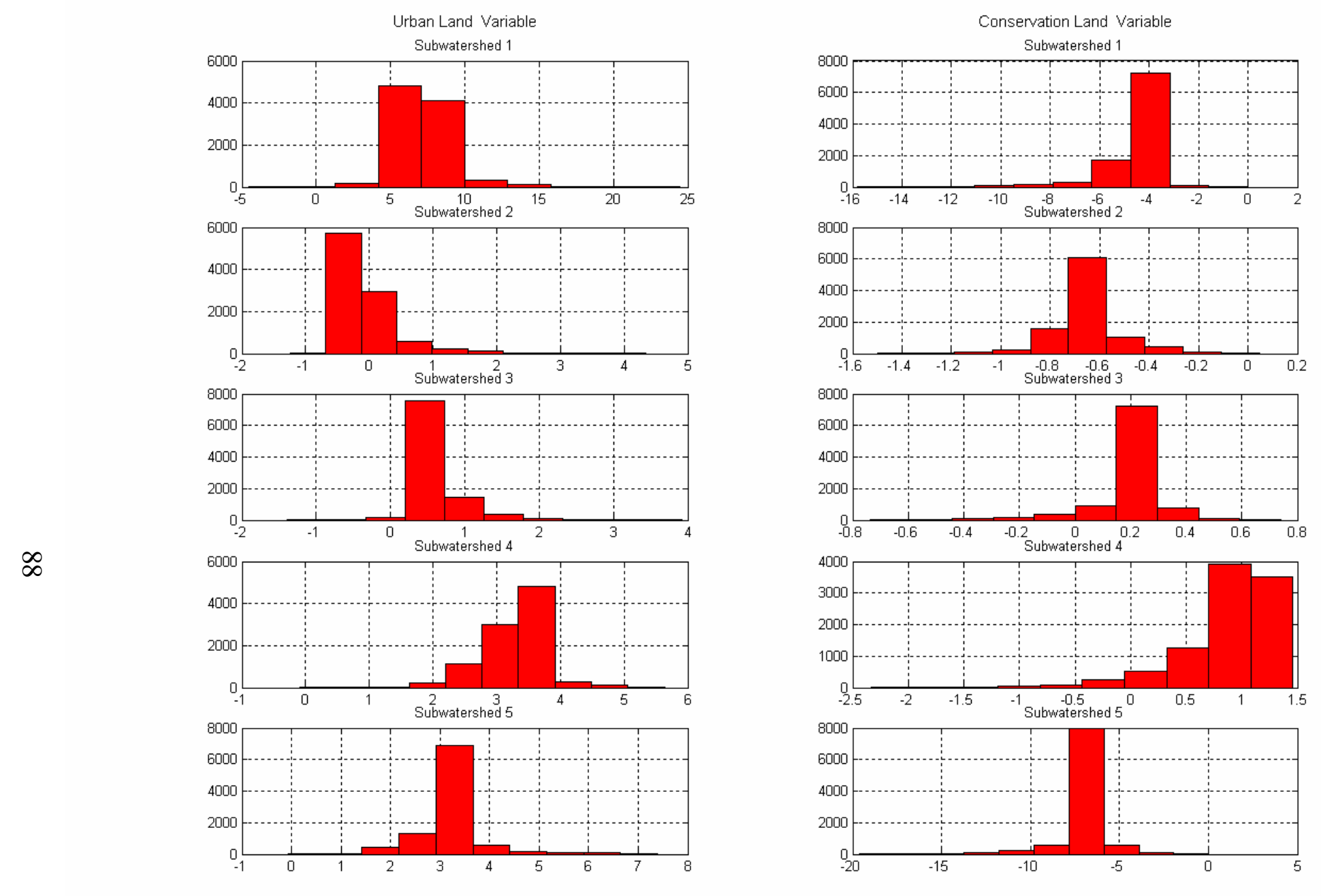

Figure 5.3: Distributions of the Average Land-Use Coefficients (M) Over the Sample of Land Use Patterns (n=9660) 
The mean values of the coefficients of the quadratic model are congruent with the coefficients of the linear model (Table 5.1). Figure 5.1 and Table 5.3 point to: (1) positive mean coefficients for urban land and negative ones for conservation land, or (2) larger mean coefficients for urban land than for conservation. This indicates that more urban land increases the peak discharge rate at the watershed outlet, while more conservation land decreases it. The larger mean coefficients for urban land imply that increases in urban land cause more dramatic change in watershed hydrology than increases in conservation. This is so because impervious urban land does not allow for infiltration of rainfall, increasing the volume of stormwater runoff. The smooth texture of urban land also increases the velocity of the overland flow, decreasing the hydraulic travel time. Combining these two factors, urban land increases stormwater runoff and provides a higher and earlier peak runoff discharge. The results show that urban land near the watershed outlet (subwatershed 1) has the largest (positive) effect, suggesting that future development should be avoided in this area. This finding is consistent with the study by Beighley and Moglen (2003).

The best areas for land conservation are those most downstream or upstream. A strong negative association between conservation land and the peak discharge rate is observed for subwatershed 1 (most downstream) and subwatershed 5 (most upstream). Buffering the downstream area with conservation land is a priority to mitigate the effects of urban land in this area. Subwatershed 5 is an important area for conservation: (1) its location with respect to the watershed outlet implies the longest traveling time for 
stormwater runoff, one of the major determinants of the peak discharge rate; and (2) its large area significantly influences the total runoff volume in the watershed.

These findings are in agreement with field studies by Matisoff et al. (1998, 2002), which were conducted to look at sediment transport phenomena in the OWC watershed under various storms. Their results point to the importance of conservation land-use practices in the most upstream areas (e.g., subwatershed 5) to reduce soil erosion. Results of sediment flux and grain size analyses confirm that most erosion occurs in subwatershed 5, due to soil types and traditional tillage practices, and eroded soils travel to the watershed outlet even under a 1-year storm (Matisoff et al., 1998). For these reasons, land use changes in subwatershed 1 and 5 must be closely regulated.

\subsection{Regression Model Results at the Drainage Level}

Regression models at the drainage level are also estimated as second-order quadratic form. In addition to the land uses in the drainage area, the model considers the upstream effects, if the sub watershed is not the most upstream (e.g., subwatersheds 4 and 5). Upstream effects are taken into consideration, by including the peak discharge rate from the upstream subwatershed(s). For the case of subwatershed 1, the peak discharge rates from the immediate upstream subwatersheds (subwatersheds 2 and 3) are included in the regression model. The most upstream effects (subwatersheds 4 and 5) are already captured by the intermediate subwatershed 2 and 3 discharges. These concepts are illustrated in Figures 5.4 and 5.5. 


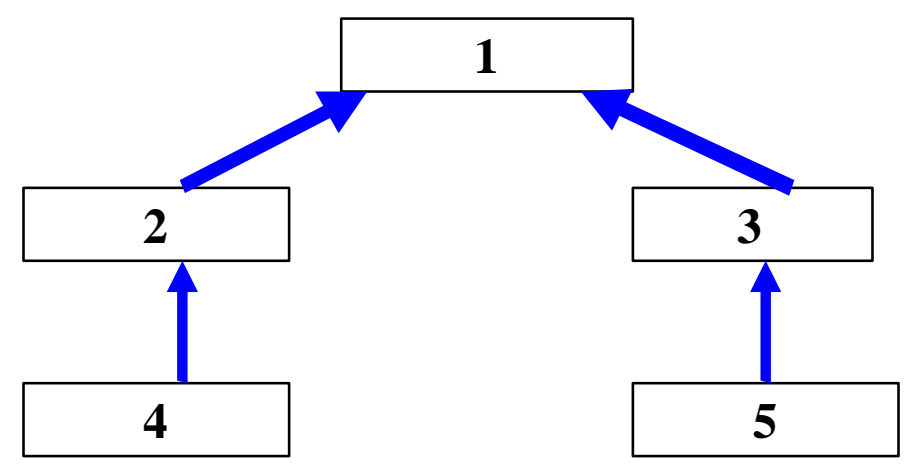

*Note: The box represents subwatershed boundary

Figure 5.4. Watershed Hierarchy and Network

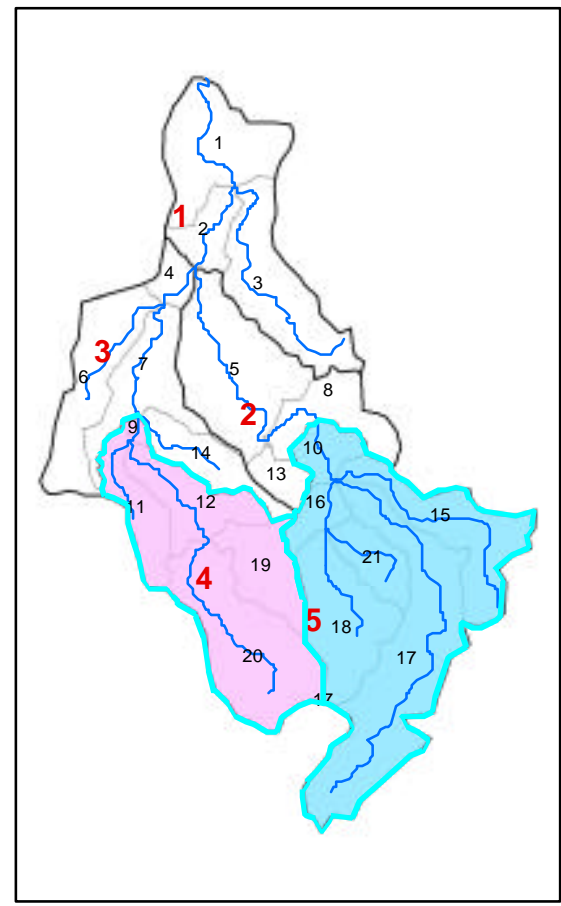

(A) Most Upstream Subwatersheds
$Q p(4) \sim F(L 9$, L11, L12, L19, L20)
$Q p(5) \sim F(L 10$, L15, L16, L18, L21

Note:

(1) $Q p(i)$ : Peak discharge rate at subwatershed i

(2) Lk : Land use in drainage $k$

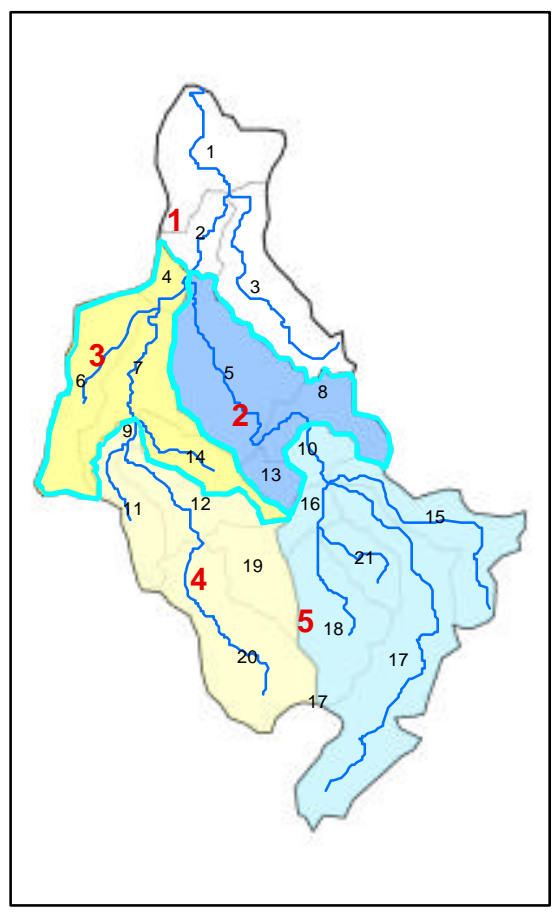

(B) Intermediate Subwatersheds

Statistical Model

Qp(2) F(L4, L6, L7, L14, Qp(4))

Qp(3) F(L5, L8, L13, Qp(5))

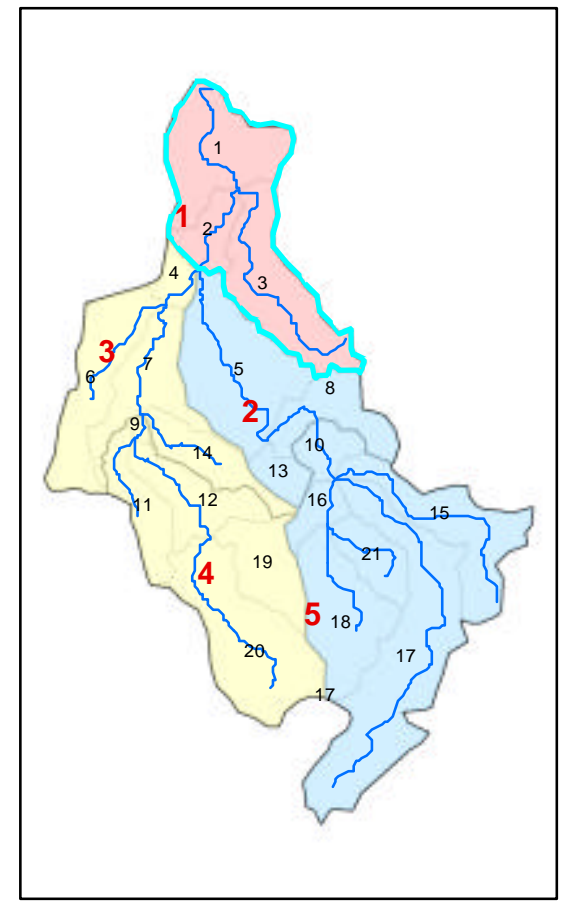

(C) Most Downstream Subwatershed

Statistical Model

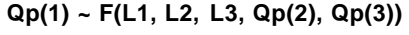

Figure 5.5: Diagrams for the Conceptual Statistical Models in Drainage Areas 
The regression model at the drainage level is formulated as:

$$
Q_{p}=f(\mathbf{x})=\mathbf{c x}+\frac{1}{2} \mathbf{x}^{T} \mathbf{H} \mathbf{x}, \mathbf{x}=\left\{x_{k}^{i}, Q_{s_{w}}^{i-1}\right\}
$$

where the amount of land use $\mathrm{k}$ in drainage area $\mathrm{i}$ within the subwatershed $\mathrm{s}_{\mathrm{w}}, x_{k}^{i_{\mathrm{w}_{\mathrm{w}}}}$, is taken as a share $(\%)$ of the total drainage area. $Q_{s_{w-1}}$ is the peak discharge rate from the upstream subwatershed, $\mathrm{s}_{\mathrm{w}-1}$. These quadratic models explain the variability of the peak discharge very well, with $\mathrm{R}^{2}>0.9$. The results are presented in Tables $5.4-5.8$.

MODEL Qp $p_{1} \sim \mathrm{f}\left\{\mathrm{XU1}\right.$ XC1, XU2, XC2, XU3, XC3, Qp $\left.2, \mathrm{Qp}_{3}\right\}$

Dependent Variable: Qp1 $\left(\mathrm{R}^{2}=0.9058, \mathrm{~N}=9660\right)$

\begin{tabular}{|c|c|c|c|c|c|c|c|}
\hline Variable & Coefficient & t-Value & p-Value & Variable & Coefficient & t-Value & p-Value \\
\hline Intercept & 2.885203 & 25.10 & $<.0001$ & XC3*XU1 & 0.061438 & 0.05 & 0.9572 \\
\hline XU1 & -0.686368 & -0.41 & 0.6845 & $\mathrm{XC} 3 * \mathrm{XC} 1$ & 0.855698 & 0.78 & 0.4335 \\
\hline $\mathrm{XC1}$ & 0.599646 & 0.32 & 0.7489 & XC3*XU12 & -0.109492 & -0.10 & 0.9197 \\
\hline XU12 & 0.329121 & 0.28 & 0.7767 & $\mathrm{XC} 3 * \mathrm{XC} 2$ & -0.103442 & -0.10 & 0.9189 \\
\hline $\mathrm{XC} 2$ & -0.828955 & -1.03 & 0.3029 & XC3*XU13 & -0.867463 & -0.56 & 0.5758 \\
\hline XU13 & 5.546961 & 3.04 & 0.0024 & XC3*XC3 & -0.357920 & -0.55 & 0.5820 \\
\hline XC3 & -3.842145 & -2.13 & 0.0336 & $\mathrm{Qp}_{2} * \mathrm{XU} 1$ & 0.289408 & 0.33 & 0.7430 \\
\hline $\mathrm{Qp}_{2}$ & 0.113898 & 5.85 & $<.0001$ & $\mathrm{Qp}_{2} * \mathrm{XC} 1$ & 0.231606 & 0.24 & 0.8104 \\
\hline $\mathrm{Qp}_{3}$ & 0.591828 & 21.38 & $<.0001$ & $\mathrm{Qp}_{2} * \mathrm{XU12}$ & 3.179055 & 5.19 & $<.0001$ \\
\hline XU1*XU1 & 5.414757 & 6.26 & $<.0001$ & $\mathrm{Qp}_{2} * \mathrm{XC} 2$ & 0.026101 & 0.20 & 0.8389 \\
\hline $\mathrm{XC} 1 * \mathrm{XU} 1$ & -9.422716 & -5.82 & $<.0001$ & $\mathrm{Qp}_{2} * \mathrm{XU13}$ & -3.169266 & -3.22 & 0.0013 \\
\hline $\mathrm{XC} 1 * \mathrm{XC} 1$ & 2.591135 & 4.03 & $<.0001$ & $\mathrm{Qp}_{2} * \mathrm{XC} 3$ & -0.390576 & -0.40 & 0.6898 \\
\hline XU12*XU1 & 0.593370 & 0.95 & 0.3434 & $\mathrm{Qp}_{2} * \mathrm{Qp}_{2}$ & -0.001226 & -3.06 & 0.0023 \\
\hline $\mathrm{XU} 12 * \mathrm{XC1}$ & -0.538546 & -0.55 & 0.5806 & $\mathrm{Qp}_{3} * \mathrm{XU} 1$ & 5.943357 & 3.80 & 0.0001 \\
\hline XU12*XU12 & 0.070674 & 0.09 & 0.9258 & $\mathrm{Qp}_{3} * \mathrm{XC} 1$ & -5.744521 & -3.30 & 0.0010 \\
\hline $\mathrm{XC} 2 * \mathrm{XU} 1$ & 0.089569 & 0.09 & 0.9266 & $\mathrm{Qp}_{3} * \mathrm{XU12}$ & -3.591996 & -3.66 & 0.0003 \\
\hline $\mathrm{XC} 2 * \mathrm{XC} 1$ & 0.151588 & 0.14 & 0.8882 & $\mathrm{Qp}_{3} * \mathrm{XC} 2$ & 1.277434 & 5.19 & $<.0001$ \\
\hline $\mathrm{XC} 2 * \mathrm{XU} 12$ & -0.918517 & -0.57 & 0.5676 & $\mathrm{Qp}_{3} * \mathrm{XU13}$ & -1.585276 & -0.94 & 0.3496 \\
\hline $\mathrm{XC} 2 * \mathrm{XC} 2$ & -0.654234 & -0.93 & 0.3508 & $\mathrm{Qp}_{3} * \mathrm{XC} 3$ & 4.214313 & 2.48 & 0.0132 \\
\hline XU13*XU1 & 1.830496 & 2.54 & 0.0110 & $\mathrm{Qp}_{2} * \mathrm{Qp}_{3}$ & 0.007405 & 6.10 & $<.0001$ \\
\hline $\mathrm{XU} 13 * \mathrm{XC1}$ & -0.912503 & -0.86 & 0.3924 & $\mathrm{Qp}_{3} * \mathrm{Qp}_{3}$ & -0.033141 & -26.43 & $<.0001$ \\
\hline XU13*XU12 & 0.098488 & 0.15 & 0.8793 & & & & \\
\hline $\mathrm{XU} 13 * \mathrm{XC} 2$ & 0.280003 & 0.32 & 0.7483 & & & & \\
\hline XU13*XU13 & -0.029065 & -0.03 & 0.9721 & & & & \\
\hline
\end{tabular}

$\mathrm{XCi}=$ conservation land use in drainage area $\mathrm{i}$;

$\mathrm{XUi}=$ urban land use in drainage area $\mathrm{i}$;

Qpi = peak discharge rate at the subwatershed $\mathrm{i}$;

Table 5.4: Quadratic Regression Estimation of the Peak Runoff Function for Subwatershed 1 
MODEL: Qp 2 f $\left\{X U 4, X C 4, X U 6, X C 6, X U 7, X C 7, X U 14, X C 14, Q_{4}\right\}$

Dependent Variable: $\mathrm{Qp}_{2}\left(\mathrm{R}^{2}=0.9714, \mathrm{~N}=9660\right)$

\begin{tabular}{|c|c|c|c|c|c|c|c|}
\hline Variable & Coefficient & t-Value & p-Value & Variable & Coefficient & t-Value & p-Value \\
\hline Intercept & 1.53208 & 32.71 & $<.0001$ & XU14*XU4 & 0.67854 & 4.77 & $<.0001$ \\
\hline XU4 & 2.20828 & 10.28 & $<.0001$ & $\mathrm{XU} 14 * \mathrm{XC} 4$ & 0.12537 & 0.61 & 0.5392 \\
\hline $\mathrm{XC4}$ & -2.95212 & -14.07 & $<.0001$ & XU14*XU6 & -0.38472 & -2.87 & 0.0041 \\
\hline XU6 & 0.08543 & 0.44 & 0.6602 & XU14*XC6 & 0.40709 & 2.72 & 0.0065 \\
\hline XC6 & 0.61365 & 3.31 & 0.0009 & XU14*XU7 & -0.61532 & -4.42 & $<.0001$ \\
\hline XU7 & 0.75645 & 3.44 & 0.0006 & $\mathrm{XU} 14 * \mathrm{XC} 7$ & 0.14529 & 0.70 & 0.4838 \\
\hline XC7 & -0.35103 & -1.47 & 0.1409 & XU14*XU14 & -0.65722 & -3.43 & 0.0006 \\
\hline XU14 & 0.32667 & 1.49 & 0.1367 & $\mathrm{XC14} * \mathrm{XU} 4$ & 0.52310 & 2.60 & 0.0093 \\
\hline $\mathrm{XC14}$ & 0.38258 & 1.70 & 0.0899 & $\mathrm{XC} 14 * \mathrm{XC} 4$ & 0.72579 & 3.01 & 0.0026 \\
\hline $\mathrm{Qp}_{4}$ & 0.44941 & 32.74 & $<.0001$ & XC14*XU6 & 0.66036 & 3.64 & 0.0003 \\
\hline XU4*XU4 & 3.14727 & 16.18 & $<.0001$ & XC14*XC6 & -0.34352 & -1.76 & 0.0779 \\
\hline $\mathrm{XC} 4 * \mathrm{XU} 4$ & -4.32503 & -11.42 & $<.0001$ & XC14*XU7 & 0.60192 & 3.21 & 0.0013 \\
\hline $\mathrm{XC} 4 * \mathrm{XC} 4$ & 1.92376 & 11.42 & $<.0001$ & $\mathrm{XC} 14 * \mathrm{XC} 7$ & 0.35460 & 1.57 & 0.1161 \\
\hline XU6*XU4 & 1.08022 & 7.89 & $<.0001$ & XC14*XU14 & -0.92157 & -2.36 & 0.0183 \\
\hline XU6*XC4 & -0.64766 & -3.28 & 0.0010 & XC14*XC14 & -0.50117 & -2.81 & 0.0050 \\
\hline XU6*XU6 & 0.11480 & 0.63 & 0.5305 & $\mathrm{Qp}_{4} * \mathrm{XU} 4$ & 0.17056 & 5.01 & $<.0001$ \\
\hline XC6*XU4 & -0.00058 & -0.00 & 0.9970 & $\mathrm{Qp}_{4} * \mathrm{XC} 4$ & -0.58872 & -13.53 & $<.0001$ \\
\hline $\mathrm{XC} 6 * \mathrm{XC} 4$ & 0.42180 & 1.97 & 0.0494 & $\mathrm{Qp}_{4} * \mathrm{XU} 6$ & 0.39471 & 11.43 & $<.0001$ \\
\hline XC6*XU6 & -1.66501 & -4.99 & $<.0001$ & $\mathrm{Qp}_{4} * \mathrm{XC6}$ & 0.64570 & 20.57 & $<.0001$ \\
\hline XC6*XC6 & -1.94823 & -10.70 & $<.0001$ & $\mathrm{Qp}_{4} * \mathrm{XU7}$ & 0.11013 & 3.49 & 0.0005 \\
\hline XU7*XU4 & 0.35543 & 2.44 & 0.0147 & $\mathrm{Qp}_{4} * \mathrm{XC7}$ & -0.19346 & -4.38 & $<.0001$ \\
\hline $\mathrm{XU7} * \mathrm{XC} 4$ & -0.14830 & -0.72 & 0.4700 & $\mathrm{Qp}_{4} * \mathrm{XU} 14$ & 0.43060 & 13.15 & $<.0001$ \\
\hline XU7*XU6 & -0.94943 & -7.08 & $<.0001$ & $\mathrm{Qp}_{4} * \mathrm{XC} 14$ & -0.44037 & -9.94 & $<.0001$ \\
\hline XU7*XC6 & 0.36617 & 2.32 & 0.0206 & $\mathrm{Qp}_{4} * \mathrm{Qp}_{4}$ & -0.00480 & -17.30 & $<.0001$ \\
\hline XU7*XU7 & -0.62498 & -3.19 & 0.0014 & & & & \\
\hline XC7*XU4 & 0.67493 & 3.43 & 0.0006 & & & & \\
\hline $\mathrm{XC} 7 * \mathrm{XC} 4$ & 0.67049 & 2.73 & 0.0063 & & & & \\
\hline XC7*XU6 & 0.37325 & 2.03 & 0.0424 & & & & \\
\hline $\mathrm{XC7} * \mathrm{XC} 6$ & 0.38567 & 1.98 & 0.0472 & & & & \\
\hline XC7*XU7 & -0.16090 & -0.41 & 0.6786 & & & & \\
\hline $\mathrm{XC} 7 * \mathrm{XC} 7$ & -0.21242 & -1.14 & 0.2525 & & & & \\
\hline
\end{tabular}

$\mathrm{XCi}=$ conservation land use in drainage area $\mathrm{i}$;

$\mathrm{XUi}=$ urban land use in drainage area $\mathrm{i}$;

Qpi = peak discharge rate at the subwatershed $\mathrm{i}$;

Table 5.5: Quadratic Regression Estimation of the Peak Runoff Function for Subwatershed 2. 
MODEL Qp $p_{3} \sim \mathrm{f}\left\{\mathrm{XU} 5, \mathrm{XC5}, \mathrm{XU} 8, \mathrm{XC8}, \mathrm{XU13}, \mathrm{XC13}, \mathrm{Qp}_{5}\right\}$

Dependent Variable: $\mathrm{Qp}_{3}\left(\mathrm{R}^{2}=0.9688, \mathrm{~N}=9660\right)$

\begin{tabular}{|c|c|c|c|c|c|c|c|}
\hline Variable & Coefficient & t-Value & p-Value & Variable & Coefficient & t-Value & p-Value \\
\hline Intercept & 0.493301 & 13.08 & $<.0001$ & XU13*XU5 & -1.192558 & -7.48 & $<.0001$ \\
\hline XU5 & 1.562795 & 6.95 & $<.0001$ & XU13*XC5 & 0.830264 & 3.54 & 0.0004 \\
\hline XC5 & -0.627572 & -3.30 & 0.0010 & XU13*XU8 & -1.476379 & -10.32 & $<.0001$ \\
\hline XU8 & -0.083732 & -0.06 & 0.9496 & XU13*XC8 & 1.403611 & 6.18 & $<.0001$ \\
\hline $\mathrm{XC8}$ & 1.119326 & 4.85 & $<.0001$ & XU13*XU13 & -0.052405 & -0.28 & 0.7771 \\
\hline XU13 & -0.687831 & -2.72 & 0.0065 & XC13*XU5 & 1.148588 & 4.43 & $<.0001$ \\
\hline $\mathrm{XC13}$ & -0.284000 & -1.55 & 0.1201 & $\mathrm{XC13} * \mathrm{XC} 5$ & 0.054134 & 0.18 & 0.8574 \\
\hline $\mathrm{XQp}_{5}$ & 0.855255 & 47.81 & $<.0001$ & XC13*XU8 & 1.040744 & 4.44 & $<.0001$ \\
\hline XU5*XU5 & 5.109709 & 26.12 & $<.0001$ & $\mathrm{XC13} * \mathrm{XC} 8$ & 0.561669 & 2.31 & 0.0207 \\
\hline XC5*XU5 & -8.063230 & -20.81 & $<.0001$ & XC13*XU13 & 1.424328 & 4.03 & $<.0001$ \\
\hline $\mathrm{XC5} * \mathrm{XC5}$ & -0.280643 & -1.01 & 0.3129 & XC13*XC13 & -0.008361 & 0.43 & 0.6640 \\
\hline XU8*XU5 & -0.345816 & -2.51 & 0.0121 & $\mathrm{XQp}_{5} * \mathrm{XU} 5$ & 0.545965 & 16.11 & $<.0001$ \\
\hline XU8*XC5 & 0.739427 & 3.26 & 0.0011 & $\mathrm{XQp}_{5} * \mathrm{XC5}$ & -0.110844 & -2.18 & 0.0295 \\
\hline XU8*XU8 & -0.484593 & -2.74 & 0.0062 & $\mathrm{XQp}_{5} * \mathrm{XU} 8$ & 0.317375 & 9.50 & $<.0001$ \\
\hline XC8*XU5 & 1.270337 & 5.10 & $<.0001$ & $\mathrm{XQp}_{5} * \mathrm{XC} 8$ & -0.453038 & -10.78 & $<.0001$ \\
\hline XC8*XC5 & 1.003700 & 3.90 & $<.0001$ & XQp ${ }_{5} * X U 13$ & -0.137815 & -3.74 & 0.0002 \\
\hline XC8*XU8 & -2.108591 & -5.21 & $<.0001$ & $\mathrm{XQp}_{5} * \mathrm{XC13}$ & -0.384086 & -6.72 & $<.0001$ \\
\hline $\mathrm{XC} 8 * \mathrm{XC} 8$ & -1.442971 & -7.50 & $<.0001$ & $\mathrm{XQp}_{5} * \mathrm{XQp}_{5}$ & -0.021466 & -16.55 & $<.0001$ \\
\hline
\end{tabular}

$\mathrm{XCi}=$ conservation land use in drainage area $\mathrm{i}$;

$\mathrm{XUi}=$ urban land use in drainage area $\mathrm{i}$;

Qpi = peak discharge rate at the subwatershed $\mathrm{i}$;

Table 5.6: Quadratic Regression Estimation of the Peak Runoff Function for Subwatershed 3 
MODEL Qp 4 〜 f $\{$ 9, C9, U11, C11, U12, C12, U19, C19, U20, C20 $\}$

Dependent Variable: $\mathrm{Qp}_{4}\left(\mathrm{R}^{2}=0.9579, \mathrm{~N}=9660\right)$

\begin{tabular}{|c|c|c|c|c|c|c|c|}
\hline Variable & Coefficient & t-Value & p-Value & Variable & Coefficie nt & t-Value & p-Value \\
\hline Intercept & 2.2646 & 15.98 & $<.0001$ & XU19*XU9 & 3.5269 & 15.99 & $<.0001$ \\
\hline XU9 & 2.2002 & 9.05 & $<.0001$ & XU19*XC9 & -1.9364 & -6.47 & $<.0001$ \\
\hline XC9 & -2.3945 & -6.76 & $<.0001$ & XU19*XU11 & -0.1369 & 3.06 & 0.0023 \\
\hline XU11 & 0.4680 & -0.17 & 0.8631 & XU19*XC11 & -0.9010 & -4.09 & $<.0001$ \\
\hline XC11 & -0.8563 & 0.39 & 0.6995 & XU19*XU12 & 0.0726 & 4.59 & $<.0001$ \\
\hline XU12 & 0.1568 & 1.03 & 0.3046 & XU19*XC12 & -0.7139 & -3.90 & 0.0001 \\
\hline $\mathrm{XC12}$ & -1.6521 & 0.11 & 0.9164 & XU19*XU19 & -1.7623 & -7.37 & $<.0001$ \\
\hline XU19 & 3.8043 & 12.17 & $<.0001$ & XC19*XU9 & -1.4407 & -8.40 & $<.0001$ \\
\hline XC19 & -2.3558 & -5.78 & $<.0001$ & XC19*XC9 & 0.6092 & 1.06 & 0.2913 \\
\hline XU20 & 2.4831 & 5.54 & $<.0001$ & XC19*XU11 & -0.3557 & -2.05 & 0.0404 \\
\hline XC20 & 0.2602 & -2.63 & 0.0085 & XC19*XC11 & 0.0698 & -0.29 & 0.7692 \\
\hline XU9*XU9 & 3.0117 & 12.31 & $<.0001$ & XC19*XU12 & -0.5537 & -2.94 & 0.0033 \\
\hline XC9*XU9 & -3.3637 & -9.58 & $<.0001$ & XC19*XC12 & 0.0013 & 0.69 & 0.4898 \\
\hline XC9*XC9 & 1.2410 & 4.80 & $<.0001$ & XC19*XU19 & -0.6982 & -2.28 & 0.0230 \\
\hline XU11*XU9 & 1.7206 & 5.74 & $<.0001$ & XC19*XC19 & 1.7095 & 5.03 & $<.0001$ \\
\hline XU11*XC9 & -0.9698 & -2.41 & 0.0160 & XU20*XU9 & 4.1654 & 20.46 & $<.0001$ \\
\hline XU11*XU11 & 0.2537 & 2.08 & 0.0378 & XU20*XC9 & -2.0322 & -6.51 & $<.0001$ \\
\hline XC11*XU9 & -0.5312 & -3.40 & 0.0007 & XU20*XU11 & -0.3168 & 3.34 & 0.0009 \\
\hline $\mathrm{XC11} * \mathrm{XC} 9$ & -0.0563 & -0.43 & 0.6652 & XU20*XC11 & -0.0609 & 0.00 & 0.9963 \\
\hline XC11*XU11 & 1.1112 & 0.17 & 0.8667 & XU20*XU12 & 0.2672 & 7.56 & $<.0001$ \\
\hline $\mathrm{XC} 11 * \mathrm{XC} 11$ & 0.8602 & 0.09 & 0.9289 & XU20*XC12 & -0.3202 & -1.60 & 0.1104 \\
\hline XU12*XU9 & 2.6302 & 10.04 & $<.0001$ & XU20*XU19 & 0.3907 & 7.71 & $<.0001$ \\
\hline XU12*XC9 & -0.7181 & -2.76 & 0.0058 & XU20*XC19 & -0.7617 & -3.60 & 0.0003 \\
\hline XU12*XU11 & -0.0167 & 4.00 & $<.0001$ & XU20*XU20 & -0.4239 & -0.47 & 0.6366 \\
\hline XU12*XC11 & -0.3696 & -2.22 & 0.0267 & XC20*XU9 & -2.7006 & -13.72 & $<.0001$ \\
\hline XU12*XU12 & 0.5027 & 1.27 & 0.2050 & XC20*XC9 & 0.8035 & 3.38 & 0.0007 \\
\hline XC12*XU9 & -1.0238 & -4.53 & $<.0001$ & XC20*XU11 & -0.5544 & -1.89 & 0.0585 \\
\hline $\mathrm{XC12*XC9}$ & 0.9971 & 2.19 & 0.0284 & $\mathrm{XC} 20 * \mathrm{XC} 11$ & -0.1261 & -0.03 & 0.9743 \\
\hline XC12*XU11 & -0.0436 & -0.60 & 0.5467 & XC20*XU12 & -0.3956 & -1.17 & 0.2416 \\
\hline $\mathrm{XC} 12 * \mathrm{XC} 11$ & 0.1186 & 0.28 & 0.7821 & $\mathrm{XC} 20 * \mathrm{XC} 12$ & 0.0465 & 1.48 & 0.1381 \\
\hline XC12*XU12 & 1.4787 & -1.03 & 0.3033 & XC20*XU19 & -2.1526 & -11.84 & $<.0001$ \\
\hline \multirow[t]{3}{*}{$\mathrm{XC} 12 * \mathrm{XC} 12$} & 0.9011 & -2.24 & 0.0249 & XC20*XC19 & 0.5728 & 3.70 & 0.0002 \\
\hline & & & & XC20*XU20 & -2.1834 & -2.84 & 0.0046 \\
\hline & & & & XC20*XC20 & -0.7387 & 0.19 & 0.8459 \\
\hline
\end{tabular}

$\mathrm{XCi}=$ conservation land use in drainage area $\mathrm{i}$;

$\mathrm{XUi}=$ urban land use in drainage area $\mathrm{i}$;

Qpi = peak discharge rate at the subwatershed $\mathrm{i}$;

RSREG = quadratic regression model.

Table 5.7: Quadratic Regression Estimation of the Peak Runoff Function for Subwatershed 4 
MODEL MODEL Qp 5 f $\{$ U10 C10 U15 C15 U16 C16 U17 C 17 U18 C18 U21 C21\}

Dependent Variable: $\mathrm{Qp}_{5}\left(\mathrm{R}^{2}=0.9656, \mathrm{~N}=9660\right)$

\begin{tabular}{|c|c|c|c|c|c|c|c|}
\hline Variable & Coefficient & t-Value & p-Value & Variable & Coefficient & t-Value & p-Value \\
\hline Intercept & 1.638756 & 65.4 & $<.0001$ & XU18*XU10 & -6.680206 & -1.99 & 0.0463 \\
\hline XU10 & 3.789021 & 46.97 & $<.0001$ & XU18*XC10 & -5.623622 & -1.12 & 0.2639 \\
\hline $\mathrm{XC10}$ & -0.756788 & -6.56 & $<.0001$ & XU18*XU15 & -0.046401 & -0.84 & 0.4037 \\
\hline XU15 & -0.12618 & -0.12 & 0.9005 & XU18*XC15 & 0.049346 & 0.7 & 0.482 \\
\hline $\mathrm{XC15}$ & 1.42064 & 1.25 & 0.2118 & XU18*XU16 & 0.012095 & 0.19 & 0.8512 \\
\hline XU16 & 0.531208 & 1.13 & 0.259 & XU18*XC16 & 0.086032 & 1.17 & 0.2427 \\
\hline $\mathrm{XC16}$ & -0.842482 & -2.2 & 0.0279 & XU18*XU17 & 0.088574 & 1.52 & 0.1288 \\
\hline XU17 & -0.830829 & -0.65 & 0.5169 & XU18*XC17 & -0.412007 & -5.99 & $<.0001$ \\
\hline $\mathrm{XC17}$ & -2.881876 & -2.57 & 0.0102 & XU18*XU18 & -0.011839 & -0.14 & 0.8849 \\
\hline XU18 & 1.515714 & 1.54 & 0.124 & XC18*XU10 & 8.457805 & 2.72 & 0.0065 \\
\hline $\mathrm{XC18}$ & -0.711973 & -0.8 & 0.4245 & $\mathrm{XC18} * \mathrm{XC10}$ & 3.867273 & 0.85 & 0.3958 \\
\hline XU21 & 1.551594 & 2.62 & 0.0088 & XC18*XU15 & -0.126248 & -1.8 & 0.0718 \\
\hline $\mathrm{XC} 21$ & -1.177852 & -2.53 & 0.0113 & XC18*XC15 & -0.02136 & -0.26 & 0.7949 \\
\hline XU10*XU10 & 2.780159 & 41.16 & $<.0001$ & XC18*XU16 & -0.013877 & -0.2 & 0.8388 \\
\hline XC10*XU10 & -3.816465 & -25.4 & $<.0001$ & $\mathrm{XC18*XC16}$ & 0.038093 & 0.46 & 0.6442 \\
\hline $\mathrm{XC} 10 * \mathrm{XC} 10$ & 0.314562 & 3.81 & 0.0001 & XC18*XU17 & -0.043617 & -0.61 & 0.5393 \\
\hline XU15*XU10 & -22.771703 & -6.29 & $<.0001$ & XC18*XC17 & 0.041045 & 0.55 & 0.5839 \\
\hline XU15*XC10 & 3.339248 & 0.65 & 0.5181 & XC18*XU18 & -0.513157 & -3.21 & 0.0013 \\
\hline XU15*XU15 & -0.041178 & -0.51 & 0.6095 & XC18*XC18 & -0.147726 & -1.54 & 0.1241 \\
\hline XC15*XU10 & -23.536694 & -6.32 & $<.0001$ & XU21*XU10 & 7.101352 & 3.14 & 0.0017 \\
\hline $\mathrm{XC} 15 * \mathrm{XC} 10$ & -9.462439 & -1.63 & 0.1036 & XU21*XC10 & -8.675897 & -2.89 & 0.0039 \\
\hline XC15*XU15 & 0.151815 & 0.86 & 0.3895 & XU21*XU15 & -0.046457 & -0.75 & 0.4514 \\
\hline $\mathrm{XC} 15 * \mathrm{XC} 15$ & 0.089094 & 0.88 & 0.3799 & XU21*XC15 & -0.012139 & -0.15 & 0.8796 \\
\hline XU16*XU10 & 3.869481 & 2.48 & 0.0133 & XU21*XU16 & -0.013468 & -0.23 & 0.8218 \\
\hline XU16*XC10 & -3.966063 & -1.67 & 0.0945 & XU21*XC16 & 0.111153 & 1.28 & 0.2014 \\
\hline XU16*XU15 & -0.069006 & -1.11 & 0.2655 & XU21*XU17 & 0.078046 & 1.27 & 0.2056 \\
\hline XU16*XC15 & 0.007319 & 0.1 & 0.9212 & XU21*XC17 & -0.153126 & -2.27 & 0.0234 \\
\hline XU16*XU16 & 0.21879 & 2.55 & 0.0106 & XU21*XU18 & -0.033037 & -0.55 & 0.5794 \\
\hline XC16*XU10 & -0.302001 & -0.2 & 0.8385 & XU21*XC18 & -0.043735 & -0.61 & 0.5445 \\
\hline $\mathrm{XC} 16 * \mathrm{XC} 10$ & 0.032965 & 0.02 & 0.9862 & XU21*XU21 & 0.198936 & 2.43 & 0.0152 \\
\hline XC16*XU15 & -0.058382 & -0.7 & 0.482 & XC21*XU10 & -1.877398 & -0.86 & 0.3916 \\
\hline XC16*XC15 & 0.118933 & 1.3 & 0.1945 & XC21*XC10 & 2.737251 & 1.18 & 0.2382 \\
\hline XC16*XU16 & 0.597386 & 3.41 & 0.0006 & XC21*XU15 & -0.072132 & -0.87 & 0.384 \\
\hline $\mathrm{XC} 16 * \mathrm{XC} 16$ & 0.579214 & 6.78 & $<.0001$ & XC21*XC15 & 0.197938 & 2.49 & 0.0128 \\
\hline
\end{tabular}

Table 5.8: Quadratic Regression Estimation of the Peak Runoff Function for Subwatershed 5 (Continued) 
Table 5.8 (Continued)

\begin{tabular}{|c|c|c|c|c|c|c|c|}
\hline Variable & Coefficient & t-Value & p-Value & Variable & Coefficient & t-Value & p-Value \\
\hline XU17*XU10 & 23.904064 & 5.12 & $<.0001$ & XC21*XU16 & -0.02385 & -0.3 & 0.7609 \\
\hline $\mathrm{XU} 17 * \mathrm{XC10}$ & 12.406099 & 1.89 & 0.059 & $\mathrm{XC} 21 * \mathrm{XC} 16$ & 0.177824 & 1.87 & 0.0621 \\
\hline XU17*XU15 & 0.059492 & 1.03 & 0.3011 & XC21*XU17 & -0.144916 & -1.85 & 0.0638 \\
\hline $\mathrm{XU17} * \mathrm{XC15}$ & -0.128221 & -1.7 & 0.09 & $\mathrm{XC} 21 * \mathrm{XC} 17$ & 0.306407 & 3.82 & 0.0001 \\
\hline XU17*XU16 & 0.06146 & 1.02 & 0.3058 & XC21*XU18 & 0.01119 & 0.14 & 0.8896 \\
\hline XU17*XC16 & 0.072793 & 0.9 & 0.3661 & $\mathrm{XC} 21 * \mathrm{XC} 18$ & 0.026926 & 0.36 & 0.7186 \\
\hline XU17*XU17 & -0.702973 & -8.77 & $<.0001$ & $\mathrm{XC} 21 * \mathrm{XU} 21$ & 0.562526 & 3.2 & 0.0014 \\
\hline XC17*XU10 & 10.41264 & 2.48 & 0.0132 & $\mathrm{XC} 21 * \mathrm{XC} 21$ & 0.284197 & 2.98 & 0.0029 \\
\hline $\mathrm{XC} 17 * \mathrm{XC} 10$ & 4.210092 & 0.74 & 0.462 & & & & \\
\hline XC17*XU15 & -0.522536 & -7.04 & $<.0001$ & & & & \\
\hline $\mathrm{XC17} * \mathrm{XC} 15$ & 0.275514 & 3.58 & 0.0004 & & & & \\
\hline $\mathrm{XC17}$ XU16 & -0.105242 & -1.49 & 0.1366 & & & & \\
\hline $\mathrm{XC17} * \mathrm{XC} 16$ & 0.039913 & 0.45 & 0.6493 & & & & \\
\hline XC17*XU17 & -2.061087 & -12.39 & $<.0001$ & & & & \\
\hline $\mathrm{XC17} * \mathrm{XC} 17$ & 1.190819 & 11.98 & $<.0001$ & & & & \\
\hline
\end{tabular}

$\mathrm{XCi}=$ conservation land use in drainage area $\mathrm{i}$;

$\mathrm{XUi}=$ urban land use in drainage area $\mathrm{i}$;

Qpi $=$ peak discharge rate at the subwatershed $\mathrm{i}$;

RSREG = quadratic regression model. 
The average effects of the land-use variables on subwatershed peak discharge rates are computed by re-arranging the quadratic model as a linear one, as shown in Equation (5.3). The results at this level are similar to those at the subwatershed level. The drainage area which is located at the most downstream of all subwatersheds displays strong mean coefficients. The statistics of $\mathrm{M}$ over the sample of land-use patterns are summarized in Table 5.8.

\begin{tabular}{|c|c|c|c|c|c|c|}
\hline Subwatershed & Drainage & Land Use & Maximum & Minimum & Mean & Standard Deviation \\
\hline \multirow[t]{6}{*}{$\bar{~} 1$} & \multirow[t]{2}{*}{$\overline{1}$} & "Urban & $\overline{111.0741}$ & -0.2371 & 3.2408 & 1.2094 \\
\hline & & Conservation & -0.7654 & -9.297 & -3.1425 & 0.9375 \\
\hline & \multirow[t]{2}{*}{2} & Urban & 0.9375 & -0.2624 & 0.3412 & 0.1037 \\
\hline & & Conservation & 0.3201 & -0.4045 & 0.1086 & 0.0839 \\
\hline & \multirow[t]{2}{*}{3} & Urban & 2.0758 & 0.3904 & 0.9131 & 0.1827 \\
\hline & & Conservation & -0.3895 & -1.2448 & -0.7977 & 0.0705 \\
\hline \multirow[t]{8}{*}{2} & \multirow[t]{2}{*}{4} & Urban & 4.2131 & -2.3182 & 2.5251 & 0.8951 \\
\hline & & Conservation & -2.024 & -4.2278 & -2.9975 & 0.1714 \\
\hline & \multirow[t]{2}{*}{6} & Urban & 0.7602 & -0.879 & 0.3022 & 0.157 \\
\hline & & Conservation & 1.7138 & -0.5781 & 0.8607 & 0.2247 \\
\hline & \multirow[t]{2}{*}{7} & Urban & 1.6994 & 0.1268 & 0.7441 & 0.1708 \\
\hline & & Conservation & 0.3287 & -0.9805 & -0.3898 & 0.0915 \\
\hline & \multirow[t]{2}{*}{14} & Urban & 1.5267 & -0.4145 & 0.4611 & 0.1863 \\
\hline & & Conservation & 0.7308 & -0.4625 & 0.1107 & 0.089 \\
\hline
\end{tabular}

Table 5.9: Descriptive Statistics of M over the Sample Land Use Patterns ${ }^{3}$ ( $\left.n=9660\right)$ (Continued)

\footnotetext{
${ }^{3}$ The bold letter indicates significant drainage land use coefficients in each subwatershed boundary.
} 
Table 5.9 (Continued)

\begin{tabular}{|c|c|c|c|c|c|c|}
\hline Subwatershed & Drainage & Land Use & Maximum & Minimum & Mean & Standard Deviation \\
\hline \multirow[t]{6}{*}{$\overline{3}$} & 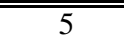 & "Urban & $\overline{77.3291}$ & -2.4836 & 1.2796 & 0.8856 \\
\hline & & Conservation & -0.0983 & -4.5644 & -0.907 & 0.5249 \\
\hline & 8 & Urban & 0.5403 & -1.4645 & 0.0107 & 0.2315 \\
\hline & & Conservation & 1.6997 & -0.2871 & 0.7671 & 0.141 \\
\hline & 13 & Urban & 1.0677 & -2.1482 & -0.2811 & 0.3049 \\
\hline & & Conservation & 1.3179 & -0.4889 & -0.2835 & 0.256 \\
\hline \multirow[t]{10}{*}{4} & 9 & Urban & 11.2336 & -2.3299 & 1.7896 & 1.3576 \\
\hline & & Conservation & 0.0233 & -6.9047 & -2.0624 & 0.719 \\
\hline & 11 & Urban & 1.7176 & -0.214 & 0.4203 & 0.2473 \\
\hline & & Conservation & 0.0275 & -1.4194 & -0.6755 & 0.1646 \\
\hline & 12 & Urban & 2.1364 & -0.4874 & 0.285 & 0.3502 \\
\hline & & Conservation & -0.1691 & -2.2647 & -1.2165 & 0.2313 \\
\hline & 19 & Urban & 5.369 & 0.4741 & 3.0188 & 0.6378 \\
\hline & & Conservation & -0.0197 & -4.261 & -1.9942 & 0.3918 \\
\hline & 20 & Urban & 4.6044 & -0.1962 & 1.9756 & 0.5983 \\
\hline & & Conservation & 0.6754 & -3.7332 & -0.0086 & 0.6045 \\
\hline \multirow[t]{12}{*}{5} & 10 & Urban & 19.3332 & -10.667 & 2.7609 & 2.4671 \\
\hline & & Conservation & 7.1043 & -8.4249 & -0.7926 & 1.1657 \\
\hline & 15 & Urban & 1.5074 & -11.758 & -0.4043 & 1.8523 \\
\hline & & Conservation & 1.6542 & -10.325 & -0.1202 & 1.9749 \\
\hline & 16 & Urban & 2.6931 & -1.3857 & 0.2867 & 0.3925 \\
\hline & & Conservation & -0.0594 & -0.9694 & -0.6316 & 0.1092 \\
\hline & 17 & Urban & 10.9955 & -1.6921 & 0.8965 & 2.0503 \\
\hline & & Conservation & 3.4529 & -4.5089 & -2.0352 & 0.9125 \\
\hline & 18 & Urban & 1.5157 & -2.1101 & 0.694 & 0.6376 \\
\hline & & Conservation & 3.5114 & -1.0823 & -0.1172 & 0.7141 \\
\hline & 21 & Urban & 5.3233 & -2.7286 & 0.8765 & 0.7669 \\
\hline & & Conservation & 0.8295 & -2.0568 & -0.7935 & 0.2376 \\
\hline
\end{tabular}




\section{CHAPTER 6}

\section{QUADRATIC LAND-USE OPTIMIZATION}

This chapter describes how the statistically approximated stormwater runoff functions are used to formulate land-use optimization models and presents the results from these models at the subwatershed and drainage area levels. Sensitivity analyses are performed to assess the impacts on the optimal solutions of land-use constraints, providing important information that can be used to formulate land-use conservation policies.

\subsection{Subwatershed and Drainage Optimization}

The land-use optimization model is developed in a hierarchical fashion. A first optimization determines the amounts of land uses at the subwatershed level. This is followed by a second optimization to allocate land uses to drainage areas, by taking the land allocations to subwatersheds as given. Finally, the land allocation to drainage areas is input to the IHLUO.

In total, six different optimization models are formulated (one for the whole watershed subwatershed, and five for the subwatersheds). The land-use optimization 
model is a quadratic program, with linear constraints and a nonlinear quadratic objective function. At the top level, the optimization model is:

$$
\text { Minimize } f(\mathbf{x})=\mathbf{c x}+\frac{1}{2} \mathbf{x}^{T} \mathbf{H x}, \mathbf{x}=\left\{x_{k}^{i}\right\}
$$

subject to:

Land-use constraints at the watershed level

$$
\begin{aligned}
& \sum_{i=1}^{5} x_{u}^{i}=X_{u, 2020} \\
& 0.2 A \leq \sum_{i=1}^{5} x_{c}^{i} \leq 0.4 A \\
& \sum_{i=1}^{5} \sum_{k=u, a, c} x_{k}^{i}=A
\end{aligned}
$$

Land-use constraints at the subwatershed level

$$
\begin{aligned}
& x_{u}^{i} \geq 2 X_{u_{o}}^{i} \\
& x_{a}^{i} \geq 0.8 X_{a_{o}}^{i} \\
& x_{c}^{i} \geq 0.85 X_{c_{o}}^{i} .
\end{aligned}
$$

$\mathbf{x}$ is the vector of conservation and urban land shares in each subwatershed i, $X_{u, 2020}$ is the projected urban land use in 2020, and $X_{k_{o}}^{i}$ is the existing (2000) land use k $(\mathrm{a}, \mathrm{c}, \mathrm{u})$ in subwatershed i. The land-use constraints at the watershed level assure that: (1) the sum of urban land in all subwatersheds is equal to the urban land projected for 2020 (Eq. 6.2); (2) total conservation land varies between $20 \%$ and $40 \%$ of the watershed area 
(Eq. 6.3); and (3) the sum of all land uses in all subwatersheds is equal to the watershed area (Eq. 6.4). Constraints applied at the subwatershed level specify lower bounds for each land use: (1) the urban (residential, excluding road) land must be at least twice as large as the existing (2000) land (Eq. 6.5); (2) the agricultural land must represent at least $80 \%$ of the existing agricultural land (Eq. 6.6); and (3) the conservation land must represent at least $85 \%$ of the existing conservation land (Eq. 6.7). These constraints are based on observed land-use trends in the OWC area and in the state of Ohio, current land-use practices, and land cover conditions. At the lower level, the optimization model is applied to each subwatershed, using the drainage regression models:

$$
\text { Minimize } f(\mathbf{x})=\mathbf{c x}+\frac{1}{2} \mathbf{x}^{T} \mathbf{H} \mathbf{x}, \mathbf{x}=\left\{x_{k}^{i}, Q^{i-1} s_{w}\right\}
$$

subject to:

$\underline{\text { Land-use constraints at the subwatershed level }}$

$$
\begin{gathered}
\sum_{i=1}^{m} x_{u}^{i}=X_{u, 2020}^{s w_{j}} \\
\sum_{i=1}^{m} x_{c}^{i}=X_{c, 2020}^{s w_{j}} \\
\sum_{i=1}^{m} \sum_{k=u, a, c} x_{k}^{i}=A_{s w}
\end{gathered}
$$

$\underline{\text { Land-use constraints at the drainage level }}$

$$
\begin{aligned}
& x_{u}^{i} \geq 1.5 X_{u_{o}}^{i} \\
& x_{a}^{i} \geq 0.75 X_{a_{o}}^{i}
\end{aligned}
$$




$$
x_{c}^{i} \geq 0.80 X_{c_{o}}^{i}
$$

where $X_{u, 2020}^{s w_{j}}=$ total urban land in subwatershed $\mathrm{j}$ for $2020, X_{c, 2020}^{s w_{j}}=$ total conservation land in subwatershed $\mathrm{j}$ in 2020, and $X_{k_{o}}^{i}=$ existing (2000) land use $\mathrm{k}(\mathrm{a}, \mathrm{c}, \mathrm{u})$ in drainage area i. The land-use constraint at the subwatershed level is derived from the top-level land optimization model. At this level, it is assured that: (1) the sum of the urban land in all drainage areas is equal to the urban land allocated to the subwatershed area (Eq. 6.9); (2) the sum of the conservation land in all drainage areas is equal to the total conservation land allocated to the subwatershed (Eq. 6.10); and (3) the sum of all land uses in all drainages is equal to the subwatershed area (Eq. 6.11). Constraints applied at the drainage level specify lower bounds for each land use. These are similar to those applied at the subwatershed level in the top model. The constraints of the lower bounds are more relaxed compared to the top model, to avoid an overly constrained optimization model: (1) the urban (residential, excluding road) land must be at least 1.5 times the existing land (2000) land (Eq. 6.12); (2) the agricultural land must represent at least $75 \%$ of the existing agricultural land (Eq. 6.13); and (3) the conservation land must represent at least $80 \%$ of the existing conservation land (Eq. 6.14).

\subsection{Results from Quadratic Optimization}

Table 6.1 summarizes the current (2000) land allocation and the resulting peak discharge rate computed with the hydrological model. The results obtained with the toplevel optimization model applied to 2020 conditions are presented in Table 6.2. Note that 
the simulation results are only based on the rearranged three land-use variables (conservation, urban, and agriculture). The optimized land allocation reduces the peak discharge rate by $65 \%$, with increases of $1.09 \%$ and $9 \%$ in urban land and conservation land, respectively, and a decrease of $10 \%$ in agricultural land. The peak discharge rate after land allocation is calculated using the watershed stormwater runoff estimated function I (Eq. 5.2 and Table 5.2). The largest increase in urban land takes place in subwatershed 3. As a consequence, the smallest increase in conservation is observed in this subwatershed. This subwatershed has the second smallest urban coefficient, and a positive (though weak) conservation coefficient ${ }^{4}$. Although the second subwatershed has a negative urban coefficient (indicating that an increase in urban land would decrease the peak discharge), its negative conservation coefficient causes the model to allocate more conservation land in this area. This leads to the allocation of more urban land in subwatershed 3, to satisfy the total urban land constraint (Eq. 6.2). Also, the third subwatershed has a positive conservation coefficient (although it is relatively small), which discourages conservation land allocation in this area. Elsewhere, urban land allocation remains at its lower bound (Eq. 6.5). Conservation land is increased in areas where the conservation coefficients are negative. The largest increase in conservation land takes place in subwatershed 5, and approximately $45 \%$ of subwatershed 1 is allocated to conservation, underlying its potential impact on the peak discharge rate.

\footnotetext{
${ }^{4}$ The linear model shows the smallest urban and conservation coefficients in subwatershed 3 . The urban coefficient is positive and conservation negative. This provides a more clear explanation on the land allocation. Refer to Table 5.1 for details.
} 


\begin{tabular}{lcccccc}
\hline Variables & \multicolumn{7}{c}{ Subwatershed } \\
\cline { 2 - 7 } & 1 & 2 & 3 & 4 & 5 & All \\
\hline Urban (\%) & 3.524 & 2.57 & 4.494 & 1.183 & 0.834 & 2.130 \\
$\quad$ Impervious Residential & 0.402 & 0.282 & 1.102 & 0.166 & 0.326 & 0.409 \\
$\quad$ Roads & 3.122 & 2.289 & 3.392 & 1.017 & 0.508 & 1.721 \\
\hline Agriculture (\%) & 63.09 & 77.72 & 64.349 & 81.868 & 86.533 & 77.298 \\
\hline Conservation (\%) & 33.386 & 19.701 & 31.119 & 16.93 & 12.624 & 20.558 \\
\hline Peak Discharge Rate & \multicolumn{7}{c}{3.892} \\
(Peak Discharge Rate, $\left.\mathrm{m}^{3} / \mathrm{s}\right)$ & & \multicolumn{7}{c}{} \\
\hline
\end{tabular}

Table.6.1: Current (2000) Land Use by Subwatershed

\begin{tabular}{lcccccc}
\hline Variables & \multicolumn{7}{c}{ Subwatershed } \\
\cline { 2 - 7 } & 1 & 2 & 3 & 4 & 5 & All \\
\hline Urban (\%) & 3.926 & 2.852 & 10.288 & 1.35 & 1.161 & 3.216 \\
$\quad$ Impervious Residential & 0.804 & 0.563 & 6.896 & 0.333 & 0.653 & 0.409 \\
$\quad$ Roads & 3.122 & 2.289 & 3.392 & 1.017 & 0.508 & 2.807 \\
\hline Agriculture (\%) & 50.472 & 62.178 & 63.256 & 84.26 & 69.219 & 67.521 \\
\hline Conservation (\%) & 45.602 & 34.970 & 26.456 & 14.391 & 29.620 & 29.263 \\
\hline Objective Function Values & & \multicolumn{7}{c}{1.3528} \\
(Peak Discharge Rate, $\left.\mathrm{m}^{3} / \mathrm{s}\right)$ & & \multicolumn{7}{c}{} \\
\hline
\end{tabular}

Table 6.2: Future (2020) Land Allocations by Subwatershed 
Table 6.3 summarizes the current (2000) land allocation in drainage areas and the resulting peak discharge rate computed with the hydrological model at the drainage outlet. The results obtained with the lower-level optimization model applied to 2020 conditions are presented in Table 6.4. The land allocations generated by the optimization models are consistent with the mean coefficients derived from the quadratic models (See Table 5.8). The peak discharge rates at the subwatershed outlets after optimal allocations may be compared with the results associated to current condition in Table 6.5. Estimation of the peak discharge rate at the subwatershed outlet is made in a cascading fashion, from the most upstream to the most downstream subwatershed. The peak discharge rate from the upstream subwatershed enters into the downstream stormwater estimation model (Eq 5.3). Therefore, the peak discharge rate is estimated first for subwatersheds 4 and 5 . The estimated peak runoff from subwatershed 5 is used to approximate the peak discharge for subwatershed 3, and that from subwatershed 4 is input to subwatershed 2. Finally, the peak discharge rates from subwatersheds 2 and 3 are inputs to the peak runoff rate in subwatershed 1 (i.e., the discharge rate at the watershed outlet). See again Figure 5.2 as an illustration of the procedure. Due to this chain of calculations, the peak discharge rate at the watershed outlet computed by the drainage regression functions is different from the one computed by the subwatershed regression function. Estimation biases are propagated from the upstream to the downstream drainage areas through these distinct regression models. The peak discharge rate at the watershed outlet computed by the drainage regressions is $1.945 \mathrm{~m}^{3} / \mathrm{s}$, which is slightly higher than the one computed by the subwatershed regression, $1.353 \mathrm{~m}^{3} / \mathrm{s}$ (Table 6.2). The improvement in peak discharge reduction is significant for all subwatersheds, 
even with the additional urban land, as illustrated in Table 6.5. The most significant improvement occurs in subwatersheds 1 and 5, the most sensitive areas for stormwater runoff control. Figure 6.1 shows the distribution of land use allocation in drainage areas, after the drainage-level optimization. 


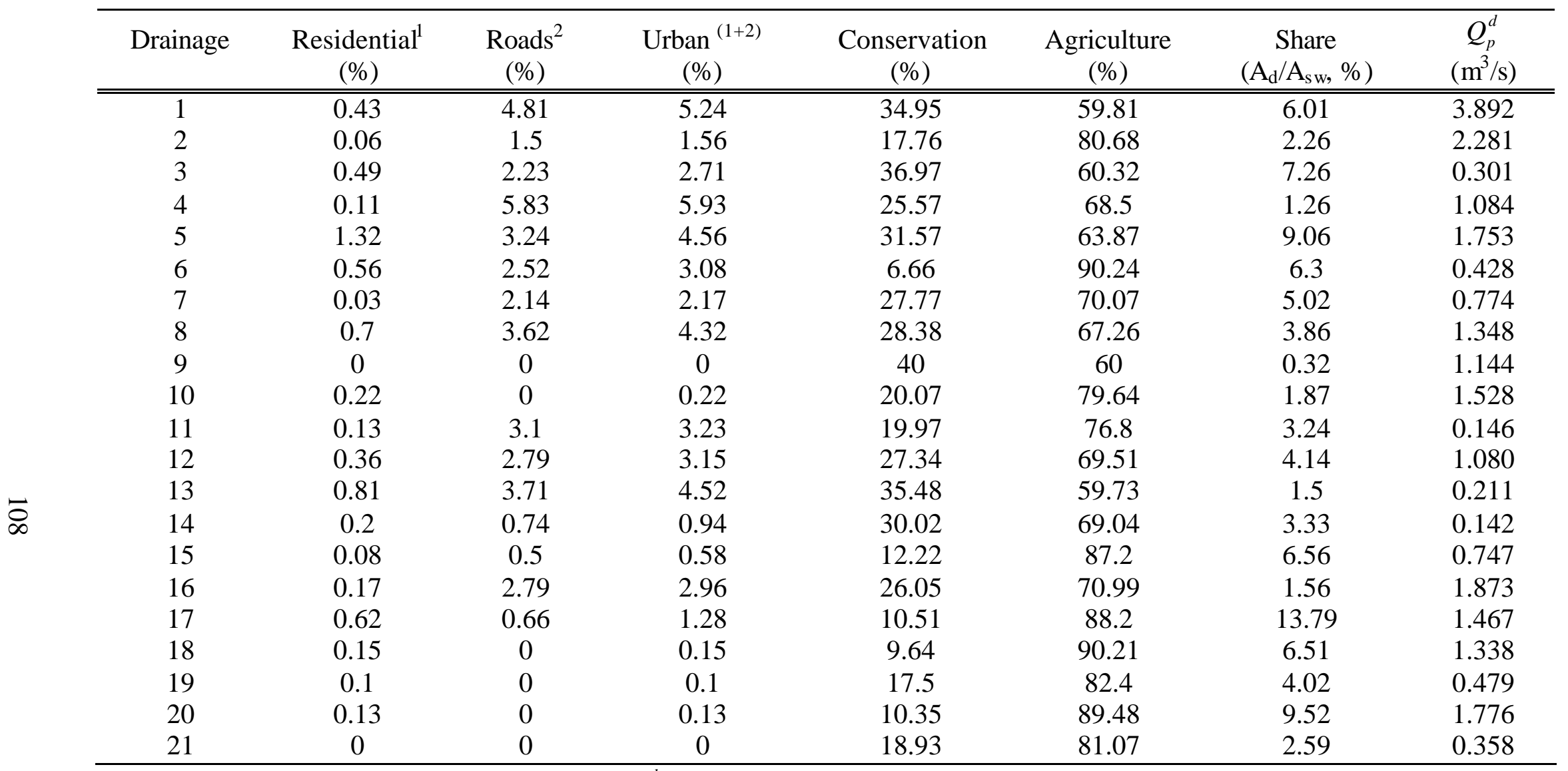

$\mathrm{A}_{\mathrm{d}}=$ total drainage area; $\mathrm{A}_{\mathrm{sw}}=$ total subwatershed area; $Q_{p}^{d}=$ peak discharge rate at the drainage outlet.

Table.6.3: Current (2000) Land Use by Drainage Area (\%) 


\begin{tabular}{ccccccc}
\hline Drainage & $\begin{array}{c}\text { Residential }^{1} \\
(\%)\end{array}$ & $\begin{array}{c}\text { Roads }^{2} \\
(\%)\end{array}$ & $\begin{array}{c}\text { Urban }^{(1+2)} \\
(\%)\end{array}$ & $\begin{array}{c}\text { Conservation } \\
(\%)\end{array}$ & $\begin{array}{c}\text { Agriculture } \\
(\%)\end{array}$ & $\begin{array}{c}\text { Share } \\
\left(\mathrm{A}_{\mathrm{d}} / \mathrm{A}_{\mathrm{sw}}, \%\right)\end{array}$ \\
\hline \hline 1 & 0.66 & 4.81 & 5.47 & 49.67 & 44.86 & 6.01 \\
2 & 1.44 & 1.5 & 2.94 & 14.93 & 82.13 & 2.26 \\
3 & 0.73 & 2.23 & 2.96 & 51.81 & 45.24 & 7.26 \\
4 & 0.21 & 5.83 & 6.04 & 42.61 & 51.35 & 1.26 \\
5 & 1.98 & 3.24 & 5.22 & 27.74 & 67.04 & 9.06 \\
6 & 1.17 & 2.52 & 3.69 & 27.95 & 68.36 & 6.3 \\
7 & 0.05 & 2.14 & 2.19 & 45.25 & 52.56 & 5.02 \\
8 & 14.17 & 3.62 & 17.79 & 22.71 & 59.49 & 3.86 \\
9 & 0.00 & 0 & 0.00 & 54.89 & 45.11 & 0.32 \\
10 & 0.38 & 0 & 0.38 & 16.97 & 82.65 & 1.87 \\
11 & 0.21 & 3.1 & 3.31 & 15.98 & 80.70 & 3.24 \\
12 & 0.91 & 2.79 & 3.70 & 21.87 & 74.43 & 4.14 \\
13 & 17.81 & 3.71 & 21.52 & 28.39 & 50.09 & 1.5 \\
14 & 0.32 & 0.74 & 1.06 & 29.86 & 69.08 & 3.33 \\
15 & 0.87 & 0.5 & 1.37 & 18.40 & 80.24 & 6.56 \\
16 & 0.26 & 2.79 & 3.05 & 43.73 & 53.22 & 1.56 \\
17 & 0.94 & 0.66 & 1.60 & 32.25 & 66.15 & 13.79 \\
18 & 0.23 & 0 & 0.23 & 32.11 & 67.66 & 6.51 \\
19 & 0.17 & 0 & 0.17 & 16.66 & 83.18 & 4.02 \\
21 & 0.20 & 0 & 0.20 & 8.28 & 91.52 & 6.52 \\
& 0.10 & 0 & 0.10 & 39.07 & 60.83 & 2.59 \\
\hline
\end{tabular}

$\mathrm{A}_{\mathrm{d}}=$ total drainage area; $\mathrm{A}_{\mathrm{sw}}=$ total subwatershed area; $Q_{p}^{d}=$ peak discharge rate at the drainage outlet.

Table 6.4: Future (2020) Land Allocations by Drainage Area (\%) 


\begin{tabular}{cccc}
\hline Subwatershed & $\begin{array}{c}\text { Peak Discharge Rate with the Simulation } \\
\text { Model and Current Condition }\end{array}$ & $\begin{array}{c}\text { Peak Discharge Rate using Regression } \\
\text { Functions for Optimal Allocation }\end{array}$ & Improvement (\%) \\
\hline \hline 1 & 3.892 & 1.945 & $50.02 \%$ \\
2 & 1.084 & 0.982 & $9.41 \%$ \\
3 & 1.753 & 0.816 & $53.45 \%$ \\
4 & 1.144 & 0.785 & $31.38 \%$ \\
5 & 1.528 & 0.534 & $65.05 \%$ \\
\hline
\end{tabular}

Table 6.5: Comparison of Peak Discharge Rates after Optimal Allocations

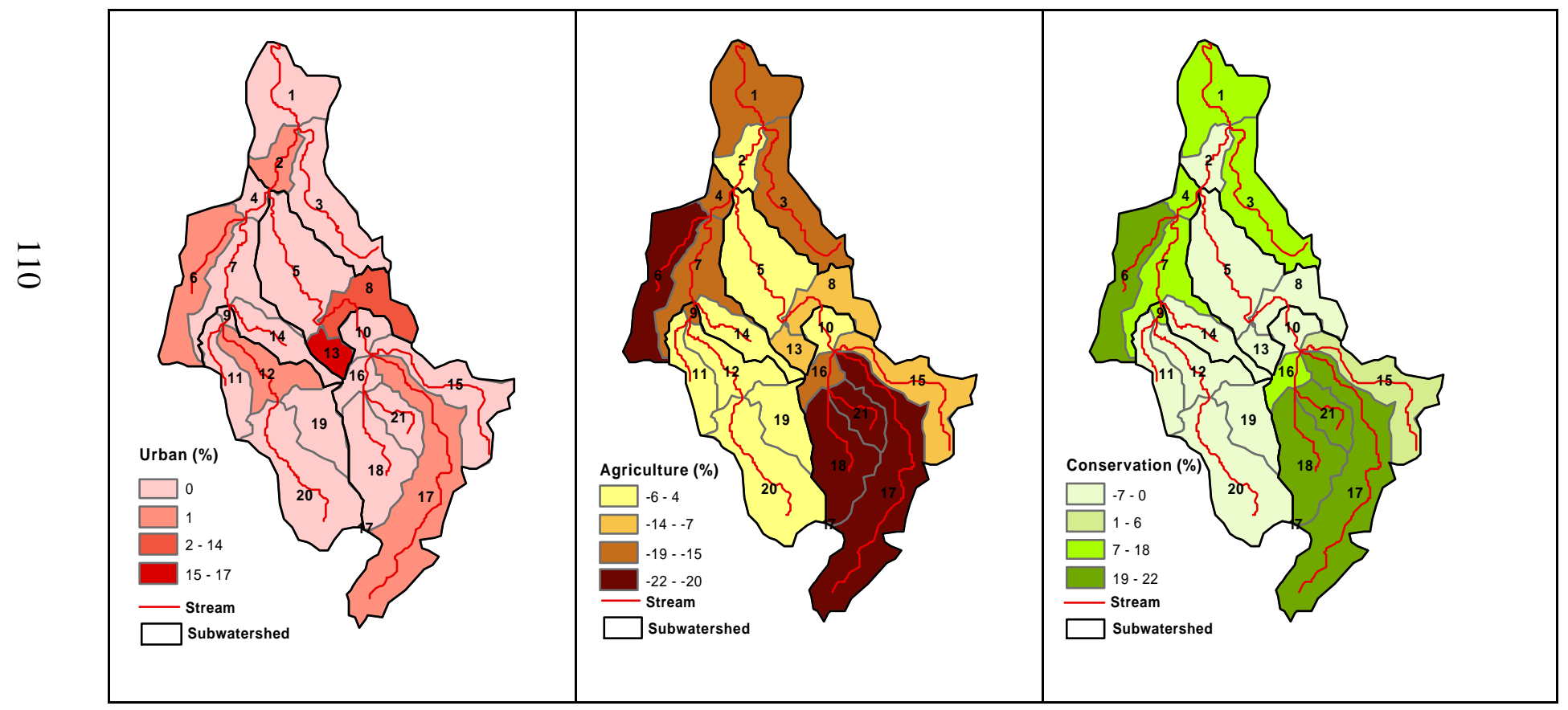

A change in land allocation is computed as \% Land (2020) - \% Land (2000).

Figure 6.1: Changes in the Distributions of Land Allocation at the Drainage Level (\%) 


\subsection{Sensitivity Analyses}

The global optimality of the solution cannot be guaranteed, because the Hessian matrix $\mathbf{H}$ (see Eq. 13) is not convex (its eigen values are of mixed signs). However, the sensitivity analyses presented below show that the optimal value of the objective function varies smoothly, without abnormal jumps, which would support the case for global optimality. Sensitivity analyses are performed to assess the impacts on the optimal solutions of discrete changes in parameters (Taha, 1971). Here, the focus is on the effects of minimum land-use targets.

\subsubsection{Minimum Conservation Land}

This sensitivity analysis focuses on changing the lower bound on total conservation land in the watershed, while maintaining all other constraints. This lower bound varies from $20 \%$ to $100 \%$ of the whole watershed area, by increments of $5 \%$. The conservation constraint (Eq.16) in the optimization model is rewritten as:

$$
\sum_{i=1}^{5} x_{c}^{i}>\lambda A, \lambda \in[0.20-1.00]
$$

The results are summarized in Figure 6.2 and Table 6.6. Figure 6.2 depicts the changes in the objective function, while the results of the land allocation are summarized in Table 6.6. Constraint (21) is binding for $\lambda \leq 30 \%$. Above 30\%, the peak discharge rate remains constant, at $1.35 \mathrm{~m}^{3} / \mathrm{s}$. Table 6.6 indicates that subwatershed 1 (the most downstream) is the most sensitive area, as its share of conservation land reaches its highest level immediately. Subwatersheds 5 and 4 (the most upland areas) follow, once the conservation constraint in subwatershed 1 becomes binding. The land allocation in subwatershed 3 remains constant, suggesting that the peak discharge rate is insensitive to 
land use changes in this area. In conclusion, this analysis suggests concentrating conservation efforts mostly in subwatersheds 1, 4, and 5. Allocating conservation land in subwatersheds 2 and 3 is inefficient. The results also point that at least $30 \%$ of the watershed area should be maintained as conservation land to mitigate hydrological impacts.

\begin{tabular}{llccc}
\hline & & \multicolumn{3}{c}{ Minimum } \\
\cline { 3 - 5 } & & 20 & 25 & 30 \\
\cline { 3 - 5 } Peak Discharge & $\mathrm{Q}_{\mathrm{p}}(\mathrm{m} 3 / \mathrm{s})$ & 2.2056 & 1.4599 & 1.3526 \\
\hline \multirow{2}{*}{ Subwatershed 1 } & Urban (\%) & 3.93 & 3.93 & 3.93 \\
& Conservation (\%) & 44.64 & 45.60 & 45.60 \\
& Agriculture (\%) & 51.43 & 50.47 & 50.47 \\
\hline \multirow{2}{*}{ Subwatershed 2 } & Urban (\%) & 6.97 & 6.97 & 6.97 \\
& Conservation (\%) & 17.09 & 17.09 & 17.09 \\
& Agriculture (\%) & 75.95 & 75.95 & 75.95 \\
\hline \multirow{2}{*}{ Subwatershed 3 } & Urban (\%) & 5.00 & 5.00 & 5.00 \\
& Conservation (\%) & 25.37 & 25.37 & 25.37 \\
& Agriculture (\%) & 69.63 & 69.63 & 69.63 \\
\hline \multirow{2}{*}{ Subwatershed 4 } & Urban (\%) & 1.37 & 1.37 & 1.37 \\
& Conservation (\%) & 14.09 & 14.09 & 32.87 \\
& Agriculture (\%) & 84.54 & 84.54 & 65.76 \\
\hline \multirow{2}{*}{ Subwatershed 5 } & Urban (\%) & 1.20 & 1.20 & 1.20 \\
& Conservation (\%) & 10.35 & 25.98 & 29.23 \\
& Agriculture (\%) & 88.45 & 72.81 & 69.56 \\
\hline
\end{tabular}

Table 6.6. Sensitivity Analysis of Land Allocation: Minimum Total Conservation Land 


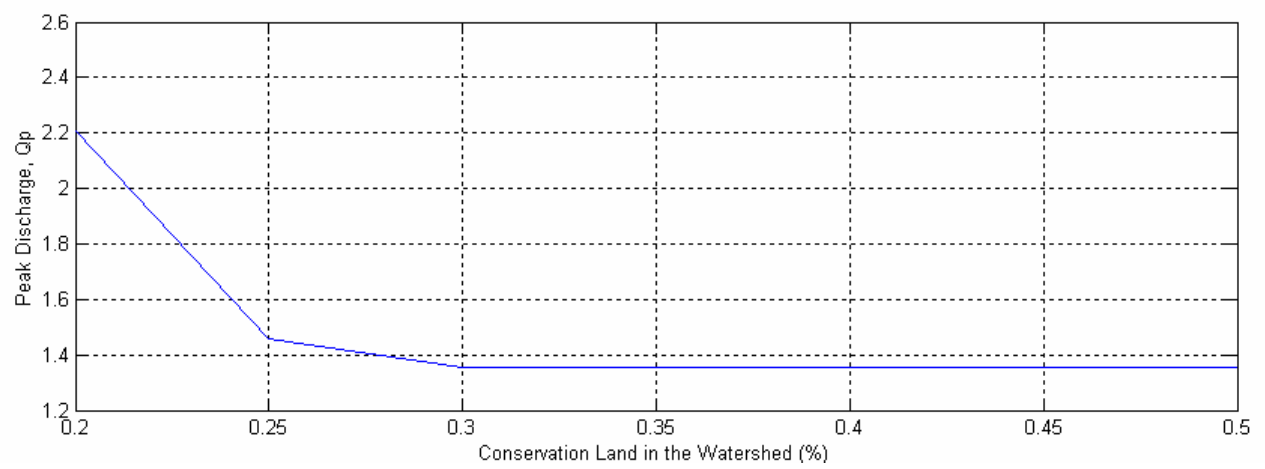

Figure 6.2: Impacts of Minimum Total Conservation Land Requirement

\subsubsection{Total Urban Land}

This sensitivity analysis focuses on changing the total amount of urban land in the watershed $\left(X_{u, 2020}\right)$, by increments of $1 \%$ (Eq. 15). Due to the other land-use constraints, the maximum amount of urban land cannot exceed $18 \%$ of the watershed area. The optimal values of the objective function are plotted in Figure 6.3, and the land allocation results are summarized in Table 6.7.

In general, the peak discharge $\left(Q_{p}\right)$ increases with increasing urban land use, particularly above the $8 \%$ share. If the share is less than $8 \%$, the variations of $\mathrm{Q}_{\mathrm{p}}$ takes the form of a parabola, and the lowest discharge rate is achieved at $5 \%$ of urban land. Once the share exceeds $8 \%, \mathrm{Q}_{\mathrm{p}}$ increases in a piece-wise linear fashion. In the interval 8$12 \%, \mathrm{Q}_{\mathrm{p}}$ increases slowly, and then more steeply beyond $12 \%$. This result suggests that urban land should represent less than $12 \%$ of the watershed. Note that the urban land used in this sensitivity analysis is the urban land cover (the amount of impervious land), rather than urban land uses, which reflect human activities on the land. 
Since the estimated stormwater runoff function explains $98 \%$ of the variations in the generated data, it is possible that the irregular pattern of the objective function in the lower range $(<8 \%)$ may be due to the unexplained share ( $2 \%)$. This pattern may also be the intrinsic outcome of the unit peak discharge function used in the hydrological simulation model. The unit peak discharge calculation is required for the hydrograph construction and is based on the Extended TR-55 procedures (Bingner and Theurer 2001). The unique peak discharge rate is determined as follows:

$$
Q_{p}=2.78 \cdot 10^{-3} P_{24} D_{a} \cdot\left[\frac{a+\left(c \cdot T_{c}\right)+\left(e \cdot T_{c}^{2}\right)}{1+\left(b \cdot T_{c}\right)+\left(d \cdot T_{c}^{2}\right)+\left(f \cdot T_{c}^{3}\right)}\right],
$$

where $Q_{Q}$ is the peak discharge, $D_{a}$ the total drainage area, $P_{24}$ the 24-hour effective rainfall over the total drainage area, $\mathrm{T}_{\mathrm{c}}$ the time of concentration , and the constants $\mathrm{a}, \mathrm{b}$, $\mathrm{c}, \mathrm{d}, \mathrm{e}$, and $\mathrm{f}$, the unit peak discharge regression coefficients (see Bingner and Theurer, 2001). The TR-55 procedure provides more curved patterns of unit peak discharge rate with higher $\mathrm{CN}$ and lower $\mathrm{I}_{\mathrm{a}} / \mathrm{P}_{24}$ ratio (USDA 1986), where $\mathrm{I}_{\mathrm{a}}$ is the initial abstraction. If urban land use increases in the watershed, $\mathrm{CN}$ increases and the $\mathrm{I}_{\mathrm{a}} / \mathrm{P}_{24}$ ratio decreases, as an increase in the impervious area reduces the soil infiltration capacity $\left(\mathrm{I}_{\mathrm{a}}\right)$. Therefore, the parabolic pattern in the objective function may be an inherent outcome of using this hydrological simulation method. 


\begin{tabular}{llcccccc}
\hline & & \multicolumn{5}{c}{ Total Urban Land Requirement (\%) } \\
\cline { 3 - 7 } Peak Discharge & $\mathrm{Q}_{\mathrm{p}}\left(\mathrm{m}^{3}\right.$ /s) & 3.0 & 5.0 & 8.2 & 12.2 & 18.0 & 18.2 \\
\cline { 3 - 7 } Subwatershed 1 & Urban (\%) & 1.36 & 1.32 & 1.36 & 1.49 & 3.15 & 3.21 \\
& Conservation (\%) & 45.60 & 45.60 & 45.60 & 45.60 & 45.60 & 45.03 \\
& Agriculture (\%) & 50.47 & 50.47 & 50.47 & 50.47 & 50.47 & 50.47 \\
\hline \multirow{2}{*}{ Subwatershed 2 } & Urban (\%) & 5.63 & 17.96 & 21.02 & 21.02 & 21.02 & 21.02 \\
& Conservation (\%) & 32.47 & 17.09 & 17.09 & 17.09 & 17.09 & 17.09 \\
& Agriculture (\%) & 61.90 & 64.96 & 61.90 & 61.90 & 61.90 & 61.90 \\
\hline \multirow{2}{*}{ Subwatershed 3 } & Urban (\%) & 5.00 & 5.00 & 18.30 & 21.74 & 21.74 & 21.74 \\
& Conservation (\%) & 25.37 & 25.37 & 28.81 & 25.37 & 25.37 & 25.37 \\
& Agriculture (\%) & 69.63 & 69.63 & 52.88 & 52.88 & 52.88 & 52.88 \\
\hline \multirow{2}{*}{ Subwatershed 4 } & Urban (\%) & 1.37 & 1.37 & 3.94 & 20.15 & 20.15 & 20.15 \\
& Conservation (\%) & 32.87 & 32.87 & 30.30 & 14.09 & 14.09 & 14.09 \\
& Agriculture (\%) & 65.76 & 65.76 & 65.76 & 65.76 & 65.76 & 65.76 \\
\hline \multirow{2}{*}{ Subwatershed 5 } & Urban (\%) & 1.20 & 1.20 & 1.20 & 1.35 & 20.05 & 20.09 \\
& Conservation (\%) & 29.23 & 29.23 & 29.23 & 29.08 & 10.39 & 10.35 \\
& Agriculture (\%) & 69.56 & 69.56 & 69.56 & 69.56 & 69.56 & 69.56 \\
\hline
\end{tabular}

Table 6.7. Sensitivity Analysis of Land Allocation: Total Urban Land

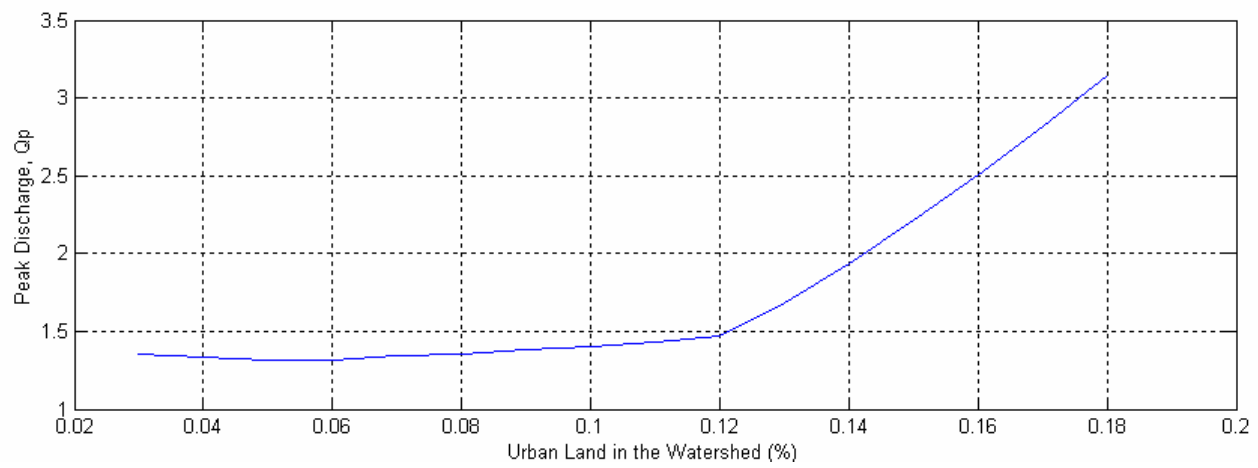

Figure 6.3: Impacts of Total Urban Land Requirement 


\subsubsection{Total Agricultural Land}

To test the impact of agricultural land use, a new constraint is added, representing the total available agricultural land in the watershed:

$\sum_{i=1}^{5} x_{a}^{i}=X_{a, 2020}$,

where $X_{a, 2020}$ is the total required agricultural land in the year 2020 .

The peak discharge rate varies little when total agricultural land represents less than $70 \%$ of the watershed. Above $70 \%$, the peak discharge rate increases strongly and regularly, suggesting that $70 \%$ should be the upper limit for agricultural land. The behavior of the objective function is displayed in Figure 6.4, and the resulting land allocations are presented in Table 6.8 .

\begin{tabular}{llcccc}
\hline & & \multicolumn{3}{c}{ Total Agricultural Land Requirement (\%) } \\
\cline { 3 - 6 } Peak Discharge & & 61.9 & 70.8 & 73.0 & 76.0 \\
\cline { 2 - 5 } & $\mathrm{Q}_{\mathrm{p}}\left(\mathrm{m}^{3} / \mathrm{s}\right)$ & 1.38 & 1.35 & 1.61 & 2.07 \\
\hline \multirow{2}{*}{ Subwatershed 1 } & Urban (\%) & 3.93 & 3.93 & 3.93 & 3.93 \\
& Conservation (\%) & 45.60 & 45.60 & 45.60 & 45.60 \\
& Agriculture (\%) & 50.47 & 50.47 & 50.47 & 50.47 \\
\hline \multirow{2}{*}{ Subwatershed 2 } & Urban (\%) & 4.11 & 6.97 & 6.97 & 6.97 \\
& Conservation (\%) & 33.99 & 17.09 & 17.09 & 17.09 \\
& Agriculture (\%) & 61.90 & 75.95 & 75.95 & 75.95 \\
\hline \multirow{2}{*}{ Subwatershed 3 } & Urban (\%) & 7.85 & 5.00 & 5.00 & 5.00 \\
& Conservation (\%) & 38.90 & 25.37 & 25.37 & 25.37 \\
& Agriculture (\%) & 53.25 & 69.63 & 69.63 & 69.63 \\
\hline \multirow{2}{*}{ Subwatershed 4 4 } & Urban (\%) & 1.37 & 1.37 & 1.37 & 1.37 \\
& Conservation (\%) & 32.87 & 14.09 & 14.09 & 14.09 \\
& Agriculture (\%) & 65.76 & 84.54 & 84.54 & 84.54 \\
\hline \multirow{2}{*}{ Subwatershed 5 5 } & Urban (\%) & 1.20 & 1.20 & 1.20 & 1.20 \\
& Conservation (\%) & 29.23 & 29.16 & 22.07 & 12.40 \\
& Agriculture (\%) & 69.56 & 69.63 & 76.73 & 86.40 \\
\hline
\end{tabular}

Table 6.8. Sensitivity Analysis of Land Allocation: Total Agricultural Land 


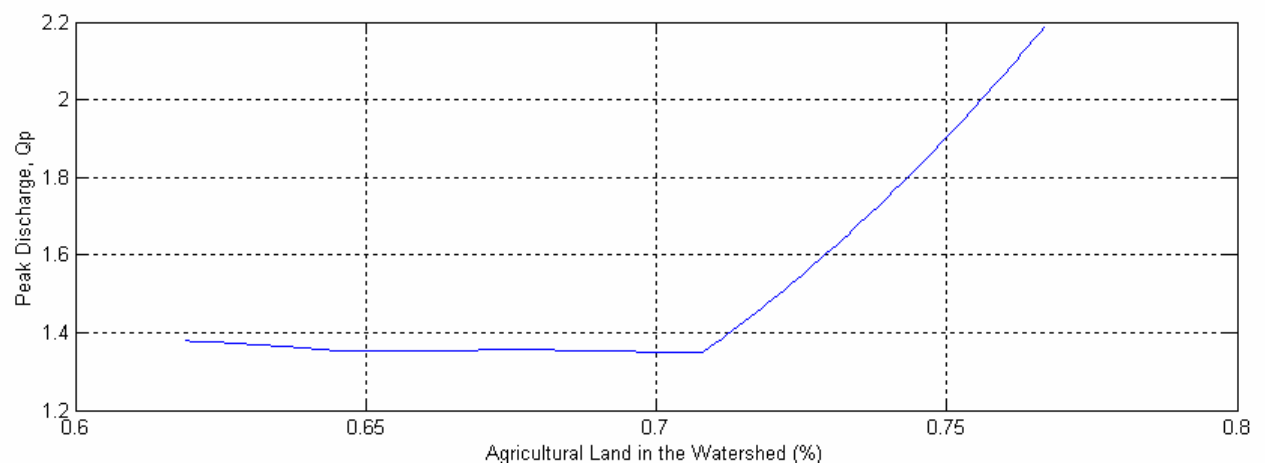

Figure 6.4: Impacts of Total Agricultural Land Requirement 


\section{CHAPTER 7}

\section{APPLICATION OF THE INTEGRATED HYDROLOGICAL LAND- USE OPTIMIZATION (IHLUO) MODEL}

This chapter presents applications of the IHLUO model, to delineate a detailed optimal land-use pattern at the 30-meter resolution. Using the IHLUO model, the spatial relationship between land-use changes and watershed hydrology is further investigated. The results from the IHLUO model are compared and contrasted with the results from the quadratic optimizations, using peak runoff approximation functions. Three additional research questions are analyzed, using a test drainage area: (1) the spatial impacts of land-use changes, (2) the influence of storm intensity on land use patterns, and (3) the optimal locations for urban sprawl.

\subsection{Overview}

Once land allocations at the drainage level are determined, the Integrated Hydrological and Land Use Optimization model (IHLUO) is used to delineate spatial land-use patterns at the 30-meter cell (raster) level. In this model (Eq 3.14-3.16), the total amounts of land uses allocated to drainage areas (Eq. 3.15) have been computed 
with the quadratic programming optimization model at the drainage level (Chapter 6). Then, IHLUO is applied to determine a cell-level land pattern for the whole watershed, using land-use allocations determined from drainage modeling. The objective function of the IHLUO model is to minimize the peak discharge rate at each drainage area outlet.

Three research questions are investigated with the IHLUO model: (1) What is the impact of the spatial land-use pattern on storm runoff, even under the same aggregate amount of land uses? (2) How does the optimal land-use pattern change with respect to storm size? (3) How should urban sprawl take place? Note that land is allocated only to minimize storm runoff, without accounting for the other purposes of buffers, such as providing wildlife habitat, preserving floodplain, or providing recreational and aesthetic benefits. These questions are answered with a pilot analysis conducted in a small drainage area (\#2). While investigating the first two questions, the IHLUO model is applied with the same aggregate land-use allocations. The second question is answered by running the IHLUO under different storm sizes. The third question is addressed by running the IHLUO while allocating more urban land.

\subsection{Optimal Land-Use Pattern for the Entire Watershed}

The IHLUO model is applied to the entire OWC watershed, with land allocations determined at the drainage level. Figure 7.1 presents the distribution of land uses for the entire watershed area. Table 7.1 summarizes the IHLUO-generated peak discharge rates and compares them with the peak discharge rates computed under current conditions (2000). The results generated by the IHLUO are very positive. The peak discharge rates are mostly everywhere reduced, except in drainage areas 11,13 and 14, where most of 
the new urban land is allocated. Note that these drainage areas have low peak discharge rates when compared to other drainage areas. The immediate downstream drainage areas $(5,9$, and 7$)$ from drainage areas $(11,13$, and 14) have runoffs reduced by $15-62 \%$, which suggests that the increases in the peak discharge rates in drainage areas 11,13 , and 14 have insignificant impacts on the downstream areas. Aggregate land allocation at the drainage level has been discussed in the previous chapter (Table 6.4). Details on the delineated optimal pattern and its relationship with physical site characteristics are discussed in Chapter 8. 


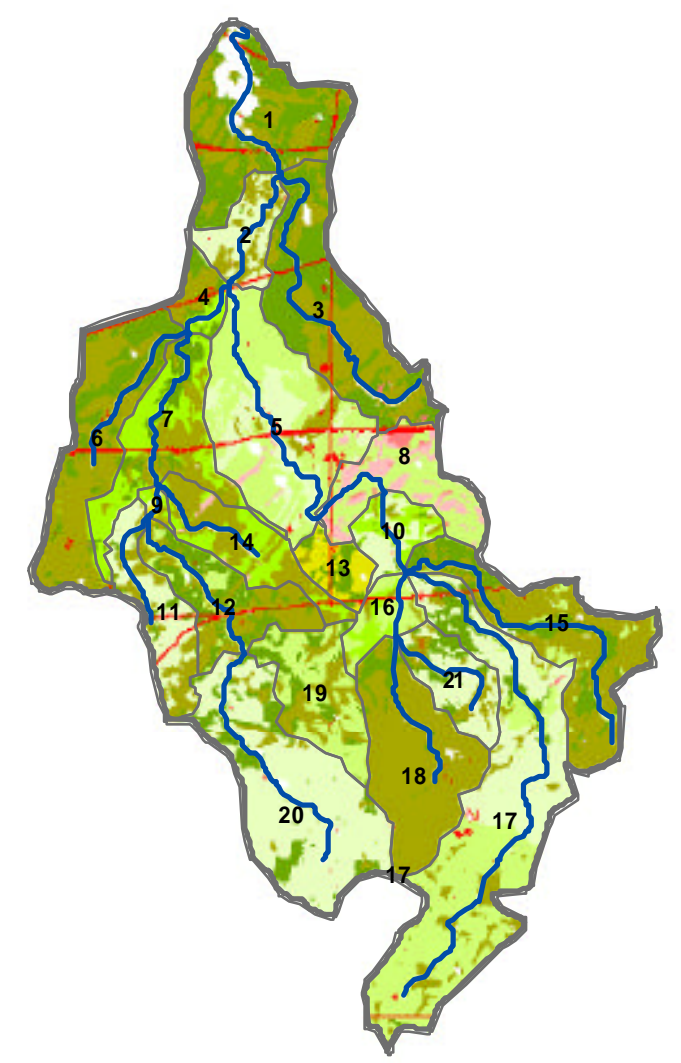

(Note: Map Overlay Order: Urban-Conservation-Agriculture)

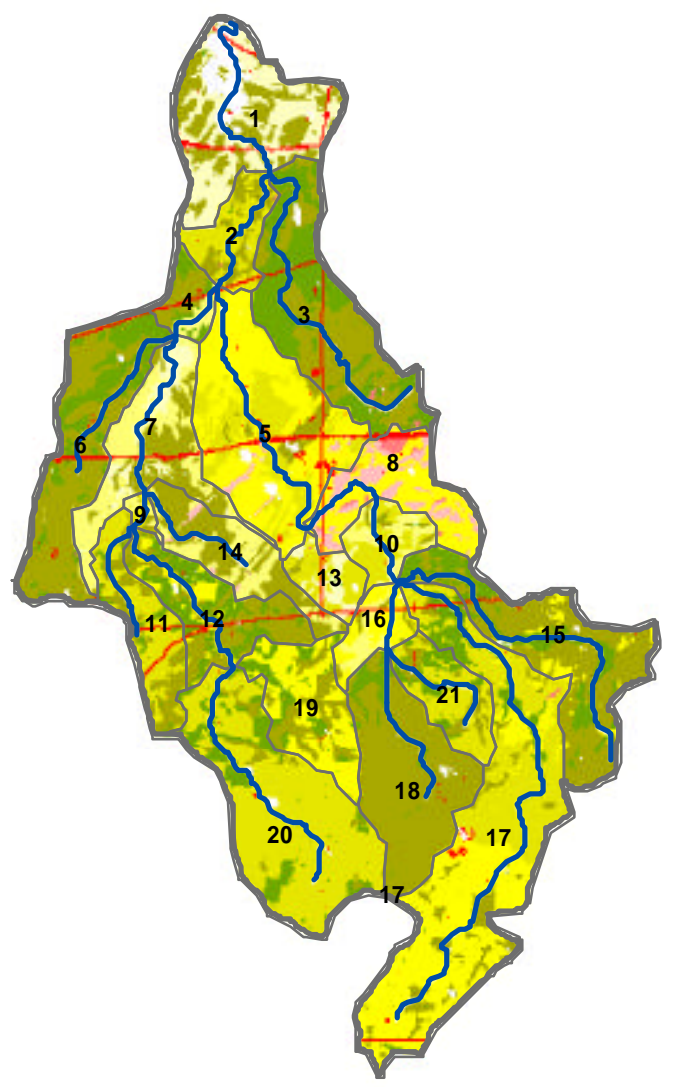

(Note: Map Overlay Order: Urban-Agriculture-Conservation)
Urban (\%)

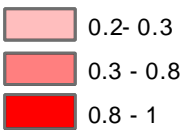

Conservation (\%)

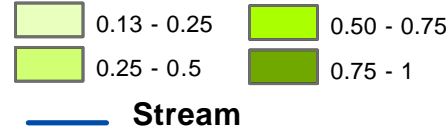

\section{Agriculture (\%)}

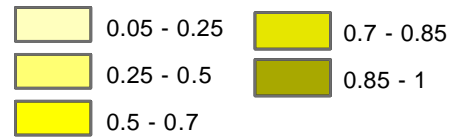

Figure 7.1: Spatial Pattern of Optimal Land Allocation at the Cell Level (30 meter) 


\begin{tabular}{cccccccc}
\hline Drainage & $\begin{array}{c}Q_{p}^{d} \\
(2000) \\
\left(\mathrm{m}^{3} / \mathrm{s}\right)\end{array}$ & $\begin{array}{c}Q_{p}^{d} \\
(2020) \\
\left(\mathrm{m}^{3} / \mathrm{s}\right)\end{array}$ & $\begin{array}{c}\text { Improvement } \\
(\%)\end{array}$ & Drainage & $\begin{array}{c}Q_{p}^{d}(2000) \\
\left(\mathrm{m}^{3} / \mathrm{s}\right)\end{array}$ & $\begin{array}{c}Q_{p}^{d} \\
(2020) \\
\left(\mathrm{m}^{3} / \mathrm{s}\right)\end{array}$ & $\begin{array}{c}\text { Improvement } \\
(\%)\end{array}$ \\
\hline 1 & 3.892 & 1.353 & $65 \%$ & 12 & 1.080 & 0.955 & $12 \%$ \\
2 & 2.281 & 1.148 & $50 \%$ & 13 & 0.211 & 0.526 & $-149 \%$ \\
3 & 0.301 & 0.16 & $47 \%$ & 14 & 0.142 & 0.189 & $-33 \%$ \\
4 & 1.084 & 1.01 & $7 \%$ & 15 & 0.747 & 0.429 & $43 \%$ \\
5 & 1.753 & 0.67 & $62 \%$ & 16 & 1.873 & 0.533 & $72 \%$ \\
6 & 0.428 & 0.193 & $55 \%$ & 17 & 1.467 & 0.402 & $73 \%$ \\
7 & 0.774 & 0.655 & $15 \%$ & 18 & 1.338 & 0.744 & $44 \%$ \\
8 & 1.348 & 0.627 & $53 \%$ & 19 & 0.479 & 0.349 & $27 \%$ \\
9 & 1.144 & 0.635 & $44 \%$ & 20 & 1.776 & 1.61 & $9 \%$ \\
10 & 1.528 & 0.539 & $65 \%$ & 21 & 0.358 & 0.155 & $57 \%$ \\
11 & 0.146 & 0.179 & $-23 \%$ & & & & \\
\hline
\end{tabular}

Table 7.1: Comparison of Peak Discharge Rates at Drainage Outlets: Current Condition vs. Optimal IHLUO Allocations

The peak discharge rates simulated with the IHLUO are compared with those obtained with the statistical runoff estimation functions. The aggregate amounts of land uses at the subwatershed and drainage area levels are identical in all three models. The outputs are consistent, which support the multi-stage hierarchical approach for watershed analysis. The estimations obtained with the lower-level quadratic models are slightly different, due to estimation errors that are propagated along the stream network of the subwatersheds.

\section{Estimation of Peak Discharge Rate $\left(\mathrm{m}^{3} / \mathrm{s}\right)$}

\begin{tabular}{cccc} 
Subwatershed & $\begin{array}{c}\text { Regression Function I } \\
\text { (Subwatershed Level) }\end{array}$ & $\begin{array}{c}\text { Regression Functions II } \\
\text { (Drainage Level) }\end{array}$ & $\begin{array}{c}\text { The IHLUO Simulation } \\
\text { (Cell Level) }\end{array}$ \\
\hline \hline 1 & 1.3528 & 1.945 & 1.353 \\
2 & - & 0.982 & 1.010 \\
3 & - & 0.816 & 0.670 \\
4 & - & 0.785 & 0.635 \\
5 & - & 0.534 & 0.539 \\
\hline
\end{tabular}

Table 7.2: Comparison of Peak Discharge Rate by Different Approximation Methods 


\subsection{Results from a Pilot Study}

\subsubsection{Spatial Land-Use Patterns and Stormwater Runoff}

The problem is set up to retain the initial (existing) total land-use allocation during the optimization process: $79 \%$ of the land for agriculture, $13 \%$ for conservation, and 1 cell for urban activities. All cells, except water cells, are assigned a land use. A one-year storm is used to simulate stormwater runoff for the second drainage area.

The results point to a $21.7 \%$ reduction in the peak runoff rate from the drainage outlet, with a 1-year storm. Figure 7.3 displays the optimal land-use patterns. The color bar in the legend indicates the density of each land-use type in a cell. Since mixed landuse types are allowed at the cell level, three different maps are generated according to the three land uses. Dark red implies that a cell is mostly dedicated to a certain land use type. For example, the agricultural land-use map shows red in most areas, indicating that this type of land use is predominantly allocated to most cells. The urban land map is mostly blue, implying a low urban density for the entire drainage area, except the outlet area. This means that dense urban land is only allowed near the outlet areas.

The spatial pattern has the following features: (1) it preserves the areas with high infiltration rates (Soil Types A and B); (2) it reduces agricultural development around the water courses; and (3) it protects upland watershed areas from development. These findings are in line with published recommendations for management plans for nonpoint source pollution control (Herson-Jones et al. 1995). The urban land use (admittedly very small: one cell out of 1591) is permitted primarily near the watershed outlet. Agriculture moves away from the water courses. Intensive agriculture (i.e., with a high proportion of 
agricultural land use in a given cell) is not allowed over high infiltration soils (A and B). This is clear when comparing the agricultural land-use pattern with the soil type of the watershed (Figure 7.2). Conservation land uses display similar characteristics. A high density of conservation land is assigned to areas with a high infiltration capacity. The previously urban cell is replaced by conservation land. The optimal land-use pattern suggests that grass/woods should be spread all over the watershed, with an overall watershed vegetation density of $15 \%$, rather than concentrating this type of land only around the streams. However, areas adjacent to the stream have a higher density of conservation land (approximately 22\%). This may imply that a small stream filter is effective for a 1-year storm to control the surface runoff, if the overall watershed is covered by grass/woods.

The mixing of conservation lands and agricultural land may be unrealistic in practice. However, implications may be drawn from the results. Agricultural lands in the drainage are assumed to be straight row crops and covered with crop residues. Crop residue cover conditions are applicable in the hydrological model if residues are on at least $5 \%$ of the surface throughout the year. The model result (adding $15 \%$ of vegetation over agricultural fields) may suggest more conservation tillage practices, which could yield runoff control effects equivalent to a $15 \%$ vegetation density. However, it is clear that the mixing of land uses at the cell level is a limitation of the model, due to the relaxation of the integer constraints.

Overall, the optimal pattern for a 1-year storm suggests retaining surface runoff on-site, using vegetation, and therefore minimizing its delivery to the stream. This technique is the most recommended management practice (Novotny and Chester, 1982). 

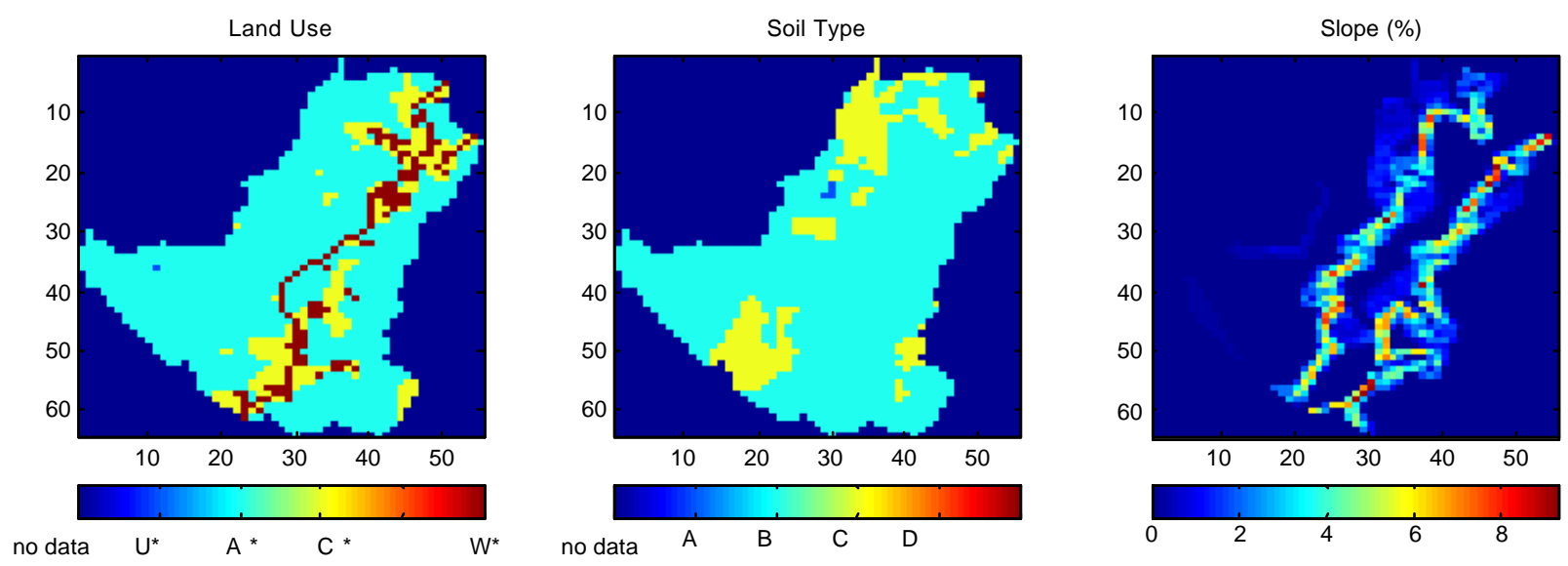

Figure 7.2: Site Characteristics -Land Use, Soil Type, and Slope
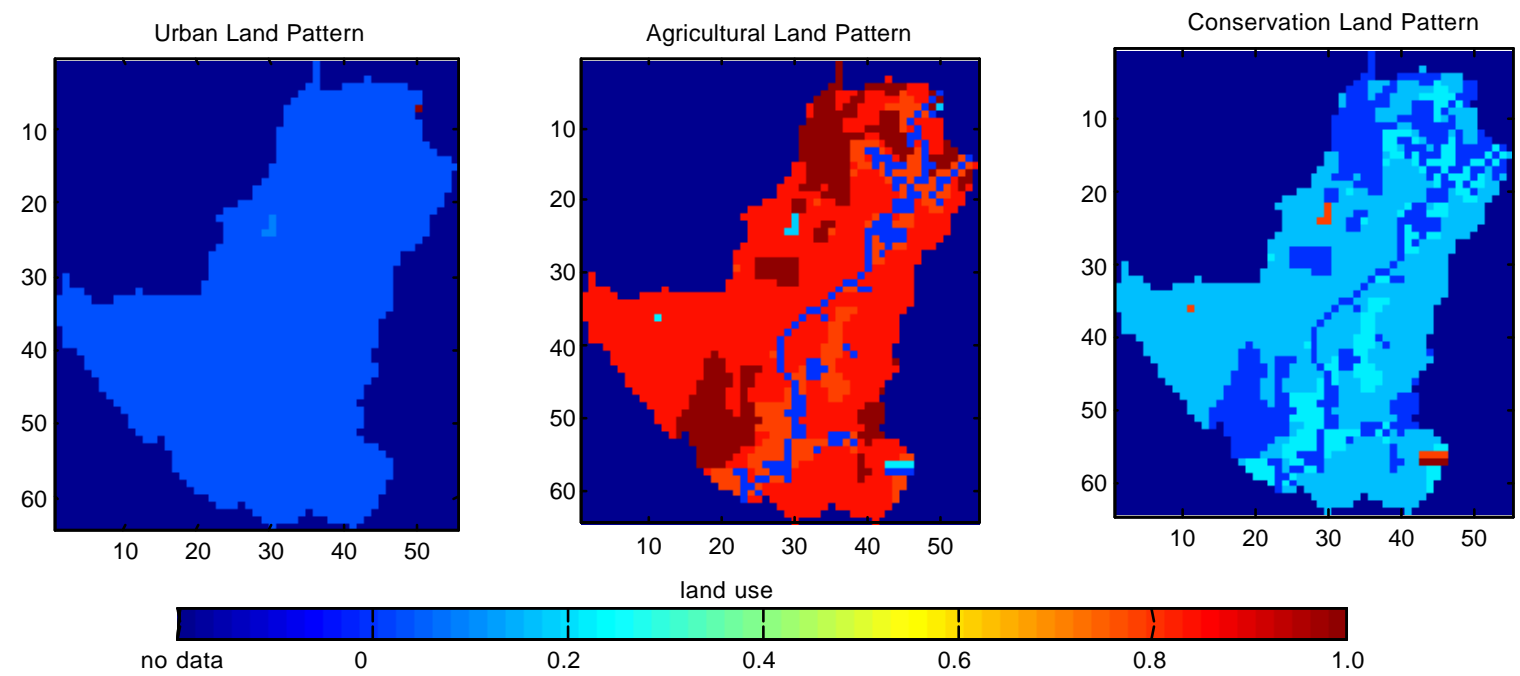

Figure 7.3: Optimal Land-Use Patterns for a 1-Year Storm 


\subsubsection{Storm Intensity and Spatial Land-Use Patterns}

The second question is whether the watershed responds differently to different storm sizes. Although runoff tends to be linearly related to storm size, the relationship between land use and the rainfall-runoff process is clearly nonlinear, as Equations (3.1), (3.2), and (3.8) show. This nonlinear relationship is clearly demonstrated in the analysis of the direct runoff of different curve numbers for different rainfall depths by USDA (1986). Optimal land-use patterns are derived under 1-year, 2-year, 5-year, and 10-year storms. No change is made in the total land-use constraints from the first simulation (79\% for agriculture, 13\% for conservation land, and 1 urban cell). The results in Table 7.3 show that the optimization model successfully reduces the peak runoff by $15-20 \%$. The optimal land-use patterns vary across storm sizes. The following can be observed: (1) vegetation buffers along the stream are effective for small storms (1- and 2-yr), but not for larger ones (5-. 10- yr); (2) the drainage area is covered with a vegetation density of approximately $15 \%$ to minimize the runoff.

\begin{tabular}{|l|l|l|l|}
\hline Storm Size & $\begin{array}{l}\text { Current Pattern } \\
\left(\mathrm{m}^{3} / \mathrm{s}\right)\end{array}$ & $\begin{array}{l}\text { Optimal Pattern } \\
\left(\mathrm{m}^{3} / \mathrm{s}\right)\end{array}$ & $\begin{array}{l}\text { Improvement } \\
(\%)\end{array}$ \\
\hline $1 \mathrm{yr}(28,9 \mathrm{~mm})$ & 0.13870 & 0.10923 & $21.1 \%$ \\
\hline $2 \mathrm{yr}(49.35 \mathrm{~mm})$ & 2.34123 & 1.93997 & $17.1 \%$ \\
\hline $5 \mathrm{yr}(61.64 \mathrm{~mm})$ & 5.32164 & 4.42405 & $16.9 \%$ \\
\hline $10 \mathrm{yr}(69.77 \mathrm{~mm})$ & 7.996370 & 6.65693 & $16.8 \%$ \\
\hline
\end{tabular}

Table 7.3: Storm Runoff vs. Optimal Land-use Patterns

Conservation land uses near the water courses increase for smaller storms (1- and 2-year). However, these lands, under a 10- year storm, display little vegetation density 
variations between the stream buffer zones and other drainage areas, indicating the ineffectiveness of stream buffers to control large storm runoff. Shifting from a 1-year storm to a 2-year storm, agricultural land-use intensity near the water course is reduced by approximately $10 \%$, indicating that more buffers around the stream are effective to control the runoff for a 2-year storm. However, if the storm is larger, agricultural activities near the stream are no longer significantly reduced. Instead, agricultural activities in areas with high infiltration capacity are reduced with larger storms (5-year and 10- year). High density vegetation appears in areas with a high infiltration capacity (soil A and B). The areas with soil A have the densest vegetation. Figure 7.4 displays the optimal land-use patterns for different storm sizes (note that the optimal land-use patterns for a 1-year storm are presented in Figure 7.3). 


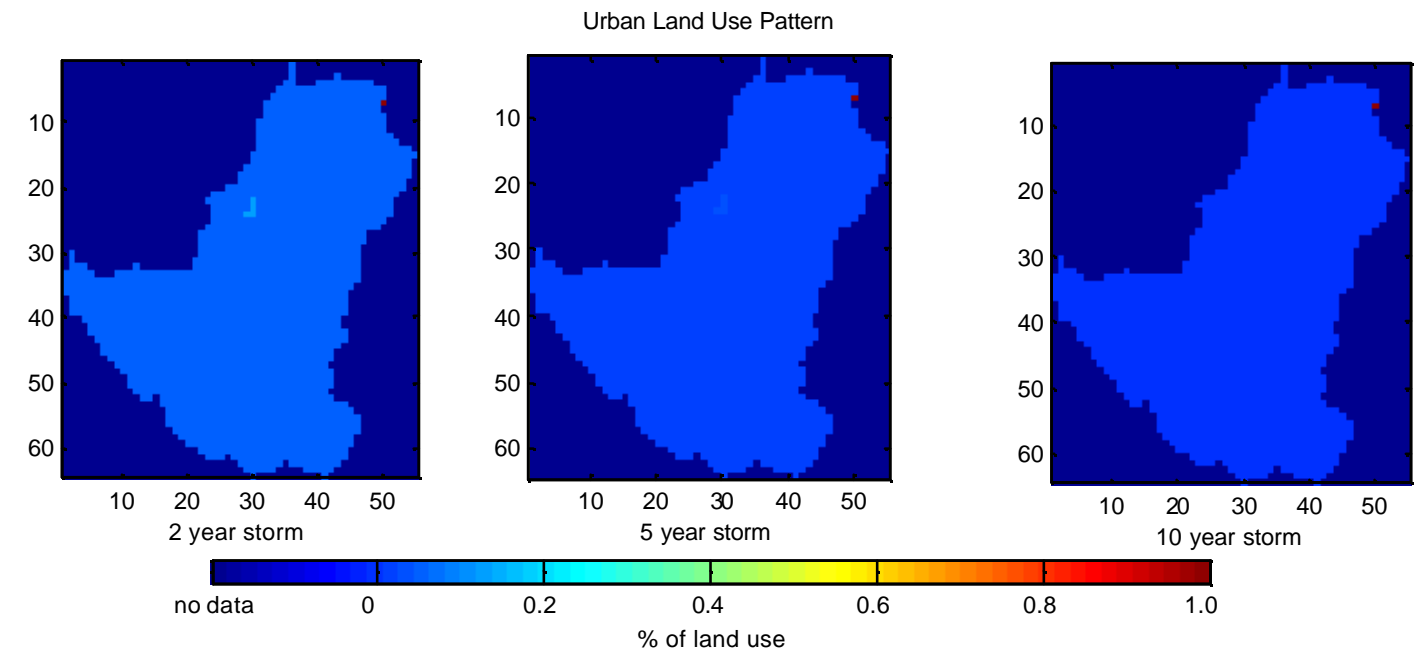

Agricultural Land Use Pattern
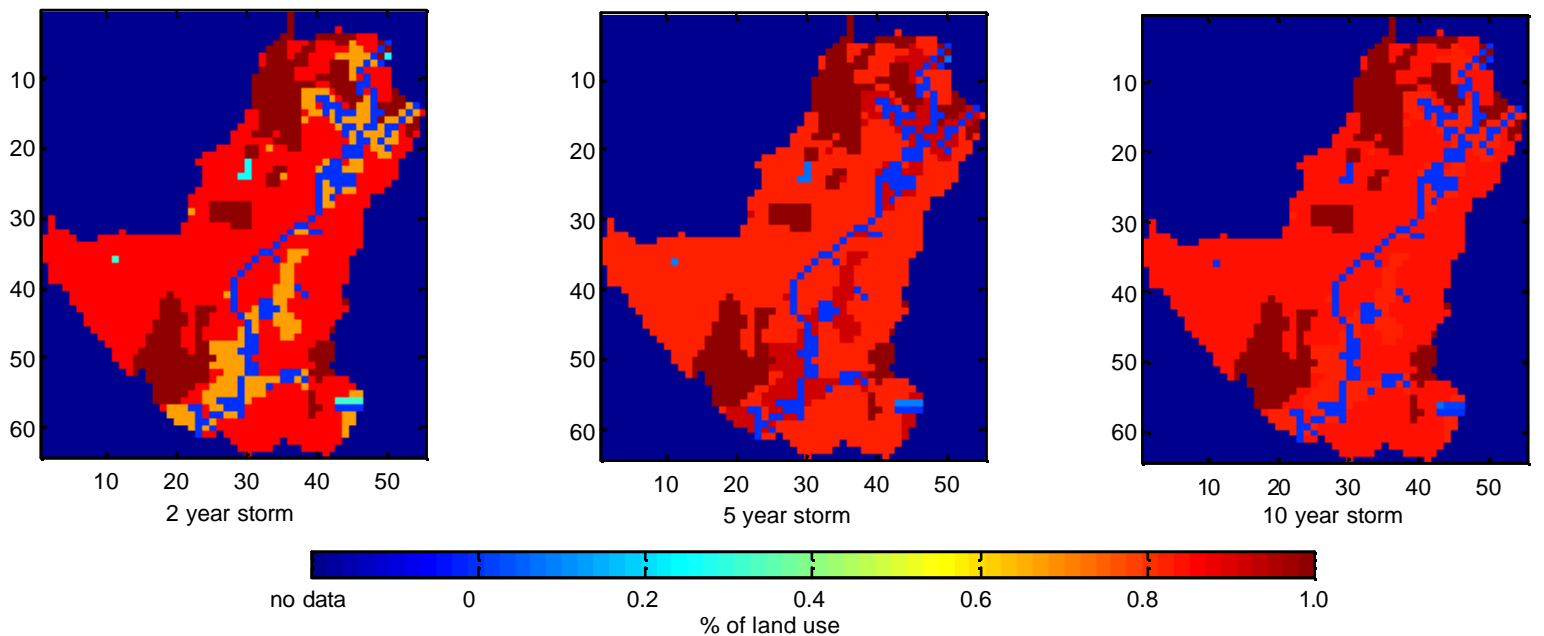

Conservation Land Use Pattern
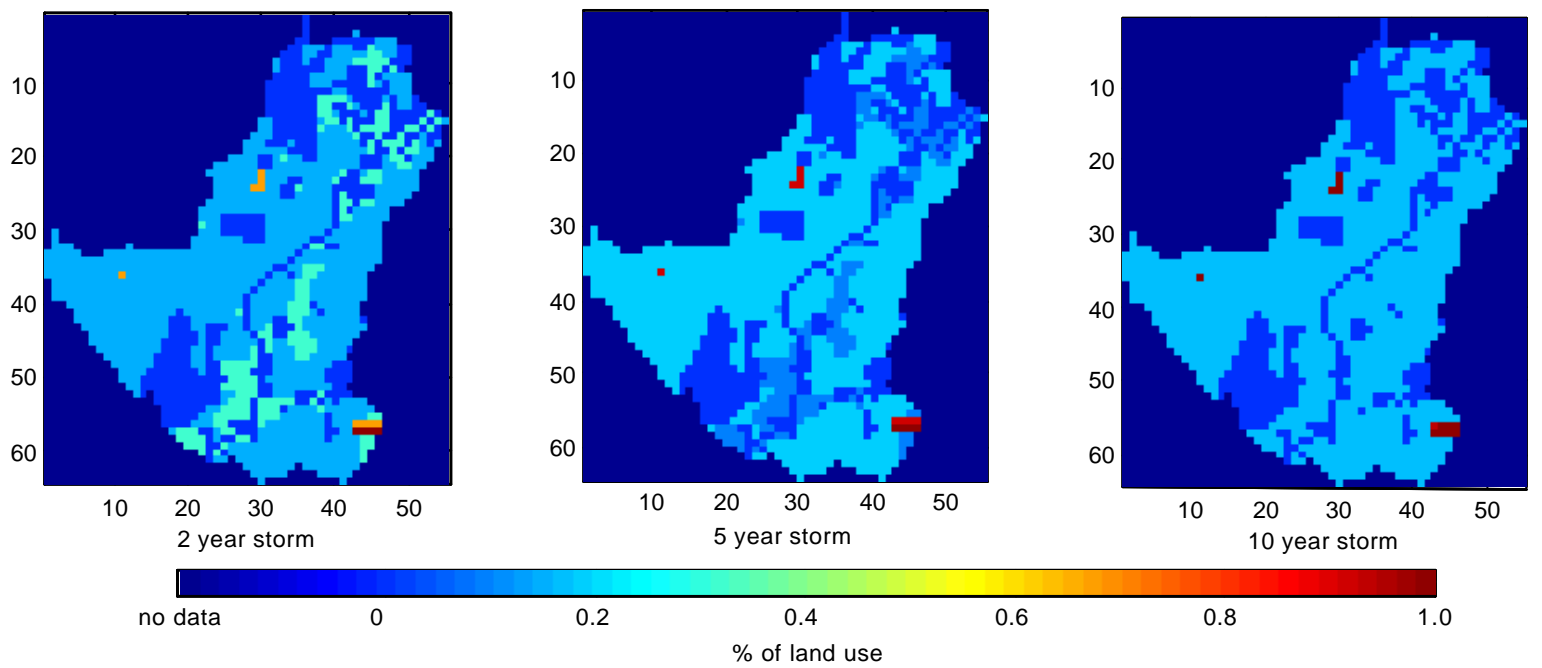

Figure 7.4: Optimal Land-use Patterns with Different Storm Sizes 


\subsubsection{Urban Sprawl and Spatial Land-Use Patterns}

The third question is how urban sprawl should take place in order to minimize storm runoff problems at the watershed outlet. To answer this question, the total urban development area is increased to represent $5 \%$ of the second drainage area. Accordingly, the total agricultural land is decreased by the same amount. The analysis is conducted with a 1-year storm. The results, presented in Figure 7.5, show that urban sprawl should be avoided in areas adjacent to the streams. Dense urban development takes place near the watershed outlet or far from the streams. The areas with high infiltration (soil A and B) are used for low-density urban development mixed with vegetation, but the surroundings of urbanized areas are protected with dense vegetation to control the storm runoff into the stream. Overall agricultural activities become more intense, allowing for decreasing activities in the stream buffer zone. Instead, denser vegetation is allocated near the streams.

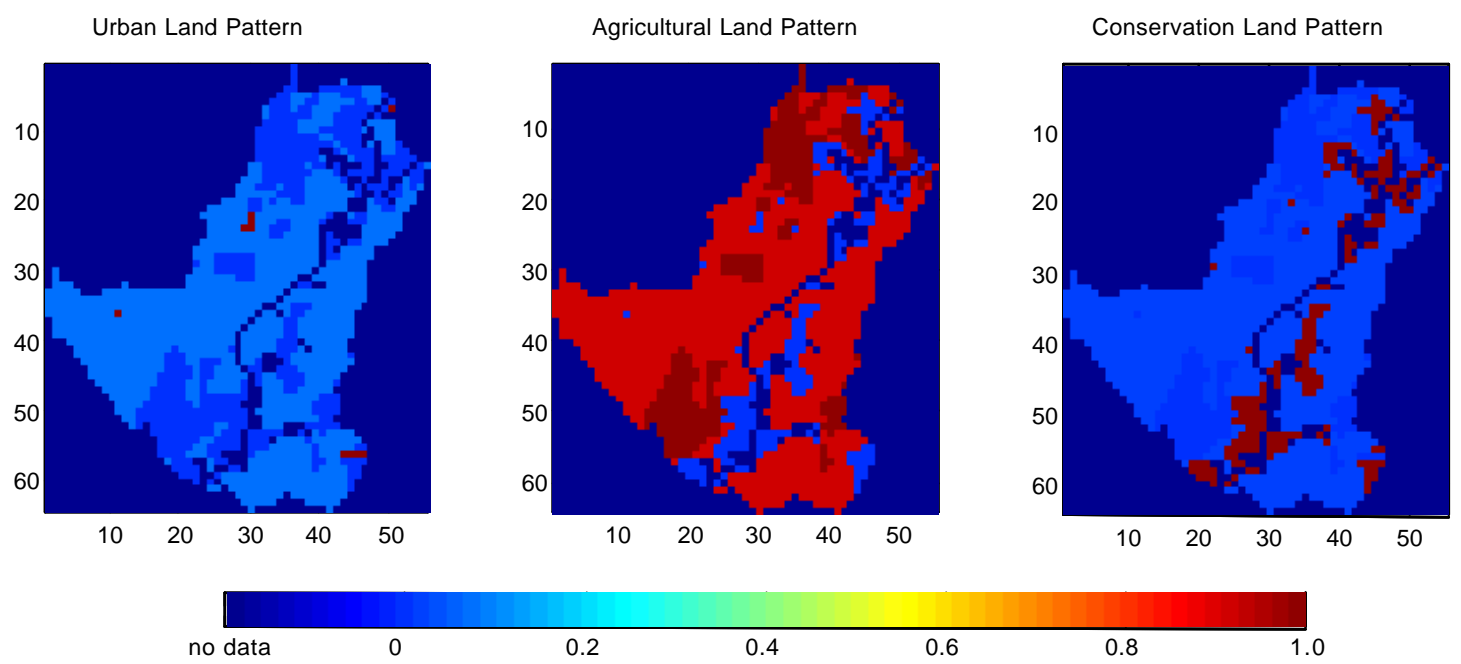

Figure 7.5: Optimal Land-use Patterns for Urban Sprawl 


\section{CHAPTER 8}

\section{LAND-USE POLICY IMPLICATIONS}

The spatial pattern of optimal land uses obtained with the IHLUO model (Chapter 7) provides detailed, site-specific, information on land allocation. This chapter analyzes important physical factors and their impacts on the optimally-delineated land-use pattern $^{5}$, and how the results can be used for comprehensive land use planning, including zoning, specific site planning guidelines, and agricultural best management practices. In this chapter, available NPS control measures and land-use planning techniques for agricultural areas are discussed, qualitative analyses of the optimal land pattern are conducted to explain the interrelationships among physical variables, and then sitespecific, yet general land-use policy guidelines are yielded for the study watershed.

\subsection{Agricultural Land-Use Techniques for Conservation}

Conventionally, agricultural land uses are zoned to encourage sprawl, with a lowdensity development (Arendt, 1994). Awareness of social, environmental, and ecological issues has change traditional planning practices, calling for planning for sustainability

\footnotetext{
${ }^{5}$ Note that qualitative analyses of spatial land-use patterns at the drainage level are also discussed in Chapter 7 (results from the pilot study).
} 
(Wheeler, 2004). "Smart Growth" is one of the sustainable planning movements, which focuses on developing innovative and alternative planning techniques with concern for the environment as well as for economic development (Wheeler, 2004; Schiffman 2001). It promotes more compact, yet economically efficient urban development, through preservation of open spaces, farmland, and critical environmental areas. The outward expansion of cities is discouraged, while clustered development or infill development is encouraged by this movement. It has become important planning practice to protect watersheds and streams (Moglen, 2000). A number of alternative land-use planning and control techniques are suggested by Schiffman (2001) and summarized in Table 8.1.

\begin{tabular}{ll}
\hline Planning Objectives & Land-Use Planning and Control Techniques \\
\hline Maintain agricultural productivity & $\begin{array}{l}\text { Agricultural Use Notice, Agricultural Buffers, } \\
\text { Cluster Development, Urban Growth Boundary, } \\
\text { Purchase of Development Rights, Transfer of } \\
\end{array}$ \\
& Development Rights \\
\hline $\begin{array}{l}\text { Preserve and enhance natural } \\
\text { recreation resources }\end{array}$ & Stream/Creek Zoning, Woodland Protection Zoning \\
\hline $\begin{array}{l}\text { Minimize conflict between new } \\
\text { development and the }\end{array}$ & Area Plans, Design Reviews, Hillside-Slope \\
community's natural and scenic & Woning, Overlay Zones, Performance Zoning, \\
resources & \\
\hline *Adapted from Schiffman (2001:10-11)
\end{tabular}

Table 8.1. Alternative Land-Use Techniques for Agricultural Watersheds* 
Agricultural buffers are used to separate urban areas from rural areas, using setback lines, fences, native vegetation, physical barriers, clustering requirements, and other landscape techniques. A Buffer Zone is a specific setback that contains $100-200 \mathrm{ft}$ of interface areas (Schiffman, 2001). The requirement of agricultural buffers results in a compact form of development at the urban fringe and insulation of urban areas from direct contact with agricultural activities. This is very important for watershed protection, as it can promote bank stability, control water temperature, and preserve ecological quality and functions (Moglen, 2000; USDA, 1998). The importance of stream corridor restoration, its characteristics, management plans, and design criteria are extensively discussed by USDA (1998). Stream/Creek Zoning is another technique applied to development in the proximity of streams and creeks. Special standards are applied along the watercourses, to protect resources for water supply, to control stormwater, and to ensure safety of development in these areas. This includes setbacks from the bank (at least $25 \mathrm{ft}$ ), restrictions on development and impervious surfaces in flood zoning (normally, in a 100 year flood zoning), limited density, and vegetation requirement for bank stability (De Chiara, 1984; Herdon-Jones et al., 1995). Overlay zoning is often applied in these areas to enforce more stringent site-design criteria.

Cluster development, a pattern that promotes clustering of small parcels, can encourage zoning in areas adjacent to the streams. Cluster development allows dense but compact development on only small parcel areas of a subdivision, while remained areas are dedicated to conservation. A Planned Unit Development (PUD) is one type of cluster development for housing. These techniques are forms of performance zoning, where the criteria for subdivision and land-use regulations are based on performance, rather than 
general site-design specifications. A land trust can create an endowment of land for conservation purposes by local residents. See Schiffman (2001) for details on land-use techniques.

\subsection{Site Design and Management Practices for Agricultural Watershed Protection}

Management practices and technical guidelines to control NPS pollution and stormwater runoff are developed and outlined in US EPA (1997, 1993), and USDANRCS (2005). Site-specific management guidelines are tested and prepared by local NRCS (i.e., Natural Resources Conservation Service) offices at the county level. In order to protect agricultural watersheds, national agricultural policies are devised to encourage wetland drainage, and to influence crop choices, tillage practices, and chemical uses (US EPA 1997). Best management practices for agricultural watersheds include zoning, better site design, public education/awareness, contour plowing, notillage (or conservation-tillage) practices, sediment and erosion control, control of stormwater runoff, vegetation buffers (especially riparian zones), control of time of fertilization and manure spreading, and setbacks on new developments (US EPA, 1997). Detailed structural and nonstructural management measures are also discussed in USEPA (1997) and USDA-NRCS (2005). Veith et al. (2004) point out important physical variables in making a BMP decision: hydrologic soil group, proximity to stream, density of livestock, erosion potential, and chemical pollution loads. As discussed in Chapter 2, BMP measures are aimed at reducing pollution generation on site, and to limit its transport to surroundings and waterways. 
Site design and plan evaluation processes inevitably involve analyses of the environment. Factors such as topography, drainage, hydrology, vegetation, geology, and climate, are often considered in assessing environmental impacts and quality (Brookes, 1988). These physical variables are very important to guide site plans and BMPs. Topography is commonly assessed by slope (Brookes, 1988). An area with a 0.5-1\% slope is ideal for any development. If the range of slopes is $1-3 \%$, the area may support residential development, but large commercial development may become problematic. An area with a 3-5\% slope would have major problems, if used for commercial, or largescale residential development. If the slope is in the range of 5-10\%, the most stringent design requirements may be required. If the slope is over $10 \%$, the area should not be used for any other land-use activities. The categories and appropriateness of slope to support specific developments are discussed in De Chiara (1984), De chiara and. Callender (1990), Lynch (1998), and Arendt (1995).

The field office technical guide (NRCS, 2005) suggests creating forest buffer zones near stream areas, in flood hazard areas, in gently (2-6\%) or highly (>8\%) sloped formally cropped areas if they are in danger of erosion, in transitional stream buffer zones, or in the vicinity of gullies. Forest buffers are used to promote biodiversity and habitats, to exclude certain land-use activities (exclusion of livestock or agricultural uses in potential erosion zones), and to maintain agricultural productivity. They also encourage no-tillage or mulch tillage, crop rotations, or crop residues (leave at least 30\%) on the field for highly erodable cropped land areas. Application of fertilizers, pesticides or manures is also prescribed for erodable agricultural fields. A filter strip to cover cropland or at the edge of the field, or grass waterways to lessen the impacts of gully 
erosion, are recommended. Steeper slopes require wider filter strips (0-10\%, 15 feet; $10-$ 20\%, 20 feet; and 30-40\% slope, 25 feet for a minimum width) and at least a 15-ft. width is required on forestland. A grass waterway depth should at least carry the peak runoff from a 10-year frequency storm. Contour buffer strips should be at least 15-ft. wide, and commonly make up 20 to $30 \%$ of the slope. Vegetation buffers for stream protection should be between 15 to $25 \mathrm{ft}$. These recommendations and specifications are provided by USEPA (1993, 1997, 2000) and USDA-NRCS (2005). Detailed management guidelines by soils are provided by the County Soil Conservation Service. The hydrologic soil groups and characteristics are discussed in Chapter 4. Group A is a sandy, free draining soil, Group D is a clayey, poorly drained soil, and groups B and C are intermediate soils. Site-planning and management guidelines indicate that clayey soils should be avoided for development. Most soils in flood zones have soil type D (Herdon-Jones et al., 1995). These soils may not be very effective to handle stormwater runoff. Therefore, the upland areas adjacent to flood zones must be included in the buffer zone. Herdon-Jones et al. (1995) provides the following criteria to select sites for riparian buffer, as a secondary stormwater runoff BMP: (1) buffers serve as BMPs where flow velocity does not exceed $1 \mathrm{fps}$, as buffers should be designed to control and treat frequent and maximum flooding events; (2) buffers with slopes greater than 10\% cannot treat pollutants effectively; (3) predominantly clay soils should be avoided; (4) soils with a minimum infiltration rate higher than $0.25 \mathrm{in} . / \mathrm{hr}$ are effective; and (5) riparian areas are intended for low-density development. 
The principles and practice guidelines for stream corridor restoration are well discussed in USDA (1998). Consideration should be given to connectivity and dimensions of the corridor, soil types, and vegetation. The key criteria include:

\section{Criteria 1: Minimum total buf fer width.}

In general, a minimum width of at least $100 \mathrm{ft}$ is recommended to provide adequate stream protection.

\section{Criteria 2: Three-zone buffer system.}

Effective urban stream buffers have three lateral zones-streamside, middle core, and outer zone. See Figure 8.1 for a ladder pattern of stream corridor.

\section{Criteria 3: Predevelopment vegetative target.}

The vegetative target should be specified as the predevelopment riparian plant community, based on the natural vegetative community present in the floodplains.

\section{Criteria 4: Buffer expansion and contraction.}

Specifically, the average width of the middle zone can be expanded to include the full extent of the 100-yr floodplain, all undevelopable steep slopes (greater than 25\%), steep slopes (5 to $25 \%$ slope), or any adjacent wetlands or critical habitats.

\section{Criteria 5: Buffer delineation.}

Clear delineation criteria should be developed considering the spatial scale of mapping, locations of streams, and extent of buffers.

\section{Criteria 6: Buffer crossings.}

The major objectives for stream buffers are to maintain connectivity of corridors, and buffer crossings should be minimized.

\section{Criteria 7: Stormwater runoff.}

Buffers can be an important component of the stormwater treatment system at a development site. They cannot, however, treat all the stormwater runoff generated within a watershed. In general, a buffer system is to treat only less than $10 \%$ of the total runoff. Therefore, some other structural or nonstructural BMPs are required to treat the remaining runoff from the watershed.

\section{Criteria 8: Buffers during plan review and construction.}

The limits and uses of stream buffer systems should be well defined during each stage of the development process.

\section{Criteria 9: Buffer education and enforcement.}


Encourage buffer awareness and stewardships among adjacent residents to maintain the integrity of a buffer system in the future.

\section{Criteria 10: Buffer flexibility.}

Care should be given to ensure fairness and flexibility when administering buffers, in order to reduce hardships and anxiety in buffer acquisition and management processes.

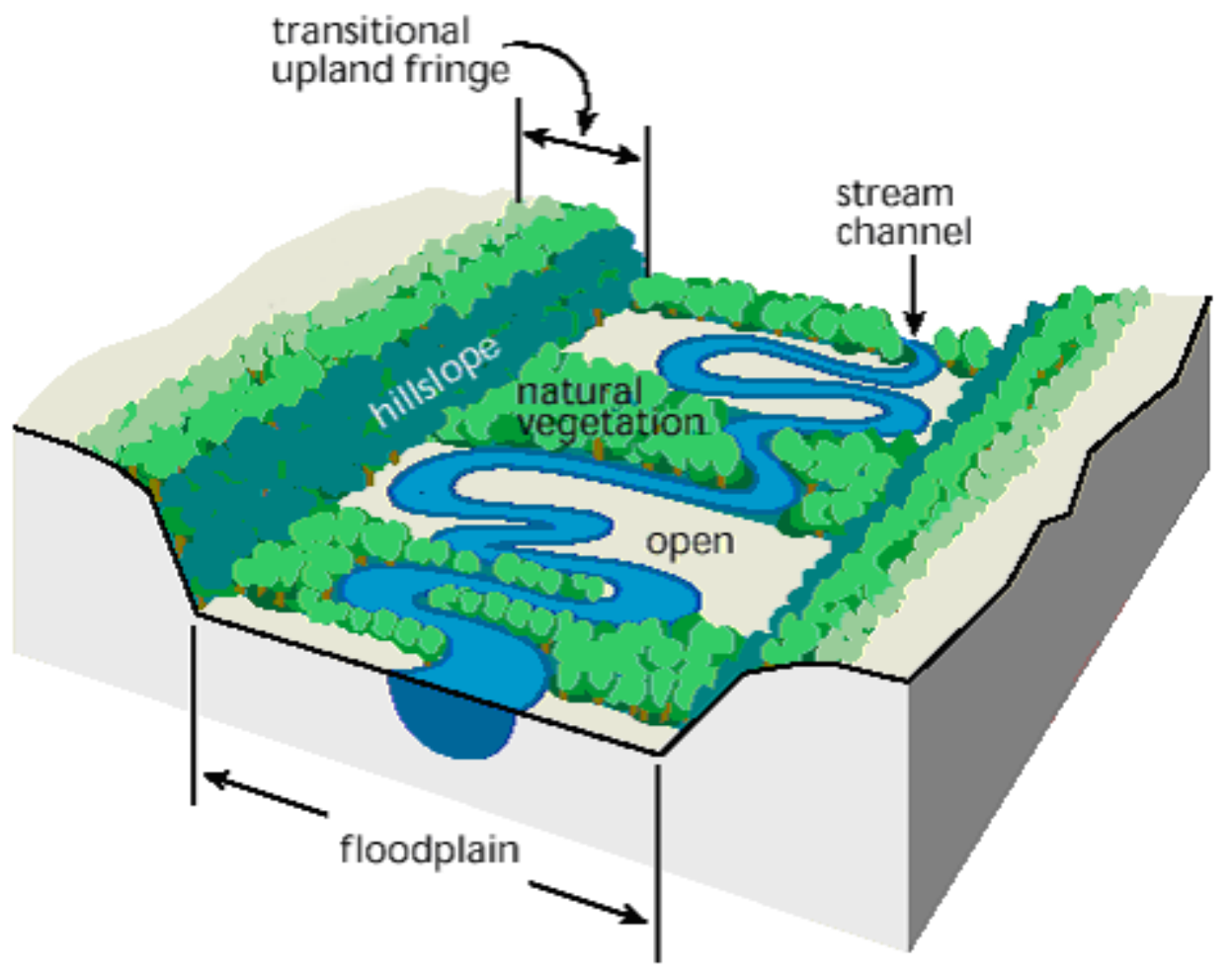

Adapted from USDA (1998).

Figure 8.1. A Ladder Pattern of Stream Corridor 


\subsection{Qualitative Analysis of Optimal Land-Use Patterns}

This section investigates qualitatively the optimal land-use patterns generated by the IHLUO, focusing on the geographical and physical characteristics of the watershed. These analyses are intended to provide land management guidelines for watershed protection. The results are summarized along a "lesson" theme and compared with current on-site conservation zoning techniques and management practices discussed in the previous sections. The spatial pattern of optimal land allocation at the cell level is presented in Figure 8.2, which is identical to Figure 7.1, and is reproduced here to facilitate the discussion.

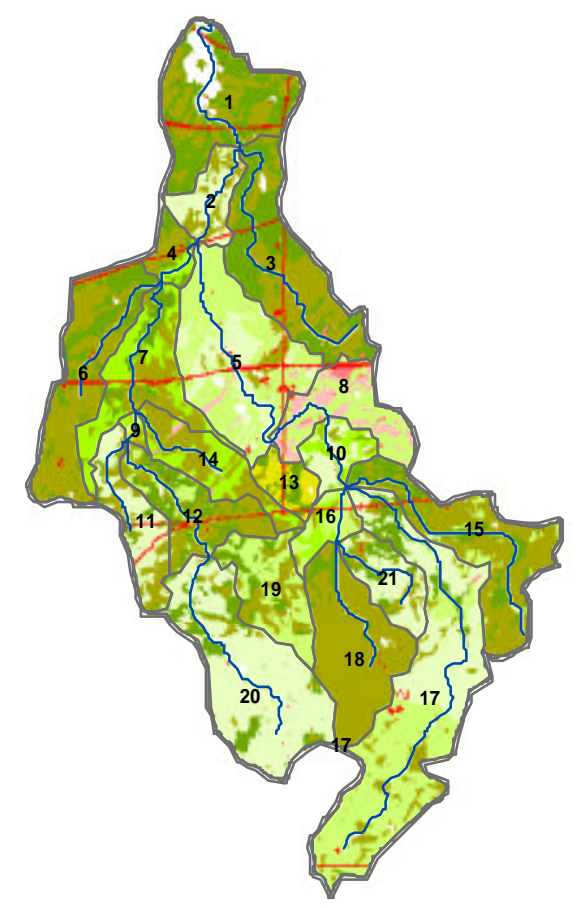

(Note: Map Overlay Order: Urban-Conservation-Agriculture)

Urban

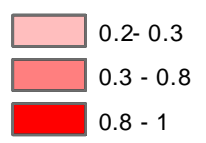

\section{Conservation}

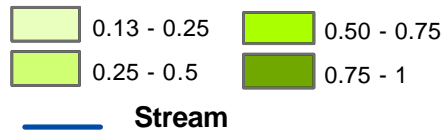

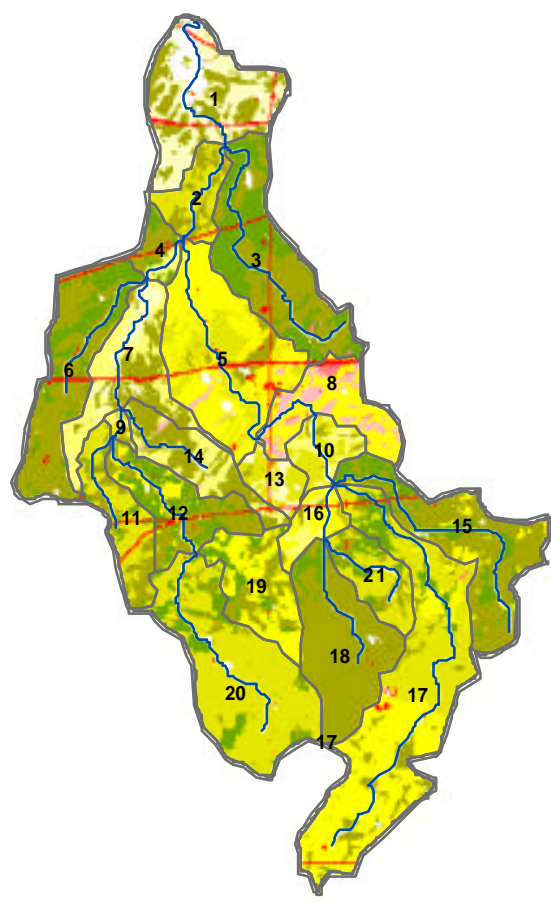

(Note: Map Overlay Order: Urban-Agriculture-Conservation) Agriculture

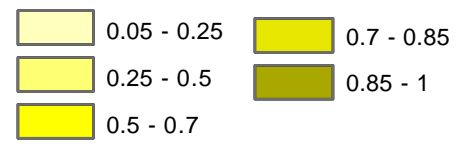

Figure 8.2: Spatial Pattern of Optimal Land Allocation at the Cell Level (30-meter) 


\section{Lesson 1: Protect the Most Upstream Drainage Areas}

Figure 8.2 shows that downstream areas are protected with dense vegetation. The left-side map is produced by overlaying the urban layer on top of the conservation and agriculture layers. The right-side map is created by overlaying the urban, agriculture and conservation layers, in that order. The left-side map clearly delineates conservation land patterns, while the right-side map delineates agricultural land patterns. The areas around the stream near the drainage outlets have a higher conservation density. Also, the upstream areas (where the stream is starting, such as drainage areas 3,6,11, 20) are protected with vegetation. As stream buffers are only designed to control $10 \%$ of total runoff, protecting the upland areas with vegetation can help retain stormwater runoff on site. The most downstream areas of the main tributary have a relatively high conservation density for the entire drainage areas, as indicated in Figure 8.3. Denser vegetative zones near the stream are found in the most upstream drainage area (drainage 1), near the outlet. The vicinity of the wetland area of drainage 1 is preserved with dense vegetation, and its immediate upstream area (e.g., drainage 3) is also protected with vegetation. Also, notice that urban land areas are surrounded with dense vegetation. Buffer zones should be applied here to mitigate the hydrological impacts of impervious areas. These findings are consistent with previous studies (Veith et al., 2004; Beighley and Moglen, 2002; Limbrunner et al., 2005; PerezPedini et al., 2005 ).

To implement the above pattern, cluster development and urban growth boundary techniques would be useful to protect the most upstream and the most downstream areas. Agricultural buffer zones near the outlet should be designed to control excessive and 
harmful stormwater runoff. Wetland mitigation zoning and woodland protection zoning can be enforced in the vicinity of the wetland. Specific and more stringent standards can be applied, if performance zoning is adopted. 


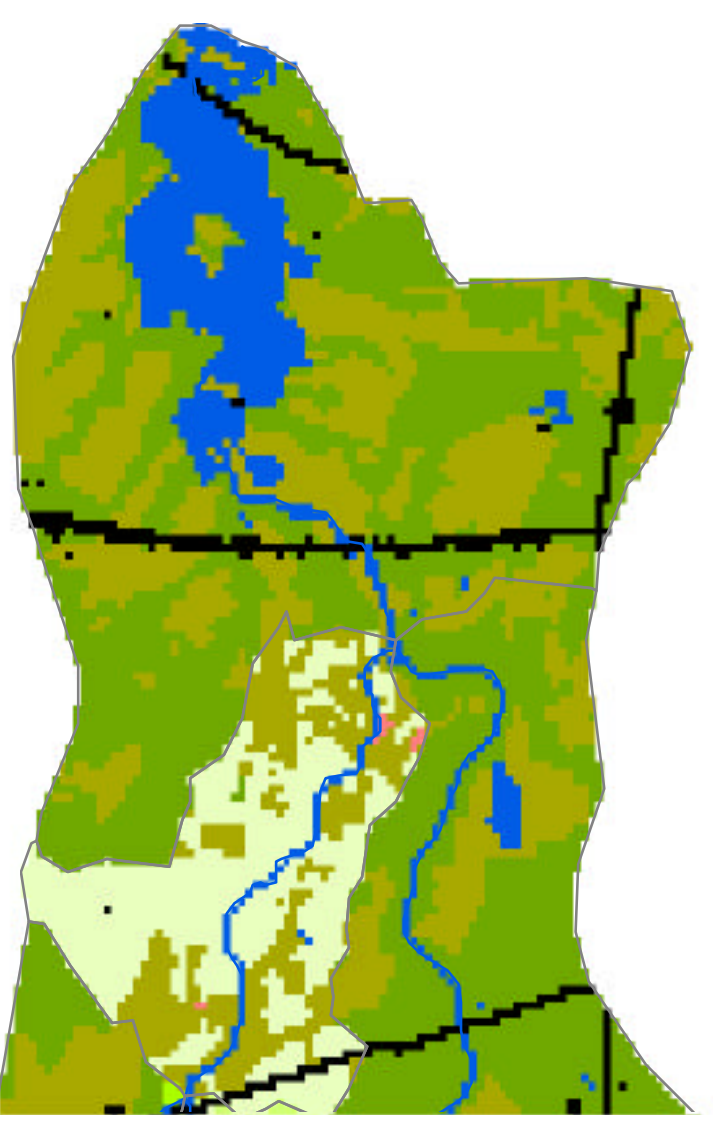

(A) Blow-up Map of Drainage Area 1

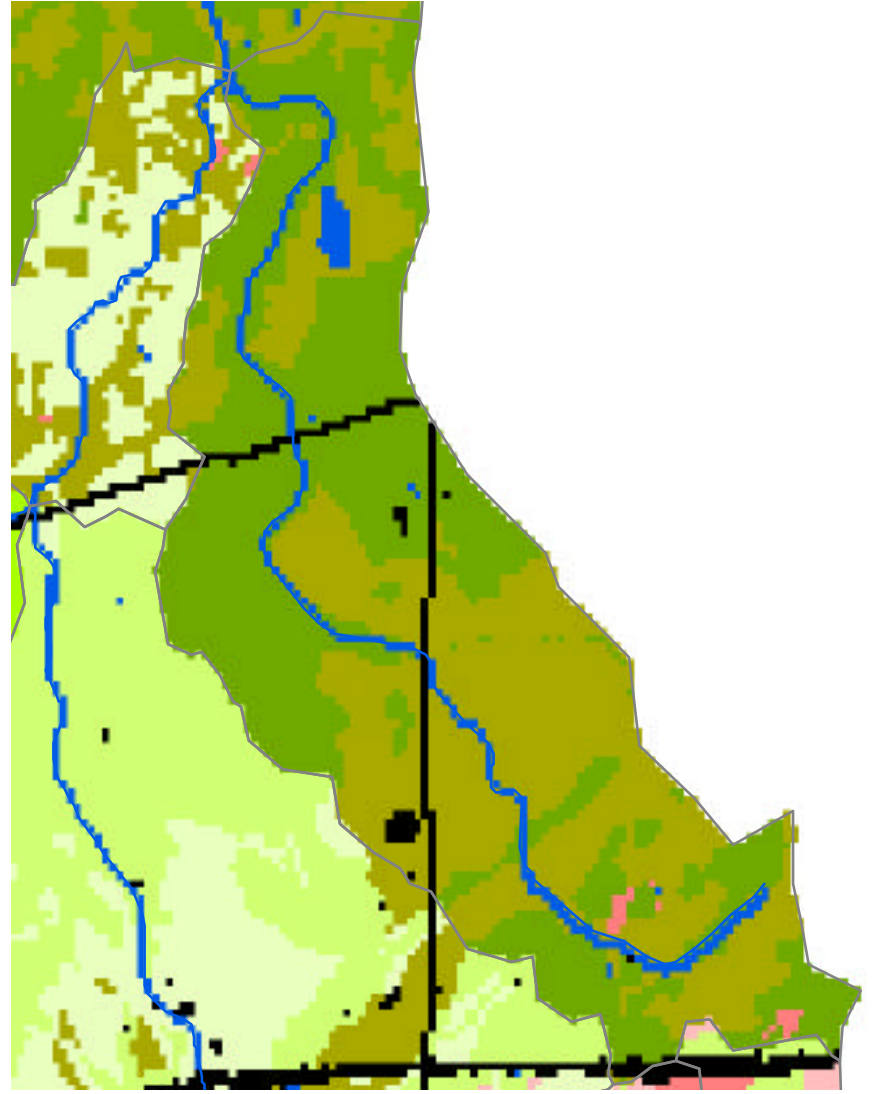

Existing Land

Urban Land

Water

Urban (\%)

0.2- 0.3

$0.3-0.8$

$0.8-1$

Conservation (\%)

$0.13-0.25$

$0.25-0.5$

$0.50-0.75$

$0.75-1$

Agriculture (\%)

$0.05-0.25$

$0.25-0.5$

$0.5-0.7$

$0.7-0.85$

$0.85-1$

Figure 8.3: Optimal Land Use Patterns in Drainage Areas 1 and 3 
Lesson 2: Allocate low-density urban development $(<30 \%)$ spread over the drainage area, but far from the drainage outlet, or high-density urban development (> 55\%) in a compacted form, surrounded by high-density conservation or agricultural land (>50\%).

Figure 8.2 clearly shows that urban development is avoided downstream near the watershed outlet. The same trend is found at the drainage level. Urban development is avoided near drainage outlets (Figure 8.4). Most urban land is allocated to drainage 8, where no tributary is initiated and no confluence takes place, and where only a small section of the main tributary flows through. Urban land is allocated at a relatively low density $(<30 \%)$ and spread over the entire drainage area.

The highest urban density in drainage 8 is approximately $60 \%$. These denser urban areas are located far from the stream. The highest urban density (> 80\%) in the entire watershed is located in the most upland drainage areas (drainage areas 6 and 21), in a very compact fashion. The amount of urban area is minimal $(<1 \%$ of the drainage area). New urban land density higher than $30 \%$ is all contiguous and compactly assigned over multiple cells. Except for drainage 8, the allocation of urban land is avoided near the outlet areas or the most upstream areas. Also, notice that dense urban lands (>50\%) are surrounded with dense vegetation or agriculture (> 50\%), to control for on-site stormwater runoff (Figures 8.5 and 8.6).

The above guidelines are in line with the site-planning guidelines applied to flood management zones and the principles of smart growth planning. The urban development pattern in the entire watershed encourages cluster development, suggesting high-density 
urban development in drainage area 8 . The density in this drainage area should not be more than $30 \%$. Notice that new urban development is discouraged in the vicinity of the watercourse, and buffers around dense urban developments are recommended to insulate urban areas.

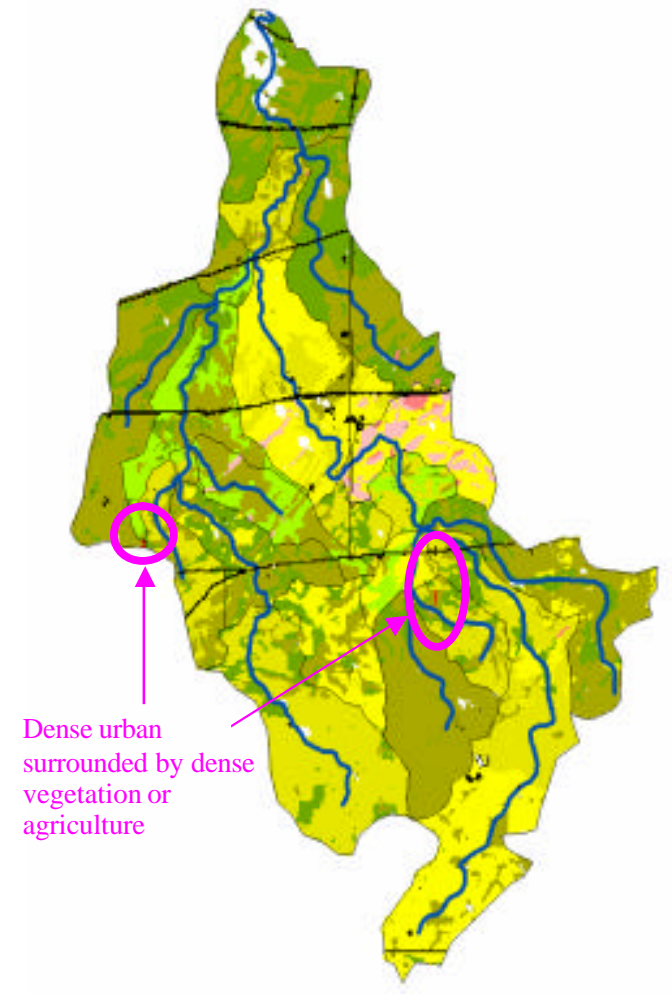

(A) Optimal Urban Land Pattern

\section{Urban}

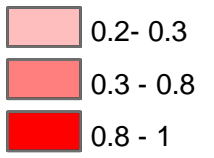

\section{Conservation}

$\square 0.13-0.25 \square 0.50-0.75$
$\square 0.25-0.5 \square 0.75-1$

Stream

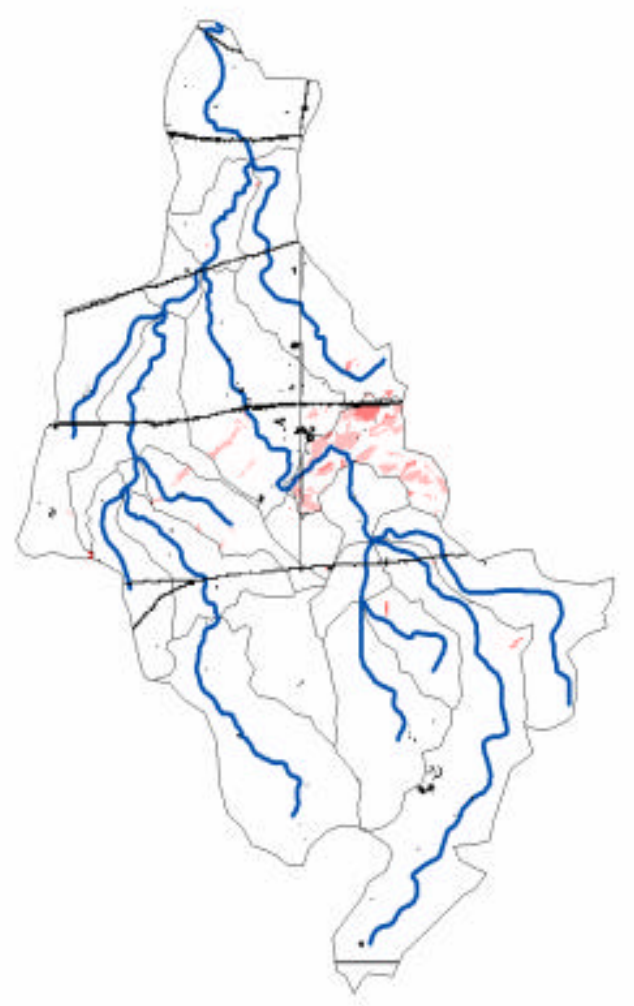

(B) Existing Urban Land Pattern

Figure 8.4: Optimal Urban Land Pattern 
Lesson 3: Buffer Zones along the stream may be unevenly distributed, and low-density urban land $(<30 \%)$ may be allocated near streams (300 m buffer zone), if mixed with conservation or agriculture.

Figures 8.2 and 8.6 show that vegetation areas are unevenly distributed, even along streams, depending on the site-specific physical characteristics of the drainage areas and buffer zones. In other words, there are stream sections that require more buffers on one side than on the other, even within the same drainage area (Figure 8.5). This finding is important in developing a site-specific optimal width of buffer zone, showing that there are stream segments and specific sides that require more conservation efforts. The areas which require more buffer strips should be prioritized, as they are more sensitive to stormwater runoff. Soil type and topography in these areas require acquisition of additional upland areas in the buffer zone, as discussed previously. Contiguous buffering patterns (Figures 8.2 and 8.6) are noticeable in the downstream drainage areas, following the principles and practices for stream corridors outlined in USDA (1998).

Mixed with conservation or agricultural land, low-density urban land is allowed near the stream (within the 300- meter buffer zone) in drainage area \#8, where most urban land is allocated. However, no urban land is allocated in the immediate area of the stream (within 30 meter, or $100 \mathrm{ft}$ buffer zone), meeting the standard for the width of the 
stream corridors. In other drainage areas, low-density urban land is rarely allowed near the stream, and this is congruent with stormwater runoff BMPs (Herdon-Jones, 1995). These findings reinforce the importance of stream/corridor zoning for watershed protection.

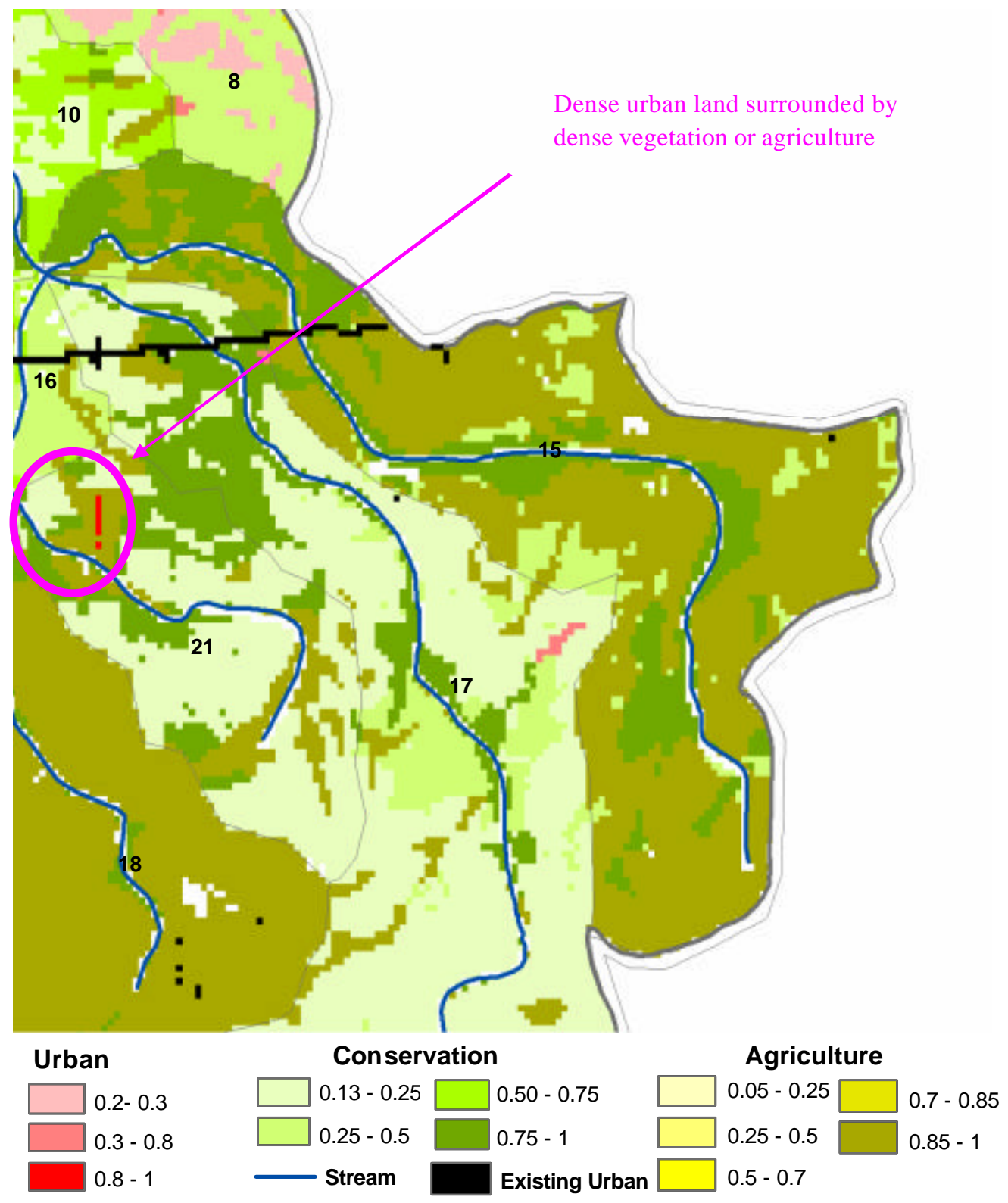

Figure 8.5: Distribution of Uneven Conservation Land in Buffer Zones 


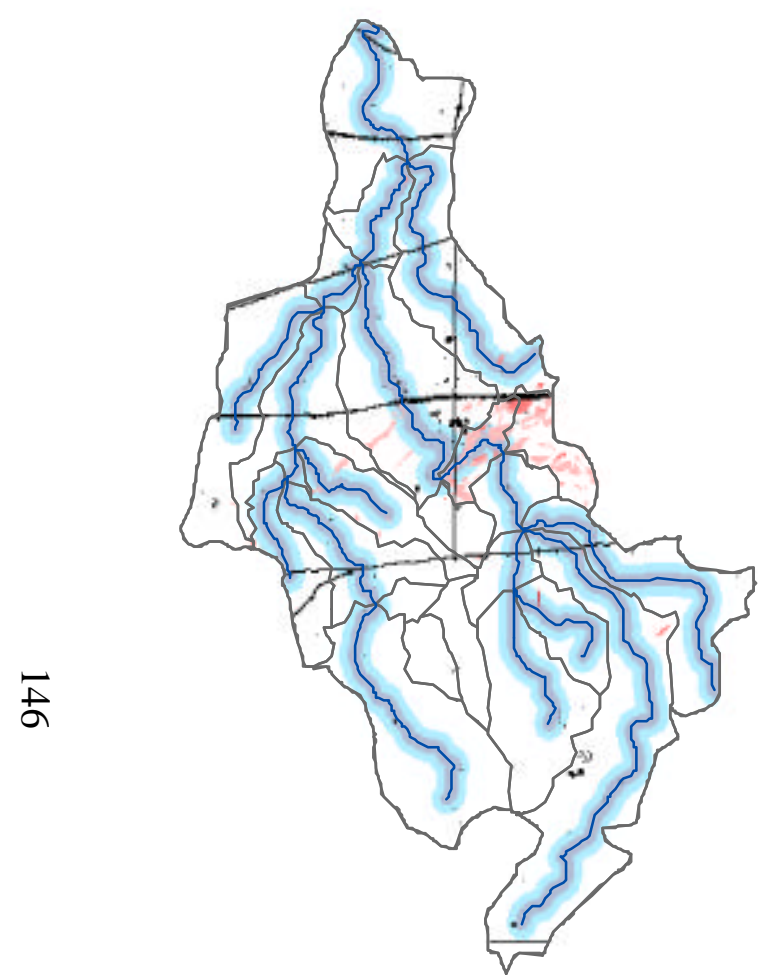

(A) Urban Land in Buffer Zones

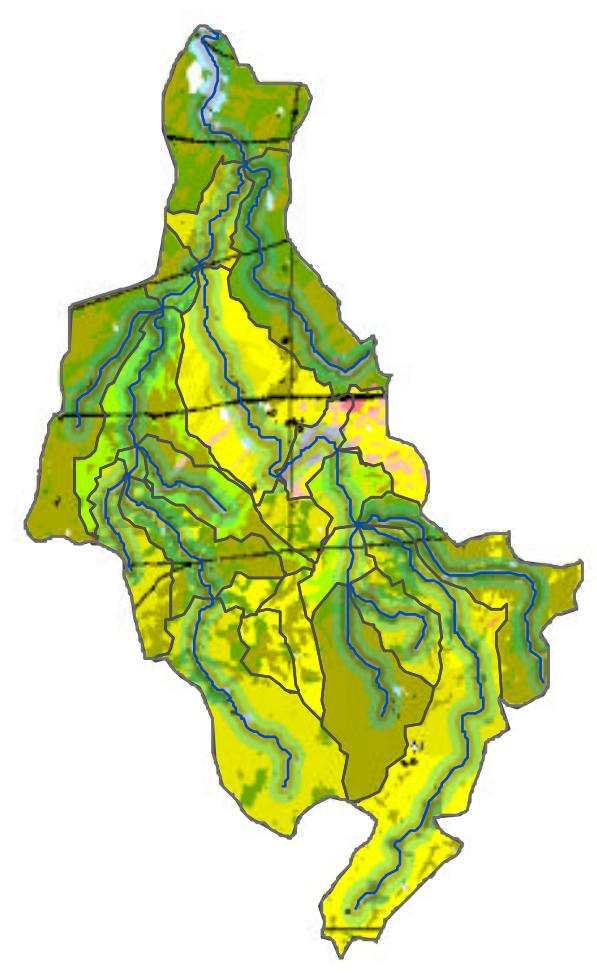

(B) Optimal Land Pattern with Buffer Zone

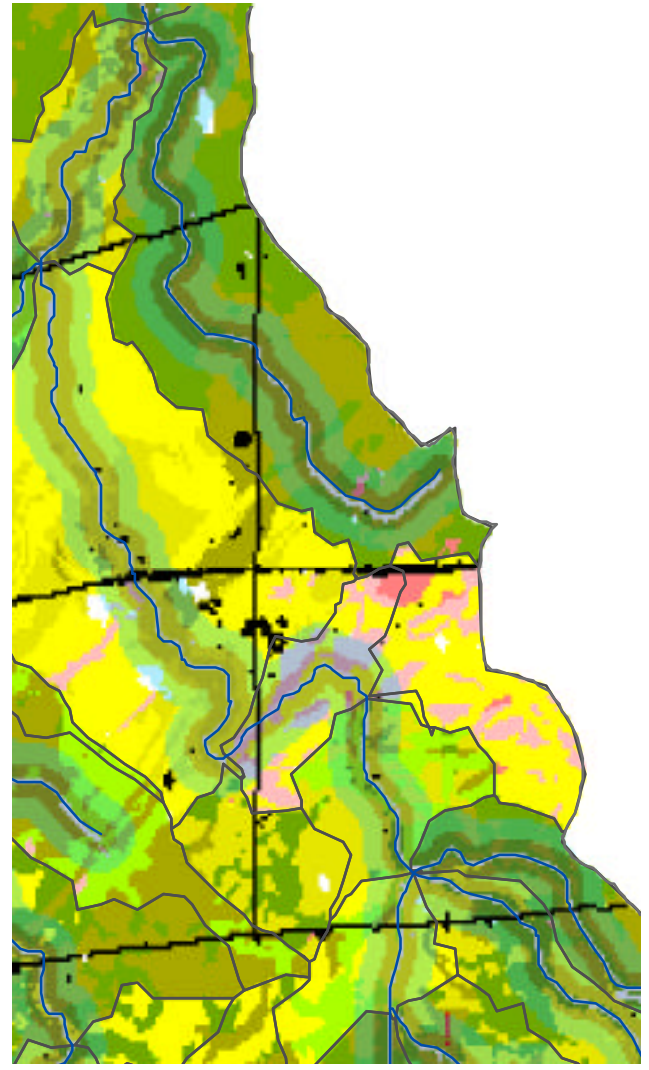

(C) Blow-up Map of Drainage Area 8

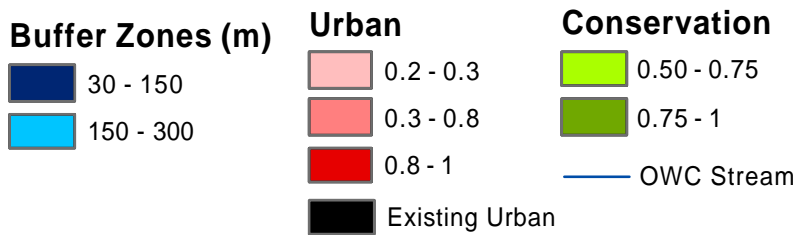

Agriculture

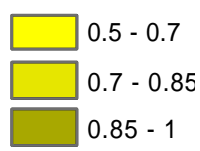

Figure 8.6: Optimal Land-Use Pattern in Buffer Zones 
Lesson 4: Locate dense conservation land in high-slope areas (> 5\%), and locate dense urban land (> 30\%) in low-slope areas $(<5 \%)$

The highest-slope areas (5-10\%) are found along the streams. Most of these areas are covered with dense vegetation $(>50 \%)$, except drainage areas \#2 and \#5, where agricultural land is predominant. Also, a large amount of dense conservation is located in the low-sloped areas $(<5 \%)$, where a smaller buffer width is required, as compared to high-sloped areas. Urban land is avoided in high-slope areas. The locations with dense vegetation can be used to identify candidate areas for conservation reserve programs (CRP), or for the installation of buffers, grass waterways, or filter strips.

Urban land with density higher than $30 \%$ is not to be allocated to areas with slope greater than 5\%. Lower-density urban areas $(<30 \%)$ in drainage 8 and 10 are allocated near the stream, where the slope is greater than 5\%. Cells with dense urban land $(>30 \%)$ are all allocated to areas whose slope is less than 5\%. This is in consistent with the guidelines of physical planning and site development (Lynch and Hack, 1984; De Chiara, 1984; De chiara and. Callender, 1990). Control of land with high slopes can be achieved by applying hillside-slope zoning. Figure 8.7 presents spatial land allocations over different slopes. 


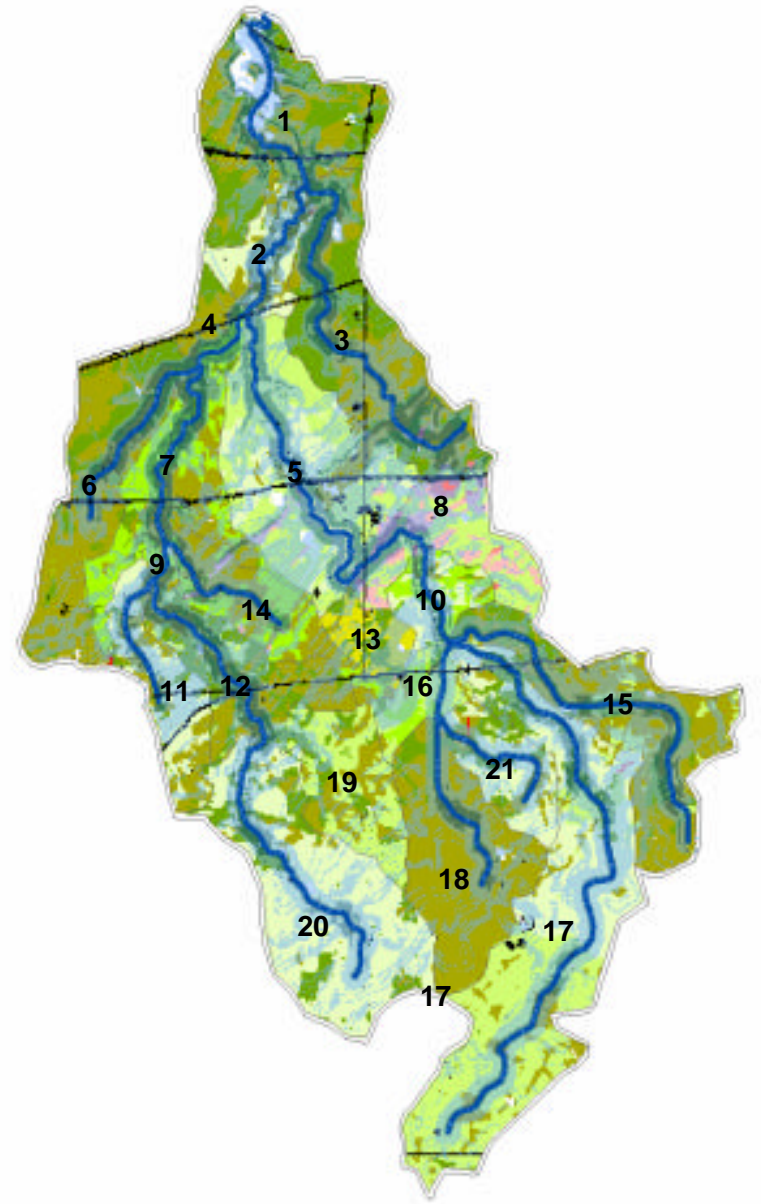

(A) Land-Use Composite Map

Figure 8.7: Slope and Land Allocation (Continued)

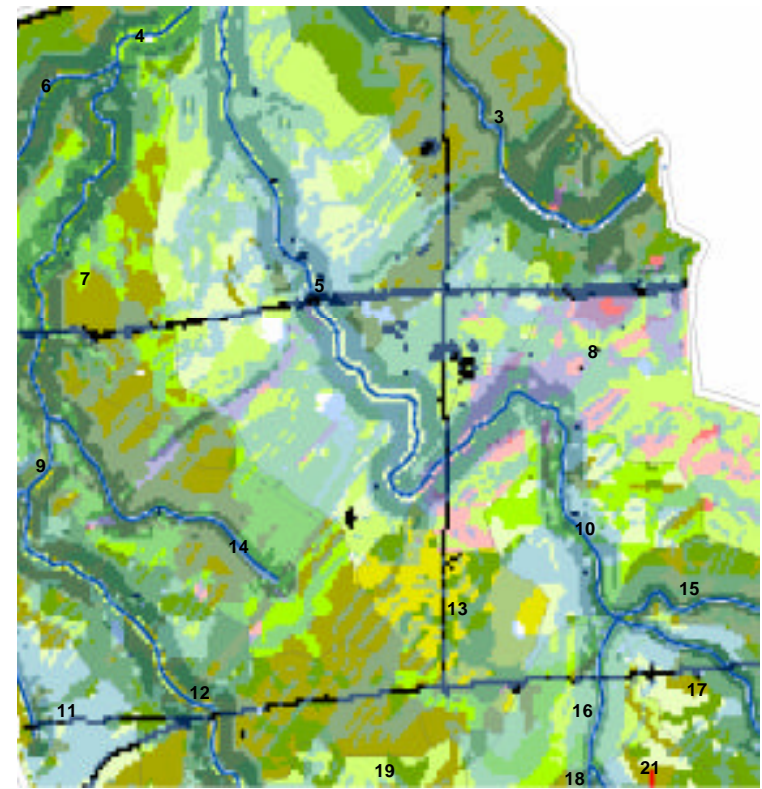

(B) Blow-up Map Slope (\%) Urban

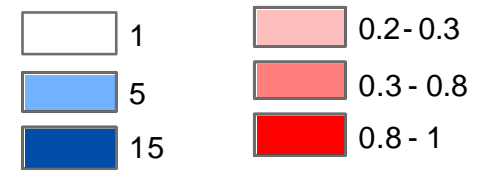

\section{Agriculture Conservation}

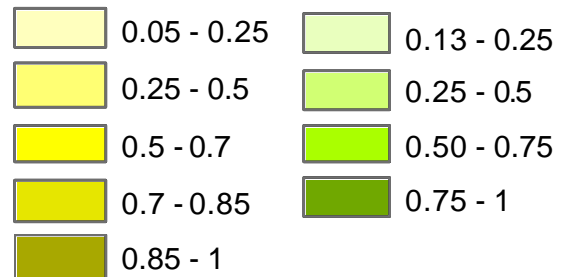


Figure 8.7 (Continued)

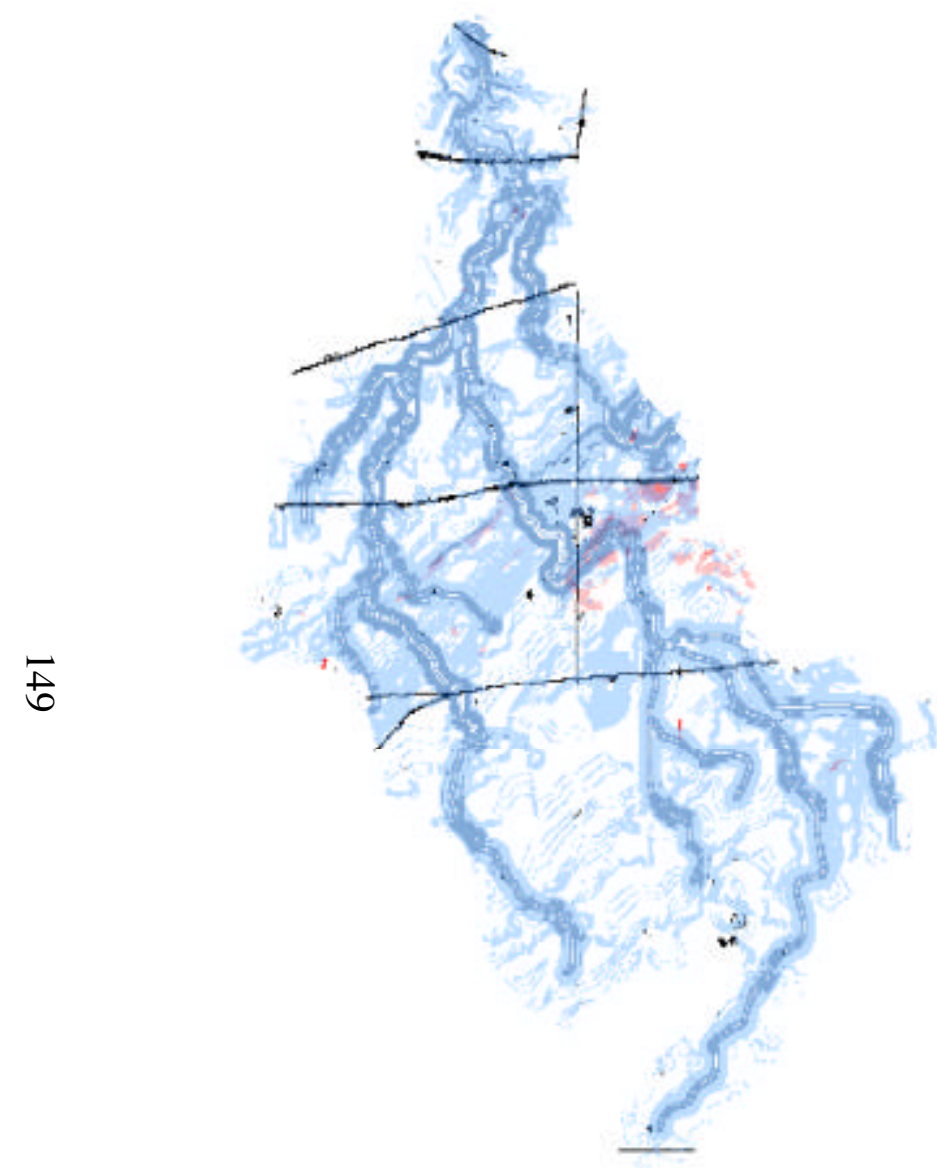

(C) Urban Land vs. Slope

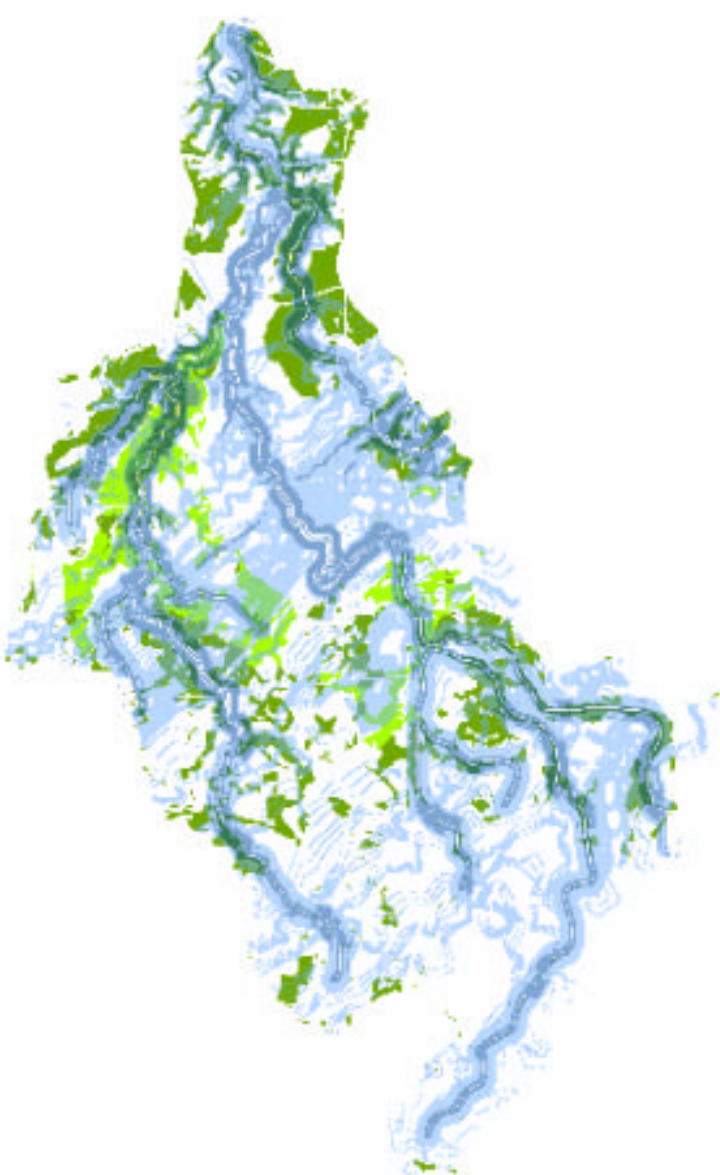

(D) Conservation Land vs. Slope 
Lesson 5: Allocate conservation to areas with high infiltration $(A / B)$.

The optimal land-use pattern can be best explained by comparing it with the pattern of hydrologic soil types. The various soils in the study area are classified into four different hydrologic soil groups. The maps in Figure 8.8 present the distributions of hydrologic soil types, overlaid with urban and conservation land patterns. They show the similarity between the spatial pattern of high infiltration soil types (A, B) and the optimal distribution of dense conservation land (>50\%): conservation is allocated to areas with high infiltration, and dense urban land is mostly allocated to low infiltration areas (C, D). This allocation maximizes moisture retention in the ground surface, preserving good soil types with vegetation, while allowing ground cover by impervious surfaces if the soil has a low moisture-retention capacity. This finding is similar to the results from the pilot study in drainage area 2 (Section 7.3). The stormwater buffer guideline is consistent with this finding. The criteria used to select stormwater runoff BMPs recommend buffer zones in areas where soils have a minimum infiltration rate greater than $0.25 \mathrm{in} . / \mathrm{hr}$, which is the case for soil types A and B.

The qualitative analyses of the optimal land-use pattern delineated by the IHLUO provide important site-specific guidelines for land-use management and practices. These findings are consistent with the principles of smart growth land-use planning techniques, conservation practices and guidelines from the EPA and USDA, and the results from previous studies. 


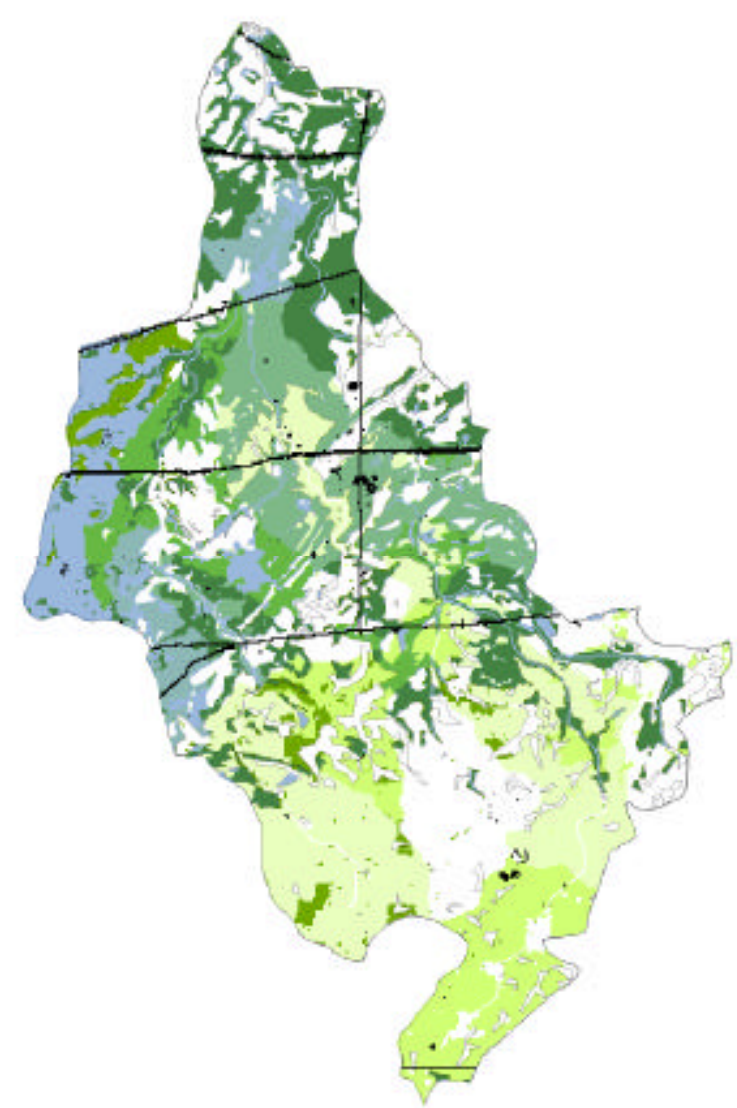

(A) Conservation Land Overlaid with Soil Type

\begin{tabular}{|c|c|c|}
\hline Soil Type & Urban & Conserv \\
\hline$A, B$ & $0.2-0.3$ & $0.13-0.25$ \\
\hline C, D & $0.3-0.8$ & $0.25-0.5$ \\
\hline & $0.8-1$ & - Stream \\
\hline
\end{tabular}

Figure 8.8: Soil Types vs. Optimal Land-Use Patterns

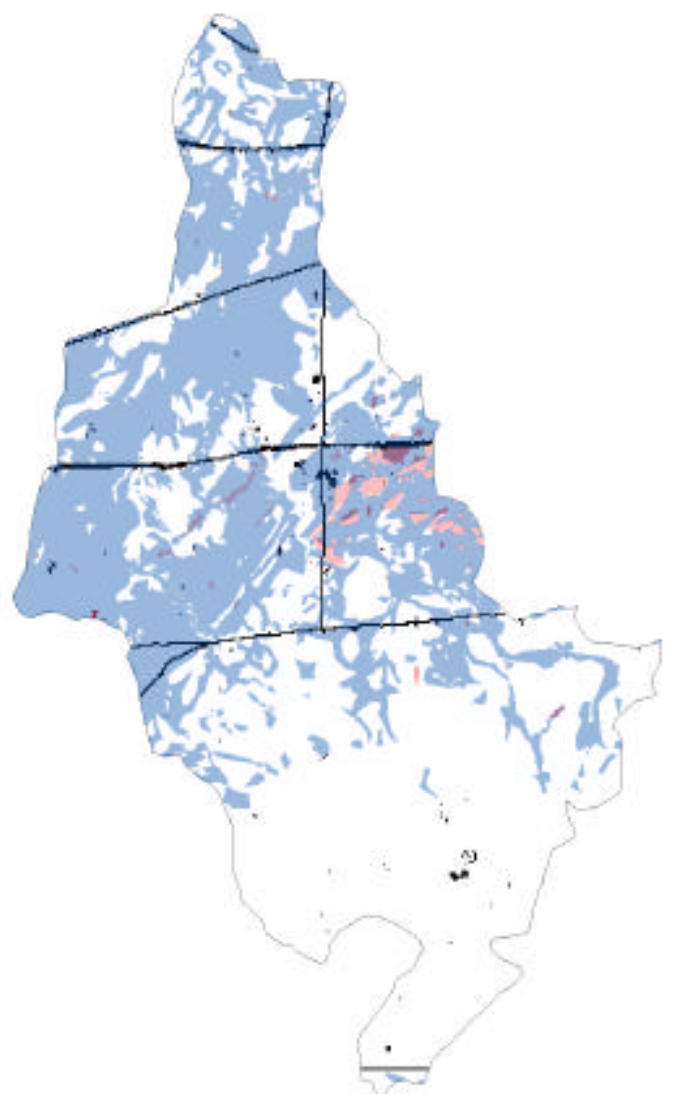

(B) Urban Land Overlaid with Soil Type

\section{Agriculture}

\begin{tabular}{|c|c|}
\hline $0.05-0.25$ & $0.7-0.85$ \\
\hline $0.25-0.5$ & $0.85-1$ \\
\hline
\end{tabular}

$0.75-1$

Existing Urban

$0.5-0.7$ 


\section{CHAPTER 9}

\section{CONCLUSIONS}

The objective of this research was to develop a methodology for delineating optimal land-use management/allocation plans to control for NPS pollution, in order to assist spatial decision-making processes for conservational land-use planning and best management practices. The general modeling approach involves a stormwater runoff simulation model, hierarchical multistep regression analyses, quadratic land-use optimization, and the integration of the runoff simulation model with nonlinear land-use optimization. This multistep approach has been adopted to quantitatively reflect watershed hierarchy, to model the spatial relationships between land and water, and to search for optimal land-use patterns at a high level of spatial resolution, which can be used for site-specific design and planning. The following questions were investigated:

1. Is watershed hydrology strongly influenced by the spatial pattern of land use?

2. What is the best way to quantify the land-water relationship, while accounting for:

a. The spatial variability of the physical characteristics of the watershed, and

b. The spatial process of stormwater runoff? 
3. Where are the critical areas to be preserved or developed in the future? How can these areas be prioritized?

4. What is the maximum amount of land development that can take place in the watershed without having detrimental impacts on watershed hydrology? What is the minimum amount of land conservation within the watershed?

The hierarchical modeling approach has been developed and applied to analyze the impacts of land-use changes on watershed hydrology and to allocate land uses to minimize stormwater runoff effects at the subwatershed and drainage area levels. A stormwater runoff simulation model and regression analysis have been used to estimate peak discharge rate functions, where the independent variables represent the amounts of various land uses, specified at the subwatershed and the drainage level. A quadratic regression function turns out to best represent these relationships $\left(R^{2}>0.90\right)$. These functions help identify sensitive areas to be preserved and candidate areas for future development, and are used in a land-use optimization model that allocates urban, agriculture, and conservation land across subwatersheds and drainage areas to minimize the peak discharge rate at the watershed and subwatershed outlets. The results are very promising, with a $46 \%$ reduction of the peak discharge rates, as compared to the rate corresponding to the current land-use pattern. Sensitivity analyses have been implemented to assess the effects on the optimal solution of changing total requirement constraints for urban, conservation, and agricultural land. The results provide policy guidance, suggesting that: (1) agricultural land should not represent more than $70 \%$ of the entire watershed, (2) urban (i.e., impervious) land should not represent more than $12 \%$ of 
the total watershed, and (3) at least $30 \%$ of the watershed should be maintained in a conservation state.

The proposed integrated model generates optimal land-use patterns to reduce the storm runoff peak at the watershed outlet. The method allows for evaluating land-use changes at specific locations. Built in the optimization framework, land-use constraints are systematically verified, and an optimal land-use pattern is derived. It should be emphasized that the land-use allocation and the identification of prioritized areas for conservation are determined solely under the goal of controlling storm runoff. Preservation goals, such as the protection of aquatic wildlife or floodplains are not considered. The integrated model provides useful results. The optimal land-use pattern reduces the peak runoff from most of the drainage areas. The peak discharge rate of the optimal land pattern delineated by the IHLUO decreased by $46 \%$, consistent with the prediction by the quadratic storm water approximation function, and supporting the validity of the overall modeling strategy. Detailed conservation and management planning guidelines are produced from the optimal land-use map. The results provide the following guidelines: (1) allocate dense conservation land to areas with high infiltration capacity; (2) reduce the urban and agricultural intensity around the stream, with vegetation buffers; (3) protect upland watershed areas from development; (4) buffer urban areas with vegetation; (5) develop urban land in a compact form; (6) locate urban land in low-slope areas and conservation in (relatively) high-slope areas around targeted urban land, but allow conservation in low-slope areas in undeveloped zones; (7) avoid development in areas immediately adjacent to the watercourses $(<100 \mathrm{ft})$, but allow it in outer buffer zones $(300 \mathrm{ft})$. These findings are consistent with conservation site-design 
criteria, guidelines for BMPs, and zoning techniques applied to maintain environmental and ecological quality.

Quantitative analyses of the physical variables and their impacts on the optimally delineated spatial land-use pattern, and development of quantitative site-design criteria for watershed conservation should be very useful, and remain areas for future research. The model results provide mixed agricultural and conservation land uses, due to the use of continuous decision variables, and this may be unrealistic in practice. This result could, however, be used in actual land-use management practices if realistic land-use patterns comparable to these mixed land uses could be delineated, possibly by allocating the optimal aggregate land-use mix to individual cells in a spatially acceptable pattern. Model improvements to correct for this limitation also remain an area for further research, including the expansion of the optimization model to create contiguous land-use patches for stream corridors and spatial urban forms. This would involve integer nonlinear programming or heuristic-based optimization approaches. While this research focuses only on the locational impacts of land-use changes on watershed hydrology, follow-up research could also investigate the impacts of changing spatial configurations of land-use patterns (e.g., contiguity, diversity, fragmentation, contagion, patch shape complexity, etc.) over the landscape (Gustafson, 1998). Note that the optimal land-use patterns are developed using an event-based model, which simulates a 1-year storm. The modeling approach could be extended to delineate optimal land-use patterns with continuous watershed modeling, which would simulate the long-term impacts of BMPs and land-use management. 


\section{BIBLIOGRAPHY}

Aerts, J.C.J.H., E., Eisinger, G.B.M., Heuvelink, and T.J. Stewart. Using Linear Integer Programming for Multi-Site Land-Use Allocation Geographical Analysis. 35(2)148-169. 2003.

American Society of Civil Engineers (ASCE Task Committee). GIS Modules and Distributed Models of Watersheds, ASCE, VA. 1999.

American Water Works Association (AWWA), Water Quality and Treatment (4th Edition), McGraw Hill, NY. 1990.

Andersson, A.E. and H Persson. 1979. Integration of Transportation and location analysis - A general equilibrium approach. Presented at the $18^{\text {th }}$ European Congress of the Regional Science Association, Fribourg, Switzerland, August 291. September 1978.

Arbabi, M. and J., Elzinga. A General Linear Approach to Stream Water Quality Modeling. Water Resources Research. 11(2): 191-196, 1975.

Arendt, Randall. Rural by Design: Maintaining small town character. Planners Press, American Planning Association, Chicago, Ill. 1994.

Arnold, J.G., J.R. Williams, and D.R. Maidment, Continuous-Time Water and Sediment Routing Model for Large Basins. Journal of Hydrology Engineering 121(2):171$183,1995$.

Aspinall, R., and D. Pearson. Integrated geographical assessment of environmental condition in water catchments: Linking landscape ecology, environmental modeling and GIS. Journal of Environmental Management. 59:299-319. 2000.

Barber, G.M. Land-use plan design via interactive multiple-objective programming. Environment and Planning A, 1976, Volume 8, 623-636

Baumer, O., P. Kenyon, and J. Bettis. MUUF V2.13 User's Manual. Natural Resources Conservation Service, Computer file which accompanies the MUUF software. 1994. 
Beasley, D. B., and L. F. Huggins. ANSWERS. Userís Manual. USEPA. Chicago, IL. Rep. 905: 9-82. Technical bulletin. 1982.

Beighley, R.E. and G.E. Moglen. Adjusting measured peak discharges from an urbanizing watershed to reflect a stationary land use signal. Water Resources Research. 39(4). 1846-1847. 2003.

Beven, K.J., and Kirkby, M.J. A physically-based, variable contributing area model of basin hydrology. Hydrological Sciences Bulletin 24: 43-69. 1979.

Bingner, R.L and F.D. Theurer, AnnAGNPS technical processes (Version 2), (http://www.sedlab.olemiss.edu/AGNPS.html), 2001.

Bobba, G.A., V.P., Singh, and L., Bengtsson. Application of environmental models to different hydrological systems. Ecological Modelling, 125:15-49, 2000.

Bouraoui, F., and T.A. Dillaha. Answers 2000: continuous simulation version. Paper presented at the 1994 International Summer Meeting, sponsored by the ASAE, June 19-22, 1994, Kansas City, Missouri.

Brookes, G.R. Site Planning: Environment, Process, and Development. Prentice Hall, NJ. 1988.

Brown, D.G., B.C. Pijanowski, and J.D. Duh. Modeling the relationships between land use and land cover on private lands in the Upper Midwest, USA. Journal of Environmental Management, 59, 247-263. 2000.

Brusseau, M.L., Z. Gerstl, PSC.Rao. Simulation solute transport in an aggregated soil with the dual porosity model: measured and optimized parameter values. Journal of Hydrology. 163:187-193. 1994.

Buchanan, D B. Transport and deposition of sediment in Old Woman Creek estuary, Erie County, Ohio. MS Thesis. Ohio State University, Columbus. 1982.

Canter, L.W. Environmental Impact Assessment. $2^{\text {nd }}$ Edition. McGraw-Hill, Inc., NY. 1996.

Center for Watershed Protection. Workshop on Alternatives to Stormwater Control Through Watershed Management and Better Site Design. The Ohio State University, Columbus, October 4-5, 2000.

Chang, S, D.E. Brill, Jr., and L.D. Hopkins. Preliminary Evaluation of the HSJ Method for Generating Alternatives: A Land Use Planning Example. Institute for Environmental Studies. Department of Civil Engineering. University of Illinois at Urbana-Champaign. 1979. 
Chang, S, D.E. Brill, Jr., and L.D. Hopkins. Efficient Random Generation of Feasible Alternatives: A Land Use Planning Example. Institute for Environmental Studies. Department of Civil Engineering. University of Illinois at UrbanaChampaign. 1980.

Chapra, S. Surface Water-Quality Modeling, McGraw Hill, NY. 1997.

Chow, V.T., D.R. Maidment, and L.W. Mays, Applied hydrology, McGraw-Hill Book Company, NY, 1989.

Claphamm Jr., W.B., T. Davenport, M.M. Holland, W. Rast, S.-O. Ryding, and J.A., Thornton. Available Nonpoint Source Pollution Control Measures. In: Assessment and Control of Nonpoint Source Pollution of Aquatic Ecosystem: A Practical Approach (J.A. Thornton, W. Rast, M.M. Holland, G. Jolankai, and S.O. Ryding, ed). The Parthenon Publishing Group Inc., NY. 1999.

Coelho, J.D., and Williams, H.C.W.C. On the design of land use plans through locational surplus maximization. Papers of the regional scale association. Vol 40. 71-85. 1978

Conservation Technology Information Center. Conservation Information National Crop Management Survey. Website at: http://www.ctic.purdue.edu/CTIC/CTIC.html. 2002.

Cova,T.J., R.L. Church. Contiguity Constraints for Single-Region Site Search Problems. Geographical Analysis. 32(4). 304-329. 2000.

Cryer, S.A., M.A. Fouch, A.L. Peacock, and P.L. Havens. Characterizing agrochemical patterns and effective BMPs for surface waters using mechanistic modeling and GIS. Environmental Modeling and Assessment. 6:195-208. 2001.

Das, P. and Y.Y. Haimes, Multiobjective optimization in water quality and land management, Water Resources Research, 15(6), 1313-1322, 1979.

David, M.B., L.E. Gentry. D.A. Kovacic, and K.M., Smith. Nitrogen balance in and export from an agricultural watershed. Journal of Environmental Quality. 26:1038-1048. 1997

De chiara. J. Time Saver Standards for Site Planning. Prentice Hall, NJ. 1984.

De chiara. J. and J.H. Callender Time-saver standards for building types. McGraw-Hill Pub. Co, NY. 1990. 
Deiniger, R.A and S.Y. Su, Modeling regional wastewater treatment systems, Water Resources Research, 9(7): 633-646, 1973.

Demers, M.N. Fundamentals of Geographic Information Systems. John Willy \& Sons, Inc. NY. 1997.

Diamond, J. T., and J. R. Wright. Efficient Land Allocation. Journal of Urban Planning and Development, 115, 81-96, 1989.

Dökmeci, V.F., Çagdas, G., and Tokcan, S. 1993. Multiobjective Land-Use Planning Model. Journal of Urban Planning and Development. Vol 119, No.1, March 1993.

Domenico, P.A., and F.W., Schwartz. Physical and Chemical Hydrogeology. John Wiley \& Sons, Inc. NY. 1990.

Dominique, D.B., V.P. Singh, and A. Musy. 1999. A geomorphologic kinematicwave(GKW) for estimation of floods from small alpine watersheds. Hydrological Processes. 13:1391-1416. 1999.

Donigian, A.S., and H.H. Davis, User Manual for Agricultural Runoff Management (ARM) Model, EPA 600/3-78-080, U.S. Environmental Protection Agency, Athens, GA. 1985.

Ecker, J.G. A Geometric Programming Model For Optimal Allocation of Stream Dissolved Oxygen. Management Science. 21(6): 658-668. 1975.

Environmental Systems Research Institute (ESRI). Cell-based modeling with GRID. ESRI Press. ESRI, Inc., Redlands, California, 1994.

Findly, R.W., D.A., Farber, and J. Freeman. Cases and Materials on Environmental Law. 6th Edition. Thomson West. MN. 2003.

Forster, D.L., and J.N. Rausch. Evaluating Agricultural Nonpoint-Source Pollution Programs in Two Lake Erie Tributaries. Journal of Environmental Quality. 31:2431. 2002.

Foster, R.G., Lane, L.J., and Nowlin, J.D., Laflen, J.M., Young, R.A. Estimating Erosion and Sediment Yield on Field Sized Areas. Transctioons of ASAE 24(50):12531262. 1981.

Garbrecht, J. and Martz, L.W. The assignment of drainage direction over flat surfaces in raster digital elevations . Journal of Hydrology 1993: 204-213. 1997. 
Gilbert, K.C., Holmes, D.D., and Rosenthal, R.E. A Multiobjective optimization model for land allocation. College of Business Administration. Working Paper Series. No.155. The University of Tennessee. 1982.

Gilbert, K., D. Holmes, and R. Rosenthal, A multiobjective discrete optimization model for land allocation, Management Sciences, 14(12), 1509-1522, 1985.

Golden, B. L., and F.B. Alt. Interval estimation of a global optimum for large combinatorial problems. Naval Research Logistics Quarterly, 26:69-77, 1979.

Gordon, S.I. and Majumder, S. Empirical Stressor-Response Relationships for Prospective Risk Analysis in the Eastern Cornbelt Plains Ecoregion, Environmental Toxicology and Chemistry, 19, 4(2): 1106-1112. 2002.

Graves, G.W., G.B. Hatfield, and A. Whinston. Water Pollution Control using By-Pass Piping. Water Resources Research. 5(1): 13-47. 1969.

Graves, G.W., G.B. Hatfield, and A. Whinston, Mathematical programming for regional water quality management. Water Resources Research, 8(2), 273-290, 1972.

Greenberg, H.J. Mathematical Programming Models for Environmental Control. Operational Research. 43(4):578-622, 1995.

Guldmann, J-M, Visual impact and the location of activities: a combinational optimization methodology, Socio-Economic Planning Sciences. 14: 47-70, 1979a.

Guldmann, J-M. 1979a. Urban Land Use Allocation and Environmental Pollution Control: An Intertemporal Optimization Approach. Socio-Econ. Plan. Soc. Vol 13 PP71-86. 1979b.

Guldmann, J-M. A Structural Framework for the design of integrated environmental and land-use planning optimization models. Mathematical Modeling. 17:61-61, 1986.

Gustafson, E.J. Quantifying Landscape Spatial Pattern: What is the state of the art? Ecosystem. 1:143-156. 1998.

Haan, C.T., B.J. Barfield, J.C. Hayes. Design Hydrology and Sedimentology for Small Catchments. Academic Press. CA. 1994.

Haan, C.T., Statistical methods in hydrology (2nd Edition). A Blackwell Publishing Company, IA, 2002.

Haith, D.A., Environmental systems optimization, John Wiley \& Sons, NY, 1982. 
Haque, M.A. Study of surface runoff using physical models. Environmental Geology. 41:797-805. 2002.

Hartwick, P.G. and J.M. Hartwick. Efficient Resource Allocation in a multinucleated city with intermediate goods. The Quarterly Journal of Economics, 88(2): 340-352, 1974.

Hawkins, R.H., and K.E. Ver Weire. Effects of prior rainfall and storm variables on curve number rainfall runoff. Proceeding in Watershed Management Conference 2005: Managing Watersheds for Human and Natural Impacts: Engineering, Ecological, and Economic Challenges. Willamsburge. July 18-22. 2005.

Hellweger, Ferdi. AGREE-DEM Surface Reconditioning System. University of Texas, Austin, $\quad$ TX. $1997 . \quad$ Website at: http://www.ce.utexas.edu/prof/maidment/gishydro/ferdi/research/agree/agree.html .2004

Henry, J. G., and G. W. Heinke. Environmental Science and Engineering, 2nd edition. Prentice-Hall, Inc. NJ. 1996.

Herson-Jones, L.M., M. Heraty, and B, Jordan, Environmental land planning (ELP) series: riparian buffer strategies for urban stream protection, Metropolitan Washington Council of Governments, Washington, D.C., 1995.

Hof, J. C.H., Sieg, and M. Bevers. Spatial and temporal optimization in habitat placement for a threatened plant: the case of the western prairie fringed orchid. Ecological Modelling. 115:31-75. 1999.

Hopkins, L.D. Plan, Projection, policy-mathematical programming and planning theory. Environment and Planning A, 6, 419-430, 1974.

Hopkins, L.D. Quadratic versus linear models for land use plan design. Environment and Planning A. 11. 291-298. 1979.

Hopkins, L.D., E.D. Brill, Jr., K.B. Kurtz, and H.G. Wenzel, Jr. Analyzing floodplain policies using an interdependent land use allocation model. Water Resources Research, 17(3), 469-477. 1981.

Hornberger, G.M., and Boyer, E.W. Recent advances in watershed modeling. Review of Geophysics, Supplemental. 949-957. July 1995.

Hundecha, Y, and A., Bárdossy. Rainfall-runoff modeling; Land use change; HBV model; Parameter regionalization; Rhine River. Journal of Hydrology. 292:281295. 2004. 
Hunsacker, C.T. and D.A., Levin. Hierarchical approaches to the study of water quality in rivers. Bioscience. 45(3):193-204. 1995.

Interagency Advisory Committee on Water Data. Guidelines for determining flood flow frequency. Bulletin 17B of the Hydrology Committee, USGS, Office of Water Data Coordination, Reston, VA. 1982.

Irwin E., and J. Reece. The Exurban Change Report: Report Number EX-4: Urbanization Trends in Ohio: Tracking Ohio's Urban Growth \& Land Use Change. Ohio State University Extension, Ohio Agricultural Research and development Center. Ohio State University. OH. 2002

Jenson S.K. and J.O, Domingue. 1988. Extracting Topographic Structure from Digital Elevation Data for geographic Information System Analysis, Photogrammetric Engineering and Remote Sensing. 57 (11), 1593-1600.

Johnson, G.D., W.L., Meyers, G.P. Patil. Predictability of Surface Water Pollution Loading in Pennsylvania Using watershed-based Landscape Measurements. Journal of American Water Resources Association. 37(4):821-835. 2001.

Jolánkai, G., J.Panuska, and W. Rast. Modelling of Nonpoint Source Pollutant Load, in Assessment and Control of Nonpoint Source Pollution of Aquatic Ecosystems: A Practical Approach, edited by Thornton, J.A., W. Rast, M.M. Holland, G.Jolankai, and S.-O. Ryding, The United Nations Educational, Scientific and Cultural Organization, France, 1999

Jones, A.L. and S.I. Gordon, From Plan to Practice: Implementing watershed-based strategies into local, state, and federal policy, Environmental Toxicology and Chemistry, 19:4(2), 1136-1142. 1998.

Jordan, T.E., D.L. Correll, D.E. Weller. Relating nutrient discharges from watersheds to land use and stream variability. Water Resources Research, 33(11), 2579-2590. 1997.

Julien, P.Y. Erosion and Sedimentation. Cambridge University Press, NY, 1995.

Kalin, L., Govindaraju, R.S., and Hantush, M.M. Development and Application of a Methodology for Sediment Source Identification II: Optimization Approach. Journal of Hydrologic Engineering. 9(3) : 194-207. 2004.

Karlqvist, A. Models of Stockholm: Policy Perspectives. Some Theoretical Aspects of Urban Modeling with special reference to TRANSLOC and TOPAZ. CSIRO. March 1977. 
Karr, J.R. and D.R., Dudley. Biological perspective on water quality goals. Environmental Management. 5:55-68. 1981.

Karr, J.R. and I.J. Schlosser. Water resources and the land-water interface. Science. 201(21):229-234.

Kepner, W.G., and D.J., Semmens, S. D., Bassett, D.A., Mouat, and D.C., Goodrich. Scenario Analysis for the San Pedro River, Analyzing Hydrological Consequences of a Future Environment. Environmental Monitoring and Assessment, 94, 115-127. 2004

Kinsel, W. G.(ed.), CREAMS: A Field Scale Model for Chemicals, Runoff, and Erosion From Agricultural ManagementSystems. U.S. Department of Agriculture, Conservation ReportNo. 26, 1980.

Kite, G.W., and N. Kouwen. Watershed modeling using land classification, Water Resources Research, 28(12):3139-3200, 1992.

Krysanova, V., Muller-Wohlfeil, D.-I. and Becker, A., 1998. Development and test of a spatially distributed hydrological/water quality model for mesoscale watersheds. Ecological Modelling 106:261-289, 1998.

Leon, L.F., E.D. Soulis, N. Kouwen, and G.J., Farquhar. Nonpoint Source Pollution: A distributed water quality modeling approach. Water Science and Technology. 35(4):997-1007. 2001.

Lillesand, T.M., R.W. Kiefer, and J.W. Chipman (2004), Remote Sensing and Image Interpretation. 5th Edition. John Wiley and Sons, Inc. NY.

Limbrunner, J.F., S.C. Hapra, R.M. Vogel, and P.H. Kirshen. Decision Support Systems for Optimal Watershed Nutrient Management. Proceeding in Watershed Management Conference 2005: Managing Watersheds for Human and Natural Impacts: Engineering, Ecological, and Economic Challenges. Willamsburge. July 18-22. 2005.

Loehle, C. (2000). Optimal control of spatially distributed process models. Ecological Modelling 131: 79-95. 2000.

Los, $\mathrm{M}$ and C. Lardinois. Combinatorial programming, statistical optimization and the optimal transportation network problem. Transportation Research - Part-B. 16B(2). 89-124. 1982.

Lowry, I.S. A Model of Metropolis (Sponsored by Pittsburgh Regional Planning Association and The RAND Corporation) Memorandum RM-4035-RC. The RAND Corporation, CA. 1964. 
Lundqvist, L. Integrated Location-Transportation Analysis: A Decomposition Approach. Regional and Urban Economics, 3(3):233-262, 1973.

Lundqvist, L. and L-G. Mattsson, Transportation systems and residential locations, European Journals of Operational Research, 12, 279-294. 1983

Lynch K., and Hack G. Site Planning (3rd Edition), The MIT Press, MA. 1984.

Maidment, D.R. Archydro: GIS for Water Modeling, ESRI Press. CA. 2002.

Maidment, D.R. Handbook of hydrology. McGraw-Hill, N.Y. 1993.

Maidment, D.R., Developing a spatially distributed unit hydrograph by using GIS, in Application of Geographic Information Systems in Hydrology and Water Resources Management, edited by Kovar, K. and H.P., Nachtnebel, IAHS. Publication, No. 211, 181-192, 1993.

Mariza C. Costa-Cabbral and Stephen J. Burges. Digital elevation model networks (DEMON): A model of flow over hillslope for compuation of contributing and dispersal areas. Water Resources Research. Vol. 30. No.6. 1681-1692. 1994.

Mark, D.M. Network Models in Geomorpholgy Modelling in Geographological Systems. John Wiley. 1988.

Matisoff, G., Whiting, P.J., Bonniwell, E.C., Evaluation of Watershed Management Programs by Tracing Sediment and Associated Contaminants: A One-Year Study at Old Woman Creek. Technical Report to Old Woman Creek National Estuaries Research Reserve. 1998.

Matisoff, Gerald, Everett C. Bonniwell, and Peter J. Whiting. Radionuclides as indicators of sediment transport in agricultural watersheds that drain to Lake Erie. Journal of Environmental Quality 31:62-72. 2002.

McCammon, B. P. Recommended Watershed Terminology, 1994. Website at: http://www.watershed.org/news/fall_94/terminology.html>, July 7, 2005

McCuen, R.H. A guide to hydrologic analysis using SCS methods. Prentice-Hall, Inc. NJ, 1982.

McDonnell, M., H. Possingham, I. Ball, and E. Cousins. Mathematical methods for spatially cohesive reserve design, Environmental Modeling and Assessment 7(2), pp. 107-114. 2002. 
McGucken, W. Lake Erie Rehabilitated: controlling cultural eutrophication, 1960s1990s. University of Akron Press. Ohio. 2000.

McNamara, J.R., An optimization model for regional water quality manage ment. Water Resources Research, 12(2), 125-134. 1976.

Millward, A. A. and J. E., Mersey. Conservation strategies for effective land management of protected areas using an erosion prediction information system (EPIS), Journal of Environmental Management. 61(4): 329-343. 2001.

Moglen, G. E., and R.E. Beighley, Spatially explicit hydrologic modeling of land-use change. Journal of the American Water Resources Association, 38(1), 241:253. 2002.

Moglen, G.E. Urbanization, Stream Buffers, and Stewardship in Maryland. Watershed Protection Techniques, 3(2): 676-680. 2000.

Montgomery, D.R., W.E. Dietrich. Source Areas, Drainage Density, and Channel Initiation. Water Resources Research. 25(8):1907-1918. 1989.

Moore, I.D., and Gallant, J.C. (1991) Overview of hydrologic and water quality modeling. In: Modeling the Fate of Chemicals in the Environment (Moore, I.D., ed) . Canberra: Centre for Resource and Environmental Studies, Australian National University.

Mostaghimi,S., S.W. Park, R.A. Cooke and Y. Wang. 1997. Assessment of Management Alternatives on a Small Agricultural Watershed. Water Research,, 31(8):1867$1878,1997$.

Muleta, M.K. and J.W., Nicklow. Evolutionary algorithms for multiobjective evaluation of watershed management decisions. Journal of Hydroinformatics, 4(2): 83-97. 2002.

Nearing, M.A., B. Y., Lu, and L.M. Risse, Using Curve Numbers to Determine Baseline Values of Green-Ampt Effective Hydraulic Conductivities. Journal of the American Water Resources Association. 31 (1):147-158. 1995.

Nearing, M.A., B.Y. Lu,_L.M. Risse, and X. Zhang. Curve Numbers and Green-Ampt Effective Hydraulic Conductivities. Journal of the American Water Resources Association. 32(1):125-136. 1996.

Novotny, V, Diffuse pollution from agriculture- a world wide look. Water Science and Technology, 39(3),1-13. 1999 
Novotny, V. and G. Chesters, Handbook of nonpoint pollution: sources and management, Van Nostrand Reinhold Company, N.Y. 1982.

O'Callaghan, J. F., and D. M. Mark, The extraction of drainage networks from digital elevation data. Computer Vision Graphics Image Processes. 28:328-344, 1984.

O’Neill,R.V., D.L., Deangelis, J.B. Waide, T.F.H. Allens.. A Hierarchical Concept of Ecosystems. Princeton University Press. Princeton, N.J. 1986.

O’Neill,R.V., J.R. Krummel, R.H. Gardner, G. Sugihara, B.Jackson, D.L., DeAngelis, B.T. Miline, M.G. Turner, B.Zygmunt, S,W, Christensen, V.H. Dale, and R.L. Graham. Indices of Landscape pattern, Landscape Ecology. 1(3):153-162. 1988.

O’Neill, R.V., R.H. Gardner, and M.G. Turner. A hierarchical neutral model for landscape analysis. Landscape Ecology. 7(1):55-61. 1992.

Odland, J. The spatial arrangement of urban activities: a simultaneous location model. Environment and Planning A. 8: 779-791. 1976.

ODNR. Lake Erie CREP http://www.ohiodnr.com/soilandwater/crephome.htm, 2002.

Ohio Lake Erie Commission. Lake Erie Protection and Restoration Plan. Toledo, $\mathrm{OH}$. 2000 .

Olivera, F. Spatially distributed modeling of storm runoff and non-point source pollution using geographic information systems, Ph.D. Dissertation, University of Texas, Austin. 1996.

Oppenheim, N. Applied models in urban and regional analysis, Englewood Cliffs, N.J. : Prentice-Hall, 1980.

Osborne, L.L. and W.J., Wiley. Empirical relationship between landuse/cover and stream water quality in an agricultural watershed. Journal of Environmental Management, 26:9-27, 1988.

Parsons, A.J. and A.D. Abrahams. Overland Flow ( $2^{\text {nd }}$ Ed), University College London, London, UK, 1992.

PerezPendini C., Limbrunner, J.F., and R.M. Vogel. Optimal number and location of BMPs for Storm water Management. Proceeding in Watershed Management Conference 2005: Managing Watersheds for Human and Natural Impacts: Engineering, Ecological, and Economic Challenges. Williamsburg. July 18-22. 2005. 
Pilgrim, D.H. and I. Cordery. Flood runoff, in Handbook of hydrology, edited by Maidment, D.R., McGraw Hill Inc, NY. 1993.

Possingham, H., I. Ball, and S. Andelman. Mathematical methods for identifying representative reserve networks. In Quantitative methods for conservation biology. Ferson, S. and M. Burgmam (eds). Springer-Verlag, NY. 2000.

Pressey, R.L., H.P. Possingham, and C.R. Margules. Optimally in Reserve Selection Algorithms: When Does it Matter and How Much? Biological Conservation 76:259-267. 1996.

Pressey, R.L., H.P. Possingham, and J.R. Day. Effectiveness of Alternative Heuristic Algorithms for Identifying Indicative Minimum Requirements for Conservation Reserves, Biological Conservation. 80. 207-219. 1997

Preti, F. Main topics and recent experiences for environmental monitoring and modeling diffuse pollution. Water Science and Technology, 33(4):63-72, 1996.

Reyes, M. R., R.L, Bengtson, J.L., Fouss, and C.E., Carter. Comparison of erosion predictions with GLEAMS, GLEAMS-WT, and GLEAMS-SWAT models for alluvial soils. Transactions of ASAE. 38: 791-796. 1995.

Richards, C. and G., Host. Examining land use influences on stream habitats and macroinvertebreates: a GIS approach. Water Resources Bulletin, 30(4):729-737, 1994.

Robien, A., T., Striebel, and R., Herrmann. Modeling of dissolved and particle-bound pollutants in urban street runoff. Water Science and Technology, 36(8):77-82, 1997.

Robinson, A.R., Sediment. Journal of Soil and Water Conservation. March-April. P6162, 1971.

Roth, N.E., Allan, J.D., and Erickson, D.L. (1996). Landscape influences on stream biotic integrity assessed at multiple spatial scales. Landscape Ecology, 11(3): 141-156.

Ryding, S.-O. and J.A. Thornton. Types of Aquatic Pollutants, Impacts on Water Quality and Determination of Critical Levels. In: Assessment and Control of Nonpoint Source Pollution of Aquatic Ecosystem: A Practical Approach (J.A. Thornton, W. Rast, M.M. Holland, G. Jolankai, and S.-O. Ryding, ed). The Parthenon Publishing Group Inc., NY. 1999.

Schiffman, I. Alternative Techniques for Managing Smart Growth. Berkeley Public Policy Press. CA. 2001 
Schueler, T. R. and H.K. Holland. The practice of watershed protection. Center for Watershed Protection, MD. 2000.

Scoging, H. Modelling overland-flow hydrology by dynamic hydraulics: Overland Flow (A.J. Parsons, and A.D. Abrahams), University College London, London, UK, 1992.

Seppelt and Voinov. Optimization Methodology for Land Use Patterns Using Spatially Explicit Landscape Models. Ecological Modelling. 151(2-3): 125-145. 2002.

Singh, V.P., Computer models of watershed hydrology, Water Resources Publications, Highlands Ranch, CO, 1995.

Skjei, S. Linear programming and comprehensive planning: the context of site development, Socio-Economic Planning Sciences, 6, 227-240. 1972.

Smith, J.D., and Liebman, J.S. A zero-one integer-programming formulation of the problem of land-use assignment and transportation network design. Environment and Planning B, June 101-115. 1978

Snoeyink, V., and Jenkins D. Environmental Chemistry, John Wiley \& Sons, NY. 1980

Srivastava, P., J.M. Hamlett, P.D. Robillard, R.L. Day. Watershed optimization of best management practices using AnnAGNPS and a genetic algorithm. Water Resources Research, 38(3):365-379, 2002.

Sun, H., P.S. Cornish, and T.M., Daniell. Turbidity-based erosion estimation in a catchment in South Australia. Journal of Hydrology, 263: 227-238. 2001.

Szymkiewicz, R. An alternative IUH for the hydrologic lumped model. Journal of Hydrology. 259:246-253, 2002.

Taha, H.A. Operations Research: An Introduction. The Macmillan Company, NY. 1971.

Tarboton, D.G. A new method for the determination of flow directions and upslope areas in grid digital elevation models. Water Resources Research. 32(5). 309-319. Feb. 1997.

Tchobanoglous, G., and Schroeder, E.D. Water Quality, Addison-Wesley Publishing Company, CA. 1985 
Tim, U.S., S, Mostaghimi, and V.O. Shanholtz. Identification of critical non-point pollution source areas using geographic information system and water quality modeling. Water Resources Bulletin 28: 877-887. 1992.

Toy, T.J., Foster, G.R., and Renard K.G. 2002. Soil Erosion: Processes, Prediction, Measurement, and Control. John Wiley \& Sons, Inc. NY.

U.S. Department of Agriculture (USDA), Urban hydrology for small watersheds: TR-55, USDA, Washington, D.C. 1986

U.S. Department of Agriculture (USDA), Predicting Soil Erosion by Water: A Guide to Conservation Planning with the Revised Universal Soil Loss Equation (RUSLE). Agricultural Handbook Number 703. Washington D.C. 1996.

U.S. Department of Agriculture (USDA), Stream Corridor Restoration: Principles, Processes, and Practices (Part 653 of National Engineering Handbooks). Washington, D.C. 1998.

U.S. Department of Agriculture (USDA), Ohio Lake Erie Buffer Program: Strategic Plan 2000-2004. Washington D.C. 2000.

U.S. Department of Agriculture (USDA), National Agricultural Statistics Service, 2002. Website at: http://www.usda.gov/nass/

USDA-NRCS. Field Office Technical Guide. Website at: http://efotg.nrcs.usda.gov. 2005.

U.S. Environmental Protection Agency (US EPA). Guidance specifying management measures for sources of nonpoint pollution in costal waters. Office of Water, USEPA, Washington D.C. 1993

U.S. Environmental Protection Agency (USEPA). Techniques for tracking, evaluating, and reporting the implementation of nonpoint source pollution measure: Agriculture. EPA 841-B-97-010. 1997a.

U.S. Environmental Protection Agency (US EPA), Technical Guidance Manual for Developing Total Maximum Daily Loads, USEPA, Washington D.C. 1997b.

U.S. Environmental Protection Agency (US EPA). National management measures for the control of nonpoint pollution from agriculture. EPA-841-B-03-004. Washington D.C. 2000a.

U.S. Environmental Protection Agency (US EPA), National water quality inventory to congress, USEPA, Washington D.C. 2000b 
U.S. Environmental Protection Agency (US EPA), BASIN2 - Better Assessment Science Integrating Point and Nonpoint Sources, 2001. Website at: http://www.epa.gov/OST/BASINS/.

U.S. Geological Survey (USGS), Standards for Digital Elevation Models. U.S. Department of Interior, Washington D.C. Website at: http://edc.usgs.gov/guides/dem.html, 1998.

U.S. Geological Survey (USGS). HSPF: Hydrological Simulation Program - Fortran, USGS, Reston, Virginia. Website at: http://water.usgs.gov/software/hspf.html, 2001.

Uhlenbrook S., and C. Leibundgut: Process-oriented catchment modeling and multiple-response validation. Hydrological Processes, 16, 423-440. 2002.

Veith, T.L., Wolfe, W.L., and Heatwole, C.D. Cost-Effective BMP placement: Optimziation Versus Targeting. Transactions of the ASAE., 47(5):1585-1594, 2004.

Venkataraman, P, Applied optimization with MATLAB programming, Wiley, NY, 2002.

Wagner, H.M., Principles of operations research: with applications to managerial decisions (2nd edition), Prentice-Hall Company, NJ, 1975.

Wang, M. A Dynamic Hydrologic and Non-Point Pollutant Transport Model Based on DEMs. Ph.D. Dissertation. University of Missouri-Columbia, 1995.

Ward, A.D., and W.J., Elliot. Environmental Hydrology. CRC Press, Inc., Florida, 1995.

Williams, J.C., and C.S. ReVelle. Applying mathematical programming to reserve selection. Environmental Modeling and Assessment. 2:167-175. 1997

Williams, J.C., and C.S., ReVelle. Reserve assemblage of critical areas: A zero-one programming approach. European Journal of Operational Research. 104:497509. 1998.

Williams, C.J. A Zero-One Programming Model for Contiguous Land Acquision. Geographical Analysis, 34(4):330-349. 2002.

Williams, C.J. Convex land acquisition with zero-one programming. Environment and Planning B: Planning and Design. 30:255-270. 2003.

Wilson, J.P. and J.C., Gallant. Terrain Analysis: Principles and Applications. John Wiley and Sons, NY. 2000. 
Wischmeier, W.H. and D.D. Smith. Predicting Rainfall Erosion Losses - A Guide to Conservation Planning. USDA Handbook 537. Washington, D.C.: U.S. GPO. 1978.

Wright, J.C., C.S. ReVelle, and J.Cohon. A Multi Objective Integer Programming Model for the Land Acquisition Problem. Regional Science and Urban Economics. 12: 31-53. 1983.

Yoder, C.O. and E.T. Rankin. The Role of Biological Criteria in Water Quality Monitoring, Assessment, and Regulation. Division of Surface Water. State of Ohio Environmental Protection Agency. Columbus, OH, 1995.

Yoon, K. S.; Yoo, K. H.; Wood, C. W.; Hall, B. M. Application of GLEAMS to predict nutrient losses from land application of poultry litter. Paper presented at the 1993 International Summer Meeting, sponsored by The American Society of Agricultural Engineers, and The Canadian Society of Agricultural Engineering. June 20-23, Spokane, Washington., 1993.

Young, C.H., and P.J. Jarvis. A simple method for predicting the consequences of land management in urban habitat. Environmental Management. 28(3):375-387. 2001.

Young, R.A., Onstad, C.A., Bosch, D.D., and Anderson, W.P. AGNPS: A non-point source pollution model for evaluating agricultural watersheds. Journal of Soil and Water Conservation. 44(2):164-172. 1989.

Young, R.A., Onstad, C.A., and Bosch, D.D. AGNPS: An Agricultural Nonpoint Source Model. In Computer Models of Watershed Hydrology (edited by Vijay P. Singh). Water Resources Publication. CO. 1995.

Yuan, Y., Bingner, R.L., Rebich, R.A. Evaluation of AnnAGNPS Nitrogen Loading in an Agricultural Watershed, Journal of the American Water Resources Association, 39(2):457-466, 2003.

Zieninsk, P.A., and K., Ponnambalam. Computational methods in stochastic river quality modeling. In: stochastic and statistical modeling with groundwater and surface water application (K.W. Hipel, ed). Kluewer Academic Publisher, Dordrecht, Netheland, 1994. 


\section{APPENDIX A.}

\section{ASSESSMENT OF LOCAL OPTIMA FOR GLOBAL OPTIMALITY}

The purpose of this section is to analyze the distribution of the local optima produced by the IHLUO model, and to numerically assess progress towards the global optimum. The optimization result from the IHLUO model cannot be guaranteed for global optimality. As the objective function of the nonlinear problem cannot be formulated analytically, it is impossible to characterize its convexity, using the Hessian matrix, as this would require calculating the second partial derivatives, $\left(\frac{\partial^{2} f}{\partial x_{i} \partial x_{j}}, \forall i, j\right)$, of the objective function. Therefore, the sufficient condition for obtaining the global optimum cannot be verified. According to classical optimization theory, this function must be convex all over the feasible domain for a minimization problem. This happens only if the Hessian matrix is negative definite everywhere.

The approach is inspired by a combination of the hill-climbing technique and statistical optimization to efficiently solve the optimal network design problem, as proposed by Los and Lardinois (1982). The basic concept is to generate many initial solutions and to obtain the resulting bcal optima using a hill-climbing algorithm. The 
global optimum value is then estimated by fitting the sample distribution of the local optima. The hill-climbing method is a local search method, which is applied to a single point. An incremental improvement of the solution value $\left(\mathbf{X}_{\mathrm{i}}\right)$ is obtained by iteratively searching the neighborhood of the current point $\left(\mathbf{X}_{\mathrm{i}-1}\right)$ in the searching space (Michalewicz and Fogel, 2000). In this study, the initial condition (.e.g., the spatial land use pattern) is assigned andomly - the locations of land uses at the cell level are determined by a random number generator. Instead of the hill climbing method to obtain local optima from initial solutions, the IHLUO model is used to improve the objective function value (i.e., the peak discharge rate).

The obtained local optima are statistically analyzed with a Weibull Distribution. This distribution has been widely used to analyze life data, to assess stability, or to measure risk. One of the great merits of this distribution is its independence from the parent distribution. This distribution is derived as the asymptotic distribution of the smallest order statistics, known as Type III asymptotic distribution of the smallest extreme (Fisher and Tippett (1928). The cumulative distribution function of the Weibull distribution and its density function is given as:

$$
\Phi(X)=1-\exp \left[-\left(\frac{X-a}{b}\right)^{c}\right]
$$

and the density function is:

$$
\begin{aligned}
& \delta(X)=\frac{c}{b}\left(\frac{X-a}{b}\right)^{c-1} \exp \left[-\left(\frac{X-a}{b}\right)^{c}\right], \\
& X \geq a>0 ; c>0, b>0 .
\end{aligned}
$$


The parameters a, b, and c are called the location, scale parameters, and shape parameters. The parameter a, lower bound of the Weibull Distribution, is also the lower bound of the parent-distribution. This is considered as the global optimum.

The best local optimum is used as an estimate of the global optimum, and the reliability of this estimate is statistically evaluated by analyzing the empirically fitted Weibull distribution of the local optima. The Weibull distribution always follows:

$$
\Phi(a+b)=1-e^{-1}
$$

If the R observations (i.e., sample size) were drawn from a Weibull distribution with $x_{(1)}^{h}$ as the best local optimum,

$$
\begin{aligned}
\operatorname{Pr}\left\{x_{(1)}^{h} \leq a+b\right\}= & 1-\operatorname{Pr}\left\{x_{(1)}^{h}>a+b\right\} \\
& =1-\left\{1-\Phi_{x_{(1)}^{h}}(a+b)\right\}\left\{1-\Phi_{x_{(2)}^{h}}(a+b)\right\} \ldots\left\{1-\Phi_{x_{(R)}^{h}}(a+b)\right\} \\
& =1-\left(e^{-1}\right)^{R}=1-e^{-R} .
\end{aligned}
$$

If $\hat{x}^{*}=\hat{a}$ is the estimate of the global optimum, its confidence interval with $100\left(1-\mathrm{e}^{-\mathrm{R}}\right) \%$ is given as (Golden and Alt, 1979)

$$
\operatorname{Pr}\left\{x_{(1)}^{h}-\hat{b} \leq \hat{x}^{*} \leq x_{(1)}^{h}\right\} \approx 1-e^{-R} .
$$

However, the interval calculated by this formula appears to be too large and does not vary with R (Los and Lardinois 1980). This confidence interval was improved by Los and Lardinois(1980) with any real number S, as:

$$
\Phi\left(a+\frac{b}{S}\right)=1-\exp \left[-\left(\frac{1}{S}\right)^{c}\right]
$$

Then, the confidence interval is given as: 


$$
\operatorname{Pr}\left\{x_{(1)}^{h}-\frac{\hat{b}}{S} \leq \hat{x}^{*} \leq x_{(1)}^{h}\right\}=1-\exp \left(-\frac{R}{S^{c}}\right)
$$

If the confidence level $(1-\alpha)$ is expressed as:

$$
1-\exp \left(-\frac{R}{S^{c}}\right)=1-\alpha
$$

Then, the real number $\mathrm{S}$ is:

$$
S=\left(-\frac{R}{\ln \alpha}\right)^{1 / \hat{c}}
$$

The analysis of local optima is done on drainage area 2, with 500 data samples. The initial spatial patterns are all generated with the same total amounts of land uses for the entire drainage area. The locations of each land-use type are assigned randomly, by using a random number generator. Then, the IHLUO model is applied to delineate the optimal land use patterns for these 500 initial maps. The peak discharge rates at the drainage outlet are analyzed using the Weibull distribution. Figure A.1 presents the sample data and fitted Weibull probability density function. Figure A.2 shows the observations and fitted values. Note that the peak discharge varies very little in the range of [0.2541-0.2543]. The empirical form of the probability density function is fitted using maximum likelihood estimation. The three parameters are estimated using SAS. As can be seen from Figure A.1, the three-parameter Weibull distribution fits well with the data. Table A.1 shows detailed statistical results for parameter estimations. 


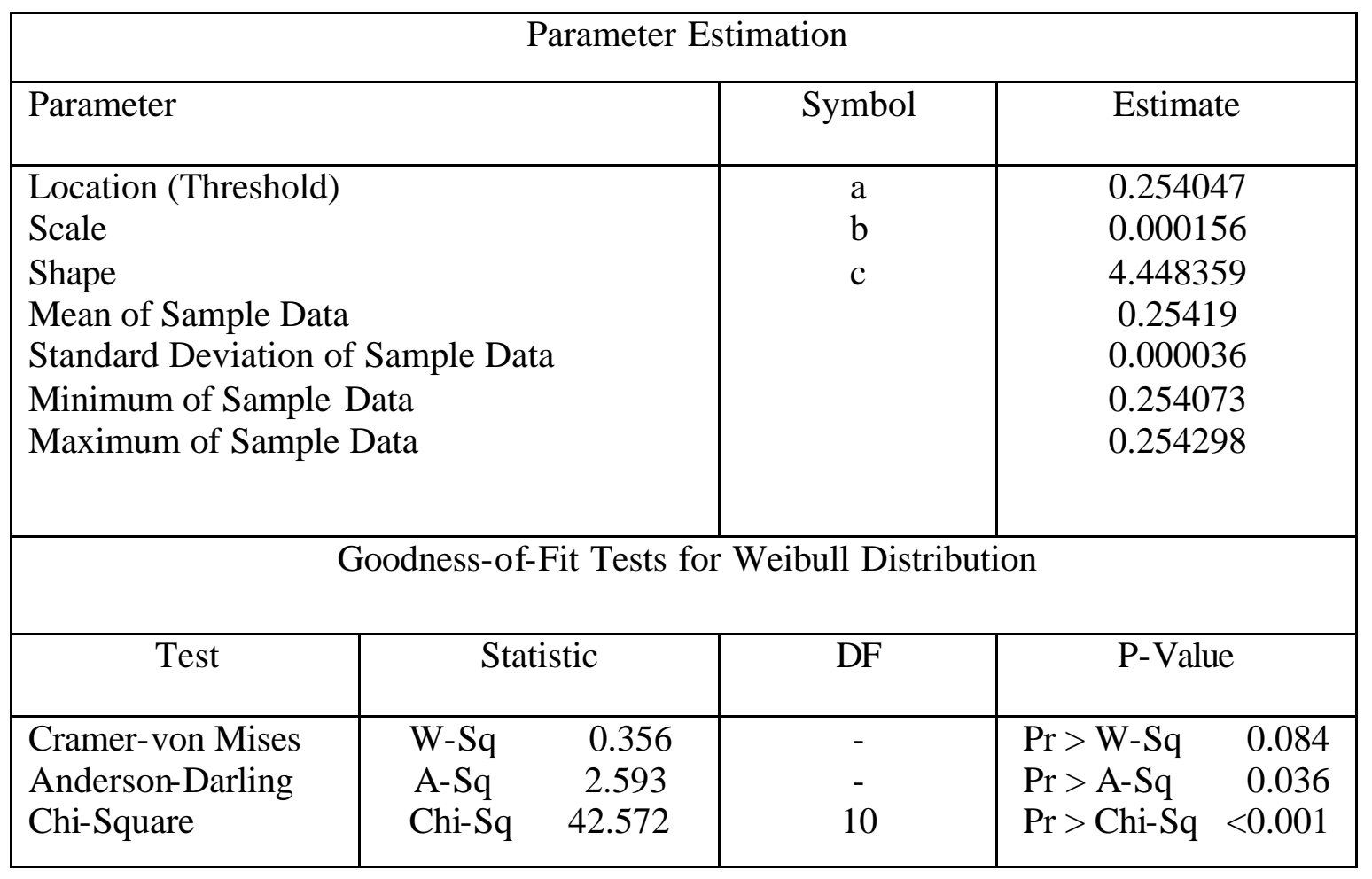

Table A.1: Weibull Distribution Data Fitting 


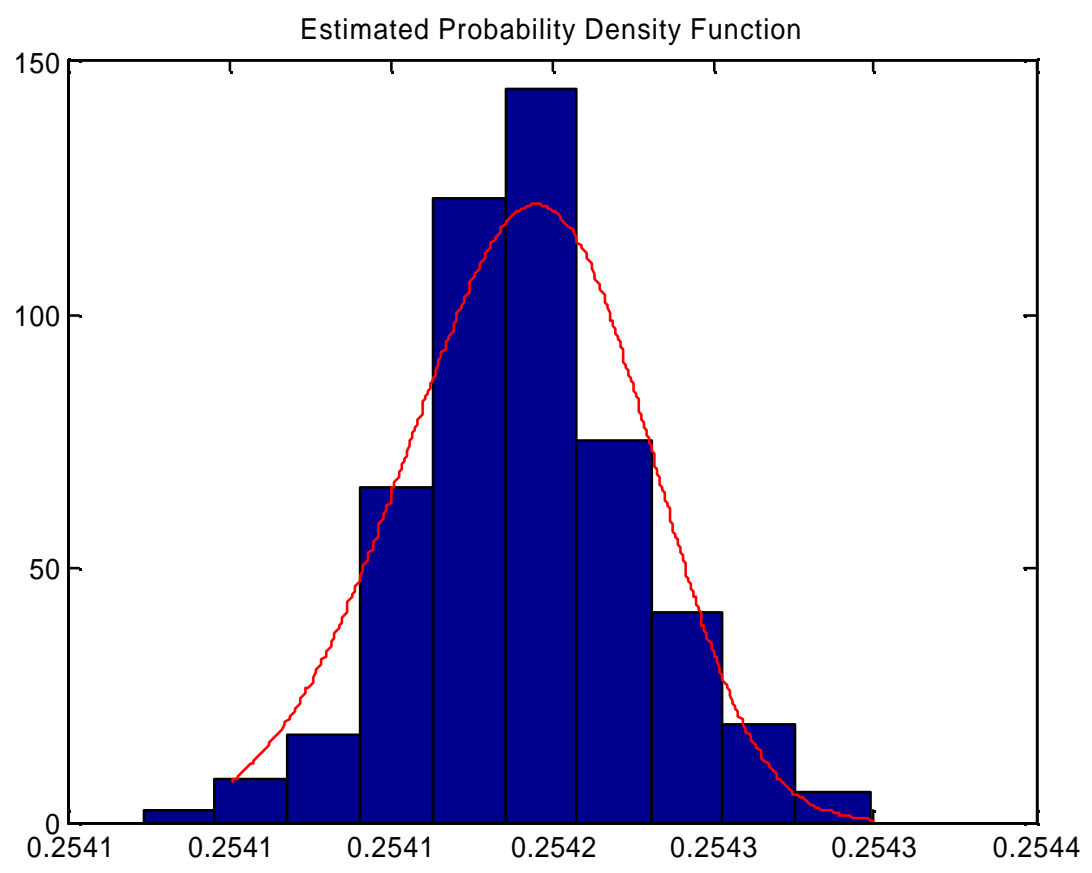

Figure A.1. Sample Data and Fitted Probability Density Distribution

Estimated Cumulative Density Function

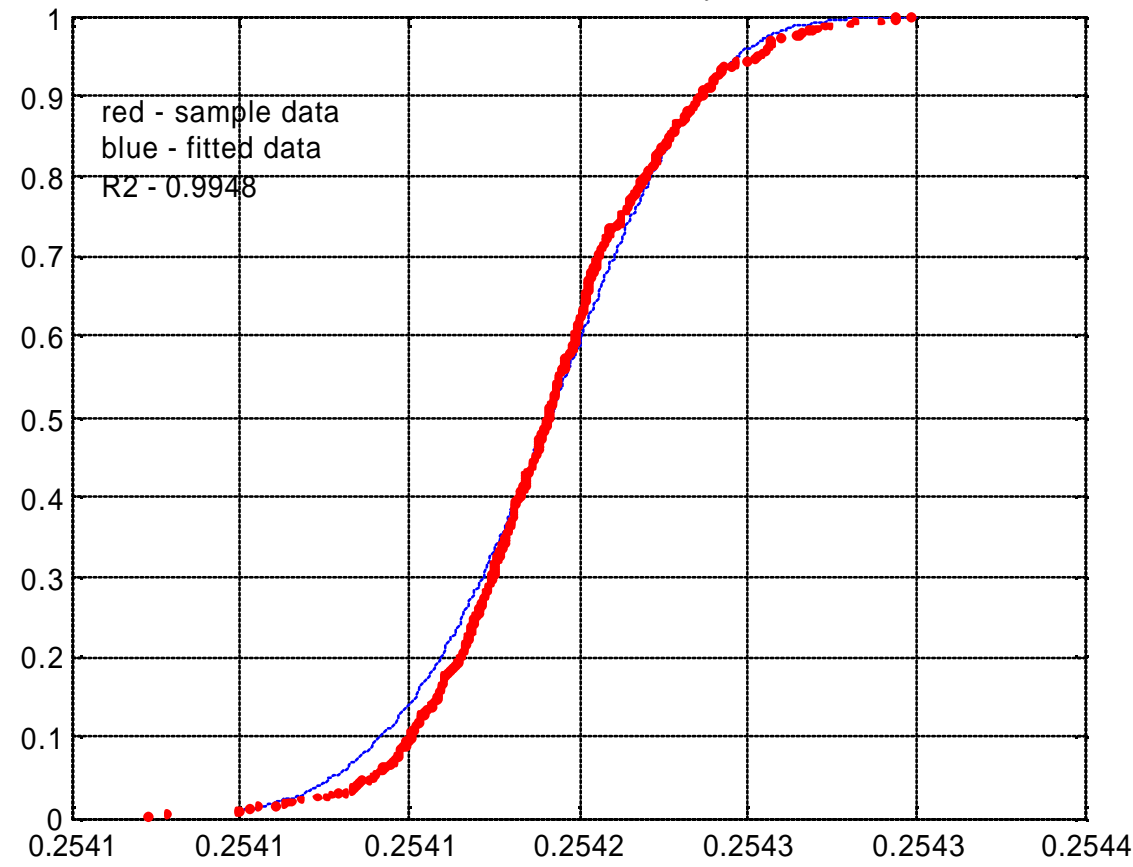

Figure A.2. Comparison of Sample Data and Fitted Data 
The global optimum and its confidence interval are calculated and compared with the local optimum values obtained by IHLUO. The results are summarized in Table A.2, showing that the best local optimal solution from the test drainage area is within the $95 \%$ confidence interval of the global optimum. This result suggests that the IHLUO model delineates optimal land use patterns, close to the global optimum.

\begin{tabular}{|l|l|}
\hline$x_{o}=0.254047$ & $\mathrm{R}=491$ \\
\hline$\hat{x}^{*}=0.254047$ & $\alpha=0.05(95 \% \mathrm{CI})$ \\
$x_{(1)}^{h}=0.254073$ & $\mathrm{~S}=3.1466$ \\
$x_{(n)}^{h}=0.254298$ & $95 \%$ CI of $\hat{x}^{*}=(0.254023,0.254073)$ \\
\hline
\end{tabular}

$x_{o}$ : Local Optimum with current conditions

R: Sample Size without replication.

$\hat{x}^{*}$ : the global optimum estimate

Table A.2. Global Optimum and Confidence Interval 


\title{
Appendix B
}

\section{Pseudo Codes for the Hydrological Simulation, Two-Level Regression- Allocation, and the IHLUO Model}

\author{
Procedure Hydrological Simulation Model \\ Begin \\ Load input data \\ Determine flow path ways \\ Calculate cell runoff volume \\ Calculate cell flow time \\ Calculate accumulated runoff volume by flow path \\ Calculate accumulated travel time by flow path \\ Calculate time of concentration \\ End \\ Calculate the peak discharge rate and hydrograph
}

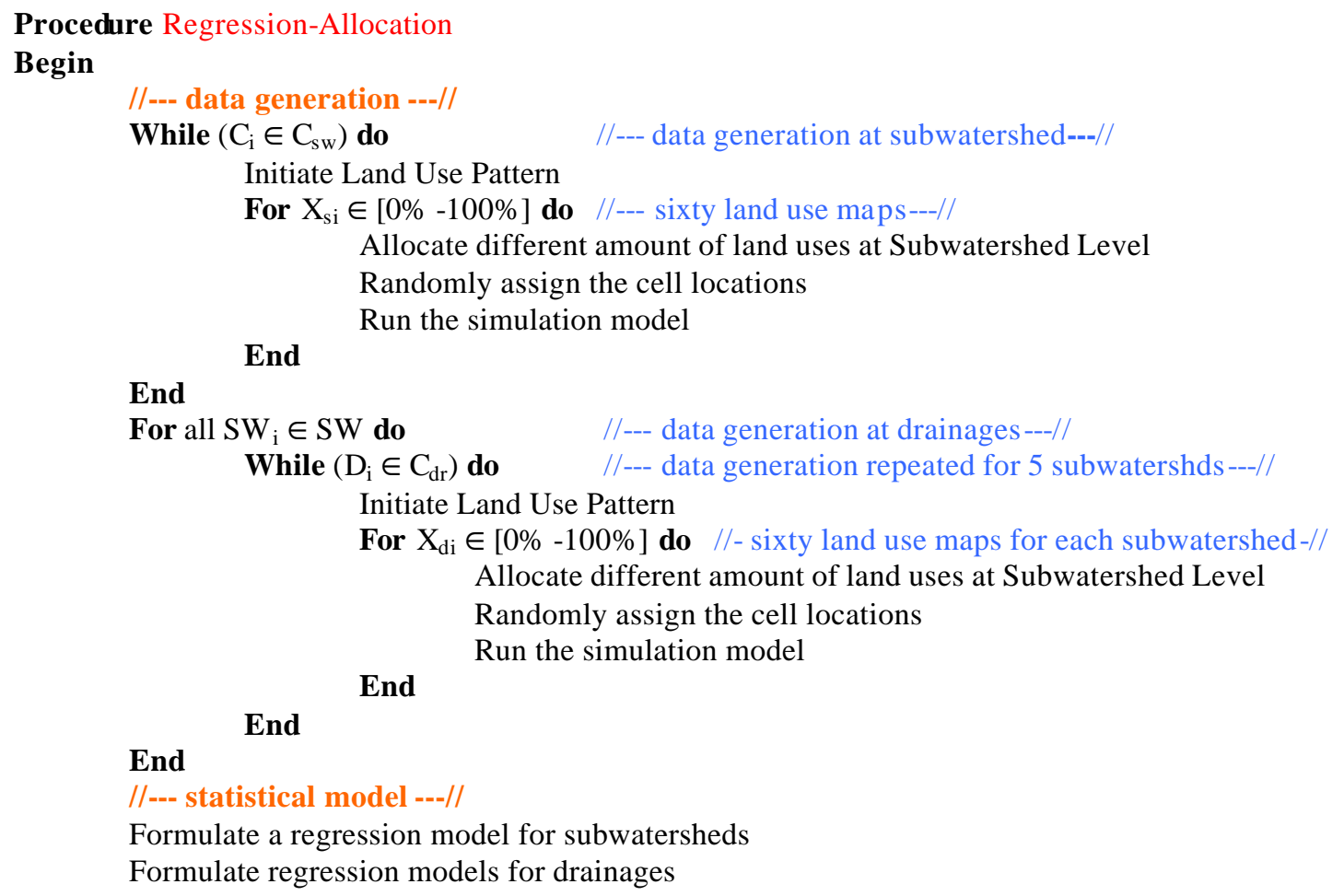


//--- land allocation model ---//

Create a quadratic program to determine land allocation at subwatersheds

Create quadratic programs to determine land allocation at drainages

End

Procedure IHLUO model

Begin

Load input data

Run simulation model with current land use pattern

Calculate the peak discharge rates $(\mathrm{Qp})$

While (not termination condition) do

Update the number of iteration $\left(\mathrm{N}_{\mathrm{i}}\right)$

Update $\mathrm{Q}_{\mathrm{p} 0}$ by $\mathrm{Q}_{\mathrm{p}}$

run linear optimization program for the first order term $(\mathrm{Eq} 3.17)$

find the gradient

calculate the optimal step size

update the land use map (X) by the gradient and optimal step size

//--stopping condition--//

If $|\mathrm{X} 0-\mathrm{X}|<\varepsilon$ or $\mathrm{Q}_{\mathrm{p} 0}<\min \left(\mathrm{Q}_{\mathrm{p}}\right)$ or $\mathrm{N}_{\mathrm{i}}>\max \left(\mathrm{N}_{\mathrm{i}}\right)$

stop and exit

Else

Update the modeling parameters

Run the simulation model with a new land-use map(X)

End

End

End 